\title{
Dietary C18 fatty acids : effects on cardiovascular risk markers and fatty acid metabolism
}

Citation for published version (APA):

Thijssen, M. A. M. A. (2006). Dietary C18 fatty acids : effects on cardiovascular risk markers and fatty acid metabolism. [Doctoral Thesis, Maastricht University]. https://doi.org/10.26481/dis.20060412mt

Document status and date:

Published: 01/01/2006

DOI:

10.26481/dis.20060412mt

Document Version:

Publisher's PDF, also known as Version of record

\section{Please check the document version of this publication:}

- A submitted manuscript is the version of the article upon submission and before peer-review. There can be important differences between the submitted version and the official published version of record.

People interested in the research are advised to contact the author for the final version of the publication, or visit the DOI to the publisher's website.

- The final author version and the galley proof are versions of the publication after peer review.

- The final published version features the final layout of the paper including the volume, issue and page numbers.

Link to publication

\footnotetext{
General rights rights.

- You may freely distribute the URL identifying the publication in the public portal. please follow below link for the End User Agreement:

www.umlib.nl/taverne-license

Take down policy

If you believe that this document breaches copyright please contact us at:

repository@maastrichtuniversity.nl

providing details and we will investigate your claim.
}

Copyright and moral rights for the publications made accessible in the public portal are retained by the authors and/or other copyright owners and it is a condition of accessing publications that users recognise and abide by the legal requirements associated with these

- Users may download and print one copy of any publication from the public portal for the purpose of private study or research.

- You may not further distribute the material or use it for any profit-making activity or commercial gain

If the publication is distributed under the terms of Article $25 \mathrm{fa}$ of the Dutch Copyright Act, indicated by the "Taverne" license above, 


\section{Dietary C18 fatty acids:}

effects on cardiovascular risk markers and fatty acid metabolism 

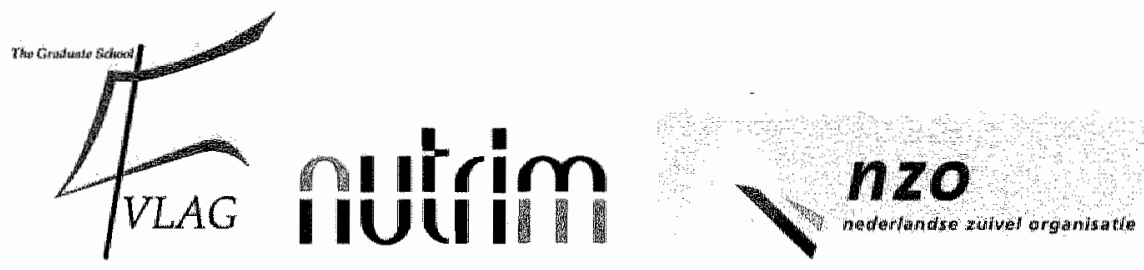

The studies presented in this thesis were performed at the Nutrition and Toxicology Research Institute Maastricht (NUTRIM), which participates in the Graduate School VLAG (Food Technology, Agrobiotechnology, Nutrition and Health Sciences) accredited by the Royal Netherlands Academy of Arts and Sciences.

The studies described in this thesis were supported by a grant of the Dutch Dairy Association.

Financial support by the Dutch Dairy Association and the Netherlands Heart Foundation for the publication of this thesis is gratefully acknowledged.

Cover design: Jochem Harteveld and Myriam Thijssen

Lay-out: $\quad$ Gert-Jan Roelofs and Myriam Thijssen

Printed by: $\quad$ Ponsen \& Looijen b.v., Wageningen

(c) Myriam Thijssen, Maastricht 2006

ISBN 90-64641-25-0 


\title{
Dietary C18 fatty acids: effects on cardiovascular risk
}

markers and fatty acid metabolism

\author{
Proefschrift
}

ter verkrijging van de graad van doctor aan de Universiteit Maastricht, op gezag van de Rector Magnificus,

Prof. mr. G.P.M.F. Mols

volgens het besluit van het College van Decanen, in het openbaar te verdedigen

op woensdag 12 april 2006 om 12.00 uur

door

Myriam Anna Maria Anthonia Thijssen

geboren op 10 september 1976 te Beers 


\section{Promotor}

Prof. dr. ir. R.P. Mensink

\section{Beoordelingscommissie}

Prof. dr. E.C.M. Mariman (voorzitter)

Prof. dr. A. Bast

Dr. M.G.A. Oude Egbrink

Prof. dr. W. Saris

Dr. ir. P.L. Zock (Unilever Health Institute, Vlaardingen) 


\section{CONTENTS}

\section{Chapter 1}

General Introduction

\section{Chapter 2}

Fatty acids and atherosclerotic risk

\section{Chapter 3}

Small differences in the effects of stearic acid, oleic acid, and linoleic acid on the serum lipoprotein profile of humans

\section{Chapter 4}

Stearic, oleic, and linoleic acids have comparable effects on markers of thrombotic tendency in healthy human subjects

\section{Chapter 5}

Effects of stearic, oleic, and linoleic acids on biomarkers of lipid peroxidation and inflammation in healthy human subjects

\section{Chapter 6}

Effects of specific CLA isomers on plasma fatty acid profile and expression of desaturases in humans.

\section{Chapter 7}

General Discussion

Fatty acid nomenclature and abbreviations

Summary

Samenvatting

Dankwoord

Curriculum vitae

List of publications. 
$\because \therefore$ 
General Introduction 


\section{GENERAL INTRODUCTION}

Besides carbohydrates and proteins, fatty acids are major macronutrients of the diet (Table 1.1). Data from the most recent food consumption survey indicated that on average $34 \%$ of the daily dietary energy intake is provided by fatty acids as present in fats and oils, whereas carbohydrates and proteins provided about $48 \%$ and $14 \%$ of energy in the Dutch diet (1). In contrast to the food consumption survey of 19971998 , intakes of the individual fatty acids were not reported. In this earlier survey, $37 \%, 45 \%$ and $15 \%$ of energy was provided by respectively fatty acids, carbohydrates, and proteins (2). With respect to the fatty acids, approximately $14 \%$ of energy was derived from saturated fatty acids. The saturated fatty acids lauric acid, myristic acid, and palmitic acid provided approximately $9 \%$ of energy, whereas stearic acid provided 3-4\% of energy. Oleic acid and linoleic acid, the major monounsaturated and polyunsaturated fatty acids, contributed for $10-11 \%$ and $7-8 \%$ to the total daily energy intake, respectively (3). Next to its well-recognised role in energy metabolism, dietary fat and fatty acids have profound effects on other metabolic processes due to their effects on for example membrane lipid composition and gene expression. Dependent on their structure and function, fatty acids exert differential effects on risk markers of cardiovascular diseases.

Cardiovascular diseases are a major cause of morbidity and mortality in western and developed countries. In the Netherlands, coronary heart disease, cerebrovascular diseases and peripheral arterial diseases are responsible for approximately $34 \%$ of all deaths (4). Because a diversity of risk markers is related with its prevalence, cardiovascular diseases have a multifactorial aetiology. Increased age, male gender, personal and family history of cardiovascular diseases and genetic background are all associated with an increased cardiovascular disease risk. Other major risk markers are smoking, physical inactivity, hypertension, obesity, diabetes mellitus, an unfavourable lipoprotein profile, increased thrombotic tendency, increased oxidative stress, and low-grade inflammation $(5,6)$. These latter factors are amenable to prevention by lifestyle changes such as the fatty acid composition of the diet.

In this thesis, the effects of dietary fatty acids are described on cardiovascular disease risk markers. In the present chapter, the structure, function, and metabolism of fatty acids are introduced, and the pathogenesis of cardiovascular diseases and risk markers of cardiovascular diseases are described. Furthermore, studies which evaluated the relationships between fatty acids, lipid and lipoprotein concentrations and cardiovascular diseases are briefly introduced. 
Table 1.1 Average daily intakes of energy and nutrients in The Netheriands.

\begin{tabular}{|c|c|c|c|c|}
\hline \multirow{2}{*}{$\begin{array}{l}\text { Food consumption survey } \\
\text { Nutrient }\end{array}$} & \multicolumn{2}{|c|}{$1997-1998$} & \multicolumn{2}{|c|}{$20103^{2}$} \\
\hline & Men & Women & $\begin{array}{l}\text { Young } \\
\text { men }\end{array}$ & $\begin{array}{l}\text { Young } \\
\text { women }\end{array}$ \\
\hline Energy (kcal) & 2668 & 2031 & 2760 & 1921 \\
\hline Energy $\left(k_{n}\right)$ & 11192 & 8519 & 11581 & 8063 \\
\hline Carbohydrates ( $\%$ of energy) & 44.6 & 45.0 & 47.2 & 49.1 \\
\hline Proteins $(\%$ of energy $)$ & 14.5 & 15.3 & 14.0 & 14.6 \\
\hline Fats (\% of energy) & 36.5 & 37.0 & 34.4 & 34.3 \\
\hline Saturated fatty acids & 13.7 & 14.1 & 12.7 & 13.0 \\
\hline Lauric acid $(\mathrm{C} 12 ; 0)$ & 0.8 & 0.8 & & \\
\hline Myristic acid (C14:0) & 1.3 & 1.4 & & \\
\hline Palmitic acid (C16:0) & 6.8 & 7.0 & & \\
\hline Stearic acid (C18:0) & 3.4 & 3.5 & & \\
\hline Monounsaturated fatty acids & 10.4 & 10.6 & $18.1^{3}$ & $17.6^{3}$ \\
\hline Oleic acid $(C 18: 1 n-9)$ & 9.7 & 9.9 & & \\
\hline Polyunsaturated fatty acids & 7.6 & 7.4 & & \\
\hline Linoleic acid (C18:2n-6) & 6.6 & 6.3 & & \\
\hline$\alpha$-Linolenic acid $(C-18: 3 n-3)$ & 0.7 & 0.6 & & \\
\hline EPA (C20:5n-3) & 0.01 & 0.01 & & \\
\hline DHA (C22:6n-3) & 0.02 & 0.02 & & \\
\hline Trans fatty acids & 1.2 & 1.4 & 1.0 & 1.1 \\
\hline Alcohol ( $\%$ of energy) & 4.5 & 2.6 & 4.3 & 1.8 \\
\hline Chollesterol (mg/MJ) & 22.2 & 23.8 & & \\
\hline Dietary fibre (g/MJ) & 2.2 & 2.4 & 2.0 & 2.1 \\
\hline
\end{tabular}

'Data are derived from the national food' consumption survey 1997-1998 in men and women aged between 19 and $50 y$ in The Nethertands $(2,3)$.

'Data are derived from the national food consimption survey 2003 in young adults aged between 19 and' $30 y$ in The Nethertands (1).

${ }^{3}$ Total \% of energy as provided by monounsaturated and polyunsaturated fatty acids.

\section{STRUCTURE AND FUNCTION OF FATTY ACIDS}

With respect to their structure, all fatty acids consist of a skeleton of carbon (C) atoms with at one end a methyl $\left(\mathrm{CH}_{3}\right)$ group and at the other end a carboxyl $(\mathrm{COOH})$ group. This carbon chain varies in length and degree of unsaturation. Moreover, the position and configuration of the double bonds in the carbon chain may differ between fatty acids (Figure 1.1). According to their structure, fatty acids are denoted as $\mathrm{Ca}: \mathrm{bn}-\mathrm{c}$, in which ' $\mathrm{a}$ ' indicates the number of carbon atoms in the fatty acid chain, ' $b$ ' the number of double bonds, and ' $c$ ' the position of the first double bond as counted from the methyl group. Based on the number of double 
bonds, fatty acids without any double bond are classified as saturated fatty acids, while fatty acids with one double bond belong to the monounsaturated fatty acids and those with two or more double bonds to the polyunsaturated fatty acids (Figure 1.1). Stearic acid is an example of a saturated fatty acid, oleic acid of a monounsaturated fatty acid and linoleic acid of a polyunsaturated fatty acid.

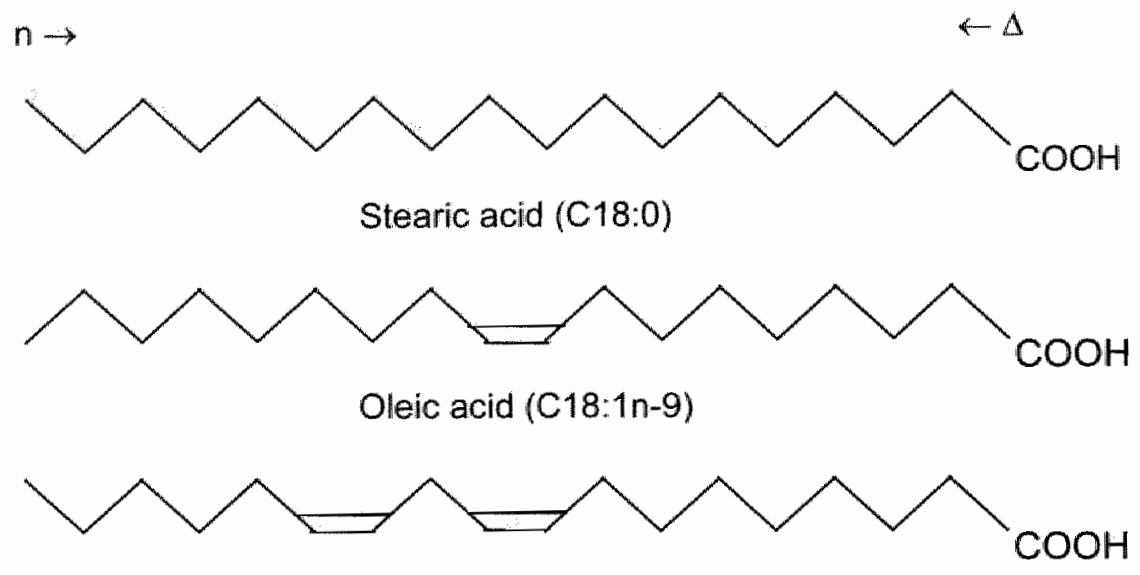

Linoleic acid $(C 18: 2 n-6)$

Figure 1.1 Chemical structures of stearic acid (a saturated fatty acid), oleic acid (a monounsaturated fatty acid) and linoleic acid (a poiyunsaturated fatty acid).

According to the position of the double bonds, unsaturated fatty acids are subdivided into various families. As counted from the methyl end of the carbon chain (n-designation), unsaturated fatty acids either belong to the $n-3, n-6, n-7$ or $n-9$ families. In contrast, the position of the double bonds may also be counted from the carboxyl end group and is then noted as ' $\Delta$ ' (Figure 1.1). Because fatty acid chain desaturation and elongation always occur between the carboxyl group and its nearest double bond, fatty acids do not change families. The major family parents of the $n-3, n-6, n-7$ and $n-9$ families are $\alpha$-linolenic acid $(c 18: 3 n-3)$, linoleic acid (C18:2n-6), palmitoleic acid (C18:1n-7) and oleic acid (C18:1n-9), respectively.

The configuration or stereochemistry of the double bonds may be cis or trans (Figure 1.2). Fatty acids, as present in natural foods mostly contain cis double bonds, whereas trans bonds result from industrial hydrogenation to harden fats or from microbial metabolism in ruminants. Conjugated linoleic acids (CLA) contain a cis as well as a trans double bond. 


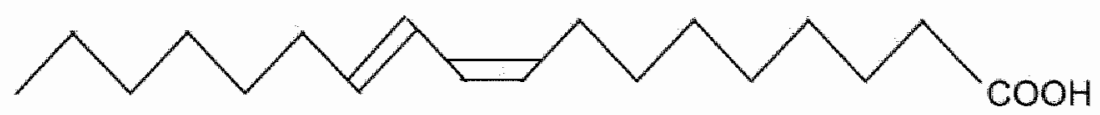

Cis- 9, trans-11 CLA $(c 9, t 11)$

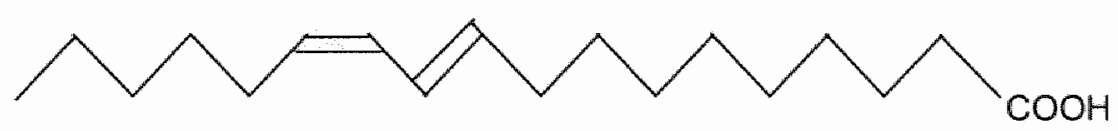

Trans-10, cis-12 CLA $(t 10, c 12)$

Figure 1.2 Chemical structures of cis-9, trans-11 $\left(c 9_{n}+11\right)$ and trans-10, cis-12 $(t 10, c 12)$ conjugated linoleic acid (CLA).

As already mentioned, fatty acids play a major role in many physiological processes. Fatty acids are components of biological membranes, function as energy suppliers and are precursors of several signalling molecules, including eicosanoids such as prostaglandins, thromboxanes, and leukotrienes. Moreover, fatty acids influence transcription of genes involved in metabolism ( 7 ). Unlike saturated fatty acids (e.g. stearic acid and palmitic acid) and monounsaturated fatty acids (e.g. oleic acid) which can be synthesised de novo in most human cells, polyunsaturated fatty acids such as linoleic acid and $\alpha$-linolenic acid can not be synthesised de novo. Therefore, these latter fatty acids of the $n-6$ and $n-3$ families have to be provided by the diet and are called essential fatty acids. The availability of long-chain polyunsaturated fatty acids in human cells greatly depends on the activity of enzymes - desaturases and elongases - involved in fatty acid biosynthesis and metabolism (8).

\section{METABOLISM OF FATTY ACIDS}

The hepatic desaturase and elongase enzymes are importantly involved in fatty acid metabolism and lipid synthesis $(8,9)$. Desaturation and elongation are involved in the maintenance of membrane fatty acid composition and fluidity, the generation of precursors for signalling molecules like eicosanoids, and the regulation of nuclear receptors. Fatty acid desaturases and elongases are involved in the conversion of fatty acids into fatty acids with a higher degree of unsaturation and a longer chain length. While fatty acid desaturases introduce a double bond in fatty acids between the carboxyl group and its nearest double bond, elongases lengthen fatty acids with a two-carbon unit from malonyl-coenzyme $A$ to the carboxyl end of a fatty acid chain 
$(8,10)$. In Figure 1.3 the biosynthesis of long-chain polyunsaturated fatty acids is shown.

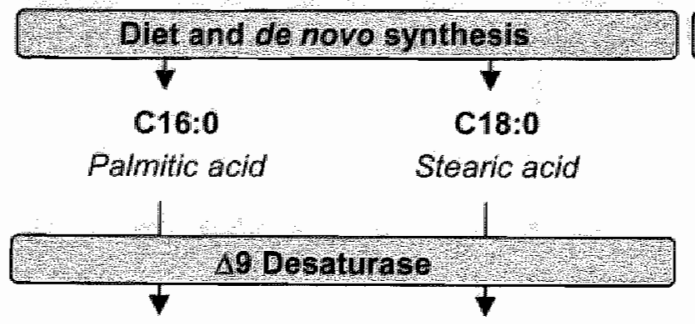

C16:1n-7

Palmitoleic acid
C18:1n-9

Oleic acid

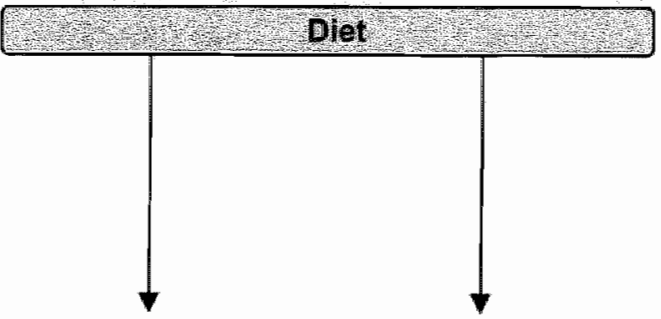

C18:2n-6
C18:3n-3

$\alpha$-Linolenic acid

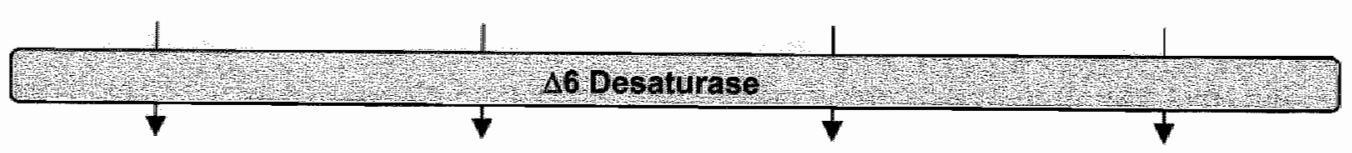

C16:2n-7

C20:2n-9

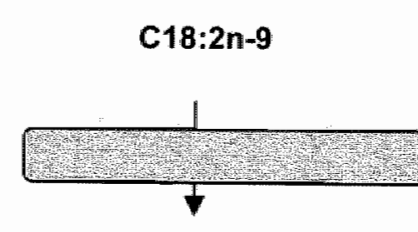

C18:3n-6

$\gamma$ Linolenic acid
C18:4n-3

Stearidonic acid

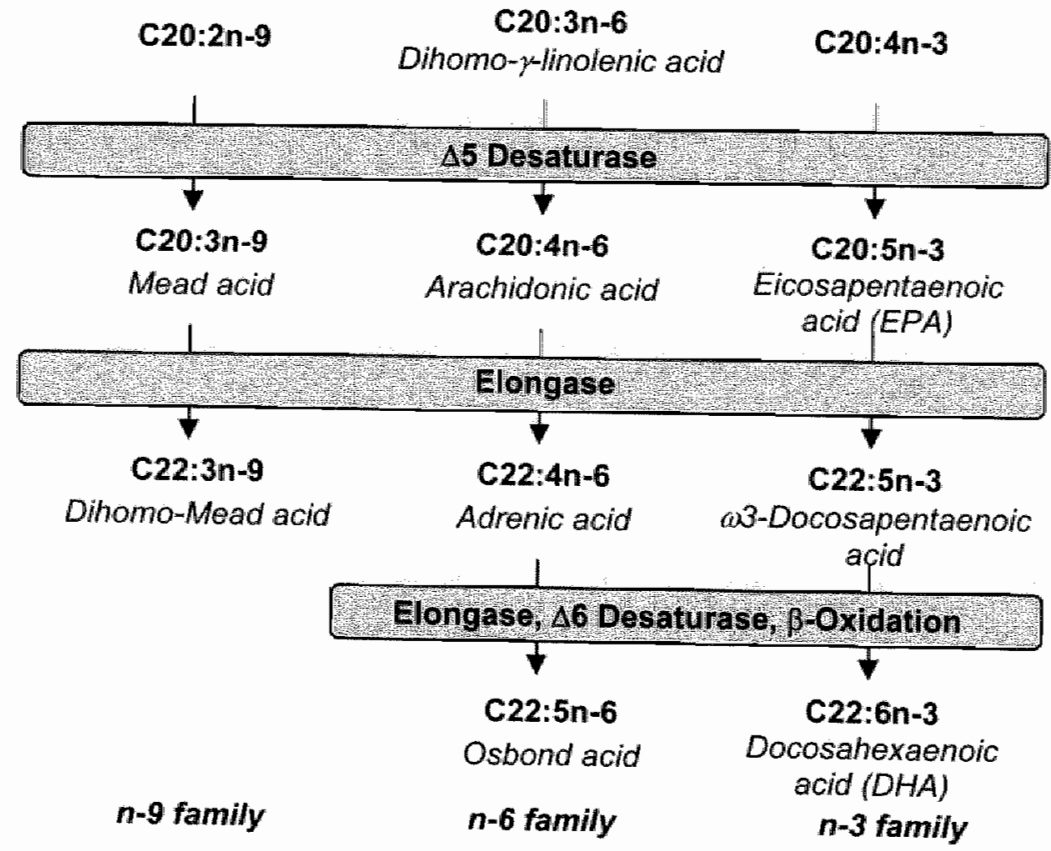

Figure 1.3 Desaturation and elongation of fatty acids. 


\section{Desaturation}

In humans, three kinds of fatty acid desaturases are present, namely $\Delta 5, \Delta 6$, and $\Delta 9$ desaturases. All three desaturases are part of a desaturase system, which includes the desaturase, $\mathrm{NADH}$-cytochrome-b5 reductase and cytochrome-b5. In this system, the desaturase enzyme is the rate-limiting enzyme. Because human desaturases are present in microsomall membranes (endoplasmatic reticulum, mitochondria and peroxisomal membranes) and use fatty acids esterified to coenzyme $A$ as substrate, they belong to the group of membrane-bound desaturases and are also called acyl-coenzyme $A(C \circ A)$ desaturases $(9)$.

The $\Delta 9$ desaturase enzyme, also called stearoyl-CoA desaturase (SCD), mediates the desaturation step of saturated fatty acids into monounsaturated fatty acids (Figure 1.3). Because desaturase enzymes are specific for the location, number, and stereochemistry of double bonds, $\Delta 9$ desaturase introduces the first cis-double bound at the $\Delta 9$ position from the carboxyl end of fatty acids (9). Since $\Delta 9$ desaturase is the rate-limiting enzyme in the cellular synthesis of monounsaturated fatty acids and a proper ratio of saturated to monounsaturated fatty acids contributes to membrane fluidity, and monounsaturated fatty acids are required in the liver for the synthesis of triacylglycerols and cholesteryl esters, $\Delta 9$ desaturase has been implicated in the regulation of cell growth and differentiation through effects on membrane fluidity and signal transduction $(9,11)$.

$\Delta 5$ and $\Delta 6$ desaturases are involved in the conversion of fatty acids into the longchain polyunsaturated members of the $n-9, n-6$ and $n-3$ families. Both $\Delta 5$ and $\Delta 6$ desaturases are called front-end desaturases because they introduce a double bond between the pre-existing double bond and the carboxyl front end of the fatty acid (9). $\Delta 6$ Desaturase introduces a double bond at the $\Delta 6$ position of fatty acids that contain already a double bond in the $\Delta 9$ position. The products of $\Delta 6$ desaturation are then converted by an elongase and subsequently desaturated by $\Delta 5$ desaturase, which is specific to desaturate $\mathrm{C} 20$ fatty acids at the $\Delta 5$ position when the fatty acid is already desaturated at the $\Delta 8$ and $\Delta 11$ positions (Figure 1.3).

The human $\Delta 5, \Delta 6$, and $\Delta 9$ desaturase genes have been identified and cloned recently. Although four isoforms of $\Delta 9$ desaturase have been identified in mice (SCD-1, SCD-2, SCD-3 and SCD-4) only one functional SCD gene that is highly homologous to mouse SCD-1 is known in humans (12). The human $\triangle 9$ desaturase gene has been locallised to chromosome 10 and consists of 6 exons and 5 introns. $A$ second known SCD locus in humans on chromosome 17 is a fully processed, transcriptionally inactive pseudogene (13). The human $\Delta 5$ and $\Delta 6$ desaturase genes are localised in a cluster on chromosome 11. Both genes consist of 12 exons and 11 
introns spanning the $17 \mathrm{~kb}$ and $39 \mathrm{~kb}$ regions, respectively. Both genes encode 444 amino acids and possess $61 \%$ amino acid identity and $75 \%$ nucleotide homology to each other $(14,15)$.

\section{Elongation}

As the desaturation steps have for long been considered to be the rate-limiting steps for the biosynthesis of long-chain polyunsaturated fatty acids, only recently interest has increased to study the role and mechanisms of elongation. The elongase system is composed of 4 enzymes namely a condensing enzyme ( $\beta$-ketoacyl coenzyme $A$ synthase), $\beta$-ketoacyl coenzyme $A$ reductase, $\beta$-hydroxyacyl coenzyme $A$ dehydrase and trans-2-enoyl coenzyme $A$ reductase. In human cells, multiple microsomal elongase enzymes have been identified with different chain length specificities. Corresponding gene sequences have been classified for the gene family of elongases (ELOVL) involved in the biosynthesis of very-long-chain fatty acids (8). ELOVL2 and ELOVL4 have been found to convert C20 as well as C22 polyunsaturated fatty acids, whereas $\gamma$-linolenic acid and $\alpha$-linolenic acid are substrates for ELOVL1, ELOVL3 and ELOVL5. In addition, ELOVL1 and ELOVL5 (or HELO1) convert arachidonic acid and EPA, and ELOVL5 also stearidonic acid (8). The human ELOVL5 gene has been localised to chromosome 6 and consists of 7 exons and 6 introns. The ELOVL5 gene encodes 299 amino acids and shares $56 \%$ amino acid identity with ELOVL2 $(16,17)$.

\section{Regulation of desaturases and elongases by fatty acids}

As the liver plays a central role in the maintenance of systemic lipid homeostasis, desaturases and elongases are predominantly expressed in the liver. However, also other human tissues including heart, brain, lung, and kidney tissues express human desaturases $(13,15)$ and elongases $(17)$. Several nutritional and hormonal factors are known to regulate the activity of desaturases and elongases $(9,12,18)$. Polyunsaturated fatty acids, especially those of the $n-6$ and $n-3$ families, have been reported to suppress the activity of desaturases and elongases (19-21). Moreover, CLA isomers, in particular $t 10, c 12 \mathrm{CLA}$, may inhibit the expression or activity of $\Delta \mathrm{g}$ desaturase (22-26). Also the expression of $\Delta 5$ and $\Delta 6$ desaturases is suppressed by linoleic acid and fish fatty acids $(14,15)$. Previous studies reported less or even no effects of saturated and monounsaturated fatty acids on the expression of desaturases and elongases $(20,21,27)$.

Most of the studies, which investigated the regulation of desaturases and elongases by fatty acids, were performed in rats and mice. For human studies, however, liver cells are not easily accessible. Prabably peripheral blood 
mononuclear cells (PBMC) obtained by venipuncture may reflect gene expression of desaturases and elongases. Whether human desaturases and elongases are regulated in a similar way as in animals is unknown.

\section{PATHOGENESIS OF CARDIOVASCULAR DISEASES}

Atherosclerosis is importantly involved in the pathogenesis of cardiovascular diseases. Morbidity and mortality from cardiovascular diseases including coronary heart disease (angina pectoris, myocardial infarction), cerebrovascular diseases (ischemic stroke) and peripheral arterial disease (gangrene, intermittent claudicatio) can largely be explained by the development of an atherosclerotic plaque in one or more coronary, cerebrovascular or peripheral arteries $(5,28)$.

Atherosclerosis is characterised by the accumulation of lipids in the arterial wall. Uptake, modification, and the subendothelial retention of cholesterol-rich, atherogenic lipoproteins within the arterial wall are thought to be initiating events in atherosclerosis (28). Through ionic interactions between positively charged residues of the lipoproteins and negatively charged residues in the extracellular matrix molecules, in particular of proteoglycans, atherogenic lipoproteins that gain entry to the subendothelial space are bound and retained in the subendothelium $(29,30)$. As a result of exposure to free radicals or reactive oxygen species, lipids and in particular low-density lipoproteins (LDL) become modified by oxidation, ultimately resulting in lipid peroxidation (31). Such modifications initially give rise to mildly oxidised LDL, which is recognised by the normal LDL receptor but not by the scavenger receptors of macrophages. Further oxidation of the LDL particles leads to highly oxidised $L D L$, which can be recognised by both receptor species mediating internalisation into macrophages resulting in the formation of foam cells $(32,33)$.

In the last decades, evidence emerged that atherosclerosis is characterised by a chronic condition of low-grade inflammation. Several inflammatory cells including monocyte-derived macrophages, T-lymphocytes and smooth muscle cells have been found to accumulate at the site of an atherosclerotic plaque (28). In the activation and chemotaxis of these cells, adhesion molecules expressed on endothelial cells as well as immune cells and chemoattractant molecules play an important role $(28,34,35)$.

Finally, this chronic inflammatory process may result in an acute clinical event. Most common complications of an atherosclerotic plaque result from plaque rupture and arterial thrombus formation (28). Arterial thrombus formation at the site of an atherosclerotic plaque results from a misbalance between thrombogenesis and thrombolysis. Platelet adhesion, activation and aggregation as well as blood 
coagulation, resulting in fibrin formation, and fibrinolysis are involved in the regulation of the thrombotic tendency $(28,34-36)$.

\section{CARDIOVASCULAR DISEASE RISK MARKERS}

\section{Lipids and lipoproteins}

The concentrations of total cholesterol are positively associated with mortality rates from cardiovascular diseases (37). Because cholesterol is transported in human blood by lipoproteins, in particular by the atherogenic low-density lipoproteins (LDL), LDL particles are a major determinant of serum total cholesterol concentrations. In contrast to LDL cholesterol, increased concentrations of cholesterol in the highdensity lipoproteins (HDL), also called the "good" cholesterol, may protect against cardiovascular diseases (38). Therefore, a decrease of the LDL or an increase of $\mathrm{HDL}$ cholesterol concentrations reduces cardiovascular disease risk. Calculated from the concentrations of total and HDL cholesterol, the ratio of total to HDL cholesterol is a strong indicator of cardiovascular disease risk. In the Netherlands, the total to HDL cholesterol ratio is used together with other major risk markers i.e. gender, age, smoking, the presence of diabetes mellitus, and the presence of hypertension to predict the risk to develop coronary heart disease in the following 10 $y$ as summarised in the cholesterol consensus (39).

\section{Thrombotic tendency}

Several thrombogenic factors are involved in the development of atheroscierosis and/or in the initiation of thrombosis at the atherosclerotic surface. Since platelets are importantly involved in arterial thrombus formation (40), measurements of platelet aggregation are widely used to examine platelet function. The principle method in platelet studies is the in vitro platelet aggregation test whereby platelet aggregation is initiated in vitro by an inducer such as adrenalin, thrombin, collagen or adenosine diphosphate (ADP). Either whole blood or plasma enriched in platelets, platelet-rich plasma (PRP), can be used for these analyses. Indeed, several studies confirmed the association between in vitro platelet aggregation and the risk to develop cardiovascular diseases $(41,42)$ but the predictive value of a platelet aggregation test remains unclear $(43,44)$. As it is difficult to assess platelet function in vivo, an ex vivo method has been developed to measure platelet aggregation using the filtragometer (45).

With respect to the blood coagulation system, often activity of coagulation factor VII, and concentrations of fibrinogen or prothrombin fragments 1 and 2 have been measured in dietary studies. Several prospective epidemiologic studies have 
associated these hemostatic markers to cardiovascular disease risk (46-48). Also a decreased fibrinolytic function, which can be due to an increased concentration or activity of plasminogen activator inhibitor-1 (PAI-1), or an impaired possibility to release tissue plasminogen activator (tPA) are correlated with the development of cardiovascular diseases $(47,49)$. In addition, concentrations of the resulting IPA/PAI1 complex are elevated in patients with cardiovascular diseases (50).

\section{Lipid peroxidation}

The atherogenicity of lipid particles is largely increased by lipid peroxidation (32). Initially, most dietary studies measured lipid peroxidation indirectly as susceptibility of LDL to modification by oxidizing agents such as metal ions in an in vitro situation. Recently, assays to measure lipid peroxidation in vivo have been developed. Isoprostanes are a complex family of prostaglandin isomers which are produced by the oxidative modification of polyunsaturated fatty acids and are therefore direct biomarkers of lipid peroxidation (51-53). Urinary concentrations of isoprostanes have been positively associated with coronary heart disease (54).

\section{Inflammation}

Over the past years, several inflammatory risk markers have been suggested to be involved in cardiovascular diseases (55-57). High sensitivity C-reactive protein (hsCRP) is a circulating acute phase reactant that reflects systemic inflammation. It has been associated with cardiovascular events (58) and the severity of atherosclerosis (59).

As response to injury, human peripheral blood mononuclear cells (PBMC) in particular monocytes and lymphocytes produce a wide range of immunomodulatory molecules. Although insights in their functions in inflammatory processes and the pathogenesis of atherosclerosis are accumulating, their use as prognostic inflammatory markers in cardiovascular diseases remains to be established (60).

\section{FATTY ACIDS AND CARDIOVASCULAR DISEASES}

Almost four decades ago, Keys and colleagues (61) already evaluated the differences in prevalence of coronary heart disease in 16 defined cohorts from seven countries (Finland, Greece, Italy, Japan, The Netherlands, the United States, and Yugoslavia). The Seven Countries Study has been the first study that showed a strong correlation between the dietary intake of saturated fatty acids and the incidence and mortality from cardiovascular diseases after 5 y of follow-up (61). Recently, the fatty acid composition of duplicate portions of the foods in the seven 
countries was analysed accurately and the vital status of the participants was verified after $25 \mathrm{y}$ of follow-up (62). Mortality rates from cardiovascular diseases were strongly associated with the average intakes of the four most common saturated fatty acids, lauric, myristic, palmitic, and stearic acids. For lauric and myristic acids, these relationships depended on serum total cholesterol concentrations, whereas palmitic and stearic acids were more strongly related to cardiovascular disease mortality rates than to serum total cholesterol concentrations (62). This may suggest that these latter two fatty acids also exert their effects on cardiovascular mortality by other metabolic pathways than lipid and lipoprotein metabolism. Several later studies supported the association between the dietary intake of saturated fatty acids and the mortality from cardiovascular diseases. In addition, monounsaturated and polyunsaturated fatty acids have been reported to be inversely associated with cardiovascular disease risk. A comprehensive review of epidemiological studies has been published recently (63).

In contrast, data of within population studies are lesis unequivocal. Moreover, the interpretation of these studies is complicated by small study sizes, inadequate dietary assessments and heterogeneity of the study designs $(63,64)$. In a large prospective cohort study in the United States, the Nurses' Health study, the incidence of cardiovascular diseases after $14 \mathrm{y}$ of follow-up was correlated to the dietary intake of saturated fatty acids in women (65). In this study, however, the relative risk to develop cardiovascular diseases was strongest associated with the intake of trans fatty acids. Dietary intakes of monounsaturated and polyunsaturated fatty acids were inversely associated. Total dietary fat intake was not significantly related to cardiovascular disease risk (65). Later analyses, after 20 y of follow-up, found similar relationships (66). Hence, the replacement of saturated and trans unsaturated fatty acids in the diet by monounsaturated and polyunsaturated fatty acids would be more effective in preventing cardiovascular diseases than reducing overall fat intake. Therefore, cardiovascular disease risk would depend on the quality rather than the quantity of dietary fat $(67)$.

Because prospective epidemiologic studies are quite difficult to perform and susceptible to confounding which may reveal inconsistent results, in most human studies the effects of dietary fats on the risk of cardiovascular diseases have been estimated in randomised clinical trials mainly from their effects on cardiovascular disease risk markers, in particular serum lipid and lipoprotein concentrations.

\section{Effects of fatty acids on lipids and lipoproteins}

In the 1950 s and 1960 s Keys et al (68) and Hegsted et al (69) summarised the results of several well-controlled studies. The relationships between changes in 
dietary fatty acid intake and changes in serum total cholesterol in men have been described in the following predictive equations:

$\Delta$ serum total cholesterol $(\mathrm{mmol} / \mathrm{L})=0.03 \times\left(2 \times \Delta\right.$ Sat $_{12-16}{ }^{\circ}-\Delta$ Poly $)$

$\Delta$ serum total cholesterol $(\mathrm{mmol} / \mathrm{L})=0.06 \times \Delta S-0.04 \times \Delta P-0.01$

Relative to an iso-energetic amount of carbohydrates, saturated fatty acids ( $\mathrm{S}$ or Sat) increased serum total cholesterol concentrations. In contrast, polyunsaturated fatty acids ( $P$ or Poly) like linoleic acid reduced serum total cholesterol concentrations about half as much as saturated fatty acids raised it $(68,69)$. The major cholesterol-raising saturated fatty acid appeared to be myristic acid. As exception to the other saturated fatty acids, stearic acid had little or no effect on serum total cholesterol concentrations. Also monounsaturated fatty acids did not change serum total cholesterol concentrations and were therefore assumed to be cholesterol-neutral $(68,69)$. These earlier studies, however, did not differentiate between the effects on LDL and HDL cholesterol nor were gender effects examined.

Table 1.2 Predictive equations for mean changes in concentrations of serum total (TC), IOWdensity lipoprotein (LDL) and high-density lipoprotein (HDL) cholesterol in mmol/L when 1\% of energy of dietary carbohydrates is replaced iso-energetically by fatty acids.

\begin{tabular}{|c|c|c|}
\hline Reference & & Equations \\
\hline \multirow{3}{*}{ Mensink and Katan, 1992} & $(70)$ & $\Delta T C=0.039^{*} \Delta S-0.003^{*} \Delta M-0.015^{*} \Delta P$ \\
\hline & & $\Delta \mathrm{LDL}=0.033^{*} \Delta S-0.006^{\star} \Delta \mathrm{M}-0.0014^{\star} \Delta \mathrm{P}$ \\
\hline & & $\Delta H D L=0.012^{*} \Delta S+0.009^{*} \Delta M+0.007^{*} \Delta P$ \\
\hline \multirow[t]{3}{*}{ Hegsted et al, 1993} & $(71)$ & $\Delta T C=0.0543^{\star} \Delta S-0.0301^{\star} \Delta P+0.00725^{\star} \Delta C$ \\
\hline & & $\Delta \mathrm{LDL}=0.0449^{*} \Delta S-0.0198^{*} \Delta \mathrm{P}+0.00475^{\star} \Delta \mathrm{C}$ \\
\hline & & $\Delta H D L=0.0110^{*} \Delta S+0.0026^{*} \Delta M+0.0056^{*} \Delta P+0.0047^{*} \Delta C$ \\
\hline
\end{tabular}

In later studies regression equations were developed to predict dietary responsiveness of concentrations of total, $L D L$, and $H D L$ cholesterol, and triacylglycerols to saturated, monounsaturated, and polyunsaturated fatty acids $(70,71)$. Predictive equations of these two studies are summarised in Table 1.2. More recent meta-analyses even distinguished between the effects of the individual saturated falty acids (72,73). Yu et al (72) provided new evidence that stearic acid would have unique effects on total, LDL, and HDL cholesterol concentrations. Unlike the other saturated fatty acids, stearic acid appeared to be cholesterol-neutral (72). In another meta-analysis of 60 clinical trials the effects of fatty acids were estimated on concentrations of total, LDL, and HDL cholesterol, and of triacylglycerols as well as on the ratio of total to HDL cholesterol. Three distinct models were used to 
estimate effects of the major lipid classes (saturated, monounsaturated, and polyunsaturated fatty acids), the individual saturated fatty acids (lauric acid, myristic acid, palmitic acid, and stearic acid), and trans fatty acids (73). Interestingly, in this meta-analysis, effects of saturated and polyunsaturated fatty acids also were less than predicted by the equations of Keys et al (68) and Hegsted et al (69). Moreover, lauric acid had a more favourable effect on the total to HDL cholesterol ratio than any other saturated or unsaturated fatty acid.

While most dietary intervention studies focused on the effects of fatty acids on the lipoprotein profile, less data are available about the effects of dietary fatty acids on biomarkers of thrombotic tendency, lipid peroxidation and inflammation.

\section{OUTLINE OF THIS THESIS}

This thesis describes the effects of fatty acids, in particular stearic acid, oleic acid, and linoleic acid, and the conjugated linoleic acid (CLA) isomers, $c 9, t 11$ and $t 10, c 12$ CLA on risk markers of cardiovascular diseases and on fatty acid desaturation and elongation.

In Chapter 2 the effects of fatty acids are described on atherosclerotic risk markers. We have critically reviewed the literature on this topic and focused on the influence of saturated, monounsaturated as well as polyunsaturated fatty acids on a variety of cardiovascular disease risk markers. In particular, effects on lipid and lipoprotein metabolism, lipid peroxidation, inflammation, and thrombotic tendency have been summarised.

In the following three chapters the results are discussed from a crossover study in which the effects of stearic acid, oleic acid, and linoleic acid on several cardiovascular disease risk markers have been compared. Chapter 3 describes the effects of these three C18 fatty acids with increased degree of unsaturation on the serum lipoprotein profile. Chapter 4 is focused on the effects on thrombotic tendency. Effects of stearic, oleic, and linoleic acids are reported on hematological variables, blood coagulation and fibrinolytic factors, and in vitro and ex vivo platelet aggregation. Chapter 5 discusses the effects on markers of non-enzymatic and enzymatic lipid peroxidation, 8-iso-prostaglandin $F_{2 a}$ and 15-keto-dihydroprostaglandin $F_{2 a}$, respectively, and inflammatory variables such as high-sensitivity C-reactive protein and the expression profile of immunomodulatory molecules. 
In another human intervention study, presented in Chapter 6, the effects of the individuall CLA isomers, cis-9, trans-11 CLA and trans-10, cis-12 CLA were investigated on the fatty acid composition of phospholipids, triacylglycerols and cholesteryl esters. To relate these changes to the enzymes involved in desaturation and elongation, also mRNA expression of desaturases and elongases was measured in peripheral blood mononuclear cells.

Finally, in Chapter 7 the main findings and implications of the studies described in this thesis are discussed.

\section{REFERENCES}

1. Hulshof KFAM, Ocké MC, Rossum van CTM, Buurma-Rethans EJM, Brants HAM, Driivers JJMM and Doest ter D. Resultaten van de voedselconsumptiepeiling 2003. Zeist: RIVM, TNO voeding, 2004.

2. Hulshof KFAM, Kistemaker $C$ and Bouman $M$. De inname van energie en woedingsstoffen door Nederlandse bevolkingsgroepen - Voedselconsumptiepeiling 1997-1998. Zeist: TNO Voeding, 1998.

3. Hulshof KFAM, Jansen-van der Vliet $M$, Westenbrink $S$ and Doest ter $D$. De inneming van vetzuren en vetzuurclusters (voedselconsumptiepeiling 1997-1998). Zeist: TNO Voeding, 2004.

4. Nederlandse Hartstichting. Hart- en vaatziekten in Nederland 2005 - Cijfers over risicofactoren, ziekte, behandeling en sterfte. Den Haag: Nederlandse Hartstichting, 2005.

5. The Intermational Task Force for Prevention of Coronary Heart Disease. Coronary heart disease: reducing the risk. Nutr Metab Cardiovasc Dis 1998; $8 ; 205-71$.

6. Prevention of coronary heart disease in clinical practice. Recommendations of the Second Joint Task Force of European and other Societies on coronary prevention. Eur Heart $J 1998 ; 19: 1434-503$.

7. Jump DB and Clarke SD. Regulation of gene expression by dietary fat. Arnu Rev Nutr 1999; 19: 6390.

8. Leonard $A E$, Pereira $S L_{n}$ Sprecher $H$ and Huang YS. Elongation of long-chain fatty acids. Prog Lipid Res 2004; 43: 36-54.

9. Nakamura MT and Nara TY. Structure, function, and dietary regulation of delta6, delta5, and delta9 desaturases. Annu Rev Nutr 2004; 24: 345-76.

10. Sprecher $H_{n}$ Luthria DL, Mohammed BS and Baykousheva SP. Reevaluation of the pathways for the biosynthesis of polyunsaturated fatty acids. J Lipid Res 1995; 36: 2471-7.

11. Ntambi JM. Regulation of stearoyl-COA desaturase by polyunsaturated fatty acids and cholesterol. $J$ Lipid Res $1999 ; 40: 1549-58$.

12. Ntambi JM and Miyazaki M. Regulation of stearoyl-CoA desaturases and rolle in metabolism. Prog Lipid Res 2004; 43: 91-104.

13. Zhang $L, G e L, P a r i m o o ~ S, ~ S t e n n ~ K$ and Prouty SM. Human stearoyl-CoA desaturase: alternative transcripts generated from a single gene by usage of tandem polyadenylation sites. Blochem $J 1999$; 340: 255-64.

14. Cho HP, Nakamura MT and Clarke SD. Cloning, expression, and nutritional regulation of the mammalian Delta- 6 desaturase. J Biol Chem 1999; $274: 471-7$.

15. Cho HP. Nakamura M and Clarke SD. Cloning, expression, and fatty acid regulation of the human delta-5 desaturase. I Biol Chem 1999; 274: 37335-9.

16. Leonard AE, Bobik EG, Dorado J, Kroeger PE, Chuang LT, Thurmond JM, Parker-Barnes JM, Das T, Huang YS and Mukerji P. Cloning of a human cDNA encoding a novel enzyme involved in the elongation of long-chain polyunsaturated fatty acids. Biocherm $J 2000 ; 350 \mathrm{Pt} 3: 765-70$.

17. Leonard $A E$, Kelder B, Bobik EG, Chuang LT, Lewis $C J$, Kopchick JJ, Mukerji $P$ and Huang $Y S$. Identification and expression of mammalian long-chain PUFA elongation enzymes. Lipids 2002; 37: $733-40$.

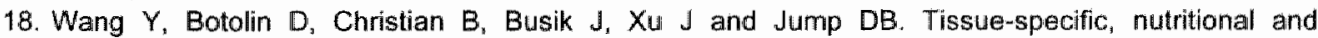
developmental regulation of rat fatty acid elongases. J Lipid Res 2005; 46: 706-715.

19. Sessler AM, Kaur N, Palta JP and Ntambi JM. Regulation of stearoyl-CoA desaturase 1 mRNA stability by polyunsaturated fatty acids in 3T3-L1 adipocytes. J Biol Chem 1996; 271: 29854-8. 
20. Landschulz KT, Jump DB, MacDougald OA and Lane MD. Transcriptional control of the stearoyt-CoA desaturase-1 gene by polyumsaturated fatty acids. Biochem Biophys Res Commun 1994; 200: 763-8.

21. Ntambi MM. Dietary regulation of stearoyl-CoA desaturase " gene expression in mouse liver. J Biol Chem 1992; 267: 10925-30.

22. Park $Y$, Storkson JM, Ntambi JM, Cook ME, Sih CJ and Pariza MW. Inhibition of hepatic stearoyl-CoA desaturase activity by trans-10, cis-12 conjugated linoleic acid and its derivatives. Biochim Biophys Acta 2000: 1486: $285-92$.

23. Lee KN, Pariza MW and Ntambi JM. Conjugated linoleic acid decreases hepatic stearoyl-CoA desaturase mRNA expression. Biochem Biophys Res Commun 1998; 248: 817-21.

24. Eder $K$, Slomma $N$ and Becker $K$. Trans-10,cis-12 conjugated linoleic acid suppresses the desaturation of linoleic and alpha-linolenic acids in HepG2 cells. J Nutr 2002; 132: 1115-21.

25. Choi $Y$, Park Y, Pariza MW and Ntambi JM. Regulation of stearoyl-CoA desaturase activity by the trans-10;cis-12 isomer of conjugated linoleic acid in HepG2 cells. Biochem Brophys Res Commun 2001: 284: 689-93

26. Bretillon $\mathrm{L}$, Chardigny $\mathrm{JM}$, Gregoire $S$, Berdeaux $O$ and Sebedio $\mathrm{JL}$. Effects of conjugated linoleic acid isomers on the hepatic microsomal desaturation activities in vitro. Lipids 1999; 34: 965-9.

27. Bene H, Lasky $D$ and Ntambi JM. Cloning and characterization of the human stearoyl-CoA desaturase gene promoter: transcriptional activation by sterol regulatory element binding protein and repression by polyunsaturated fatty acids and cholesterol. Bioctiem Biophys Res Commun 2001; 284 : 1194-8.

28. Ross R. Atherosclerosis--an inflammatory disease. N Engl J Med 1999; 340: 115-26.

29. Williams $\mathrm{KJ}$ and Tabas I. The response-to-retention hypothesis of early atherogenesis. Arterioscler Thromb Vasc Biol 1995; 15: 551-61

30. Gustafsson $M_{2}$ Flood $C_{\text {, }}$ Jirholt $P$ and Boren J. Retention of atherogenic lipoproteins in atherogenesis. Cell Mol Life Sci 2004; 61 : 4-9.

31. Steinberg $D_{n}$ Parthasarathy $S$, Carew TE, Khoo JC and Witztum JL. Beyond cholesterol. Modifications of low-density lipoprotein that increase its atherogenicity. N Engl J Med 1989; 320: 91524.

32. Berliner JA, Navab M, Fogelman AM, Frank JS, Demer LL, Edwards PA, Watson AD and Lusis AJ. Atherosclerosis: basic mechanisms. Oxidation, inflammation, and genetics. Circulation 1995; 91 : 2488-96.

33. Navab M, Berliner JA, Watson AD, Hama SY, Territo MC, Lusis AJ, Shih DM, Van Lenten BJ, Frank JS, Demer LL et al. The Yin and Yang of oxidation in the development of the fatiy streak. A review based on the 1994 George Lyman Duff Memorial Lecture. Arterioscler Thromb Vasc Biol 1996; 16: $831-42$.

34. Lusis AJ. Atherosclerosis. Nature 2000; 407: 233-41.

35. Libby P, Ridker PM and Maseri A. linflammation and atherosclerosis. Circulation 2002; 105: 1135-43.

36. Robbie $L$ and Libby P. Inflammation and atherothrombosis. Ann $N$ Y Acad Sci 2001; 947: 167-79; discussion $79-80$.

37. Anderson KM. Castelli WP and Lewy D. Chollesterol and mortality. 30 years of follow-up from the Framingham study. JAMA 1987; 257: 2176-80.

38. Gordon DJ and Rifkind BM. High-density lipoprotein-the clinical implications of recent studies. N Engl I Med 1989; 321: 1311-6.

39. Centraal Begeleidingsorgaan voor de Intercollegiale Toetsing. Consensus Cholesterol - Syllabus behandeling en preventie van coronaire hartziekten door verlaging van de plasmacholesterolconcentratie. Tweede herziening. Utrecht, 1998.

40. Ruggeri ZM. Platelets in atherothrombosis. Nat Med 2002; 8: 1227-34.

41. Elwood PC, Renaud S, Sharp DS, Beswick AD, O'Brien JR and Yarnell JW, Ischemic heart disease and platelet aggregation. The Caerphilly Collaborative Heart Disease Study. Circulation 1991; 83: $38-$ 44.

42. Thaulow E, Erikssen J, Sandvik L, Stormorken H and Cohn PF. Blood platelet count and function are related to total and cardiovascular death in apparently healthy men. Circulation 1991; 84: 613-7.

43. Elwood PC, Renaud $S$, Beswick $A D$, O'Brien $J R$ and Sweetnam PM. Platelet aggregation and incident ischaemic heart disease in the Caerphilly cohort. Heart 1998; 80: 578-82.

44. Meade TW, Cooper JA and Miller GJ. Platelet counts and aggregation measures in the incidence of ischaemic heart disease (IHD). Thromb Haemost 1997; 78: 926-9.

45. Hornstra $G$ and ten Hoor $F$. The filtragometer: a new device for measuring platelet aggregation in venous blood of man. Thromb Diath Haemorrh 1975; 34: 531-44. 
46. Danesh $\downarrow$, Collins $R$, Appleby $P$ and Peto R. Association of fibrinogen, C-reactive protein, albumin, or leukocyte count with coronary heart disease: meta-analyses of prospective studies. JAMA 1998; 279: $1477-82$.

47. Folsom AR. Hemostatic risk factors for atherothrombotic disease: an epidemiologic view. Thromb Haemost 2001; 86: 366-73.

48. Miller GJ, Bauer KA, Barzegar $S$, Cooper JA and Rosenberg RD. Increased actiwation of the haemostatic system in men at high risk of fatal coronary heart disease. Thromb Haemost 1996; 75 : $767-71$.

49. Ridker PM. Fibrinolytic and inflammatory markers for arterial occlusion: the evolving epidemiology of thrombosis and hemostasis. Thromb Haemost 1997; 78: 53-9.

50. Wiman B, Andersson T, Hallquist $\mathbb{J}$, Reuterwall $\mathrm{C}$. Ahibom A and deFaire U. Plasma levels of tissue plasminogen activator/plasminogen activator inhibitor-1 complex and von Willebrand factor are significant risk markers for recurrent myocardial infarction in the Stockholm Heart Epidemiology Program (SHEEP) study. Arterioscler Thromb Vasc Biol 2000; 20: 2019-23.

51. Roberts $L J$, 2nd and Morrow JD. Isoprostanes. Novel markers of endogenous lipid peroxidation and potential mediators of oxidant injury. Ann N Y Acad Sci 1994; 744: 237-42.

52. Pratico D. $F(2)$-isoprostanes: sensitive and specific non-invasive indices of lipid peroxidation in vivo. Atherosclerosis 1999; 147: 1-10.

53. Cracowski JL, Durand T and Bessard $G$. Isoprostanes as a biomarker of lipid peroxidation in humans: physiology, pharmacology and clinical implications. Trends Pharmacol Sci 2002; 23: 360-6.

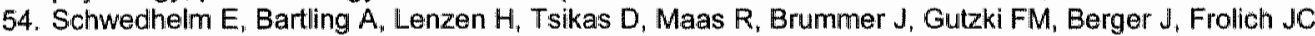
and Boger RH. Urinary 8-iso-prostaglandin F2alpha as a risk marker in patients with coronary heart disease: a matched case-control study. Circulation 2004; 109: 843-8.

55. Magliano DJ, Liew D, Ashton EL, Sundararajan V and McNeil JJ. Novel biomedical risk markers for cardiovascular disease. $J$ Cardiovase Risk 2003; 10: 41-55.

56. Lind $L_{\text {. }}$ Circulating markers of inflammation and atherosclerosis. Atherosclerosis 2003; 169: 203-14.

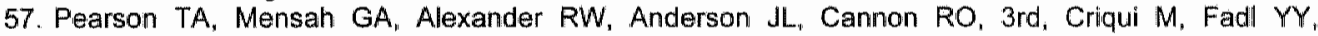
Fortmann SP, Hong $Y$, Myers GL et al. Markers of inflammation and cardiovascular disease: application to clinical and public health practice: A statement for healthcare professionals from the Centers for Disease Control and Prevention and the American Heart Association. Circulation 2003; 107: 499-511.

58. Ridker $\mathrm{PM}_{1}$ Rifai N, Rose $\mathrm{L}_{\mathrm{n}}$ Buring JE and Cook NR. Comparison of C-reactive protein and lowdensity lipoprotein cholesterol levels in the prediction of first cardiovascular events. $N$ Engl $d$ Med 2002; 347: 1557-65.

59. van der Meer IM, de Maat MP, Bots ML, Breteler MM, Meijer J, Killiaan AJ, Hofman A and Witteman $\mathrm{JC}$. Inflammatiory mediators and cell adhesion molecules as indicators of severity of atherosclerosis: the Rotterdam Study. Arterioscler Thromb Vasc Biol 2002; 22: 838-42.

60. Young $\mathrm{JL}$, Libby $\mathrm{P}$ and Schonbeck $\mathrm{U}$. Cytokines in the pathogenesis of atherosclerosis. Thromb Haemost 2002; 88: 554-67.

61. Keys A. Coronary heart disease in seven countries. Circulation 1970; 41: 1-198.

62. Kromhout $D$, Menotti $A$, Bloemberg $B$, Aravanis $C$, Blackburn $H$, Buzina $R$, Dontas $A S$, Fidanza $F$, Giampaoli $S$, Jansen $A$ et al. Dietary saturated and trans fatty acids and cholesterol and 25-year mortality from coronary heart disease: the Seven Countries Study. Prev Med 1995; 24: 308-15.

63. Caggiula AW and Mustad VA. Effects of dietary fat and fatty acids on coronary artery disease risk and total and lipoprotein cholesterol concentrations: epidemiologic studies. Am I Clin Nutr 1997; 65 1597 S-610S.

64. Hu FB, Manson JE and Willett WC. Types of dietary fat and risk of cononary heart disease: a critical review. J Am Coll Nutr 2001; 20: 5-19.

65. Hu FB, Stampfer MJ, Manson JE, Rimm E, Colditz GA, Rosner BA, Hennekens CH and Willett WC. Dietary fat intake and the risk of coronary heart disease in women. N Engl J Med 1997: 337; 1491-9.

66. Oh K. Hu FB, Manson JE, Stampfer Mل and Willett WC. Dietary fat intake and risk of coronary heart disease in women: 20 years of follow-up of the nurses' health study. Am J Epidemiol 2005; $161: 672$ 9 .

67. Ascherio A. Epidemiologic studies on dietary fats and coronary heart disease, Am J Med 2002; 113 Suppl 9B: 9S-12S.

68. Keys A, Anderson UT and Grande F. Serum cholesterol response to changes in the diet. IV. Particular saturated fatty acids in the diet. Metabolism 1965; 14: 776-87. 
69. Hegsted DM, McGandy RB, Myers ML and Stare FJ: Quantitative effects of dietary fat on serum cholesterol in man. Am iJ Clin Nutr 1965; 17: 281-95.

70. Mensink RP and Katan MB. Effect of dietary fatty acids on serum lipids and lipoproteins. A metaanalysis of 27 trials. Arterioscler Thromb 1992; $12 ; 911-9$.

71. Hegsted DM, Ausman $\mathrm{LM}_{3}$ Johnson $\mathrm{JA}$ and Dallal GE. Dietary fat and serum lipids: an evaluation of the experimental data. Am J Clin Nutr $1993,57875-83$.

72. Yu $S$, Derr $J_{1}$ Etherton TD and Kris-Ethertan PM. Plasma cholesterol-predictive equations: demonstrate that stearic acid is meutral and monounsaturated fatty acids are hypocholesterolemic. Am J Clin Nutr 1995, 61: 1129-39.

73. Mensink RP, Zock PL. Kester AD and Katan MB. Effects of dietary fatty acids and carbohydrates on the ratio of serum total to HDL cholesterol and on serum lipids and apolipoproteins: a meta-analysis of 60 controlled trials. Am J Clin Nutr 2003; 77: 1146-55. 


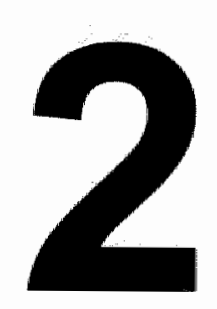

\title{
Fatty acids and atherosclerotic risk
}

\author{
Myriam A.M.A. Thijssen ${ }^{1}$ and Ronald P. Mensink"
}

Chapter in: Handbook of Experimental Pharmacology 170: Atherosclerosis: Diet and Drugs, edited by A. von Eckardstein, 2005

'Nutrition and Toxicology Research Institute Maastricht (NUTRIM), Department of Human Biology, Maastricht University, Maastricht, The Netherlands 


\section{ABSTRACT}

Most research concerning the effects of dietary fatty acids on atherosclerotic risk has focused on their effects on lipid and lipoprotein metabolism. However, it is known that fatty acids also influence a number of other relevant mechanisms involved in atherosclerosis such as lipid peroxidation, inflammation and hemostasis.

The most favourable distribution of cholesterol over the various lipoproteins is achieved when a mixture of cis-unsaturated fatty acids replaces saturated and trans fatty acids. Furthermore, fatty acids from fish oil lower concentrations of triacylglycerols. Effects on other atherosclerotic risk markers are less evident. Monounsaturated fatty acids may be preferable above other fatty acids with respect to low-density lipoprotein ( $L D L$ ) oxidation as measured by indirect in vitro assays. The relevance of these assays for the in vivo situation is, however, limited. With respect to inflammation, mainly the effects of n-3 polyunsaturated fatty acids from fish oil have been studied but results were inconsistent. Also results from studies evaluating the effects of fatty acids on hemostatic risk markers were inconsistent, which may be partly related to the use of different analytical methods. The most consistent finding, however, is the potential beneficial effect of moderate intakes of fish oil on platelet aggregation. Furthermore, reducing total fat intake rather than changing the fatty acid composition of the diet may beneficially affect the coagulation system.

in conclusion, while beneficial effects on atherosclerotic risk are mainly ascribed to cis-unsaturated fatty acids, it remains debatable whether trans and saturated fatty acids in the diet have to be replaced by cis-unsaturated fatty acids or by carbohydrates. To answer this question adequately more validated methods are needed that reflect in vivo lipid peroxidation, inflammation and hemostasis. 


\section{DIETARY FATTY ACIDS}

Although dietary fats and oils always consist of a mixture of fatty acids, each fat and oil has its own characteristic fatty acid composition. Usually, one or two fatty acids are predominant (Table 2.1), each with its characteristics. Based on chain length, fatty acids can be classified as short-chain fatty acids ( 4 to 6 carbon atoms), medium-chain fatty acids ( 8 to 10 carbon atoms), long-chain fatty acids ( 12 to 18 carbon atoms) and very-long-chain fatty acids (more than 18 carbon atoms). In addition, fatty acids may vary in the number of double bonds. Major fatty acid classes are saturated fatty acids with no double bonds, monounsaturated fatty acids with one double bond, and polyunsaturated fatty acids with two or more double bonds. Based on the position of the double bond nearest to the methyl end of the carbon chain, fatty acids are divided into families. So palmitoleic acid, a metabolite of palmitic acid, belongs to the $n-7$ family, oleic acid to the $n-9$ family, linoleic acid to the $n-6$ family, and $\alpha$-linolenic acid to the $n-3$ family. Finally, the configuration of the double bond can be cis or trans.

Table 2.1 Major fatty acids in some edible fats ands oils.

\begin{tabular}{|c|c|c|}
\hline Common name & Formula & Source \\
\hline \multicolumn{3}{|l|}{ Saturated fatty acids } \\
\hline Medium-chain fatty acids & $\mathrm{C} 4: 0-\mathrm{C} 10: 0$ & Dairy fat, coconut oil, palm kernel oil \\
\hline Lauric acid & $\mathrm{C} 12: 0$ & Dairy fat, coconut oil, palm kernel oil \\
\hline Myristic acid & C14:0 & Dairy fat, coconut oil, palm kernel oil \\
\hline Palmitic acid & C16:0 & Meat, palm oil \\
\hline Stearic acid & C18:0 & Meat, cocoa butter \\
\hline \multicolumn{3}{|l|}{ Monounsaturated fatty acids } \\
\hline Oleic acid & C18:1n-9 & Olive oil, rapeseed oil, avocado, nuts \\
\hline \multicolumn{3}{|l|}{ Polyunsaturated fatty acids } \\
\hline Linoleic acid & C18:2n-6 & Sunflower oil, safflower oil, soybean oill \\
\hline$\alpha$-linolenic acid & C18:3n-3 & Soybean oill, rapeseed oil, flaxseed \\
\hline EPA & $\mathrm{C} 20: 5 n-3$ & Fish \\
\hline DHA & $\mathrm{C} 22: 5 n-3$ & Fish \\
\hline
\end{tabular}

In most diets, about $30-40 \%$ of total dietary energy intake is provided by fat. Palmitic and stearic acids are the most prevailing saturated fatty acids, while the most widespread monounsaturated and polyunsaturated fatty acids are oleic acid and linoleic acid, respectively. Ultimately all fatty acids are degraded and oxidised for energy via $\beta$-oxidation in the mitochondria of cells. However, fatty acids not only provide energy but also are important structural components of cell membranes and 
precursors of a wide range of eicosanoids (prostaglandins, thromboxanes and leukotrienes) involved in hemostasis and inflammation. Furthermore, fatty acids are ligands for transcription factors, thereby modulating gene expression. In this manner, dependent on their characteristics, fatty acids exert different effects on atherosclerotic risk markers. In this chapter, the effects of fatty acids on lipid and lipoprotein metabolism, lipid peroxidation, inflammation and hemostasis will be discussed (Table 2.2).

Table 2,2 Factors that are positively (1) or negatively $(4)$ related to atherasclerotic risk.

\begin{tabular}{lc}
\hline Risk marker & Atherosclerotic risk \\
\hline Lipid and lipoprotein metabolism & $\uparrow$ \\
Total cholesterol & $\uparrow$ \\
LDL cholesterol & $\downarrow$ \\
HDL cholesterol & $\uparrow$ \\
Total to HDL cholesterol ratio & $\uparrow$ \\
Triacylglycerols & $\uparrow$ \\
\hline Oxidative stress & $\uparrow$ \\
In vitro LDL susceptibility to oxidation & $\uparrow$ \\
Oxidised LDL & $\uparrow$ \\
F2-isoprostanes & \\
\hline Inflammation & $\uparrow$ \\
Adhesion molecules & $\uparrow$ \\
Pro-inflammatory cytokines & $\downarrow$ \\
Anti-inflammatory cytokines & \\
\hline Hemostatic function & $\uparrow$ \\
Platelet aggregation & \\
Coagulation & $\uparrow$ \\
Factor VII & $\uparrow$ \\
Fibrinogen & $\uparrow$ \\
Prothrombin fragment 1 and 2 & $\uparrow$ \\
Fibrinolysis & \\
Tissue plasminogen activator (IPA) & \\
Plasminogen activator inhibitor 1 (PAI-1) & $\uparrow$ \\
D-dimers & \\
\hline
\end{tabular}

\section{FATTY ACIDS AND LIPOPROTEIN METABOLISM}

Lipoproteins are the major transporters of lipids in the blood. While the classical risk factor for coronary heart disease is an increased concentration of serum total cholesterol, later studies have demonstrated that the various lipoproteins each have 
its specific effects on cardiovascular risk. Two major cholesterol-transporting lipoproteins are the low-density lipoproteins (LDL) and high-density lipoproteins (HDL), carrying respectively $60-70 \%$ and $20-30 \%$ of the total amount of cholesterol in the blood. While LDL is atherogenic, HDL may protect against atherosclerosis. Epidemiological studies now suggest that an increment of $0.1 \mathrm{mmol} / \mathrm{L}$ in $\mathrm{LDL}$ cholesterol results in an increase of $3.5-4.0 \%$ in cardiovascular risk, while an increase of $0.1 \mathrm{mmol} / \mathrm{L}$ in $\mathrm{HDL}$ cholesterol lowers cardiovascular risk with $8-12 \%$ (1). However, the total to HDL cholesterol ratio may be an even more specific marker to predict cardiovascular risk than total or lipoprotein cholesterol concentrations. A decrease of 0.1 unit in this ratio is associated with a $5.3 \%$ reduction in the risk of myocardial infarction (2). Another, less-validated, risk marker is the concentration of triacylglycerols. Triacylglycerols, which are mainly found in the very-low density lipoproteins (VLDL), are positively related to cardiovascular risk and a $0.1 \mathrm{mmol} / \mathrm{L}$ increase in triacylglycerols is associated with a $1.4 \%$ increase in cardiovascular risk for men and a $3.7 \%$ increase for women (3).

As outlined below, these cardiovascular risk markers are differently affected by the various fatty acids in the diet. However, the definition of a cholesterol-raising or cholesterol-lowering fatty acid is not straightforward. When fat is added to a diet energy intake increases and as result body weight will increase also. As body weight is an important determinant of serum total cholesterol concentrations, it will not be possible to disentangle dietary effects from those of changes in body weight. Therefore, in dietary intervention studies or meta-analyses intended to compare the effects of fatty acids on the serum lipoprotein profile, any change in the saturated, monounsaturated or polyunsaturated fatty acid, or carbohydrate composition of the diet is balanced by opposite changes in one or more of the others. Therefore, the effects of specific fatty acids are generally expressed relative to those of an isocaloric amount of carbohydrates or of another fatty acid.

\section{Mixtures of saturated fatty acids}

Well-controlled dietary studies carried out in the 1950s and 1960s by Keys et al and Hegsted et al found that - relative to an iso-energetic amount of carbohydrates - a mixture of saturated fatty acids increased serum total cholesterall concentrations $(4,5)$. These earlier studies, however, did not examine the effects of fatty acids on specific lipoproteins. From a recent meta-analysis, it can be concluded that replacement of carbohydrates with saturated fatty acids not only increased serum total cholesterol concentrations but also those of LDL and HDL (Figure 2.1). The totall to $\mathrm{HDL}$ cholesterol ratio, however, was not affected. In addition, effects on the 
serum lipoprotein profile were dependent on the chain length of the saturated fatty acid (6).
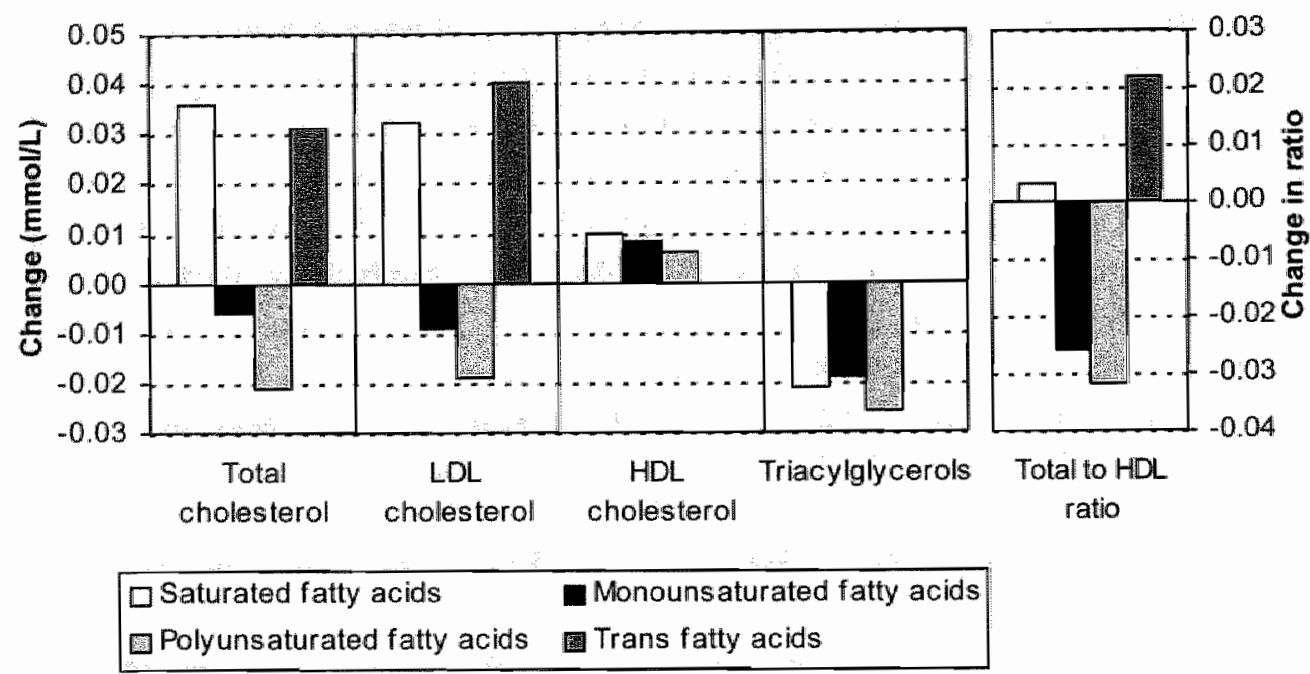

Figure 2.1 Effects of the major fatty acids on serum total $L D L$, and HDL cholesterol, triacylglycerol concentrations, and total to $H D L$ cholesterol ratio when $1 \%$ of dietary carbohydrates are replaced by fatty acids under iso-energetic conditions.

\section{Medium-chain fatty acids}

Although medium-chain fatty acids are found in significant quantities in several natural fats and oils, the total amount in regular diets is in general low. This may explain why effects of medium-chain fatty acids on lipoprotein metabolism have not been well studied. Initially, it was suggested that medium-chain fatty acids had a neutral effect on serum total cholesterol concentrations $(4,5)$. Results from two recent studies, however, suggested that relative to oleic acid, medium-chain fatty acids slightly increased serum total and LDL cholesterol but did not affect HDL cholesterol concentrations. Triacylglycerol concentrations were slightly increased $(7,8)$.

\section{Lauric, myristic, and palmitic acids}

Palmitic acid (C16:0) along with lauric (C12:0) and myristic (C14:0) acids, are the most potent cholesterol-raising saturated fatty acids. Their relative cholesterol elevating effects, however, are controversial. In fact, it is difficult to examine the effects of the individual saturated fatty acids, because in natural fats high levels of one fatty acid are associated with high levels of another fatty acid. Coconut oil, for example, contains high amounts of both myristic and lauric acids, while dairy fat is 
rich in both myristic and palmitic acids. This makes it difficult to ascribe the observed effects to one single fatty acid. Therefore, more recent studies have used synthetic and semi-synthetic fats, specifically enriched in one of the saturated fatty acids.

Palmitic acid is the major saturated fatty acid in the diet. It is well accepted that palmitic acid raises total, LDL and HDL cholesterol and decreases triacyl|glycerol concentrations, relative to carbohydrates. Effects of palmitic acid relative to those of oleic acid are more controversial. In studies that compared the effects of palmolein oil (rich in palmitic acid) with olive oil (rich in oleic acid), palmitic and oleic acids had comparable effects on the serum lipoprotein profile $(9,10)$. However, the majority of well-controlled studies have found that relative to oleic acid, palmitic acid increased total and LDL cholesterol concentrations (11-13).

Myristic acid has for long been suspected to be the most cholesterol-raising fatty acid (4). Several studies concluded that myristic acid increased total cholesterol concentrations relative to oleic acid, due to an increase in LDL as well as in HDL cholesterol $(7,13)$. However, these effects of the semi-synthetic fats enriched in myristic acid were much less than suggested by two independent meta-analyses $(4,6)$.

Lauric acid is the fourth most common saturated fatty acid in the diet after palmitic, stearic and myristic acids. Hegsted et al (4) already reported that lauric acid had only a mild cholesterol-raising effect relative to carbohydrates. The effects of lauric acid on lipoprotein concentrations were compared with those of oleic acid by Denke and Grundy (11). It was concluded that lauric acid elevated total and LDL cholesterol concentrations relative to oleic acid but did not have any effect on $\mathrm{HDL}$ cholesterol and triacylglycerol concentrations. Using mixtures of natural fats, these results were confirmed by Temme et al (12) but in that study also an additional, significant increase in HDL cholesterol concentrations was observed.

In a recent meta-analysis, the effects of the individual saturated fatty acids on the serum lipoprotein profile have been estimated (6). Iso-energetic replacement of carbohydrates with lauric, myristic, and palmitic acids all resulted in increased total, LDL and HDL cholesterol concentrations (Figure 2.2). With increasing chain length, these effects decreased. Because the cholesterol-raising effects of lauric acid were proportionally higher on $\mathrm{HDL}$ than on $\mathrm{LDL}$ cholesterol, replacement of carbohydrates by lauric acid resulted in a significantly lower total to HDL cholesterol ratio, which suggests a decrease in atherosclerotic risk. Compared with carbohydrates, myristic and palmitic acids did not affect the ratio of total to HDL cholesterol, whereas lauric, myristic, and palmitic acids lowered triacylglycerol concentrations to the same extent (6). 

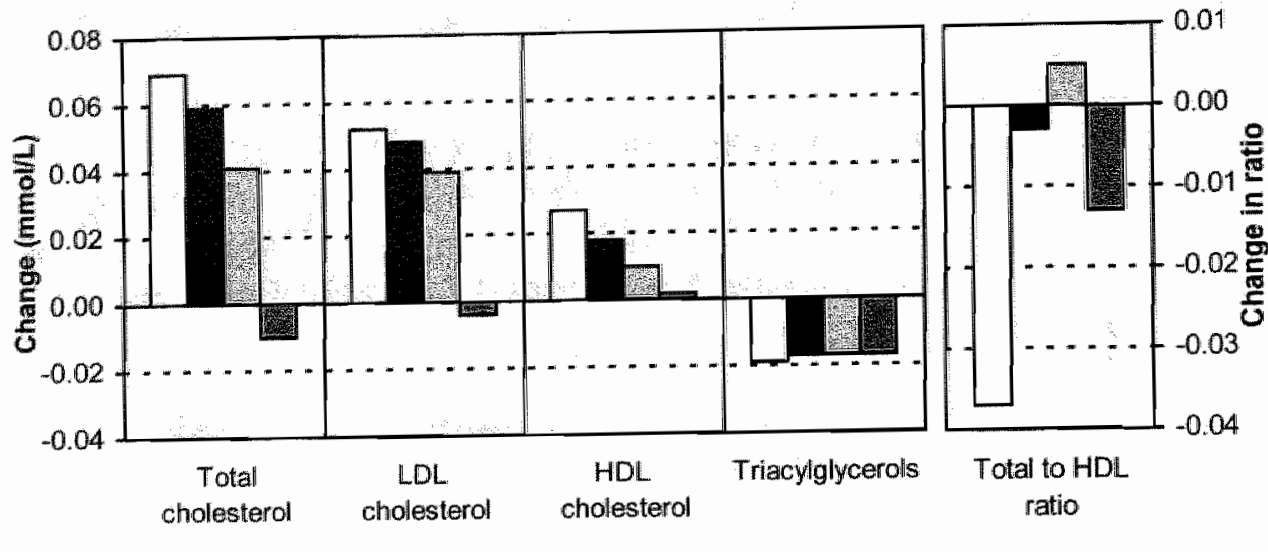

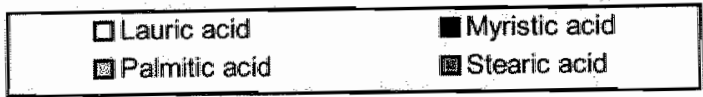

Figure 2.2 Effects of the individual saturated fatty acids lauric acid (C12:0), myristic acid (C14:0), palmitic acid (C16:0) and stearic acid (C18:0) on serum total, LDL, and HDL cholesterol, triacylglycerol concentrations, and total to HDL cholesterol ratio when $1 \%$ of dietary carbohydrates is replaced by a specific fatty acid under iso-energetic conditions.

\section{Stearic acid}

Compared with the other long-chain saturated fatty acids, stearic acid significantly lowered total, LDL and HDL cholesterol concentrations $(14,15)$. In fact, it has been found that stearic acid and oleic acid, the major monounsaturated fatty acid, had similar effects on serum lipoproteins (16). However, other studies found an HDL cholesterol-lowering effect of stearic acid relative to unsaturated fatty acids $(17,18)$. Thus, stearic and oleic acids are equivalent in their effects on LDL cholesterol and triacylglycerols but may differ somewhat in their effects on HDL. These effects of

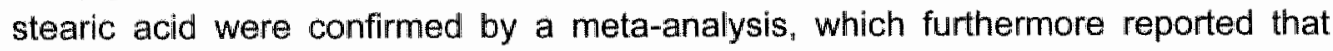
stearic acid did not change the total to HDL cholesterol ratio when compared with carbohydrates (6).

\section{Monounsaturated fatty acids}

Mortality rates of coronary heart disease in traditional Mediterranean populations consuming high-fat diets rich in olive oil, a major source of monounsaturated fatty acids, are low (19). Previous studies concluded that monounsaturated fatty acids had similar effects on serum total cholesterol concentrations as carbohydrates $(4,5)$. Hence, many researchers compared the effects of monounsaturated fatty acids, in particular of oleic acid, and carbohydrates on the distribution of cholesterol over the 
different lipoproteins $(20,21)$. From these studies; it appeared that effects of oleic acid and carbohydrates on total cholesterol concentrations are indeed similar but that oleic acid increased HDL cholesterol and lowered VLDL cholesterol and triacylglycerol concentrations. As a result, a significant decrease in the total to $\mathrm{HDL}$ cholesterol ratio was observed. Similar conclusions were drawn based on results of a meta-analysis (6). Thus, monounsaturated fatty acids have a more favourable effect on atherosclerotic risk than carbohydrates, because of the increase in HDL and decrease in VLDL concentrations.

\section{Polyunsaturated fatty acids}

Polyunsaturated fatty acids belong to either the $n-6$ or $n-3$ famillies. Unlike saturated and monounsaturated fatty acids, the polyunsaturated fatty acids, linoleic acid and $\alpha$-linolenic acid, cannot be synthesised de novo by humans. These fatty acids need to be provided by the diet and are therefore called essential fatty acids. The most abundant essential fatty acid in the diet is linoleic acid $(C 18: 2 n-6)$, whereas a small part of the dietary polyunsaturates is provided by $\alpha$-linolenic acid (C18:3n-3). Linoleic acid, a member of the n- 6 family of fatty acids, serves as the precursor of arachidonic acid (C20:4n-6), which has important biological effects in the body. $\alpha$ Linolenic acid, an n-3 fatty acid, can be converted into eicosapentaenoic acid ( $C 20: 5 n-3$, EPA), which can be further elongated, desaturated and $\beta$-oxidised into docosahexaenoic acid $(\mathrm{C} 22: 6 n-3, \mathrm{DHA})$. However, the major part of the very-long chain fatty acids in the human body are provided through the consumption of fatty fish, rich in EPA and DHA.

\section{N-6 polyunsaturated fatty acids}

Relative to carbohydrates, Keys et al (5) have estimated that the hypocholesterolemic effect of linoleic acid is half as much as the hypercholesterolemic effect of saturated fatty acids. However, more recent metaanalyses reported slightly less but still significant effects of linoleic acid, not only on serum total cholesterol but also on LDL cholesterol concentrations. Moreover, linoleic acid lowered triacylglycerols and increased HDL cholesterol concentrations compared with carbohydrates. Although linoleic acid may raise HDL cholesterol less than monounsaturated and saturated fatty acids, linoleic acid still has the most favourable effect on the total to HDL cholesterol ratio (6).

To investigate whether linoleic acid is more beneficial than oleic acid, several studies compared the effects of linoleic acid with those of oleic acid side-by-side. However, results are inconsistent, which may relate to differences in the intake of linoleic acid. When intake of linoleic acid exceeds $15 \%$ of energy, linoleic acid 
lowered serum total, $\mathrm{LDL}$, and $\mathrm{HDL}$ cholesterol, and serum triacylglycerol concentrations compared to oleic acid (22). At more realistic intakes of linoleic acid (less than $15 \%$ of energy), differences in effects on lipoprotein profile between linoleic and oleic acids are marginal (23-25).

\section{N-3 polyunsaturated fatty acids}

The principal n-3 fatty acids are eicosapentaenoic acid (EPA) and docosahexaenoic acid (DHA), which are typically present in fatty fish and fish oils. Although normally dietary intakes of these long-chain, highly unsaturated fatty acids are very low, almost 30 times lower than that of linoleic acid (26), these fatty acids lower triacylglycerols and VLDL concentrations compared to carbohydrates and other fatty acids. Furthermore, fish fatty acids may slightly raise LDL cholesterol, especially in hypertriglyceridemic subjects but do not affect HDL cholesterol (27).

The metabolic precursor of the marine $n-3$ fatty acids is $\alpha$-linolenic acid, a plantderived fatty acid. The effects of $\alpha$-linolenic acid are comparable to those of linoleic acid, an n-6 polyunsaturated fatty acid. In particular, the characteristic effects of EPA and DHA on serum triacylglycerol concentrations are not shared by $\alpha$-linolenic acid (27).

\section{Trans fatty acids}

Trans and cis isomers of unsaturated fatty acids are produced during hydrogenation of vegetable oils, either by bacteria in the first stomach (rumen) of ruminant animals or by industrial hardening of oil. The main purpose of this latter process is to convert the liquid cil into a solid or semi-solid fat, which can be used for the production of certain types of margarines or shortenings for frying or baking. More than $80 \%$ of all trans fatty acids in the diet are trans isomers of oleic acid, and more than $10 \%$ are isomers of trans linoleic acid.

Many studies have shown unfavourable effects of trans fatty acids on serum lipids. Relative to cis-monounsaturated fatty acids, trans-monounsaturated fatty acids raise total and LDL cholesterol, and lower HDL cholesterol concentrations, resulting in an increased total to HDL cholesterol ratio. Furthermore, trans fatty acids elevate triacylglycerol concentrations $(17,28,29)$. Effects of trans fatty acids and saturated fatty acids on total and LDL cholesterol concentrations are not very different. However, trans fatty acids lower HDL cholesterol as compared to saturated fatty acids $(28,29)$. This means that the total to HDL cholesterol ratio is also unfavourably changed (6). Therefore, trans fatty acids have the worst effects on blood lipids among all dietary fatty acids. 


\section{Conclusions}

Dietary fatty acid composition affects the distribution of cholesterol over the various lipoproteins. Under iso-energetic metabolic conditions, the most favourable lipoprotein profile to lower atherosclerotic risk is achieved when a mixture of cisunsaturated fatty acids replaces saturated and trans fatty acids. However, which unsaturated fatty acid - oleic acid, linoleic acid or fish fatty acids - is the most beneficial, is hard to conclude, because fatty acids also affect other pathways involved in the development of atherosclerosis. Furthermore, it should be noted, that not much is known about the effects of diet on the composition and particle size distribution of LDL, HDL, and VLDL, which may also affect cardiovascular risk. For example, carbohydrates lower LDL cholesterol concentrations but at the same time unfavourably change LDL particle size (30). These effects are more difficult to translate into cardiovascular risk and are as yet not a solid basis for dietary recommendations. Therefore, more information is needed to elucidate how fatty acids affect lipid and lipoprotein metabolism at the molecular level.

\section{FATTY ACIDS AND LIPID PEROXIDATION}

Reactive oxygen species, as present in vivo, induce the oxidation of lipids. This may lead to oxidative modification of LDL, which is critical in the initiation and evolution of atherosclerosis. Increased uptake of oxidised LDL by macrophages via the scavenger pathway results in the formation of foam cells and, ultimately, atherosclerotic plaques (Figure 2.3). Oxidised LDL is cytotoxic and induces atherogenic mechanisms such as chemotaxis, and transmigration and transformation of monocytes into macrophages. In addition, oxidised LDL is a potent inducer for the production of inflammatory molecules (31). 


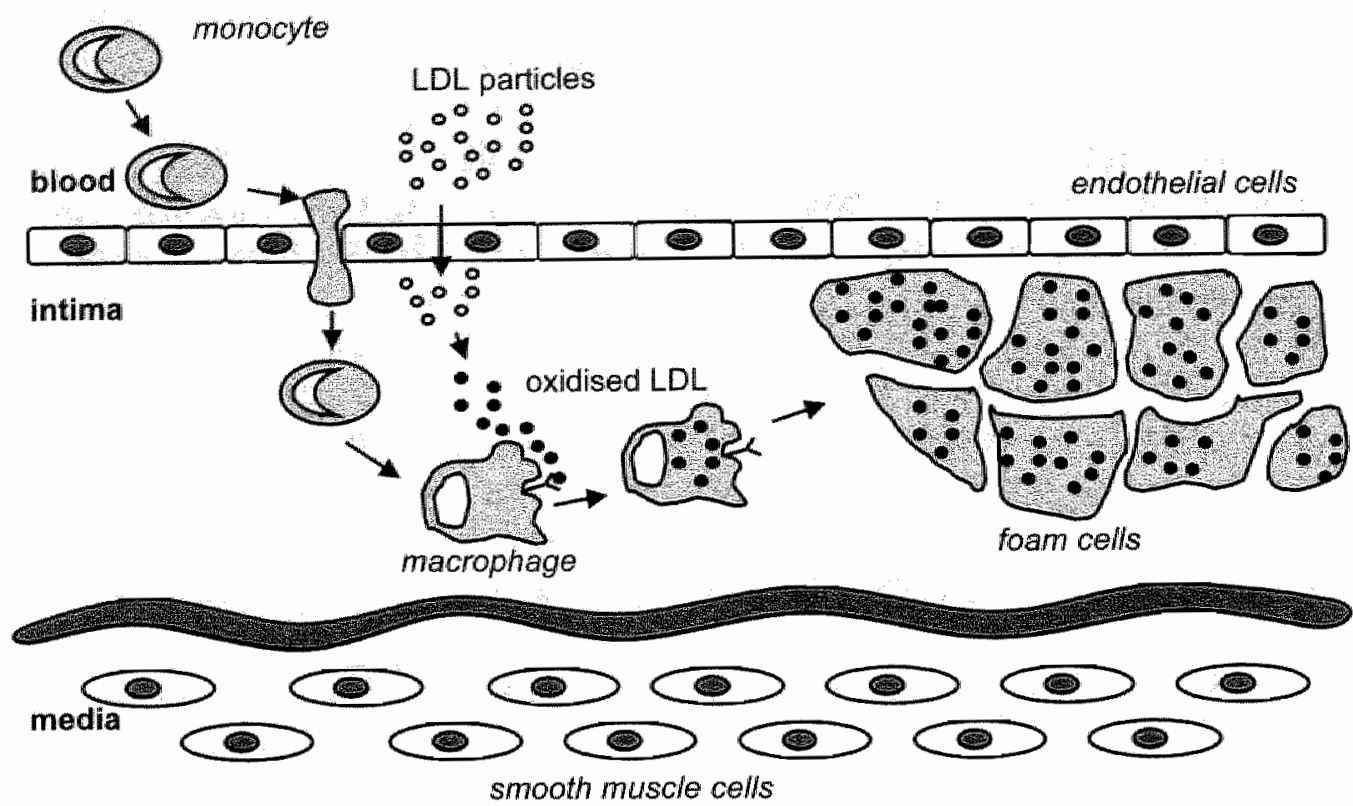

Figure 2.3 Involvement of lipid peroxides and inflammation in the development of atherosclerosis."

${ }^{1}$ Endothelial dysfunction causes increased endothelial permeability to lipoproteins and up-regulation of leukocyte and endothelial adhesion molecules followed by the recruitment of manocytes and $T$ lymphocyrtes into the arterial wall. LDL enters the intimal layer of the vascular endothelium and is modified by reactive oxygen species into oxidised LDL. Oxidised LDL causes endothelial damage resulting in the release of cytokines. Monocytes recruited into the artery wall become macrophages and express scavenger receptors that bind oxidised LDL particles. Macrophages become lipid-loaded foam cells by enguifing oxidised $L D L$.

A variety of methods had been developed to assess LDL oxidation but no golden standard exists. In fact, there is a clear need for validated biomarkers to measure in vivo lipid peroxidation and LDL oxidation. Methods for evaluation of LDL oxidation include direct and indirect assays. Direct assays measure certain lipid peroxides, such as malondialdehydes (MDA), thiobarbituric acid reactive substances (TBARS), or conjugated dienes. However, these assays lack specificity in particular for body fluids and tissue samples. In this respect, measurement of isoprostanes is more promising. Isoprostanes are isomers of prostaglandin, which are primarily generated by free-radical mediated peroxidation of polyunsaturated fatty acids and are chemically stabile. Urinary concentrations of $F_{2}$-isoprostanes were indeed increased in patients with hypercholesterolemia (32). Another assay measures the concentrations of MDA-modified LDL, a lipid peroxide decomposition product, which 
is increased in patients with unstable atherosclerotic cardiovascular disease (33). Also the amount of circulating oxidised LDL can be measured and is associated with cardiovascular diseases (34). Furthermore, the presence of auto-antibodies against epitopes on oxidised LDL can be quantified and is an independent predictor of the progression of atherosclerosis (35). However, all of these assays need further validation. In the past mainly indirect assays were used, which measured the in vitro susceptibility of LDL to oxidation induced by metal ions. Three parameters are usually measured in these assays. The lag time indicates the time until oxidation of the LDL particle starts, whereas the rate of oxidation denotes the amount of peroxidation products formed per unit of time. Finally, the total amount of lipid peroxidation products formed can be analysed. Frequently used methods are based on the spectrophotometric measurements of the cytotoxic aldehydes, conjugated dienes, lipid hydroperoxides or apo B-100 fluorescence after induction of LDL oxidation with copper (35). Although this has been the most frequently used assay to examine effects of fatty acids on LDL oxidation, the relevance of these outcome parameters for the in vivo situation is doubtful.

Due to the presence of double bonds, the susceptibility of fatty acids to oxidative modification increases with the degree of unsaturation. Because the fatty acid composition of the diet is reflected by the fatty acid composition of the LDL particle, dietary fat not only determines LDL cholesterol concentrations but also the in vitro susceptibility of LDL to oxidative modification. Particle size may also be important, as small dense LDL is more readily modified than larger LDL (36) but effects of fatty acid intake on LDL particle size as related to LDL modification has not been studied in detail.

\section{Dietary fat and saturated fatty acids}

Low-fat diets and high-fat diets rich in monounsaturated fatty acids do not differ in their effects on the susceptibility of LDL to oxidation (37). Effects of saturated fatty acids on LDL oxidation have not been well examined. In theory, saturated fatty acids should affect in vitro LDL susceptibility beneficially, because they do not have any double bonds. However, some studies surprisingly found unfavourable effects on the susceptibility of LDL to oxidation, when monounsaturated fatty acids were replaced by saturated fatty acids $(38,39)$. In particular, the lag time was decreased. This suggests that minor dietary components from edible oils affect LDL oxidation as well. 


\section{Oleic acid versus linoleic acid}

Several human studies have shown that enrichment of the diet with oleic acid at the expense of linoleic acid increased resistance of LDL to oxidative modification. When oleic acid is replaced with linoleic acid, lag time decreased, oxidation rate increased, and production of conjugated dienes was higher after copper-induced LDL oxidation $(38,39)$. Whether or not these results also indicate that compared with oleic acid, linoleic acid elevates atherogenicity of lipoproteins in vivo has to be shown.

\section{N-6 and n-3 polyunsaturated fatty acids}

Replacement of n-6 with n-3 polyunsaturated fatty acids in the normal diet did not affect lag time and TBARS but conjugated diene production was significantly increased after the n-3 enriched diet (39). In another study, effects of fish oil and oils rich in $n-6$ polyunsaturated fatty acids were compared using indirect (in vitro LDL oxidation and TBARS) and direct $\left(\mathrm{F}_{2}\right.$-isoprostanes and MDA-modified $\left.L D L\right)$ assays but a trend towards higher LDL susceptibility to in vitro oxidation was only found on the diet rich in $n-3$ fatty acids (40). Only one study evaluated the effects of $\alpha$ linolenic acid, and found a beneficial effect of $\alpha$-linolenic acid on susceptibility of LDL to oxidation above EPA and DHA (41).

The effects of diets supplemented with n-3 polyunsaturated fatty acids, mainly EPA and DHA from fish oils, on LDL oxidation are contradictory. Using fish oil supplements for 3 or 6 weeks, some studies observed an increased susceptibility of LDL to oxidation $(42,43)$ but other studies did not see any effects when supplements were given for 2 or 4 months $(44,45)$. Not only may the duration of supplementation but also differences in the doses of $n-3$ polyunsaturated fatty acids explain these apparent discrepancies.

\section{Conclusions}

While polyunsaturated fatty acids have a larger hypocholesterolemic effect, in vitro assays suggest that the effects of monounsaturated fatty acids on LDL oxidation are the most beneficial. However, the relevance of these indirect, in vitro, assays to measure LDL oxidation, for the in vivo situation is limited. Future studies should therefore use more direct measurements of lipid peroxidation products such as $F_{2^{-}}$ isoprostanes and MDA-modified LDL.

\section{FATTY ACIDS AND INFLAMMATION}

During the early phases of plaque development, inflammatory processes already play an important role, starting with the interaction between the vascular 
endothelium and circulating blood leukocytes. After recruitment and infiltration of mainly monocytes and T-lymphocytes into the arterial intima, monocytes are transformed into macrophages, which can take up oxidised $L D L$ rapidly. This process results in the formation of foam cells and ultimately a fatty streak (46). Moreover, T-lymphocytes produce several pro- and anti-inflammatory cytokines, which play an important role in orchestrating the inflammatory process (47). More recently, C-reactive protein (CRP), an acute phase reactant produced by the liver during systemic inflammation, has also been identified as an important risk marker for cardiovascular disease (48).

\section{Endothelial cell adhesion}

Cellular adhesion molecules mediate the attachment of leukocytes to vascular endothelial cells and the subsequent trans-endothelial migration of monocytes and lymphocytes into the arterial wall. While selectins are involved in the initial rolling of the circulating leukocyte over the endothelium, other cellular adhesion molecules such as intercellular adhesion molecule-1 (ICAM-1) and vascular cell adhesion molecule-1 (VCAM-1), mediate the final firm attachment (46).

Because in vivo the accessibility of human endothelial cells is limited, effects of fatty acids on expression of adhesion molecules have been examined mainly in vitro using endothelial cell lines. From a series of experiments in which endothelial cells were incubated with various fatty acids, it was concluded that with increased degree of unsaturation of the fatty acid, VCAM-1 expression on the surface of endothelial cells decreased. These effects were observed when cells were stimulated with lipopolysaccharide or cytokines (interleukin-1 $\alpha$ (IL-1 $\alpha$ ) or interleukin-1 $\beta$ (IL-1 $\beta$ ) or tumour necrosis factor $\alpha$ (TNF $\alpha)$ ). Inhibitory potencies of the fatty acids were not influenced by chain length, cis/trans configuration, or the position of the double bond. Results were confirmed by analysis of messenger RNA (mRNA) expression of VCAM-1. Without stimulation, however, none of the fatty acids affected VCAM-1 expression (49). In contrast, another study reported that the addition of linoleic acid and $\alpha$-linolenic acid to the medium increased mRNA expression of ICAM-1 and VCAM-1 even in unstimulated endothelial cells. On the other hand, oleic acid inhibited mRNA expression of these adhesion molecules (50). Whether these changes in mRNA expression also resulted in changes in surface protein expression was not examined. These contrasting findings indicate that in vitro findings depend on the experimental conditions used and are difficult to extrapolate to the in vivo situation.

In contrast with endothelial cells, peripheral blood mononuclear cells (PBMC) are easily sampled which gives the opportunity to use PBMC to examine the effects of 
dietary fatty acids on the expression of the ligands for the endothelial adhesion molecules. Furthermore, ICAM-1 is also present on PBMC. Until now, not many studies have made use of these possibilities. In one study, effects of fish oil supplementation for 3 weeks were studied on ICAM-1 and LFA-1 expression, the ligand for ICAM-1. After stimulation of monocytes with interferon- $\gamma$, the expression of these adhesion molecules was lowered in the fish oil group relative to baseline values and to those of control subjects (51). In a study with healthy volunteers, who consumed diets enriched with $\alpha$-linolenic acid or fish oil for 12 weeks, no effect on ICAM-1 surface expression was found. In this latter study. PBMC were not stimulated (52). In another study with healthy men, the effects of consumption for 2 months of a diet rich in monounsaturated fatty acids were compared with those of a regular diet. Expression of ICAM-1 on PBMC was decreased in the subjects on the monounsaturated fatty acid enriched diet (53).

Alternatively, the soluble variants of the above mentioned adhesion molecules sICAM-1, sVCAM-1 and sE-selectin - can be analysed in plasma. Increased concentrations of these soluble adhesion molecules in the blood, which may indicate increased expression of membrane-bound malecules and impaired endothelial function, are indeed associated with future cardiovascular events in apparently healthy individuals (54). It should be emphasised, however, that SVCAM-1 and SEselectin are almost exclusively derived from endothelial cells, whereas ICAM-1 is expressed and shed from several cell types (55). In patients with increased atherosclerotic risk, the effects of supplementation with relatively high doses of $n-3$ fatty acids (4-5 g per day) have been investigated but results were inconsistent (56). In healthy subjects, $\alpha$-linolenic acid and fish oil but not purified $D H A$, decreased sVCAM-1 expression. This suggests that possible favourable effects of fish oil should be attributed to EPA (57).

\section{Cytokines}

Inflammation is mediated by cytokines, which modulate infiltration and accumulation of immuno-competent cells (T-lymphocytes and macrophages) by increasing the expression of adhesion molecules by endothelial cells. Furthermore, cytokines mediate activation and proliferation of both smooth muscle cells and macrophages. With respect to atherosclerosis, cytokines can be divided into three major classes. The pro-inflammatory cytokines typically mediate pro-atherogenic processes, whereas anti-inflammatory cytokines are involved in anti-atherogenic pathways. Major pro-inflammatory cytokines are interleukin-1 (IL-1), interleukin-6 (IL-6) and tumour necrosis factor $\alpha$ (TNF $\alpha$ ), whereas interleukin-4 (IL-4) and interleukin-10 (IL10) are examples of anti-inflammatory cytokines. In addition, some cytokines, such 
as interferon-y have pro- as well as anti-inflammatory effects (47). TNFa, which is produced by endothelial cells, smooth muscle cells and macrophages, plays a pivotal role in the cytokine cascade as it stimulates the synthesis of other cytokines. Also IL-1 and IL-6 are versatile cytokines. For example IL-6 is a central mediator of the acute-phase response and the primary determinant of CRP production by the liver (58).

In one of the earlier studies, production of the pro-inflammatory cytokines IL-1 and TNF $\alpha$ by in vitro stimulated PBMC was suppressed after supplementation with a high dose (18 g fish oil per day) of $\mathrm{n}-3$ polyunsaturated fatty acids (59). Because some $(60)$ but not all $(52,57)$ confirmed these results, it was suggested that in vitro production of pro-inflammatory cytokines is only decreased when EPA plus DHA was consumed for at least 4 weeks and daily intake exceeded $2.4 \mathrm{~g}$ (61). However, even long-term supplementation with $3.2 \mathrm{~g}$ of fish oil per day for 6 or 12 months did not decrease in vitro production of IL-1 and TNF $\alpha$ after whole-blood stimulation (62). Despite these inconsistent results, fish fatty acids are considered to exert antiinflammatory properties.

In another study, it was found that replacement of the habitual fat from the diet of Dutch volunteers by palm oil reduced TNF $\alpha$ production, whereas IL-6 and IL-8 - two other pro-inflammatory cytokines - concentrations were not affected (63). Compared with soybean oil (linoleic acid with $\alpha$-linolenic acid), hydrogenated fat rich in trans fatty acids increased production of IL-6 and TNF $\alpha$ but not of IL-1 in humans with moderately elevated LDL cholesterol levels. In this study, soybean oil and butter, the latter rich in saturated fatty acids, had similar effects (64). Finally, supplementation of arachidonic acid did not alter pro-inflammatory cytokine production (65).

Though most studies investigated in vitro or ex vivo cytokine production after exposing PBMC to an inflammatory stimulant, a few studies have evaluated the effects of in particular polyunsaturated fatty acids on circulating plasma cytokine concentrations. It was found that fish oil decreased circulating concentrations of several pro- as well as anti-inflammatory cytokines in patients with a wide variety of inflammatory diseases (61). In healthy volunteers, fish oil did not reduce plasma cytokine concentrations (62). Compared with linoleic acid, consumption of $\alpha$ linolenic acid for 3 months decreased concentrations of the pro-inflammatory IL-6 in dysilipidemic patients (66).

\section{C-reactive protein}

With the newly developed high-sensitive assays, even slightly elevated C-reactive protein (CRP) concentrations can be detected in individuals with mild, non-overt inflammation that may result from the ongoing atherosclerotic process. However, 
effects of fatty acids on serum CRP concentrations have not been studied very well. Some studies focused on the effects of $n-3$ fatty acids but results are equivocal. In studies with healthy volunteers no effects of fish oil supplements on CRP concentrations were found, despite reductions of several other acute-phase proteins $(67,68)$. In dyslipidemic patients, however, replacement of linoleic acid for $\alpha$-linolenic acid during 3 months reduced CRP concentrations, independently of lipid changes (66).

\section{Conclusions}

As atherosclerosis has a strong inflammatory component, it is important to examine the effects of fatty acids on inflammatory risk markers. Until now, many in vivo studies have focused on the effects of $n-3$ polyunsaturated fatty acids from fish oil. However, results are inconsistent. Effects of other fatty acids on in vivo inflammatory markers have been studied even less and this area of research clearly deserves further exploration. Furthermore, attention has to be paid to underlying mechanisms.

\section{FATTY ACIDS AND THROMBOTIC TENDENCY}

Under normal physiological conditions, hemostatic balance between thrombus formation and dissolution is regulated by the endothelial wall, blood platelets, and coagulation and fibrinolytic factors. Any disturbances of this delicate balance might result in activation of the hemostatic system and in increased thrombotic tendency. In this way, the most common complications of cardiovascular disease result from thrombus formation, caused by the exposure of blood platelets to the subendothelial matrix material or disruption of an atherosclerotic plaque (Figure 2.4). Thrombosis is initiated by platelet activation, adhesion and aggregation. Platelets become activated by compounds released from the endothelium, or exposed during rupture of an atherosclerotic plaque. After activation "platelets adhere on the place of injury and release their granules, which results in platelet aggregation. Activation of platelets also leads to the release of free arachidonic acid, which can be metabolised into eicosanoids. Following platelet activation, the coagulation cascade is initiated, resulting in the activation of several clotting factors. Ultimately fibrinogen is converted by activated thrombin into fibrin monomers, which polymerise into a fibrin network. In this fibrin network, blood cells and aggregated platelets are captured to form a thrombus, which can occlude the blood vessel. The dissolution of the blood thrombus is regulated by the fibrinolytic system (69).

Because of the findings from the 1960 s showing a very low incidence of thrombosis among fish-eating Greenland Eskimos, considerable work has been 
carried out in the past few decades to understand how dietary fat and fatty acids, especially long-chain n-3 fatty acids, affect hemostatic risk markers.

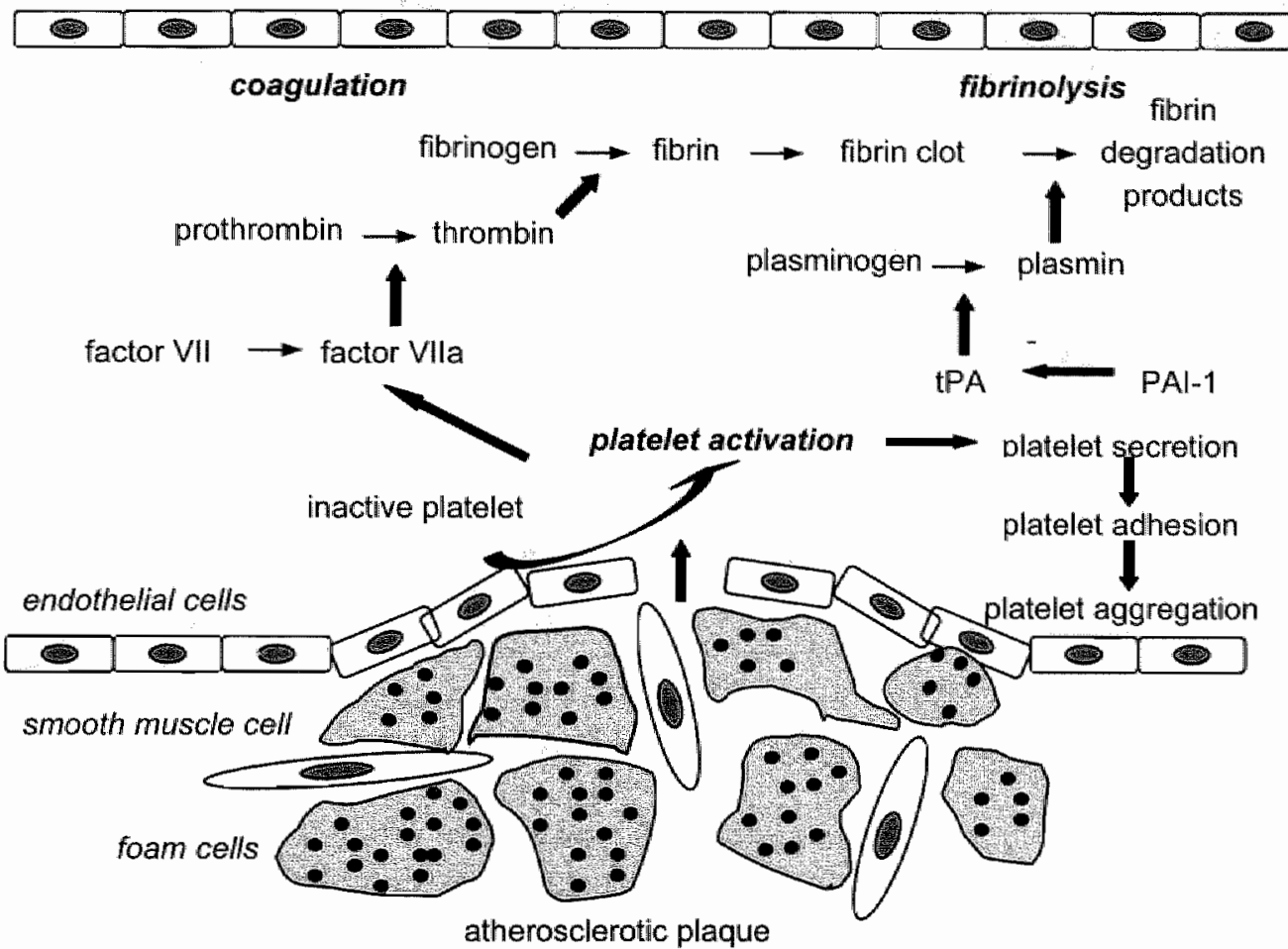

Figure 2.4 Schematic representation of the activation of the hemostatic system at the site of an atherosclerotic plaque.

\section{Platelet aggregation}

A frequently used method to assess platelet aggregability is the in vitro platelet aggregation test. However, this method measures the ability of platelets to react to a single external stimulus, a situation not comparable with platelet aggregation in vivo. Still, increased ADP-induced platelet aggregation is associated with increased atherosclerotic risk (70). Unfortunately, however, studies are difficult to compare due to the many different methods used to measure platelet aggregation. For example, blood can be anti-coagulated with citrate, heparin or hirudin, while platelet aggregation - in either whole blood or platelet-rich plasma - can be triggered with collagen, ADP, adrenalin or thrombin.

Many studies have focused on the effects of n-3 polyunsaturated fatty acids. In general, collagen-induced aggregation decreased, whereas results of ADP-induced 
aggregation were very inconsistent (71). Effects of other fatty acids have also been examined but results are conflicting. When saturated fatty acids in the diet are replaced by oleic acid or linoleic acid, platelet aggregation was increased, decreased; or did not change. Comparable conflicting results have been found when oleic acid and linoleic acid were compared side-by-side (72-74). Some studies compared the effects of the different saturated fatty acids with each other. Relative to oleic acid, medium-chain fatty acids, lauric acid, myristic acid or palmitic acid did not affect collagen-induced aggregation in whole blood. Furthermore, ADP-induced aggregation was not changed by medium-chain fatty acids or myristic acid (75). Thus, dietary fatty acids can modulate platelet aggregation but the use of many different in vitro methods makes comparison and extrapolation to the in vivo situation difficult.

\section{Eicosanoid production}

Thromboxanes (TX) and prostaglandins (PG), two eicosanoids, play an important role in the hemostatic balance. Both types of eicosanoids are synthesised from the C20 fatty acids, arachidonic acid (C20:4n-6) and eicosapentaenoic acid (C20:5n-3, EPA) after release from membrane phospholipids (Figure 2.5). Eicosanoids of the 2-series such as thromboxane $A_{2}\left(T X A_{2}\right)$ are synthesised from the n-6 fatty acid arachidonic acid in platelets, whereas prostaglandin $\mathrm{I}_{2}\left(\mathrm{PGI}_{2}\right)$ is synthesised in the vascular endothelium. $\mathrm{TXA}_{2}$ is a potent vasoconstrictor and a stimulus for platelet aggregation, whereas $\mathrm{PGI}_{2}$ has opposite effects. Eicosanoids of the 3-series such as thromboxane $A_{3}\left(T X A_{3}\right)$ and prostacyclin $\left(\mathrm{PGI}_{3}\right)$ are principal metabolites of the $\mathrm{n}$ 3 fatty acid EPA. However, $T X A_{3}$ is biologically less active than $T X A_{2}$, while the antiaggregatory effects of $\mathrm{PGI}_{3}$ and $\mathrm{PGI}_{2}$ are comparable. This may explain why fish oils lower platelet aggregation (76).

Eicosanoids have a short half-life time and are quickly catabolised into their stable metabolites, such as $\mathrm{TXB}_{2}$ and 6-keto-PGF 1 . These metabolites can be converted into respectively 2,3 dinor- $\mathrm{TXB}_{2}$ or 11 -dehydro-TXB ${ }_{2}$, and 2,3 dinor-6keto-PGF $f_{\alpha}$, which are excreted in the urine. In this way, analysis of these urinary metabolites represents a non-invasive surrogate to assess in vivo eicosanoid formation (77). In line with the anti-aggregatory effects of fish oils, several studies showed that $\mathrm{n}-3$ fatty acids indeed decreased urinary excretion of $\mathrm{TXA}_{2}$ metabolites. Prostaglandin excretion, however, was not always affected $(74,76)$. With respect to saturated fatty acids, lauric, myristic , palmitic, and stearic acids had similar effects on urinary thromboxane and prostaglandin excretion $(78,79)$. Also the effects of trans fatty acids were comparable with those of stearic acid (80). Furthermore, n-6 polyunsaturated fatty acids increased urinary 11-dehydro- $\mathrm{TXB}_{2}$ excretion compared 
with saturated and monounsaturated fatty acids, which seemed to reflect ADPinduced platelet aggregation results (74).

\section{Membrane phospholipids}

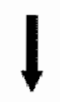

Arachidonic acid

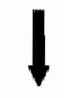

$\mathrm{PGH}_{2}$
Phospholipase $A_{2}$

Cyclo-oxygenase

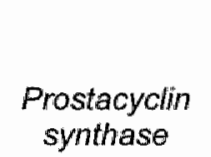

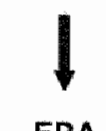

EPA

\begin{tabular}{|c|c|c|c|}
\hline \multicolumn{2}{|c|}{$\mathrm{PGH}_{2}$} & \multicolumn{2}{|c|}{$\mathrm{PGH}_{3}$} \\
\hline $\begin{array}{l}\text { Thromboxane } \\
\text { synthase }\end{array}$ & $\begin{array}{r}\text { Pro } \\
\text { sy }\end{array}$ & $\begin{array}{l}\text { acyclin } \\
\text { thase }\end{array}$ & $\begin{array}{c}\text { Thromboxane } \\
\text { synthase }\end{array}$ \\
\hline $\begin{array}{c}\text { TxA }_{2} \\
\text { pro-aggregatory } \\
\text { vasoconstriction }\end{array}$ & $\begin{array}{c}\mathbf{P G I}_{\mathbf{2}} \\
\text { anti-aggregatory } \\
\text { vasodilatation }\end{array}$ & $\begin{array}{c}\mathbf{P G I}_{3} \\
\text { anti-aggregatory } \\
\text { vasodilatation }\end{array}$ & $\begin{array}{c}\operatorname{TxA}_{3} \\
\text { biologically inactive }\end{array}$ \\
\hline
\end{tabular}

2-series

3-series

Figure 2.5 Formation of eicosanoids from n-3 and n-6 polyunsaturated fatty acids.

\section{Blood coagulation}

Important risk markers of the blood coagulation system associated with cardiovascular events are factor $\mathrm{VII}$, fibrinogen, and prothrombin fragment 1 and 2 (81). Factor VII plays a key role in the initiation of the tissue factor pathway of blood coagulation. Ultimately, the blood coagulation cascade results in the formation of an insoluble fibrin clot from fibrinogen, which can be cleaved by thrombin. Fragment 1 and 2, a prothrombin fragment, reflects the amount of prothrombin converted into thrombin.

\section{Factor VII}

Increased concentrations of coagulation factor VII, which are associated with fatal cardiovascular events (81), can be lowered by reduction of the total fat intake. In contrast "effects of the individual fatty acids were negligible, although some studies have indicated that stearic acid may slightly decrease factor VII $(14,82)$. This, however, might be explained by the poorer digestibility and absorption of the highstearic acid fats used in these studies. Interestingly, in one study it was reported that replacement of oleic acid for lauric acid or palmitic acid increased factor VII activity only in women (83). These gender-specific effects need to be confirmed in future 
experiments. Markedly, although n-3 fatty acids from fish oil affected platelet aggregation favourably, no effects on factor VII were observed (84).

Likewise, postprandial studies have indicated that the total fat content of the diet, rather than the fatty acid composition, increased factor VII concentrations $(85,86)$. In one study, postprandial increases in activity of factor VIl were less after consumption of meals rich in saturated fat, especially stearic acid, than after consumption of meals enriched with unsaturated fatty acids (87).

\section{Fibrinogen}

Although fibrinogen plays a crucial role in the clotting cascade to stabilise a loose thrombus, it is doubtful whether this functional role of fibrinogen explains the association between fibrinogen and atherosclerosis (81). Because fibrinogen is also an acute phase reactant, fibrinogen concentrations might also increase at least in part as a consequence of inflammatory reactions that occur in atherosclerosis. However, dietary fatty acid composition does not seem to regulate fibrinogen levels $(15,83,84,88,89)$.

\section{Prothrombin fragment 1 and 2}

Fasting prothrombin fragment 1 and 2 concentrations are not changed by the fatty acid composition of the diet $(83,84,88,89)$. Postprandially, concentrations increased after a high-fat meal independently of the fatty acid composition, which agrees with the finding that high-fat diets increase factor VII (90).

\section{Fibrinolysis}

Fibrinolysis is initiated by the conversion of plasminogen into plasmin through the action of tissue plasminogen activator (tPA). Plasmin catalyses the degradation of cross-linked fibrin of a thrombus. TPA activity is inhibited by plasminogen activator inhibitor-1 (PAl-1). Decreased concentrations of tPA and elevated concentrations of PAl-1 are associated with increased atherosclerotic risk. Furthermore, degradation products of cross-linked fibrin such as D-dimers reflect fibrinolytic activity and increased concentrations are surprisingly associated with an increased risk for atherosclerosils $(91)$.

\section{Tissue plasminogen activator}

Several studies examined the effects of fatty acid composition of the diet on tissue plasminogen activator (tPA) activity but no different effects of specific fatty acids were found $(14,88,89,92)$. Also reduction of dietary fat content did not affect tPA activity (93). Postprandial tPA levels also did not change significantly from fasting 
levels after consumption of a high-fat meal $(90,94)$. However, in one study diets rich in saturated fatty acids (stearic, palmitic or a mixture of myristic with palmitic acids) resulted in a greater rise in postprandial tPA concentrations than unsaturated test fats rich in oleic, linoleic, or trans fatty acids (87).

\section{Plasminogen activator inhibitor-1}

While high-fat diets do not affect plasminogen activator inhibitor-1 (PAl-1) concentrations, effects of the fatty acid composition of the diet on PAl-1 are not uniform. Although some studies concluded that n-3 polyunsaturated fatty acids increased PAl-1 activity, others found no effects. A recent meta-analysis, however, concluded that fish oil had no specific effects on PAI-1 (95). Effects of other fatty acids on PAl-1 are also marginal, although in one study an increase in PAl-1 activity was found when oleic acid in the diet was replaced by palmitic acid (83). Postprandially, however, PAl-1 concentrations decreased but these changes were not related to the fat content or fatty acid composition of the diet $(90,96)$.

\section{D-dimers}

No changes in D-dimers concentrations after consumption of specific fatty acids have been detected $(89,92,97)$.

\section{Conclusions}

Interpretation of the effects of fatty acids on hemostatic risk markers is difficult, partly due to the use of several methods and difficulties in extrapolating in vitro findings to the more complex in vivo situation. The most consistent finding is that $n-3$ fatty acids lower collagen-induced in vitro platelet aggregation. Furthermore, reducing total fat intake rather than changing the fatty acid composition of the diet may beneficially affect the coagulation system.

\section{CONCLUDING REMARKS}

To prevent the development of atherosclerosis, no doubt exists that the dietary intake of trans fatty acids should be as low as possible. Saturated fat intake should also decrease, although effects of the various saturated fatty acids differ. These conclusions are based mainly on effects of fats and oils on the lipoprotein profile, because effects on the other atherosclerotic risk markers discussed in this chapter are less evident. An exception, however, are the potential beneficial effects of moderate intakes of fish oil on inflammatory markers and on platelet aggregation, whereas total fat intake has unfavourable effects on both fasting and postprandial 
factor VII concentrations. Furthermore, monounsaturated fatty acids may be preferable above polyunsaturated fatty acids with respect to oxidative processes measured by indirect in witro assays. However, this latter conclusion has to be confirmed by direct methods measuring lipid peroxidation products.

The question can then be raised if saturated and trans fatty acids have to be replaced by unsaturated fatty acids or by carbohydrates. The favourable effects of unsaturated fatty acids on lipoprotein metabolism might be opposed by unfavourable effects of high-fat diets on thrombotic tendency mainly due to effects on the coagulation system. Furthermore, high-fat diets might promote weight gain resulting in obesity. Also increased amounts of dietary fat have been related to changes in insulin sensitivity leading to diabetes and an increased risk to develop cancer. However, evidence for these latter associations is still a matter of debate. With respect to atherosclerosis, both prospective epidemiological and intervention studies have shown that high-unsaturated fat diets lower atherosclerotic risk (98). Therefore, fat is not necessarily bad, as long as body weight is not increased. However, when body weight is increased, it is advisable to reduce not only the intake of fat but also of the other macronutrients.

\section{REFERENCES}

1. Gordon DJ and Rifkind BM. High-density lipoprotein-the clinical implications of recent studies. NEng/ J Med 1989; 321: 1311-6.

2. Stampfer MJ, Sacks FM. Salvini S, Willett WC and Hennekens $C H$. A prospective study of cholesterol, apolipoproteins, and the risk of myocardial infarction. N Eng/ I Med 1981; 325: 373-81.

3. Hokanson JE and Austin MA. Plasma triglyceride level is a risk factor for cardiovascular disease independent of high-density lipoprotein cholesterol level: a meta-analysis of population-based prospective studies. J Cardiovasc Risk 1996; 3: 213-9.

4. Hegsted DM, McGandy RB, Myers ML and Stare FJ. Quantitative effects of dietary fat on serum cholesterol in man. Am J Cin Nutr 1965; 17: 281-95.

5. Keys A Andersom. JT and Grande F. Serum cholesterol response to changes in the diet. IV. Particular saturated fatty acids in the diet. Metabolism 1965; 14: 776-87.

6. Mensink RP, Zock PL, Kester AD and Katan MB. Effects of dietary fatty acids and carbohydrates on the ratio of serum total to $\mathrm{HDL}$ cholesterol and on serum lipids and apolipoproteins: a meta-analysis of 60 controlled trials. Am J Clin Nutr 2003; 77: 1146-55.

7. Temme EH, Mensink RP and Hornstra G. Effects of medium chain fatty acids (MCFA), myristic acid, and oleic acid on serum lipoproteins in healthy subjects. J Lipid Res 1997; 38: 1746-54.

8. Cater NB, Heller HJ and Denke MA. Comparison of the effects of medium-chain triacylglycerols, palim oil, and high oleic acid sunflower oil on plasma triacylglycerol fatty acids and lipid and lipoprotein concentrations in humans. Am J Clin Nutr $1997 ; 65: 41-5$,

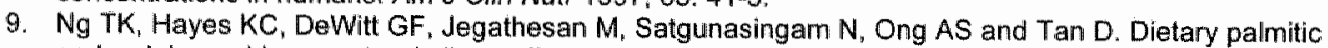
and oleic acids exert similar effects on serum cholesterol and lipoprotein profiles in normocholesterolemic men and women. J Am Coll Nutr 1992; 11:383-90.

10. Choudhury N, Tan L and Truswell AS. Comparisom of palmolein and olive oil: effects on plasma lipids and vitamin $E$ in young adults. Am J Clin Nutr 1995; 61: 1043-51.

11. Denke MA and Grundy SM. Comparison of effects of lauric acid and palmitic acid on plasma lipids and lipoproteins. Am J Clin Nutr 1992; 56: 895-8.

12. Temme EH, Mensink RP and Hornstra G. Comparison of the effects of diets enriched in lauric, palmitic ${ }_{n}$ or oleic acids on serum lipids and lipoproteins in healthy women and men. Am J Clin Nutr 1996; 63: 897-903. 
13. Zock PL; de Vries JH and Katan MB. Impact of myristic acid wersus palmitic acid on serum lipid and lipoprotein levels in healthy women and men. Arterioscler Thromb 1994; 14: 567-75.

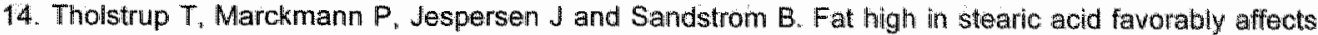
blood lipids and factor VII coagullant activity in comparison with fats high in paimitic acid or high in myristic and lauric acids. Am J Clin Nutr 1994; 59 : $371-7$.

15. Tholstrup $T$, Marckmann $P$, Jespersen J, Vessby $B$, Jart A and Sandstrom B. Effect on blood lipids, coagulation, and fibrinolysis of a fat high in myristic acid and a fat high in palmitic acid. Am $\sqrt{ }$ Clin Nutr 1994; $60: 919-25$.

16. Bonanome A and Grundy SM. Effect of dietary stearic acid on plasma cholesterol and lipoprotein levels. N Engl J Med 1988; 318: 1244-8.

17. Zock PL and Katan MB. Hydrogenation altematives: effects of trans fatty acids and stearic acid wersus linoleic acid on serum lipids and lipoproteins in humans. J Lipid Res 1992; 33: 399-410.

18. Kris-Etherton PM. Derr J, Mitchell DC, Mustad VA, Russell ME, McDonnell ET, Salabsky D and Pearson TA. The role of fatty acid saturation on plasma lipids, lipoproteins, and apolipoproteins: 1. Effects of whole food diets high in cocoa butter, olive oil, soybean oil, dairy butter "and milk chocolate on the plasma lipids of young men. Metabolism 1993; 42: 121-9.

19. Keys A. Coronary heart disease in seven countries. Circulation 1970; $41: 11.198$

20. Grundy SM. Comparison of monounsaturated fatty acids and carbohydrates for lowering plasma cholesterol. N Engl J Med 1986; 314: 745-8.

21. Mensink RP and Katan MB. Effect of monounsaturated fatty acids versus complex carbohydrates on high-density lipoproteins in healthy men and women. Lancet 1987; 1: 122-5.

22. Mattson FH and Grundy SM. Comparison of effects of dietary saturated, monounsaturated, and polyunsaturated fatty acids on plasma lipids and lipoproteins in man. J Lipid Res 1985; 26: 194-202.

23. Howard BV, Hannah JS, Heiser CC, Jablonski KA, Paidi MC, Alarif L, Robbins DC and Howard W. Polyunsaturated fatty acids result in greater cholesterol lowering and less triacylglycerol elevation than do monounsaturated fatty acids in a dose-response comparison in a multiracial study group. Am $J$ Clin Nutr 1995; 62 : 392-402.

24. Hodson L, Skeaff CM and Chishoim WA. The effect of replacing dietary saturated fat with polyunsaturated or monounsaturated fat on plasma lipids in free-living young adults. Eur $J$ Clin Nutr 2001; 55: 908-15.

25. Mensink RP and Katan MB. Effect of a diet enriched with monounsaturated or polyunsaturated fatty acids on levels of low-density and high-density lipoprotein cholesterol in healthy women and men. $N$ Engl J Med 1989; 321: 436-41.

26. Katan MB, Zock PL and Mensink RP. Effects of fats and fatty acids on blood lipids in humans; an overview. Am $J$ Cin Nutr 1994; 60: 1017S-22S.

27. Harris WS. n-3 fatty acids and serum lipoproteins: human studies. Am J Clin Nutr 1997; 65: 1645S$54 \mathrm{~S}$.

28. Mensink RP and Katan MB. Effect of dietary trans fatty acids on high-density and low-density lipoprotein cholesterol levels in healthy subjects. N Engl J Med 1990; 323: 439-45.

29. Judd JT, Clevidence BA, Muesing RA, Wittes J, Sunkin ME and Podczasy JJ. Dietary trans falty acids: effects on plasma lipids and lipoproteins of healthy men and women. Arr J Clin Nutr 1994; 59 : $861-8$.

30. Dreon DM, Fernstrom HA, Williams PT and Krauss RM. A very low-fat diet is not associated with improved lipoprotein profiles in men with a predominance of large, low-density lipoproteins. Am J Clin Nutr 1999; 69: 411-8.

31. Berliner JA, Navab M, Fogelman AM, Frank JS, Demer LL, Edwards PA, Watson AD and Lusis AJ. Atherosclerosis: basic mechanisms. Oxidation, inflammation, and genetics. Circulation 1995; 91 : 2488-96.

32. Reilly MP, Pratico D, Delanty N, DiMinno G, Tremoll E, Rader D, Kapoor S, Rokach ل, Lawsion J and FitzGerald GA. Increased formation of distinct F2 isoprostanes in hypercholesterolemia. Circulation 1998; $98: 2822-8$.

33. Holvoet P, Perez G, Zhao Z, Brouwers E, Bernar H and Collen D. Malondialdehydemonodified low density lipoproteins in patients with atherosclerotic disease. J Clin Invest 1995; 95: 2611-9.

34. Holvoet $P$, Vanhaecke $J$ Janssens $S$, Van de Werf $F$ and Collen $D$. Oxidised LDL and malondialdehyde-modified LDL in patients with acute coronary syndromes and stable coronary artery disease. Circulation 1998; 98: 1487-94.

35. Jialal I and Devaraj S. Low-density lipoprotein oxidation, antioxidants, and atherosclerosis: a clinical biochemistry perspective. Clin Chem 1996; 42: 498-506 
36. de Graal $\downarrow_{1}$ Haklemmers HLx Hectors MP. Demacker PN, Hendriks JC and Stalenhoef AF. Enhanced susceptibitity to in vitro oxidation of the dense low density lipoprotein subfraction in healthy subjects. Arterioscler Thromb 1991; 11: 298-306.

37. Hargrove RL; Etherton TD, Pearson TA, Harrison EH and Kris-Etherton PM. Low fat and high monounsaturated fat diets decrease human low density lipoprotein oxidative susceptibility in vitro. If Nutr 2001; 131: 1758-63.

38. Kratz $M$, Cullen $P$, Kannenberg $F$, Kassner $A$, Fobker $M$, Abuja PM, Assmann $G$ and Wahrburg $U$. Effects of dietary falty acids on the composition and oxidizability of low-density lipoprotein. Eur $J$ Clin Nutr 2002: $56: 72-81$.

39. Mata $P$, Alonso $R$, Lopez-Farre $A$, Ordovas $J M$, Lahoz $C_{\text {, }}$ Garces $C$. Caramelo $C$, Codoceo $R$, Blazquez $E$ and de Oya $M$. Effect of dietary fat saturation on $L D L$ oxidation and monocyte adhesion to human endothelial cells in vitro. Arterioscier Thromb Vasc Biol 1996; 16: 1347-55.

40. Higdon JV, Liu J, Du SH, Morrow JD, Ames BN and Wander RC. Supplementation of postmenopausal women with fish oil rich in eicosapentaenoic acid and docosahexaenoic acid is not associated with greater in wivo lipid peroxidation compared with oils rich in oleate and linoleate as assessed by plasma malondialdehyde and F(2)-isoprostanes. Am J Clin Nutr 2000; 72: 714-22.

41. Finnegan YE, Minihane AM, Leigh-Firbank EC, Kew S, Meijer GW, Muggli R, Calder PC and Williams CM. Plantit- and marine-derived $n-3$ polyunsaturated fatty acids have differential effects on fasting and postiprandial blood lipid concentrations and on the susceptibility of LDL to oxidative modification in moderately hyperlipidemic subjects. Am J Clin Nutr 2003; 77: 783-95.

42. Oostenbrug GS, Mensink RP and Hornstra G. Effects of fish oil and vitamin $E$ supplementation on copper-catalysed oxidation of human low density lipoprotein in vitro. Eur J Clin Nutr 1994; 48: 895-8.

43. Leigh-Firbank EC, Minihane AM, Leake DS, Wright JW, Murphy MC, Griffin BA and Williams CM. Eicosapentaenoic acid and docosahexaenoic acid from fish oils: differential associations with lipid responses. $\mathrm{Br} J$ Nutr 2002; $87: 435-45$.

44. Higgins $\mathrm{S}$, Carroll $\mathrm{YL}$, McCarthy $\mathrm{SN}$, Corridan $\mathrm{BM}$, Roche HM, Wallace JM, O'Brien NM and Morrissey PA. Susceptibility of LDL to axidative modification in healthy volunteers supplemented with low doses of n-3 polyunsaturated fatty acids. Br J Nutr 2001; 85: 23-31.

45. Bonanome A, Biasia F, De Luca M, Munaretto $G$, Biffanti $S$, Pradella $M$ and Pagnan $A, n-3$ fatty acids do not enhance LDL susceptibility to oxidation in hypertriacylglycerolemic hernodialyzed subjects. Am $J$ Clin Nutr 1996; 63: 261-6.

46. Lusis A.J. Atherosclerasis. Nature 2000; 407: 233-41.

47. Young $\mathrm{JL}$, Libby $P$ and Schonbeck $U$. Cytokines in the pathogenesis of atherosclerosis. Thromb Haemost 2002; 88: 554-67.

48. Ridker PM, Hennekens $\mathrm{CH}$, Buring JE and Rifai N. C-reactive protein and other markers of inflammation in the prediction of cardiovascular disease in women. N Engl J Med 2000; 342: 836-43.

49. De Caterina R, Bernini W, Carluccio MA, Liao JK and Libby P. Structural requirements for inhibition of cytokine-induced endothelial activation by unsaturated fatty acids. J Lipid Res 1998; 39: 1062-70.

50. Toborek $M$, Lee $Y W$, Garrido $R$, Kaiser $S$ and Hennig $B$. Unsaturated fatty acids selectively induce an inflammatory environment in human endothelial cells. Am J Clin Nutr 2002:75: 119-25.

51. Hughes $D A_{i}$ Pinder $A C_{i}$ Piper $Z$, Johnson IT and Lund EK. Fish oil supplementation inhibits the expression of major histocompatibility complex class II molecules and adhesion molecules on human monocytes. Am J Clin Nutr 1996; 63: 267-72.

52. Wallace FA, Miles EA and Calder PC. Comparison of the effects of linseed oil and different doses of fish oil on mononuclear cell function in healthy human subjects. Br J Nutr 2003; 89: 679-89.

53. Yaqoob P, Knapper JA, Webb DH, Williams CM, Newsholme EA and Calder PC. Effect of olive oil on immune function in middle-aged men. Am J Clin Nutr 1998; 67: 129-35.

54. Blankenberg $S$, Rupprecht $H J$, Bickel $C$, Peetz $D$, Hafner $G$, Tiret $L$ and Meyer J. Circulating cell adhesion molecules and death in patients with coronary artery disease. Circulation 2001; 104: 133642.

55. Gearing AJ and Newman W. Circulating adhesion molecules in disease. Immunol Today 1993; 14: 506-12.

56. Brown $\mathrm{AA}$ and Hu FB. Dietary modulation of endothelial function: implications for cardiovascular disease. Am J Clin Nutr 2001; 73:673-86.

57. Thies $F$. Miles EA, Nebe-von-Caron $G$, Powell JR, Hurst TL, Newsholme EA and Calder PC. Influence of dietary supplementation with long-chain $n-3$ or $n-6$ polyunsaturated fatty acids on blood inflammatory cell populations and functions and on plasma soluble adhesion molecules in healthy adults. Lipids 2001; 36: 1183-93. 
58. Yul $H$ and Rifai $N$. High-sensitivity C-reactive protein and atherosclerosis: from theory to therapy. Clin Biochem 2000; 33: 601-10.

59. Endres $S_{n}$ Ghorbani $R$, Kelley VE, Georgilis $K$, Lonnemann $G$, van deir Meer JW, Cannon JG, Rogers TS, Klempner MS, Weber PC et al. The effect of dietary supplementation with n-3 polyunsaturated fatty acids on the synthesis of interleukin- 1 and tumor necrosis factor by mononuclear cells. N Engl $J$ Med 1989; 320: 265-71.

60. Caughey GE, Mantzioris E, Gibson RA, Cleland LG and James MJ. The effect on human tumor necrosis factor alpha and interleukin 1 beta production of diets enriched in $n-3$ fatty acids from vegetable oil or fish oil. Am J Clin Nutr 1996; 63: 116-22.

61. Kelley DS. Modulation of human immune and inflammatory pesponses by dietary fatty acids. Nutrition 2001; 17: 669-73.

62. Blok WL, Deslypere JP, Demacker PN, van der Ven-Jongekrijg J Hectors MP, van der Meer JW and Katan MB. Pro- and anti-inflammatory cytokines in healthy volunteers fed various dases of fish oill for 1 year. Eur J Clin Invest 1997; 27: 1003-8.

63. Engelberts $I_{\text {. }}$ Sundram K, Van Houwelingen AC, Hornstra $G_{\text { }}$ Kester $A D$, Ceska M, Francot G. van der Linden C.J and Buurman WA. The effect of replacement of dietary fat by palm oil on in vitro cytokine release. Br J Nutr 1993; 69: 159-67.

64. Han SN, Leka LS, Lichtenstein AH, Ausman LM, Schaefer EJ and Meydani SN. Efrect of hydrogenated and saturated, relative to polyunsaturated, fat on immune and inflammatory responses of adults with moderate hypercholesterolemia. J Lipid Res $2002 ; 43 ; 445-52$.

65. Kelley DS, Taylor PC, Nelson GJ and Mackey BE. Arachidonic acid supplementation enhances synthesis of eicosanoids without suppressing immune functions in young healthy men. Lipids 1998; 33: 125-30.

66. Railidis $L S$, Paschos $G_{1}$ Liakos $G_{k}$ Velissaridou $A H$, Anastasiadis $G$ and Zampelas A. Dietary alphalinolenic acid decreases C-reactive protein, serum amyloid $A$ and interleukin-6 in dyslipidaemic patients. Atherosclerosis 2003; 167: 237-42.

67. Ernst $E$, Saradeth $T$ and Achhammer G. $n-3$ fatty acids and acute-phase proteins. Eur $J$ Clin Invest $1991 ; 21: 77-82$.

68. Madsen $T$, Christensen $\mathrm{JH}, \mathrm{Blom} \mathrm{M}$ and Schmidt EB. The effect of dietary $\mathrm{m}-3$ fatty acids on serum concentrations of C-reactive protein: a dose-response study. Br J Nutr 2003; 89: 517-22.

69. Kelly CM, Smith RD and Williams CM. Dietary monounsaturated fatty acids and haemostasis. Proc Nutr Soc 2001; 60: 161-70.

70. Elwood PC, Renaud S, Sharp DS, Beswick AD "O'Brien JR and Yarnell JW. Ischemic heart disease and platelet aggregation. The Caerphilly Collaborative Heart Disease Study. Circulation 1991; 83; 38m 44.

71. Mutanen M. Cis-unsaturated fatty acids and platelet function. Prostaglandins Leukot Essent Fatty Acids 1997; 57: 403-10.

72. Turpeinen $A M$, Pajari $A M$, Freese $R$, Sauer $R$ and Mutanen M. Replacement of dietary saturated by unsaturated fatty acids: effects of platelet protein kinase $C$ activity, urinary content of 2,3 -dinor $-T \times B 2$ and in vitro platelet aggregation in healthy man. Thromb Haemost 1998; 80: 649-55.

73. Mutanen $M_{1}$ Freese $R$, Valsta $L M$, Ahola $I$ and Ahlstrom $A$. Rapeseed oil and sunflower oil diets enhance platelet in vitro aggregation and thromboxane production in healthy men when compared with milk fat or habitual diets. Thromb Haemost 1992; 67: 352-6.

74. Lahoz $C$. Alonso R, Ordovas JM, Lopez-Farre A, de Oya M and Mata P. Effects of dielary fiat saturation on eicosanoid production, platelet aggregation and blood pressure. Eur J Clin Invest 1997; 27: $780-7$.

75. Temme $E H$, Mensink RP and Hornstra $G$. Individual saturated fatty acids and effecls on whole blood aggregation in vitro. Eur J Clin Nutr 1998; 52: 697-702.

76. Abeywardena $M Y$ and Head RJ. Longchain n-3 polyunsaturated latty acids and blood vessel function. Cardiovasc Res 2001: 52: 361-71.

77. Oates JA, FitzGerald GA, Branch RA, Jackson EK, Knapp HR and Roberts LJ, 2nd. Clinical implications of prostaglandin and thromboxane A2 formation (1). N Engl J/Med 1988; 319:689-98.

78. Mustad VA, Kris-Etherton PM, Derr J, Reddy CC and Pearson TA. Comparison of the effects of diets rich in stearic acid versus myristic acid and lauric acid on platelet fatty acids and excretion of thromboxane A2 and PGI2 metabolites in healthy young men. Metabolism 1993; 42: 463-9.

79. Blair IA, Dougherty RM and lacono JM. Dietary stearic acid and thromboxane-prostacyclin biosynthesis in normal human subjects. Am J Clin Nutr 1994; 60: 1054S-8S. 
80. Turpeinen AM, Wubert $d_{i}$ Aro A, Lorenz $R$ and Mutanen M. Similar effects of diets rich in stearic acid or trans-fatty acids on platelet function and endothelial prostacyclin production in humans. Anterioscler Thromb Vasc Biol 1998; 18: 316-22.

81. Miller $\mathrm{GJ}$, Bauer $K A$, Barzegar $S$, Cooper JA and Rosenberg RD. Increased activation of the haemostatic system in men at high risk of fatal coronary heart disease. Thromb Haemost 1996; 75: 767-71.

82. Kelly FD, Sinclair AJ, Mann $N \mathrm{~J}$, Turner AH, Abedin L and Li D. A stearic acid-rich diet improves thrombogenic and atherogenic risk factor profiles in healthy males. Eur J Cin Nutr 2001; 55: 88-96.

83. Temme EH, Mensink RP and Homstra G. Effects of diets enriched in lauric, palmitic or oleic acids on blood coagulation and fibrinolysis. Thromb Haemost 1999; 81: 259-63.

84. Agren $J J_{\text {, Vaisanen }} S$, Hanninen $O$, Muller $A D$ and Hornstra $G$. Hemostatic factors and platelet aggregation after a fish-enriched dief or fish oil or docosahexaenoic acid supplementation. Prostaglandins Leukot Essent Fatty Acids 1997: 57: 419-21.

85. Sanders TA, de Grassi $T$, Miller GJ and Morrissey $J \mathrm{H}$. Influence of fatty acid chain length and cis/trans isomerization on postprandial lipemia and factor VII in healthy subjects (postprandial lipids and factor VII). Atheroscierosis 2000; 149: 413-20.

86. Hunter KA, Crosbie LC, Weir A, Miller GJ and Dutta-Roy AK. The effects of structurally defined triglycerides of differing fatty acid composition on postprandial haemostasis in young, healthy men. Atherasclerosis $1999 ; 142: 151-8$.

87. Tholstrup T, Miller GJ, Bysted A and Sandstrom B. Effect of individual dietary fatty acids on postprandial activation of blood coagulation factor VII and fibrinolysis in healthy young men. $A m$ I Clin Nutr 2003; 77 : 1125-32.

88. Hunter KA, Crosbie LC, Weir A, Miller GJ and Dutta-Roy AK. A residential study comparing the effects of diets rich in stearic acid, oleic acid, and linoleic acid on fasting blood lipids, hemostatic variables and platelets in young healthy men. Joumal of Nutritional Biochemistry 2000; 11: 408-16.

89. Junker R, Kratz M. Neufeld M, Erren M, Nofer JR, Schulte $H$, Nowak-Gottl $U$, Assmann $G$ and Wahrburg $U$. Effects of diets containing olive oil, sunflower oill, or rapeseed oil on the hemostatic system. Thramb Haemost 2001; 85: 280-6.

90. Hunter KA. Crosbie LC, Horgan GW, Miller GJ and Dutta-Roy AK. Effect of diets rich in oleic acid, stearic acid and linoleic acid on postprandial haemostatic factors in young healthy men. $\mathrm{Br} J \mathrm{Nutr}$ 2001; 86: 207-15.

91. Ridker PM. Fibrinolytic and inflammatory markers for arterial occlusion: the evolving epidemiology of thrombosis and hemostasis. Thromb Haemost 1997; 78: 53-9.

92. Mutanen $M$ and Aro A. Coagulation and fibrinolysis factors in healthy subjects consuming high stearic or trans fatty acid diets. Thromb Haemost 1997; 77: 99-104.

93. Marckmann $P$, Sandstrom $B$ and Jespersen J. Low-fat, high-fiber diet favorably affects several independent risk markers of ischemic heart disease: observations on blood lipids, coagulation, and fibrinolys is from a trial of middle-aged Danes. Am J Clin Nutr 1994; 59: 935-9.

94. Tholstrup T, Andreasen $K$ and Sanstrom B. Acute effect of high-fat meals rich in either stearic or myristic acid on hemostatic factors in healthy young men. Am J Clin Nutr 1996; 64: 168-76.

95. Hansen J, Grimsgaard S, Nordoy A and Bonaa KH. Dietary supplementation with highly purified eicosapentaenoic acid and docosahexaenoic acid does not influence PAl-1 activity. Thromb Res 2000; $98: 123-32$.

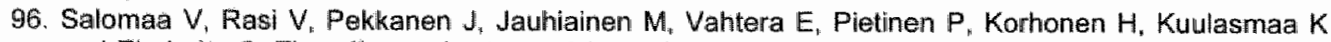
and Ehnholm $C$. The effects of saturated fat and $n-6$ polyunsaturated fat on postprandial lipemia and hemostatic activity. Atherosclerosis 1993; 103:1-11.

97. Turpeinen AM and Mutanen M. Similar effects of diets high in oleic or linoleic acids on coagulation and fibrinolytic factors in healthy humans. Nutr Metab Cardiovasc Dis 1999; 9: 65-72.

98. Sacks FM and Katan M. Randomized clinical trials on the effects of dietary fat and carbohydrate on plasma lipoproteins and cardiovascular disease. Am J Med 2002; 113 Suppl 9B: 13S-24S. 


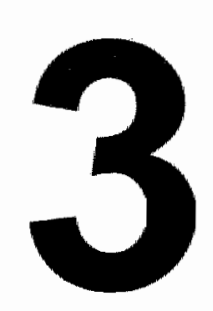

\section{Small differences in the effects of stearic acid, oleic acid, and linoleic acid on the serum lipoprotein profile of humans}

Myriam A.M.A. Thijssen ${ }^{1}$ and Ronald P. Mensink ${ }^{1}$

American Journal of Clinical Nutrition 2005; 82(3): 510-516

'Nutrition and Toxicalogy Research Institute Maastricht (NUTRIM), Department of Human Biology: Maastricht University, Maastricht, The Netherlands 


\section{ABSTRACT}

Background: Studies have suggested that oleic and stearic acids, as well as oleic and linoleic acids, have comparable effects on the serum lipoprotein profile. If so, then substituting these three C18 fatty acids for each other would result in similar effects on the serum lipoprotein profile.

Objective: The aim of this study was to compare simultaneously the effects of stearic, oleic, and linoleic acids on the serum lipoprotein profile of healthy subjects.

Design: Forty-five subjects (27 women and 18 men) consumed in random order 3 experimental diets, each for 5 weeks. The diets provided 38 percent of energy ( $\%$ of energy) from fat, of which $60 \%$ was supplied by the experimental fats. The dietary compositions were the same, except for $7 \%$ of energy, which was provided by stearic, oleic, or linoleic acid. At the end of each intervention period, serum lipid and lipoprotein concentrations were measured. In addition, LDL, HDL, and VLDL particle sizes and particle concentrations of lipoprotein subclasses were analysed by nuclear magnetic resonance (NMR) spectroscopy.

Results: No significant diet-induced changes in serum lipids and lipoproteins were found. Mean ( \pm standard deviations) serum $L D L$ cholesterol concentrations were $3.79 \pm 0.91,3.71 \pm 0.79$, and $3.65 \pm 0.91 \mathrm{mmol} / \mathrm{L}$ with the high-stearic acid, higholeic acid, and high-linoleic acid diets, respectively $(P=0.137$ for diet effects). Mean ( \pm standard deviations) $H D L$ cholesterol concentrations were $1.45 \pm 0.43,1.46 \pm$ 0.45 and $1.46 \pm 0.44 \mathrm{mmol} / \mathrm{L}(P=0.866)$. LDL, HDL, and VLDL particle sizes and lipoprotein subclass distributions also did not differ significantly between the 3 diets.

Conclusions: With realistic intakes of stearic, oleic, and linoleic acids, differences between their effects on the serum lipoprotein profile are small. 


\section{INTRODUCTION}

It is well known that the various fatty acids in the diet exert different effects on serum lipid and lipoprotein concentrations. Saturated fatty acids are thought to increase cardiovascular risk because they elevate serum total and LDL cholesterol concentrations relative to monounsaturated and polyunsaturated fatty acids. These effects have been quantified by earlier well-controlled dietary studies $(1,2)$. Relative to an iso-energetic amount of carbohydrates, a mixture of saturated fatty acids elevated serum total cholesterol concentrations, monounsaturated fatty acids had comparable effects, and polyunsaturated fatty acids were hypocholesterolemic. As an exception to the other saturated fatty acids, stearic acid - a saturated fatty acid with 18 carbon atoms - had no effects on serum total cholesterol concentrations $(1,2)$. These earlier studies, however, did not examine the effects of fatty acids on specific lipoproteins, which is important because of the opposing effects of LDL and $\mathrm{HDL}$ cholesterol on cardiovascular disease risk.

More recentlly, several studies have compared the effects of stearic acid on lipid and lipoprotein concentrations with those of unsaturated fatty acids. When stearic acid was substituted for oleic acid, effects on serum LDL and HDL cholesterol concentrations did not differ (3). Similarly, the use of realistic intakes of linoleic acid (less than $13 \%$ of energy), oleic acid and linoleic acid had similar effects on the serum lipoprotein profile $(4,5)$. If these findings are true (3-5), then the consequence is that the effects of stearic, oleic ${ }_{n}$ and linoleic acids on serum lipid and lipoprotein concentrations would be comparable. To examine this hypothesis, we compared the effects of diets enriched in these three $\mathrm{C} 18$ fatty acids on serum total, LDL, and HDL cholesterol and triacylglycerol concentrations in a controlled crossover study in healthy subjects. In addition, we investigated the effects of these diets on LDL, HDL, and VLDL particle sizes and on the subclass distributions of these lipoprotein particles by nuclear magnetic resonance (NMR) spectroscopy.

\section{SUBJECTS AND METHODS}

\section{Subjects}

Healthy, male and female non-smoking volunteers were recruited via advertisements in local newspapers and in a university hospital newsletter and via posters in university buildings. Persons who were interested were informed about the purposes and requirements of the study and had to give their written informed consent before entering the screening phase. At screening, two fasting blood samples were taken for the measurement of serum lipid and lipoprotein 
concentrations and hematological variables, and blood pressure and urinary glucose and protein from a morning urine specimen were measured. Subjects were included in the study if they were aged 18-65 $y$, were healthy on the basis of a medical questionnaire, were not pregnant; were weight stable and had a body mass index (BMI) below $32 \mathrm{~kg} / \mathrm{m}^{2}$, had a diastolic blood pressure below $95 \mathrm{mmHg}$, had a systolic blood pressure below $160 \mathrm{mmHg}$, had a fasting serum total cholesterol concentration between 5.0 and $8.0 \mathrm{mmol} / \mathrm{L}$, and had a serum triacylglycerol concentration below $4.0 \mathrm{mmol} / \mathrm{L}$. Subjects with a history of atherosclerotic disease, glycosuria, proteinuria, or anemia, and who were taking medications known to affect blood lipids or hemostatic variables were excluded from the study. Fifty-eight persons met the eligibility criteria. Blood donation or participation in another biomedical trial was not allowed within 4 weeks before the start of the study or during the study. The study protocol was approved by the Medical Ethics Committee of the Maastricht University.

Subjects withdrew mainly in the first 2 weeks of the study, for reasons specifically related to the strict study protocol ( $n=4$ subjects), stressful personal or job circumstances ( $n=5$ subjects), and physical illness ( $n=2$ subjects in the first intervention period and 1 subject in the second intervention period). One subject was excluded after the first period, because he did not follow the protocol. Ultimately, 45 subjects ( 18 men and 27 women) aged $28-66$ y (mean \pm standard deviation: $51 \pm 10 \mathrm{y}$ ) completed the protocol. During the screening period, body mass indexes ranged from 18.0 to $29.8 \mathrm{~kg} / \mathrm{m}^{2}\left(24.9 \pm 2.7 \mathrm{~kg} / \mathrm{m}^{2}\right)$. The subjects' fasting serum lipid concentrations ranged from 4.97 to $7.76 \mathrm{mmol} / \mathrm{L}$ for total cholesterol $(6.04 \pm 0.75 \mathrm{mmol} / \mathrm{L})$, from 0.83 to $3.60 \mathrm{mmol} / \mathrm{L}$ for $\mathrm{HDL}$ cholesterol $(1.48 \pm 0.54 \mathrm{mmol} / \mathrm{L})$, and from 0.49 to $2.80 \mathrm{mmol} / \mathrm{L}$ for triacylglycerols $(1.15 \pm 0.55$ $\mathrm{mmol} / \mathrm{L}$ ). Sixteen women were postmenopausal and five used oral contraceptives.

\section{Experimental design and diets}

The study had a randomised, multiple crossover design and consisted of 3 consecutive periods. Each participant consumed each of the 3 different diets during three 5-week periods. One diet was high in stearic acid (C18:0), another was high in oleic acid (C18:1), and the third was high in linoleic acid (C18:2). Before the study started, the subjects were categorised according to sex and were then randomly divided into 6 groups. Each group received the diets in 1 of the 6 possible treatment orders. Between each 5-week intervention period was a washout period of at least 1 week during which time the participants consumed their habitual diets (Figure 3.1).

The prescribed nutrient composition of the diets did not differ, except for a 7 percent difference in energy intake (\% of energy) provided by stearic acid, oleic 
acid, or linoleic acid. Before the participants started the study, their total energy intake was estimated with the Harris-Benedict equation (6). The diets were formulated to provide 16 different energy intakes ranging from 6 to $13.5 \mathrm{MJ}$ per day. The experimental products supplied $60 \%$ of the total fat energy at a targeted total fat intake of $37 \%$ of energy. For the remaining $40 \%$ of the total daily fat intake, subjects were free to consume a certain amount of 'free-choice' fat-containing products. Therefore, participants received a list of fat-containing products to which points had been assigned on the basis of fat content ( 1 point equals $1 \mathrm{~g}$ fat). These products had to be recorded in a diary. Furthermore, alcohol consumption, medications used, signs of illness, menstruation, and any deviations from the study protocol were noted in this diary. The subjects were asked not to change their level of physical exercise or their use of alcohol, vitamins or oral contraceptives during the study.

\begin{tabular}{|c|c|c|c|c|c|}
\hline & & & & \multicolumn{2}{|c|}{ Subjects } \\
\hline & \multicolumn{3}{|c|}{ Period } & \multirow{3}{*}{$\begin{array}{c}\text { Men } \\
n=18\end{array}$} & \multirow{3}{*}{$\begin{array}{c}\text { Women } \\
n=27\end{array}$} \\
\hline & 1 & 2 & 3 & & \\
\hline Group & Diet & Diet & Diet & & \\
\hline 1 & C18:0 & e e & C18:2 & 3 & 5 \\
\hline 2 & C18:0 & $\mathrm{C} 18: 2$ & 26. 181 & 4 & 4 \\
\hline 3 & (y) & C18:0 & C18:2 & 3 & 4 \\
\hline 4 & (6) 6 & C18:2 & C18:0 & 3 & 5 \\
\hline 5 & C18:2 & C18:0 & (7) & 3 & 5 \\
\hline 6 & C18:2 & (6) 16 & $\mathrm{C} 18: 0$ & 2 & 4 \\
\hline & 5 weeks & 5 weeks & 5 weeks & & \\
\hline
\end{tabular}

Figure 3.1 Experimental design of the study.

During the study periods, the subjects visited the university at least once every week to receive a new supply of products and to be weighed. Any leftover products had to be returned and were weighed. Individual allowances were adjusted if weight changed more than $1.5 \mathrm{~kg}$ from the initial weight during the first week or more than 2 $\mathrm{kg}$ during the following weeks. At each visit, the diary was checked by a dietician. In the last week of each intervention period "the subjects filled in a food-frequency questionnaire to estimate energy and nutrient intakes. These food-frequency questionnaires were immediately checked by a dietician. Items were coded, and the composition of the diets was calculated according to the Dutch food-composition table (7). 


\section{Experimental fats}

Experimental fats were produced by NIZO Food Research (Ede, The Netherlands). The high-stearic acid fat was composed of $9.0 \%$ palm oil, $5.5 \%$ safflower oil, $5.0 \%$ olive oil, $33.5 \%$ cocoa butter, $18.0 \%$ high-oleic acid sunflower oil and $29.0 \%$ glycerol tristearate. The high-oleic acid fat consisted of $19.5 \%$ palm oil, $26.0 \%$ olive oil, $7.5 \%$ cocoa butter, and $47.0 \%$ high-oleic acid sunflower oil. The high-linoleic acid fat was a mixture of $20.0 \%$ palm oil, $52.0 \%$ safflower oil, $7.0 \%$ olive oil, $9.0 \%$ cocoa butter and $12.0 \%$ high-oleic acid sunflower oil. The fatty acid compositions of the experimental fats as determined by gas-liquid chromatography are shown in Table 3.1. From these fats, margarines were produced with a fat content $(w / w)$ of $84 \%$. The margarines were used to bake sponge cakes with a margarine content of $25 \%$ and bread with a margarine content of $10 \%$. Products were labelled with a blue, orange, or yellow label to blind the subjects.

Table 3.1 Fatty acid composition of the 3 experimental fats. ${ }^{\prime}$

\begin{tabular}{lccc}
\hline Fatty acid & Stearic acid fat & Oleic acid fat & Linoleic acid fat \\
\hline Saturated fatiy acids & 57.0 & \% of total fatty acids $(w / w)$ & 23.0 \\
Lauric acid (C12:0) & 0.1 & 2.6 & 0.1 \\
Myristic acid (C14:0) & 0.2 & 0.1 & 0.3 \\
Palmitic acid (C16:0) & 16.2 & 0.3 & 15.8 \\
Stearic acid (C18:0) & 38.6 & 15.3 & 5.9 \\
Monounsaturated fatty acids & 33.9 & 6.7 & 32.6 \\
Palmitoleic acid (C16:1n-7) & 0.2 & 0.4 & 0.2 \\
Oleic acid (C18:1n-9) & 33.0 & 64.9 & 31.3 \\
Polyunsaturated fatty acids & 9.2 & 10.9 & 44.4 \\
n-6 polyunsaturated fatty acids & 9.0 & 10.6 & 44.0 \\
Linoleic acid (C18:2n-6) & 8.9 & 10.6 & 43.9 \\
n-3 polyunsaturated fatty acids & 0.1 & 0.2 & 0.3 \\
$\alpha$-Linolenic acid (C18:3n-3) & 0.1 & 0.2 & 0.2 \\
\hline
\end{tabular}

Values were determined by gas-liquid chromatography of tripticate samples of the margarines.

\section{Blood sampling}

Venous blood samples were obtained twice at the end of each period (weeks 4 and 5) while the subjects were in a recumbent position and after they had fasted overnight. Blood was collected with minimum stasis by using a $0.9 \mathrm{~mm}$-needle (PrecisionGlide, Becton-Dickinson Vacutainer systems, Plymouth, United Kingdom) in week 4 or with a $1.0-\mathrm{mm}$ infusion needle (Microflex, Vygon, Ecouen, France) in 
week 5 . All venipunctures were done by the same person, in the same room, and mostly at the same time of the day.

For lipid and lipoprotein analyses, $10 \mathrm{~mL}$ blood was collected into a serum tube (Corvac, Becton Dickinson Vacutainer Systems, Plymouth, UK). At least 1 hour after venipuncture, serum was obtained by centrifugation at $3500 \times \mathrm{g}$ for $30 \mathrm{~min}$ at $4^{\circ} \mathrm{C}$ and stored at $-80^{\circ} \mathrm{C}$.

\section{Lipids and apolipoproteins}

Serum total cholesterol (ABX Diagnostics, Montpellier, France), HDL cholesterol (precipitation method; Roche Diagnostics Corporation, Indianapoilis, United States)。 and triacylglycerol (Sigma Aldrich Chemie, Steinheim, Germany) concentrations were analysed enzymatically. The within-run coefficients of variation (CV) were $1.3 \%$ for total cholesterol, $4.8 \%$ for $\mathrm{HDL}$ cholesterol and $3.7 \%$ for triacylglycerols. $\mathrm{LDL}$ cholesterol was calculated by using the equation of Friedewald (8).

Apolipoprotein A-I (apo A-1) and apolipoprotein B (apo B) were measured in serum by using an immunoturbidimetric method ( $A B X$ Diagnostics). The within-run CVs for apo $A-I$ and apo $B$ were $0.9 \%$ and $1.2 \%$, respectively. All samples from one subject were analysed within one run.

Serum concentrations of lipoprotein particles and their subclasses and particle sizes of lipoproteins were analysed in a randomly chosen subset (stratified for sex) of 22 subjects ( 9 men and 13 women) by NMR spectroscopy (Liposcience, Raleigh, United States) as previously described (9). Before NMR analysis, serum samples from the end of each intervention period (weeks 4 and 5) were pooled.

\section{Fatty acid composition}

The fatty acid compositions of serum phospholipids in a pooled sarnple from weeks 4 and 5 and of the margarines were analysed as previously described (10). Briefly, total lipids were extracted from $100 \mu \mathrm{L}$ serum or $10 \mathrm{mg}$ margarine according to the method of Bligh and Dyer (11). Aminopropyl-bonded silica columns (Varian, Harbor City, CA united States) were used to separate phospholipids from the total lipid extract of serum (12). The phospholipids from the serum and the triacylglycerols from the margarines were then saponified, and the resultant fatty acids were methylated into their corresponding fatty acid methyl esters (FAMEs) (13). Fatty acids were separated on an Autosystem (Perkin Elmer, Norwalk, Connecticut, United States) gas chromatograph that was fitted with a sillica-gel column ( $\mathrm{Cp}$-sill 88 for FAME, $50 \mathrm{~m} \times 0.25 \mathrm{~mm}, 0.2-\mu \mathrm{m}$ film thickness, Chrompack, Middelburg. The Netherlands) with helium gas $(130 \mathrm{kPa})$ as the carrier gas (10). A comparable protocol was used to separate FAMEs from the triacylglycerols. For triacylglycerols, 
the injection and detection temperatures were both $300^{\circ} \mathrm{C}$. The starting temperature of the column was $160^{\circ} \mathrm{C}$. Ten minutes after injection, the temperature was increased up to $190^{\circ} \mathrm{C}$ at a rate of $2.5^{\circ} \mathrm{C} / \mathrm{min}$. After $20 \mathrm{~min}$ at $190^{\circ} \mathrm{C}$, the temperature was increased up to $230^{\circ} \mathrm{C}$ at a rate of $4^{\circ} \mathrm{C} / \mathrm{min}$. The final temperature of $230^{\circ} \mathrm{C}$ was maintained for $10 \mathrm{~min}$.

Data were analysed using Chromcard software (version 1.21, CE instruments, Milan, Italy). The fatty acid compositions of the margarines and serum phospholipids are expressed in relative amounts ( $\%$ of total fatty acids identified, $w / w)$.

Table 3.2 Mean mutrient composition of the 3 diets according to the food-frequency questionnaires."

\begin{tabular}{lllll}
\hline & $\begin{array}{c}\text { Stearic acid } \\
\text { diet }\end{array}$ & $\begin{array}{c}\text { Oleic acid } \\
\text { diet }\end{array}$ & $\begin{array}{c}\text { Linolleic } \\
\text { acid diet }\end{array}$ & $\begin{array}{c}\text { P for diet } \\
\text { effects }^{2}\end{array}$ \\
\hline Energy & & & & \\
(MJ/dlay) & $8.4 \pm 1.5$ & $8.6 \pm 1.7$ & $8.6 \pm 1.7$ & 0.086 \\
(Kcal/day) & $1997 \pm 348$ & $2047 \pm 400$ & $2058 \pm 406$ & 0.086 \\
Protein (\% of energy) & $14.0 \pm 1.8$ & $14.0 \pm 2.1$ & $13.8 \pm 2.0$ & 0.412 \\
Fat (\% of energy) & $38.2 \pm 5.1$ & $37.7 \pm 5.6$ & $38.0 \pm 5.3$ & 0.701 \\
Saturated fatty acids & $18.0 \pm 2.3^{\mathrm{a}}$ & $11.0 \pm 2.0^{\mathrm{b}}$ & $11.2 \pm 1.9^{\mathrm{b}}$ & $<0.001$ \\
Stearic acid (C18:0) & $7.7 \pm 1.1^{\mathrm{a}}$ & $1.2 \pm 0.2^{\mathrm{b}}$ & $1.2 \pm 0.2^{\mathrm{b}}$ & $<0.001$ \\
Monounsaturated fatty & $12.9 \pm 2.0^{\mathrm{a}}$ & $19.1 \pm 2.9^{\mathrm{b}}$ & $12.5 \pm 1.8^{\mathrm{a}}$ & $<0.001$ \\
Olleic acid (C18:1) & $6.8 \pm 1.0^{\mathrm{a}}$ & $13.1 \pm 2.0^{\mathrm{b}}$ & $6.6 \pm 1.0^{\mathrm{a}}$ & $<0.001$ \\
Polyunsaturated fatty acids & $4.7 \pm 1.2^{\mathrm{a}}$ & $5.0 \pm 1.1^{\mathrm{a}}$ & $11.8 \pm 1.8^{\mathrm{b}}$ & $<0.001$ \\
Linoleic acid (C18:2) & $2.1 \pm 0.3^{\mathrm{a}}$ & $2.4 \pm 0.3^{\mathrm{a}}$ & $9.3 \pm 1.3^{\mathrm{b}}$ & $<0.001$ \\
$\quad$ a-Linolenic acid (C18:3) & $0.2 \pm 0.1^{\mathrm{a}}$ & $0.2 \pm 0.1^{\mathrm{ab}}$ & $0.2 \pm 0.1^{\mathrm{b}}$ & 0.006 \\
Carbohydrates (\% of energy) & $45.8 \pm 5.6$ & $46.3 \pm 6.6$ & $46.3 \pm 6.2$ & 0.624 \\
Alcohol (\% of energy) & $2.3 \pm 2.4$ & $2.2 \pm 2.3$ & $2.1 \pm 2.3$ & 0.418 \\
Cholesterol (mg/MJ) & $17.7 \pm 3.2$ & $17.4 \pm 4.2$ & $17.9 \pm 3.3$ & 0.502 \\
Dietary fibre (g/MJ) & $3.1 \pm 0.6$ & $3.1 \pm 0.7$ & $3.1 \pm 0.7$ & 0.686 \\
\hline
\end{tabular}

All values are means \pm standard deviations, $n=45$ (18 men and 27 women). Valcues in a row with different superscript letters are significantly different, $P<0.05$ (Bonferroni-correcied pairwise comparisans in general tinear madel).

${ }^{2}$ Calculated by using a general linear model with subject number as random factor and diet and period as fixed factors.

${ }^{3}$ As provided by the experimental fats only.

\section{Statistics}

For serum lipids and (apo)lipoproteins, the results of the 2 serum samples from weeks 4 and 5 were averaged before the statistical analyses. The statistical power to detect a true difference in total cholesterol of $0.21 \mathrm{mmol} / \mathrm{L}$, in LDL cholesterol of 
$0.17 \mathrm{mmol} / \mathrm{L}$, and in HDL cholesterol of $0.06 \mathrm{mmol} / \mathrm{L}$ was more than $80 \%$. The data were analysed with the general linear model procedure of the SPSS 11 for Macintosh OS $X$ package. A probability level ( $P$-value) of less than 0.05 was considered statistically significant. Differences in effects on lipid and lipoprotein concentrations were examined with diet and period as fixed factors and subject number as random factor. To analyse whether the effects of diet were modified by sex or $\mathrm{BMI}$, the diet $\mathrm{x}$ sex or diet $\mathrm{x} \mathrm{BMI}$ interactions terms were added to the model as fixed factors. To examine effects of BMl, the subjects were divided into 2 groups. One group consisted of subjects with a BMI below $25 \mathrm{~kg} / \mathrm{m}^{2}(n=25)$ and the other group of subjects with a BMI equal to or above $25 \mathrm{~kg} / \mathrm{m}^{2}(n=20)$. When the analyses indicated a significant effect of diet, the diets were compared pairwise. When the interaction terms diet $x$ sex or diet $x$ BMI were significant, the diets were compared pairwise for the two sex or BMI groups separately. Between-diets comparisons were corrected for 3-group comparisons by the Bonferroni correction; confidence intervals $(\mathrm{Cl}, 95 \%)$ were calculated for the differences between the diets. Values are presented as means \pm standard deviations. Pearson's correlations were determined to examine linear relationships between parameters.

\section{RESULTS}

\section{Diets and dietary adherence}

The mean daily energy intake and the composition of the 3 diets, as determined by the food-frequency questionnaires (Table 3.2), agreed well with the prescribed composition of the diets. Intakes of test products (bread, cake, and margarines) did not differ between diets. Total fat intake, on average, was $38 \%$ of energy, and did not differ between the 3 diets $(P=0.701)$. The nutrient composition of the diets also did not differ, except that $7 \%$ of energy was provided by different fats: stearic, oleic, or linoleic acid. Because of minor differences in the fatty acid composition of the experimental fats, the estimated intakes of $\alpha$-linolenic acid were, respectively, $0.02 \%$ of energy $(P=0.214)$ higher with the oleic acid diet and $0.03 \%$ of energy ( $P=0.004)$ with the linoleic acid diet than with the stearic acid diet. The mean amount of fat consumed as free-choice fat-containing products denoted in the subjects' diaries was $41.5 \%$ of total fat intake. This agreed well with the intended amount of $40 \%$.

Mean body weights at the end of each dietary period did not differ significantly between the 3 diets $(P=0.449)$ and were $72.5 \pm 13.0 \mathrm{~kg}$ with the stearic acid diet, $72.5 \pm 13.2 \mathrm{~kg}$ with the oleic acid diet, and $72.7 \pm 12.9 \mathrm{~kg}$ with the linoleic acid diet.

Dietary adherence was confirmed by the fatty acid compositions of serum phospholipids (Table 3.3). During the stearic acid diet, the proportion of stearic acid 
was increased mainly at the expense of oleic acid. Likewise, the proportion of oleic: acid increased after consumption of the oleic acid diet, mainly at the expense of stearic acid. During the diet rich in linoleic acid, the proportion of linoleic acid increased, whereas those of $\alpha$-linolenic acid, eicosapentaenoic acid, oleic acid, and stearic acid decreased.

Table 3.3 Fatty acid composition of serum phospholipids during the 3 dietary periods."

\begin{tabular}{lcccc}
\hline Fatty acid & $\begin{array}{c}\text { Stearic acid } \\
\text { dliet }\end{array}$ & $\begin{array}{c}\text { Oleic acid } \\
\text { Diet }\end{array}$ & $\begin{array}{c}\text { Linoleic acid } \\
\text { diet }\end{array}$ & $\begin{array}{c}\text { P for diet } \\
\text { effects }^{2}\end{array}$ \\
\hline Saturated fatty acids & \multicolumn{4}{c}{$\%$ of total fatty acids $(\mathrm{W} / \mathrm{w})$} \\
Paimitic acid (C16:0) & $46.5 \pm 1.5^{\mathrm{a}}$ & $45.6 \pm 1.5^{\mathrm{b}}$ & $46.2 \pm 1.9^{\mathrm{a}}$ & 0.001 \\
Stearic acid (C18:0) & $26.5 \pm 1.6^{\mathrm{a}}$ & $26.8 \pm 1.4^{\mathrm{ab}}$ & $26.9 \pm 1.6^{\mathrm{b}}$ & 0.014 \\
Monounsaturated fatty acids & $14.3 \pm 1.2^{\mathrm{a}}$ & $13.1 \pm 1.1^{\mathrm{b}}$ & $113.7 \pm 1.3^{\mathrm{a}}$ & $<0.001$ \\
Oleic acid (C18:1n-9) & $13.6 \pm 1.1^{\mathrm{a}}$ & $15.0 \pm 1.3^{\mathrm{b}}$ & $12.2 \pm 0.9^{\mathrm{c}}$ & $<0.001$ \\
Polyunsaturated fatty acids & $9.3 \pm 1.1^{\mathrm{a}}$ & $10.5 \pm 1.2^{\mathrm{b}}$ & $7.7 \pm 0.8^{\mathrm{c}}$ & $<0.001$ \\
N-6 polyunsaturated fatty acids & $39.1 \pm 1.6^{\mathrm{a}}$ & $38.6 \pm 1.7^{\mathrm{a}}$ & $40.6 \pm 2.1^{\mathrm{b}}$ & $<0.001$ \\
Linoleic acid (C18:2n-6) & $20.7 \pm 1.8^{\mathrm{a}}$ & $20.5 \pm 2.0^{\mathrm{a}}$ & $23.2 \pm 2.4^{\mathrm{b}}$ & $<0.001$ \\
Arachidonic acid (C20:4n-6) & $8.9 \pm 1.5$ & $8.7 \pm 1.5$ & $8.6 \pm 1.7$ & 0.103 \\
N-3 polyunsaturated fatty acids & $5.2 \pm 1.2^{\mathrm{a}}$ & $5.1 \pm 1.0^{\mathrm{a}}$ & $4.7 \pm 1.0^{\mathrm{b}}$ & $<0.001$ \\
$\alpha-L i n o l e n i c ~ a c i d ~(C 18: 3 n-3)$ & $0.1 \pm 0.0^{\mathrm{a}}$ & $0.1 \pm 0.0^{\mathrm{a}}$ & $0.1 \pm 0.0^{\mathrm{b}}$ & $<0.001$ \\
EPA (C20:5n-3) & $0.8 \pm 0.4^{\mathrm{a}}$ & $0.7 \pm 0.3^{\mathrm{a}}$ & $0.5 \pm 0.3^{\mathrm{b}}$ & $<0.001$ \\
DHA (C22:6n-3) & $3.4 \pm 0.9$ & $3.3 \pm 0.7$ & $3.2 \pm 0.7$ & 0.063 \\
Trans fatty acids & $0.8 \pm 0.3$ & $0.8 \pm 0.2$ & $0.9 \pm 0.2$ & 0.060 \\
\hline
\end{tabular}

"All values are means \pm standard deviations, $n=45$ (18 men and 27 women). EPA, eicosapentaenoic acid: DHA, docosahexaenoic acid. Values in a row with different superscript vetters are significantly different, $P<0.05$ (Bonferroni-corrected pairwise comparisons in gleneral linear model).

${ }^{2}$ Calculated by using a general linear model with subject number as random factor and diet and period as fixed factors.

\section{Serum lipids and (apo)lipoproteins}

The effects of the 3 different diets on the serum lipid and lipoproteins concentrations are given in Table 3.4. No statistically significant changes in serum concentrations of total ( $P=0.110$ for diet effects) and LDL $(P=0.137$ for diet effects) cholesterol were found. Effects on HDL cholesterol $(P=0.866)$ and triacylglycerol $(P=0.670)$ concentrations also did not differ between the 3 diets. With respect to the total to HDL cholesteral ratio, no significant differences existed between the 3 diets ( $P=$ $0.303)$. Changes in concentrations of apo $B(P=0.122)$ and $A-I(P=0.534)$ were also not statistically significant between the 3 diets and they paralleled those of LDL and HDL cholesterol, respectively. A statistically significant diet $x$ BMI interaction 
effect $(P=0.029)$ was observed for apo $B$. In the high-BMi group $(P=0.011$ for diet effects), the linoleic acid diet reduced apo $B$ concentrations by $0.08 \mathrm{~g} / \mathrm{L}$ relative to stearic acid $(P=0.010,95 \% \mathrm{Cl}$ for the difference 0.02 to $0.15 \mathrm{~g} / \mathrm{L})$. In the low-BMI group, apo $B$ concentrations did not differ between the three diets $(P=0.689)$. None of the dietary effects differed significantly between men and women (data not shown).

Table 3.4 Fasting serum lipids and lipoproteins concentrations and the ratio of total to HDL cholesterol during consumption of diets enriched in stearic, oleic and linoleic acids for 5 weeks by healthy men and women. ${ }^{1}$

\begin{tabular}{lcccc}
\hline & $\begin{array}{c}\text { Stearic } \\
\text { acid diet }\end{array}$ & $\begin{array}{c}\text { Oleic acid } \\
\text { diet }\end{array}$ & $\begin{array}{c}\text { Linoleic } \\
\text { acid diet }\end{array}$ & $\begin{array}{c}\text { P for diet } \\
\text { effects }^{2}\end{array}$ \\
\hline Total cholesterol $(\mathrm{mmo} / \mathrm{L})$ & $5.81 \pm 0.94$ & $5.73 \pm 0.81$ & $5.66 \pm 0.91$ & 0.110 \\
LDL cholesterol $(\mathrm{mmol} / \mathrm{L})$ & $3.79 \pm 0.91$ & $3.71 \pm 0.79$ & $3.65 \pm 0.91$ & 0.137 \\
HDL cholesterol $(\mathrm{mmol} / \mathrm{L})$ & $1.45 \pm 0.43$ & $1.46 \pm 0.45$ & $1.46 \pm 0.44$ & 0.866 \\
Triacylglycerols $(\mathrm{mmol} / \mathrm{L})$ & $1.24 \pm 0.55$ & $1.22 \pm 0.52$ & $1.21 \pm 0.60$ & 0.670 \\
Apolipoprotein A-I $(\mathrm{g} / \mathrm{L})$ & $1.39 \pm 0.23$ & $1.41 \pm 0.25$ & $1.40 \pm 0.24$ & 0.534 \\
Apolipoprotein B $(\mathrm{g} / \mathrm{L})$ & $1.08 \pm 0.20$ & $1.06 \pm 0.19$ & $1.04 \pm 0.17$ & 0.122 \\
Total to HDL cholesterol ratio & $4.31 \pm 1.33$ & $4.22 \pm 1.23$ & $4.19 \pm 1.28$ & 0.303 \\
\hline
\end{tabular}

${ }^{\bar{T}}$ All values are means \pm standard deviations, $n=45$ (18 men and 27 women).

${ }^{2}$ There were no significant differences between the 3 diets (general linear model with subject number as random factor and diet and period as fixed factors).

\section{Lipoprotein particle concentrations and sizes}

Changes in VLDL, LDL, and HDL particle sizes and subclass concentrations did not differ significantly between the 3 diets (Table 3.5). No sex-dependent diet effects were observed (data not shown). The diet $\times \mathrm{BMI}$ interaction was significant for small VLDL concentrations $(P=0.030)$. In the low-BMI group $(P=0.043$ for diet effects), linoleic acid increased the small VLDL concentration by $9.7 \mathrm{nmol} / \mathrm{L}(\mathbb{P}=0.042,95 \%$ $\mathrm{Cl}$ for the difference 0.3 to $19.1 \mathrm{nmol} / \mathrm{L}$ ) when compared with oleic acid. In the highBMI group, diet effects were not statistically significant $(P=0.189)$. Concentrations of small VLDL particles were $19.9 \mathrm{nmol} / \mathrm{L}(\mathrm{P}=0.002,95 \% \mathrm{Cl}-31.2$ to $-8.6 \mathrm{mmol} / \mathrm{L})$, of intermediate-density lipoprotein (IDL) particles were $31.5 \mathrm{nmol} / \mathrm{L}(\mathrm{P}=0.018,95 \%$ $\mathrm{Cl}-57.0$ to $-5.9 \mathrm{nmol} / \mathrm{L})$, of total LDL particles were $402 \mathrm{nmol} / \mathrm{L}(\mathrm{P}=0.024,95 \% \mathrm{Cl}$ 745 to $-59 \mathrm{nmol} / \mathrm{L})$, of small LDL particles were $535 \mathrm{nmol} / \mathrm{L}(\mathrm{P}=0.010,95 \% \mathrm{Cl}-927$ to $-143 \mathrm{nmol} / \mathrm{L})$, of medium-small $L D L$ particles were $108 \mathrm{nmol} / \mathrm{L}(\mathrm{P}=0.016,95 \% \mathrm{Cl}$ -193 to $-22 \mathrm{nmol} / \mathrm{L})$, and of very small $L D L$ particles were $427 \mathrm{nmol} / \mathrm{L}(P=0.009$, $95 \% \mathrm{Cl}-734$ to $-120 \mathrm{nmol} / \mathrm{L}$ ) lower in women than in men. Large HDL particle concentrations were $3.9 \mu \mathrm{mol} / \mathrm{L}(P=0.002,95 \% \mathrm{Cl} 1.7$ to $6.1 \mu \mathrm{mol} / \mathrm{L}$ ) higher in women. $\mathrm{LDL}$ and $\mathrm{HDL}$ particle size were $1.0-\mathrm{nm}(\mathrm{P}=0.005,95 \% \mathrm{Cl} 0.3$ to $1.6 \mathrm{~nm})$ 
and $0.6-\mathrm{nm}(\mathrm{P}=0.003,95 \% \mathrm{Cl} 0.2$ to $0.9 \mathrm{~nm})$ higher, respectively, in women than in men. With the high-oleic acid diet, BMI was significantly correlated with total LDL ( $r$ $=0.491, \mathrm{P}=0.020)$, IDL $(r=0.431, \mathrm{P}=0.045)$, small $\mathrm{LDL}(r=0.440, \mathrm{P}=0.040)$, medium-small $\operatorname{LDL}(r=0.457, \mathrm{P}=0.032)$, and very small $\operatorname{LDL}(r=0.435, \mathrm{P}=0.043)$ particle concentrations and with HDL particle size $(r=-0.532, \mathrm{P}=0.011)$. Age correlated with $\operatorname{LDL}(r=0.468, \mathrm{P}=0.028)$ and IDL $(r=0.486, \mathrm{P}=0.022)$ particle concentrations. Comparable relations were observed when subjects consumed the high-stearic acid or high-linoleic acid diets.

Table 3.5 Particle concentrations of lipoprotein subclasses and lipoprotein particle sizes as measured by NMR spectroscopy during consumption of diets enriched in stearic, oleic, or linoleic acid for 5 weeks by healthy men and women."

\begin{tabular}{|c|c|c|c|c|}
\hline & $\begin{array}{c}\text { Stearic } \\
\text { acid diet }\end{array}$ & $\begin{array}{c}\text { Oleic acid } \\
\text { diet }\end{array}$ & $\begin{array}{l}\text { Linoleic } \\
\text { aciid diet }\end{array}$ & $\begin{array}{l}\text { P for dilet } \\
\text { effects }^{2}\end{array}$ \\
\hline \multicolumn{5}{|l|}{ Particle concentrations } \\
\hline \multicolumn{5}{|l|}{ VLDL (nmol/L) } \\
\hline Total VLDL & $83.5 \pm 29.1$ & $82.1 \pm 30.8$ & $86.3 \pm 33.2$ & 0.560 \\
\hline Large VLDL and chylomicrons & $2.6 \pm 3.1$ & $2.8 \pm 3.2$ & $2.1 \pm 3.4$ & 0.209 \\
\hline Medium VLDL & $31.4 \pm 15.7$ & $32.8 \pm 14.9$ & $33.5 \pm 20.7$ & 0.716 \\
\hline Small VLDL & $49.5 \pm 16.3$ & $46.6 \pm 17.8$ & $50.8 \pm 18.4$ & 0.332 \\
\hline IDL (nmol/L) & $47.8 \pm 43.6$ & $44.5 \pm 30.2$ & $36.7 \pm 33.0$ & 0.215 \\
\hline \multicolumn{5}{|l|}{$\mathrm{LDL}(\mathrm{nmol} / \mathrm{L})$} \\
\hline Total LDL & $1305 \pm 468$ & $1244 \pm 437$ & $1262 \pm 387$ & 0.213 \\
\hline Largie LDL & $561 \pm 204$ & $551 \pm 221$ & $567 \pm 223$ & 0.875 \\
\hline Small LDL & $696 \pm 558$ & $648 \pm 542$ & $658 \pm 441$ & 0.568 \\
\hline Medium small LDL & $133 \pm 118$ & $124 \pm 108$ & $130 \pm 101$ & 0.595 \\
\hline Very small LDL. & $563 \pm 441$ & $524 \pm 435$ & $528 \pm 342$ & 0.550 \\
\hline \multicolumn{5}{|l|}{ HDL $(\mu \mathrm{mol} / \mathrm{L})$} \\
\hline Total HDL & $33.8 \pm 4.3$ & $33.4 \pm 4.3$ & $34.1 \pm 4.5$ & 0.545 \\
\hline Large HDL & $8.4 \pm 3.6$ & $8.3 \pm 3.0$ & $8.8 \pm 3.3$ & 0.468 \\
\hline Medium HDL & $3.2 \pm 3.6$ & $3.4 \pm 3.9$ & $3.4 \pm 3.6$ & 0.942 \\
\hline Small HDL & $22.2 \pm 4.4$ & $21.7 \pm 4.8$ & $21.9 \pm 3.6$ & 0.759 \\
\hline \multicolumn{5}{|l|}{ Lipoprotein particle size $(\mathrm{nm})$} \\
\hline VLDL particle size & $45.4 \pm 4.1$ & $45.0 \pm 4.4$ & $46.2 \pm 5.9$ & 0.277 \\
\hline LDL particle size & $21.5 \pm 0.9$ & $21.5 \pm 1.0$ & $21.5 \pm 0.8$ & 0.985 \\
\hline HDL particle size & $9.1 \pm 0.5$ & $9.2 \pm 0.5$ & $9.2 \pm 0.5$ & 0.907 \\
\hline
\end{tabular}

${ }^{7}$ All values are means \pm standard deviations, $n=22$ (9 men and 13 women).

${ }^{2}$ There were no significant differences botween the 3 diets (general linear model with subject number as random factor and diet and period as fixed factors.l. 


\section{DISCUSSION}

In this well-controlled crossover study of healthy subjects, we found that the differences in effects of stearic, oleic, and linoleic acids on the serum lipoprotein profile were less than expected. Although total and LDL cholesterol concentrations tended to decrease with the increasing degree of unsaturation, the changes between the 3 diets were not significant. Based on the classic equations derived by Keys et al (1), a decrease of $0.21 \mathrm{mmol} / \mathrm{L}$ in total cholesterol concentrations is expected when $7 \%$ of energy from stearic acid or oleic acid in the diet is exchanged for linoleic acid. However, we found decreases of $0.15 \mathrm{mmol} / \mathrm{L}$ and $0.07 \mathrm{mmol} / \mathrm{L}$, respectively.

Until now, only a few studies have examined simultaneously the effects of stearic acid, oleic acid, and linoleic acid. Consistent with our results, Hunter et al (14) found no differences in the effects of these fatty acids on plasma total or LDL cholesterol concentrations. However, only 6 healthy male subjects participated in that study, and the statistical power may have been too low to detect any changes. KrisEtherton et al (15) examined in 19 young men the effects of natural edible fats and oils rich in stearic acid (cocoa butter), oleic acid (olive oil) or linoleic acid (soybean oil) on the serum lipoprotein profile. It was found that the diet rich in linoleic acid significantly lowered serum total cholesterol concentrations relative to stearic acid or oleic acid. In addition, the LDL cholesterol concentration was lower with the diet rich in linoleic acid than with the diet rich in stearic acid. A possible explanation for these apparent discrepancies with our results might be that in their study approximately $10 \%$ of energy from stearic acid and $16 \%$ of energy from oleic acid was exchanged for linoleic acid. The expected decreases in total and LDL cholesterol concentrations were therefore greater. In that study (15), the high-oleic acid diet also decreased total and LDL cholesterol concentrations significantly more than did the high-stearic acid diet. The difference in response between these 2 diets can at least partly be explained by the higher intake of palmitic acid from the diet rich in stearic acid. Palmitic acid is known to increase serum total and LDL cholesterol levels relative to stearic or oleic acid $(3,16)$.

Our results agree with the many studies that compared stearic acid with oleic acid (3) or oleic acid with linoleic acid $(4,5,17,18)$ and also found no different effects on the serum lipoprotein profile. In one study, however, an exchange of $8 \%$ of energy from stearic acid for oleic acid significantly decreased serum LDL cholesterol by $0.15 \mathrm{mmol} / \mathrm{L}$. Surprisingly, no effects on apo $B$ concentrations were found (19). In addition, Zock and Katan (20) found that when $8 \%$ of energy from stearic acid was replaced by linoleic acid, the linoleic acid diet significantly decreased serum LDL 
cholesterol by $0.17 \mathrm{mmol} / \mathrm{L}$. When expressed as a percentage of energy, however, their effects did not differ from those in our study.

In a recent meta-analysis, equations were developed to describe the effects of individual fatty acids on serum lipids and lipoproteins (21). On the basis of these equations, replacement of $7 \%$ of energy from stearic acid by oleic acid may result in a decrease in $L D L$ cholesterol concentrations of $0.04 \mathrm{mmol} / \mathrm{L}$ and a decrease of $0.11 \mathrm{mmol} / \mathrm{L}$ when replaced by linoleic acid. These estimates agree well with the observed differences in LDL cholesterol concentrations of $-0.08 \mathrm{mmol} / \mathrm{L}$ between the diets enriched in stearic and oleic acids and of $-0.14 \mathrm{mmol} / \mathrm{L}$ between the diets high in stearic acid and linoleic acid. The power of our study to pick up this latter difference was $60 \%$. Taken together, evidence continues to accumulate to suggest that the earlier formulas $(1,2)$ overestimate the effects of linoleic acid on serum total cholesterol concentrations.

On the basis of the earlier meta-analysis (21), decreases in HDL cholesterol concentrations of $0.04 \mathrm{mmol} / \mathrm{L}$ were predicted when oleic acid was replaced by stearic acid, and of $0.03 \mathrm{mmol} / \mathrm{L}$ when stearic acid was exchanged for linoleic acid. In our study, however, decreases were slightly but not significantly lower when stearic acid replaced either oleic or linoleic acid. Other studies also reported no differential effects of oleic and linoleic acids on HDL cholesterol concentrations $(4,5,14,15)$. In contrast, some studies have reported that linoleic acid decreases HDL cholesterol concentrations relative to oleic acid $(17,18)$. Zock and Katan (20) reported a decrease in HDL cholesterol when linoleic acid was exchanged for stearic acid, whereas Judd et al (19) reported a decrease when oleic acid was replaced for stearic acid. A non-significant decrease was also observed by Bonanome and Grundy (3). Thus, these 3 studies suggest that stearic acid may lower HDL relative to oleic and linoleic acids, which is not supported by our results or the studies that simultaneousiy compared stearic, oleic, and linoleic acids $(14,15)$. In the 3 other studies, stearic acid was largely provided by interesterified and hydrogenated synthetic fats $(3,19,20)$. In these fats, stearic acid was not only located at the $s n-1$ and $s n-3$ positions, as is the case in natural fats, but also at the $s n-2$ position (22). Because of these stereospecific distributions, it is possible that the effects of natural fats rich in stearic acid on the serum lipoprotein profile are different from those of synthetic fats. This suggestion, however, requires further investigation.

No differential effects of stearic acid, oleic acid, or linoleic acid were found on lipoprotein particle sizes and concentrations. As is true for small, dense LDL particles $(23,24)$, small $\mathrm{HDL}$ particles $(25,26)$ are positively associated with increased cardiovascular disease risk. Therefore, we also examined the effects of 
stearic, oleic, and linoleic acids on LDL, HDL, and VLDL particle size and subclass particle concentrations by using NMR spectroscopy. Until now, only a few studies have examined the effects of quality of dietary fat on lipoprotein particle sizes or subclass distributions of lipoprotein particles. Relative to saturated fat; monounsaturated and $n-6$ and $n-3$ polyunsaturated fatty acids slightly but significantly decreased LDL particle size (27). In contrast, in another study no significant changes in LDL particle size were observed when saturated fatty acids were exchanged for monounsaturated fatty acids (28). Unfortunately, no details about the individual saturated fatty acid composition of the diets were given. Observed differences in particle sizes and particle concentrations between men and women in our study agreed well with those of The Framingham Offspring study, in which these variables were measured in a large group of 1574 men and 1692 women (9).

In summary, the effects of stearic acid, oleic acid, and linoleic acid on LDL cholesterol concentrations were less than expected. Effects on HDL cholesterol and triacylglycerol concentrations as well as the size and the concentration of the lipoprotein particles also did not differ significantly between diets. These findings, however, do not imply that these three $\mathrm{C} 18$ fatty acids can be exchanged without affecting cardiovascular disease risk, because other cardiovascular disease risk markers (e.g. hemostatic function, oxidative stress, and low-grade inflammation) are also influenced by the fatty acid composition of the diet.

\section{REFERENCES}

1. Keys A, Anderson JT and Grande F. Serum cholesterol response to changes in the diet. IV. Particular saturated fatty acids in the diet. Metabolism 1965; 14: 776-87.

2. Hegsted DM, McGandy RB, Myers ML and Stare FJ. Quantitative effects of dielary fat on serum cholesterol in man. Am J Clin Nutr 1965; 17: 281-95.

3. Bonanome A and Grundy SM. Effect of dietary stearic acid on plasma cholesterol and lipoprotein levels. N Engl J Med $1988 ; 318: 1244-8$.

4. Mensink RP and Katan MB. Effect of a diet enriched with monounsalturated or polyunsaturated fatty acids on levels of low-density and high-density lipoprotein cholesterol in thealthy women and men. $N$ Engl $J$ Med 1989; $321: 43641$

5. Howard BV, Hannah JS, Heiser CC, Jablonski KA, Paidi MC, Alarif L, Robbins DC and Howard WJ, Polyunsaturated fatty acids result in greater cholesterol lowering and less triacylglycerol elevalion than do monounusaturated fatty acids in a dose-response comparison in a multiraciall study group. Am $J$ Clin Nutr 1995; $62: 392-402$

6. Harris $J$ and Benedict $F$. A biometric study of basal metabolism in man. Carnegie Institute of Washington, Washington, 1919.

7. Stichting Nederlands Voedingsstoffenbestand. NEVO tabel, Nederlands voedingsstoffenbestand. (Dutch food composiltion table). Voorlichtingsbureau voor de voeding, Den Haag. 1996: 1-235.

8. Friedewald WT. Levy RI and Fredrickson DS. Estimation of the concentration of low-density lipoprotein cholesterol in plasma, without use of the preparative ultracentrifuge. Clin Chem 1972; 18 ; 499-502.

9. Freedman DS, Otwos JD, Jeyarajah EJ, Shalaurova I, Cupples LA, Parise H, D'Agostino RB, Wilson PW and Schaefer EJ. Sex and age differences in lipoprotein subclasses measured by nuclear magnetic resonance spectroscopy: the Framingham Study. Clin Chem 2004: 50: $1189-200$. 
10. Wensing AG, Mensink RP and Hornstra $G$. Effects of dietary $n-3$ polyunsaturated fatty acids from plant and marine origin on platelet aggreglation in healthy ellderly subjects. Br $J$ Nutr 1999; 82: 18391.

11. Bligh EG and Dyer WJ. A rapid method of total lipid extraction and purification. Canadian Joumal of Biochemistry and Physiology 1959; $37: 911-7$.

12. Kaluzny MA, Duncan LA, MerritL MV and Epps. DE. Rapid separation of lipid classes in high yield and purty using bonded phase columins. J'Lipid Res $1985 ; 26: 135-40$.

13. Morrison WR and Smith LM. Preparation of fatty acid methyl esters and dimethylacetals from lipids with boron fuoride-methanol. Journal of fipid research 1964: 5: 600-8.

14. Hunter KA, Crosbie LC, Weir A, Miller GJ and Dutta-Roy AK. A residential study comparing the effects of diets rich in stearic acid, oleic acid, and linoleic acid on fasting blood lipids, hemostatic wariables and platelets in young healthy men. Joumal of Nutritional Biochemistry 2000; 11: $408-16$.

15. Kris-Etherton PM, Derr J, Mitchell DC, Mustad VA, Russell ME, McDonnell ET, Salabsiky D and Pearson TA. The role of fatty acid saturation on plasma lipids, lipoproteins, and apolipoproteins: 1. Effects of whole food diets high in cocoa butter, olive oil soybean oil, dairy butter, and milk chocolate on the plasma lipids of young men. Metabolism 1993; 42: 121-9.

16. Termme EH. Mensink RP and Hornstra G. Comparison of the effects of diets enriched in lauric, palmitic, or oleic acids on serum lipids and lipoproteins in thealthy women and men. Am J Clin Nutr 1996; 63:" 897-903.

17. Mattsion FH and Grundy SM. Comparison of effects of dietary saturated, monounsaturated, and polyunsaturated fatty acids on plasma liplds and lipoproteins in man. J Lipid Res 1985; 26: $194-202$.

18. Hodson $L$, Skeaff $C M$ and Chisholm WA. The effect of replacing dietary saturated fat with polyunsaturated or monounsaturated fat on plasma lipids in free-living young adults. Eur I Clin Nutr 2001; $55: 908-15$.

19. Judd JT, Baer D., Clevidence BA, Kris-Etherton P, Muesing RA and Iwane M. Dietary cis and trans monounsaturated and saturated FA and plasma lipids and lipoproteins in men. Lipids 2002; 37: 12331.

20. Zack PL and Katan MB. Hydrogenation alternatives: effects of trans fatty acids and stearic acid vers us linoleic acid on serum lipids and lipoproteins in humans. I Lipid Res 1992; 33: 399-410.

21. Mensink RP, Zock PL, Kester AD and Katan MB. Effects of dietary fatty acids and carbohydrates on the ratio of serum total to HDL cholesterol and on serum lipids and apolipoproteins: a meta-analysis of 60 controlled trials. Am I Clin Nutr 2003; 77: 1146-55.

22. Hunter JE. Studies on effects of dietary fatty acids as related to their position on triglycerides. Lipids 2001; 36: 655-68.

23. Griffin BA, Freeman DJ, Tait GW, Thomson J, Caslake MJ, Packard CJ and Shepherd J. Role of plasma triglyceride in the regulation of pllasma low density lipoprotein (LDL) subfractions: relative contribution of small, dense LDL to coronary heart disease risk. Atherosclerosis 1994; 106: $241-53$.

24. Gardner CD. Fortmann SP and Krauss RM. Association of small Iow-density lipoprotein particles with the incidence of coronary artery disease in men and women. JAMA 1996;276:875-84.

25. Cheung MC. Brown BG, Wolf AC and Albers JJ. Altered particle size distribution of apolipoprotein A-Icontaining lipoproteins in subjects with coronary artery disease. J Lipid Res 1991; 32: 383-94.

26. Freedman DS, Otvos JD, Jeyarajah Ej, Barboriak $\mathrm{JJ}$, Anderson $A J$ and Walker JA. Relation of lipoprotein subclasses as measured by proton nuclear magmetic resonance spectroscopy to coronary artery disease. Arterioscler Thromb Vasc Biol 1998; 18: 1046-53.

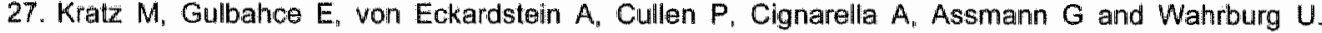
Dietary mono- and polyunsaturated fatty acids similarly affect LDL size in healthy men and women. $J$ Nutr 2002; 132: 715-8.

28. Rivellese AA, Maffeltone A, Vessby $B$, Uusitupa $M$, Hermansen $K$, Bergiund L, Louheranta $A$, Meyer BJ and Riccardi G. Effects of dietary saturated, monounsaturated and $n-3$ fatty acids on fasting lipoproteins, LDL size and post-prandial lipid metabolism in healthy subjects. Atherosclerosis 2003; $167: 149.58$ 


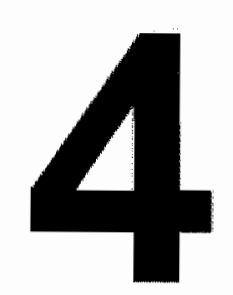

Stearic, oleic, and linoleic acids have comparable effects on markers of thrombotic tendency in healthy human subjects

Myriam A.M.A. Thijssen ${ }^{1}$, Gerard Hornstra ${ }^{9}$, and Ronald P. Mensink ${ }^{1}$

Journal of Nutrition 2005; 135(12): 2805-2811

'Nutrition and Toxicology Research Institute Maastricht (NUTRIM), Department of Human Biology. Maastricht University, Maastricht, The Netherlands 


\section{ABSTRACT}

Because human studies concerning the effects of stearic acid on thrombotic tendency are inconsistent, we compared the effects of stearic acid with those of its unsaturated derivatives, oleic acid and linoleic acid. In this randomised, crossover study, 45 subjects (27 women and 18 men) consumed, in random order, 3 experimental diets, each for 5 weeks. Diets contained approximately $38 \%$ of energy as fat. Dietary compositions were the same except for $7 \%$ of energy from stearic, oleic, or linoleic acids. At the end of each period, ex vivo and in vitro platelet aggregation, and variables of coagulation, fibrinolysis, and hematology were evaluated. In men, ex vivo platelet aggregation time as measured by filtragometry ( $P$ $=0.036$ for diet effects) was favourably prolonged during consumption of the linoleic acid diet compared with the stearic acid diet $(P=0.040)$, but there was no difference with consumption of the oleic acid diet $(P=0.198)$. In vitro platelet aggregation induced by collagen and $A D P$, and variables of coagulation (factor VII amidolytic activity and concentrations of fibrinogen and prothrombin fragment 1 and 2) and fibrinolysis (plasminogen activator inhibitor (PAl) activity and concentrations of tissue plasminogen activator (tPA)/PAl-1 complexes) did not differ among the 3 diets. The mean platelet volume of the subjects decreased during consumption of the stearic acid diet by $0.32 \mathrm{fL}$ compared with the oleic acid diet $(P<0.001)$ and by $0.35 \mathrm{fL}$ compared with the linoleic acid diet $(P<0.001)$. In conclusion, our results do not suggest that stearic acid is highly thrombogenic compared with oleic and linoleic acids. 


\section{INTRODUCTION}

The most common complications of cardiovascular disease result from the formation of an arterial thrombus $(1,2)$, which is initiated by disturbances in the hemostatic balance. Key regulators of this delicate balance are the endothelial wail, blood platelets, and coagulation and fibrinolytic factors (3). Indeed, epidemiological studies showed that factors related to an enhanced thrombotic tendency such as increased blood platelet aggregation $(4,5)$, increased concentrations of coagulation and decreased concentrations of fibrinolytic factors (6-8), are positively associated with cardiovascular risk. Furthermore, it was demonstrated that the thrombotic tendency of the blood is influenced by total fat intake as well as the fatty acid composition of the diet. Although the biochemical basis of the effects of dietary fatty acids on thrombotic tendency have not been fully elucidated, dietary fatty acids can modulate the fatty acid compositions of platelets and other cell membranes, thereby changing the availability of arachidonic acid. This fatty acid is a precursor for eicosanoid synthesis, which is involved in platelet aggregation (9).

The effects of individual fatty acids on thrombotic tendency were evaluated in animal models and in human studies. In rats, arterial thrombosis tendency as measured with the aortic loop technique, was decreased by $n-6$ and $n-3$ polyunsaturated fatty acids, whereas saturated fatty acids with 12 to 16 carbon atoms promoted arterial thrombus formation. The effects of oleic acid as a major monounsaturated fatty acid were neutral or even antithrombotic compared with saturated fatty acids (10). In these studies, stearic acid did not seem to affect arterial thrombosis tendency, whereas other studies in rats indicated that stearic acid was highly thrombogenic in a model of venous thrombosis (11). Studies in humans also suggested that stearic acid is prothrombotic. In French farmers, for example, dietary stearic acid intake was related to increased platelet activity (12). In another study, plasma concentrations of free stearic acid correlated positively with factor VII activation (13). In contrast, later studies reported beneficial effects of stearic acid on platelet aggregation (14) and coagulation variables $(15,16)$ compared with other saturated fatty acids. Not only are the data for stearic acid inconsistent, but also the data for oleic acid and linoleic acid, two other fatty acids with 18 carbon atoms (1719). The objective of the present study was therefore to compare the effects of stearic, oleic, and linoleic acids on platelet aggregation, coagulation, fibrinolysis, and hematological variables. 


\section{SUBJECTS AND METHODS}

\section{Experimental design}

The study had a randomised; multiple crossover design. The effects of stearic, oleic, and linoleic acids on lipid and lipoprotein concentrations were investigated earlier in this study, and the study protocol was described in detail (20). Briefly, each participant consumed 3 different diets in random order over three 5-week periods: After each intervention period, there was a washout period of at least 1 week, when participants consumed their habitual diets. The protocol of the study was approved by the Medical Ethics Committee of Maastricht University.

\section{Diets}

The prescribed nutrient composition of the 3 diets did not differ ${ }_{1}$ except for $7 \%$ of energy provided by stearic acid, oleic acid, or linoleic acid. The experimental products (margarines, bread, and sponge cakes) supplied $60 \%$ of total daily fat intake at a targeted total fat intake of $37 \%$ of energy. For the remaining $40 \%$ of the total fat intake, subjects had to consume a certain amount of 'free-choice' fatcontaining products. These products had to be recorded in a diary, in which alcohol consumption, medication used, any sign of illness, menstruation, and any deviations from the study protocol also were noted. At least once every week, subjects visited a dietician at the university to receive a new supply of products and to be weighed. Individual allowances were adjusted when subjects ${ }^{t}$ weight differed by $>1.5 \mathrm{~kg}$ from initial weight during week $1 \mathrm{or}>2 \mathrm{~kg}$ during the following weeks. The mean daily energy intake and the composition of the diets were determined from food-frequency questionnaires, which were filled out by the subjects in week 5 of each intervention period.

\section{Subjects}

The screening procedure and eligibility criteria of the subjects were described in detail earlier (20). Briefly, 45 healthy, non-smoking, slightly hypercholesterolemic subjects, 18 men and 27 women, completed the study protocol. All subjects were between 28 and $66 \mathrm{y}$ old (mean age was $51 \pm 10 \mathrm{y}$ ). The men had body mass indexes ranging from 21.8 to $29.8 \mathrm{~kg} / \mathrm{m}^{2}$ (mean $26.0 \pm 2.2 \mathrm{~kg} / \mathrm{m}^{2}$ ); those of the women ranged from 18.0 to $29.4 \mathrm{~kg} / \mathrm{m}^{2}$ (mean $24.1 \pm 2.8 \mathrm{~kg} / \mathrm{m}^{2}$ ). Among the women, 16 were postmenopausal and 5 used oral contraceptives. All subjects had given their written informed consent, before they entered the study protocol. 


\section{Blood sampling}

At the end of each period (in weeks 4 and 5), blood samples were drawn after the subjects had fasted overnight. Blood was sampled by venipuncture with minimum stasis using a $0.9 \mathrm{~mm}$-needle (PrecisionGlide, Becton-Dickinson Vacutainer systems, Plymouth, United Kingdom) in week 4 or with a $1.0 \mathrm{~mm}$-infusion needle (Microflex, Vygon, Ecouen, France) in week 5 . The first $6 \mathrm{~mL}$ was collected into EDTA tubes (Becton Dickinson Vacutainer Systems, Plymouth, United Kingdom) and used for analysis of hematological variables. Platelet, erythrocyte, and leukocyte counts, hemoglobin concentration, and hematocrit were measured with the Coulter Microdiff 18 (Beckman Coulter, Miami, United States). The next $9 \mathrm{~mL}$ was collected in sodium citrate tubes (Becton Dickinson Vacutainer Systems) and immediately placed on ice. Within 1 hour of collection, plasma was separated by centrifugation at $3500 \times \mathrm{g}$ for $30 \mathrm{~min}$. Plasma samples were snap-frozen in liquid nitrogen and stored at $-80^{\circ} \mathrm{C}$ until analyses of coagulation and fibrinolytic factors. In week 5 , an extra sodium citrate tube was drawn, which was kept at $37^{\circ} \mathrm{C}$, for in vitro platelet aggregation measurements. Then, $10 \mathrm{~mL}$ of blood was collected into a serum tube (Corvac, Becton Dickinson Vacutainer Systems) for the analysis of the fatty acid composition of serum phospholipids. At least 1 hour after venipuncture, serum was obtained by centrifugation at $3500 \times \mathrm{g}$ for $30 \mathrm{~min}$ at $4^{\circ} \mathrm{C}$ and stored at $80^{\circ} \mathrm{C}$. Finally, after blood sampling in week 5 , the tube of the infusion needle was connected to the filtragometer for the measurement of ex vivo platelet aggregation. A pool of citrated plasma was obtained from healthy blood donors, and prepared by methods described above.

\section{Fatty acid composition}

Fatty acid compositions of serum phospholipids in a pooled sample of weeks 4 and 5 were anallysed, as described previously (20). Values were expressed as a percentage of total fatty acids $(w / w)$.

\section{Ex vivo platelet aggregation}

Ex vivo platelet aggregation was measured using filtragometry. The principle of this method was described and validated by Hornstra and ten Hoor (21). Filtragometry is based on the continuous measurement of the pressure difference $(\triangle P)$ across a filter with pores of $20 \mu \mathrm{m}$ in diameter through which blood flows. Platelet aggregates, obstructing the filter, cause a change in the $\Delta \mathrm{P}$, which is proportional to the mass of the platelet aggregates that obstruct the filter. For measurements, blood from a forearm vein was drawn via an infusion needle by a motor-driven syringe at a flow rate of $2 \mathrm{~mL} / \mathrm{min}$. The infusion needle was connected by a tubing system with the 
filtragometer. Initially, the blood was anticoagulated with heparin. When $\Delta \mathrm{P}$ reached $5 \mathrm{mmHg}$, which corresponded to $25 \%$ of filter pore occlusion, the heparin was switched off and a citrate infusion was started, which may partially reverse the occlusion of the filter resulting in a transient decrease in $\triangle P$. The change in $\triangle P$ was monitored continuously for 10 minutes after connecting the filtragometer, and registered as aggregation curves. Aggregation variables that were calculated from these aggregation curves were the aggregation time ( $\mathrm{Ta}$ in $\mathrm{s}$, the time necessary to reach a $\Delta P$ of $5 \mathrm{mmHg}$ ), the aggregation slope ( $T \mathrm{~s}$ in $\mathrm{mmHg} / \mathrm{s}$, the slope of the tangent to the curve at $\Delta \mathrm{P}=5 \mathrm{mmHg}$ ), the maximum aggregation ( $\mathrm{Amax}$ in $\mathrm{mmHg}$, the maximum height of the aggregation curve), and the desaggregation induction time (Tdi in $\mathrm{s}$, time between the termination of the heparin infusion and the beginning of the desaggregation). For 3 measurements, $\Delta \mathrm{P}$ did not reach $5 \mathrm{mmHg}$ within 10 minutes and the aggregation time (Ta) was then set at $600 \mathrm{~s}$. For these measurements, other aggregation variables could not be calculated. Evaluation by scanning electron microscopy showed that filter occlusion is due mainly to platelet aggregates. In addition, it was demonstrated that treatment with acetylsalicylic acid prolonged ex vivo platelet aggregation (21).

\section{In vitro platelet aggregation}

in vitro platelet aggregation was measured in whole blood with a dual-sample aggregometer (whole blood aggro-meter model 540, Chrono-log corporation, Havertown, PA, United States), immediately after blood sampling. For each measurement, $1 \mathrm{~mL}$ of anticoagulated blood was transferred into a pre-warmed plastic cuvette and electrodes were inserted into the cuvettes. The sample was kept at $37^{\circ} \mathrm{C}$ and stirred. After equilibration of the sample and calibration of the instrument, aggregation was induced by the addition of collagen (Chrono-PAR \#385 Collagen Reagent, Chrono-log corporation) or ADP (Chrono-PAR \#384 ADP Reagent, Chrono-log corporation). The change in impedance was monitored continuously for 15 minutes and registered as aggregation curves. Collagen-induced aggregation was measured at a final concentration of $2 \mathrm{mg} / \mathrm{L}$ collagen and ADP. induced aggregation was measured at final concentrations of 15 and $5 \mu \mathrm{mol} / \mathrm{L}$ ADP. Whole-blood platelet aggregation was quantified by measuring the aggregation time (Tai), the aggregation velocity ( $\mathrm{Va}$ ) and the maximum aggregation (Imax).

\section{Measurements of coagulation and fibrinolysis}

Before analysis of coagulation and fibrinolytic factors, equal volumes of the citrated plasma samples from weeks 4 and 5 were pooled. A chromogenic assay (Coaset F.VII, Chromogenix Instrumentation Laboratory, Milano, Italy) was used to assess 
factor VII amidolytic (factor Vllam) activity. Activities were expressed as the percentage of a plasma pool. Prothrombin fragment 1 and 2 (PTF1 +2 ) concentrations were analysed with an enzyme immuno assay (Enzygnost $F 1+2$ micro, Dade Behring, Marburg, Germany). Plasma fibrinogen concentrations were measured by a clotting assay (Dade Thrombin reagent, Dade Behring, Marburg, Germany) based upon the method of Clauss (22). Plasminogen activator inhibitor (PAI) activity was determined with a chromogenic assay (Spectrolyse/pL PAI, Trinity Biotech, Wicklow "Ireland). Concentrations of tPA/PAl-1 complexes were analysed by an enzyme-linked immunosorbent assay (TPA/PAI-1 Complex ELISA reagent kit, Technoclone, Vienna, Austria). All samples from one subject were performed in the same analytic run. The coefficients of variation within runs were $1.8 \%$ for fibrinogen, $4.2 \%$ for factor Vllam, $9.5 \%$ for PTF1 + 2, 8.3\% for PAl activity, and $13.6 \%$ for tPA/PAl-1 complexes.

\section{Statistics}

For hematological variables, the mean of the 2 plasma samples from weeks 4 and 5 was calculated before statistical analyses. All data were analysed with the general linear model (GLM) procedure of the SPSS 11 for Mac OS X package. A probability level ( $P$-value) of $<0.05$ was considered significant. Differences in effects were examined with diet and period as fixed factors and subject number as random factor. Because previous studies showed gender-dependent effects of dietary fatty acid intake on the variables of interest or examined effects only in men, we also analysed data by gender. It should be noted, however, that the study was not specifically designed to look for gender-dependent effects and the statistical power may have been too limited to specifically address this question. To analyse whether effects of diet were modified by gender, the diet $x$ gender interaction term was added to the model as a fixed factor. When the analyses indicated a significant effect of diet $(P<0.05)$, the diets were compared pair-wise. Between diets comparisons were corrected for 3-group comparisons by the Bonferroni correction, and $95 \%$ confidence intervals were calculated for the differences among the diets. Values are presented as means \pm standard deviations.

\section{RESULTS}

\section{Dietary composition}

The subjects' body weights at the end of each dietary period were $72.5 \pm 13.0 \mathrm{~kg}$ after consumption of the stearic acid diet, $72.5 \pm 13.2 \mathrm{~kg}$ after the oleic acid diet and $72.7 \pm 12.9 \mathrm{~kg}$ after the linoleic acid diet. Weights did not differ among those 
consuming the 3 diets $(P=0.449)$. Daily intakes of energy, protein, carbohydrates, fat, cholesterol, and fibre did also not differ among subjects consuming the 3 diets (Table 4.1). Fatty acid intakes were comparable, except for about $7 \%$ of energy, which was provided by stearic acid, oleic acid, or linoleic acid.

Table 4.1 Daily intakes of fat and fatty acids by healthy men and women during consumption of the 3 diets for 5 weeks. ${ }^{1,2}$

\begin{tabular}{|c|c|c|c|c|}
\hline & $\begin{array}{c}\text { Stearic } \\
\text { acidl diet }\end{array}$ & $\begin{array}{c}\text { Oleic } \\
\text { acid diet }\end{array}$ & $\begin{array}{l}\text { Linoleic } \\
\text { acid diet }\end{array}$ & $\begin{array}{l}\text { P for diet } \\
\text { effects }^{3}\end{array}$ \\
\hline & & $\%$ of energy & & \\
\hline Fat & $38.2 \pm 5.1$ & $37.7 \pm 5.6$ & $38.0 \pm 5.3$ & $P=0.701$ \\
\hline Saturated fatty acids & $18.0 \pm 2.3^{\mathrm{a}}$ & $11.0 \pm 2.0^{\mathrm{b}}$ & $11.2 \pm 1.9^{b}$ & $P<0.001$ \\
\hline Stearic acid $(C 18: 0)^{4}$ & $7.7 \pm 1.1^{\mathrm{a}}$ & $1.2 \pm 0.2^{b}$ & $1.2 \pm 0.2^{\mathrm{t}}$ & $P<0.001$ \\
\hline Monounsaturated fatty acids & $12.9 \pm 2.0^{b}$ & $19.1 \pm 2.9^{\mathrm{a}}$ & $12.5 \pm 1.8^{\mathrm{b}}$ & $P<0.001$ \\
\hline Oleic acid $(C 18: 1 n-9)^{4}$ & $6.8 \pm 1.0^{b}$ & $13.1 \pm 2.0^{\mathrm{a}}$ & $6.6 \pm 1.0^{b}$ & $P<0.001$ \\
\hline Polyunsaturated fatty acids & $4.7 \pm 1.2^{b}$ & $5.0 \pm 1.1^{b}$ & $11.8 \pm 1.8^{\mathrm{a}}$ & $P<0.001$ \\
\hline Linoleic acid $(C 18: 2 n-6)^{4}$ & $2.1 \pm 0.3^{b}$ & $2.4 \pm 0.3^{b}$ & $9.3 \pm 1.3^{a}$ & $P<0.001$ \\
\hline
\end{tabular}

"Values are means \pm standard deviations, $n=45$ (18 men and 27 women) as calculated from the food" frequency questionnaires. Means in a row with superscripts without a common letter differ, $P<0.05$.

${ }^{2}$ Intakes of energy $(8.5 \pm 1.6 \mathrm{MJ})$, carbohydrates $(46.1 \pm 6.1 \%$ of energy), proteins $(13.9 \pm 2.0 \%$ of energy), alcohol (2.2 $\pm 2.3 \%$ of energy), chalesterol ( $17.7 \pm 3.6 \mathrm{mg} / \mathrm{MJ}$ ) and dietary fibre $(3.1 \pm 0.7 \mathrm{~g} / \mathrm{MJ}$ ) did not differ significantly among the 3 diets.

${ }^{3}$ P-values for diet effects were calculated by the general linear model with subject number as random factor and diet and period as fixed factors.

${ }^{4}$ As provided by the experimental fats only.

Dietary adherence of the subjects was confirmed by the fatty acid composition of serum phospholipids (Table 4.2). The 3 diets differed in their effects on the proportions of stearic acid, oleic acid, and linoleic acid $(P<0.001$ for diet effects). The proportions of arachidonic acid ( $P=0.103$ for diet effects) and docosahexaenoic acid (DHA; $P=0.063$ for diet effects) did not differ. The proportions of the n-3 polyunsaturated fatty acids, $\alpha$-linolenic acid $(P<0.001$ for diet effects) and eicosapentaenoic acid (EPA; $P<0.001$ for diet effects) were lower during consumption of the linoleic acid diet compared with the other 2 diets. 
Stearic, oleic, and linoleic acids and thrombotic tendency

Table 4.2 Fatty acid composition of serum phospholipids in healthy men and women during consumption of the 3 diets for 5 weeks."

\begin{tabular}{lllll}
\hline Fatty acid & $\begin{array}{c}\text { Stearic acid } \\
\text { diet }\end{array}$ & $\begin{array}{c}\text { Oleic acid } \\
\text { diet }\end{array}$ & $\begin{array}{c}\text { Linoleic acid } \\
\text { diet }\end{array}$ & $\begin{array}{c}\text { P for diet } \\
\text { effects }^{2}\end{array}$ \\
\hline Saturated fatty acids & \multicolumn{4}{c}{$\%$ of total fatty acids $(w / W)$} \\
Stearic acid (C18:0) & $46.5 \pm 1.5^{\mathrm{a}}$ & $45.6 \pm 1.5^{\mathrm{b}}$ & $46.2 \pm 1.9^{\mathrm{a}}$ & $\mathrm{P}=0.001$ \\
Monounsaturated fatty acids & $14.3 \pm 1.2^{\mathrm{a}}$ & $13.1 \pm 1.1^{\mathrm{b}}$ & $13.7 \pm 1.3^{\mathrm{c}}$ & $\mathrm{P}<0.001$ \\
Oleic acid (C18:1n-9) & $9.3 \pm 1.1^{\mathrm{a}}$ & $15.0 \pm 1.3^{\mathrm{b}}$ & $12.2 \pm 0.9^{\mathrm{b}}$ & $\mathrm{P}<0.001$ \\
Polyunsaturated fatty acids & $39.1 \pm 1.6^{\mathrm{a}}$ & $38.6 \pm 1.2^{\mathrm{a}}$ & $7.7 \pm 0.8^{\mathrm{a}}$ & $\mathrm{P}<0.001$ \\
Linoleic acid (C18:2n-6) & $20.7 \pm 1.8^{\mathrm{a}}$ & $20.5 \pm 2.0^{\mathrm{a}}$ & $23.2 \pm 2.4^{\mathrm{b}}$ & $\mathrm{P}<0.001$ \\
Arachidonic acid (C20:4n-6) & $8.9 \pm 1.5$ & $8.7 \pm 1.5$ & $8.6 \pm 1.7$ & $\mathrm{P}=0.103$ \\
$\alpha$-Linolenic acid (C18:3n-3) & $0.14 \pm 0.04^{\mathrm{a}}$ & $0.13 \pm 0.04^{\mathrm{a}}$ & $0.11 \pm 0.04^{\mathrm{b}}$ & $\mathrm{P}<0.001$ \\
EPA (C20:5n-3) & $0.8 \pm 0.4^{\mathrm{a}}$ & $0.7 \pm 0.3^{\mathrm{a}}$ & $0.5 \pm 0.3^{\mathrm{b}}$ & $\mathrm{P}<0.001$ \\
DHA (C22:6n-3) & $3.4 \pm 0.9$ & $3.3 \pm 0.7$ & $3.2 \pm 0.7$ & $\mathrm{P}=0.063$ \\
Trans fatty acids & $0.8 \pm 0.3$ & $0.8 \pm 0.2$ & $0.9 \pm 0.2$ & $\mathrm{P}=0.060$ \\
\hline
\end{tabular}

Values are means \pm standard deviations, $n=45$ (18 men and 27 women). Means in a row with superscripts without a common letter differ, $P<0.05$.

${ }^{2} P$-values for diet effects were calculated by the general linear model with subject number as random factor and diet and period as fixed factors.

\section{Hematological variables}

When all subjects were analysed together, the 3 diets differed significantly in their effects on the number of erythrocytes and mean platelet volumes (Table 4.3). The number of erythrocytes tended to be lower when subjects consumed the diet high in linoleic acid rather than the stearic acid diet $(P=0.054,95 \% \mathrm{Cl}$ for the difference 0.259 to $-0.001 \times 10^{12} / \mathrm{L}$ ). In men, the numbers of erythrocytes during consumption of the linoleic acid diet were lower than during consumption of the oleic acid diet ( $P$ $=0.005,95 \% \mathrm{Cl}$ for the difference -0.365 to $-0.057 \times 10^{12} / \mathrm{L}$ ) and only slightly lower than during consumption of the stearic acid diet $(P=0.106,95 \% \mathrm{Cl}$ for the difference -0.288 to $0.020 \times 1012 / L$ ). Hematocrit values were slightly lower in men consuming the linoleic acid diet compared with the diets high in stearic acid $(P=$ $0.107,95 \% \mathrm{Cl}$ for the difference -0.026 to $0.002 \mathrm{~L} / \mathrm{L})$ and oleic acid $(\mathrm{P}=0.021,95 \%$ $\mathrm{Cl}$ for the difference -0.030 to $-0.002 \mathrm{~L} / \mathrm{L}$ ). No other gender-dependent effects were observed. When subjects consumed the stearic acid diet, the platelet volume decreased by $0.32 \mathrm{fL}$ compared with the oleic acid diet $(\mathrm{P}<0.001,95 \% \mathrm{Cl}$ for the difference -0.495 to $-0.144 \mathrm{fL}$ ) and by $0.35 \mathrm{fL}$ compared with the linoleic acid diet ( $P$ $<0.001,95 \% \mathrm{Cl}$ for the difference -0.526 to $-0.175 \mathrm{fL}$ ). These effects were evident in both men and women. 
Table 4.3 Hematological variables during consumption of diets enriched in stearic, oleic, and linoleic acids for 5 weeks by healthy men and women."

\begin{tabular}{|c|c|c|c|c|}
\hline & $\begin{array}{c}\text { Stearic acid } \\
\text { diet }\end{array}$ & $\begin{array}{c}\text { Oleilc acid } \\
\text { dilet }\end{array}$ & $\begin{array}{c}\text { Linoleic acid } \\
\text { diet }\end{array}$ & $\begin{array}{l}\text { P for diet } \\
\text { effects }\end{array}$ \\
\hline Leukocytes & & $\times 10^{3} / \mathrm{L}$ & & \\
\hline All & $6.05 \pm 1.28$ & $6.23 \pm 1.26$ & $6.05 \pm 1.29$ & $P=0.211$ \\
\hline Men & $6.33 \pm 1.20$ & $6.41 \pm 1.07$ & $6.24 \pm 1.15$ & $P=0.540$ \\
\hline Women & $5.86 \pm 1.32$ & $6.12 \pm 1.38$ & $5.92 \pm 1.38$ & $P=0.244$ \\
\hline Erythrocytes & & $\times 10^{12} / L$ & & \\
\hline All & $4.74 \pm 0.55$ & $4.72 \pm 0.49$ & $4.61 \pm 0.44$ & $P=0.046$ \\
\hline Men & $4.98 \pm 0.53^{\mathrm{ab}}$ & $5.06 \pm 0.47^{a}$ & $4.84 \pm 0.48^{b}$ & $P=0.006$ \\
\hline Women & $4.59 \pm 0.51$ & $4.48 \pm 0.36$ & $4.46 \pm 0.34$ & $P=0.254$ \\
\hline Hemoglobin & & $g / L$ & & \\
\hline All & $145 \pm 127$ & $143 \pm 102$ & $142 \pm 111$ & $P=0.133$ \\
\hline Men & $153 \pm 95$ & $151 \pm 84$ & $151 \pm 93$ & $P=0.504$ \\
\hline Women & $139 \pm 116$ & $138 \pm 71$ & $136 \pm 77$ & $P=0.255$ \\
\hline Hematocrit & & $L /$ & & \\
\hline All & $0.41 \pm 0.04$ & $0.41 \pm 0.03$ & $0.40 \pm 0.03$ & $P=0.108$ \\
\hline Men & $0.43 \pm 0.03^{\mathrm{ab}}$ & $0.44 \pm 0.03^{\mathrm{a}}$ & $0.42 \pm 0.03^{b}$ & $P=0.019$ \\
\hline Women & $0.40 \pm 0.04$ & $0.39 \pm 0.02$ & $0.39 \pm 0.02$ & $P=0.302$ \\
\hline Platelets & & $\times 10^{9} / \mathrm{L}$ & & \\
\hline All & $273 \pm 64$ & $265 \pm 62$ & $266 \pm 60$ & $P=0.457$ \\
\hline Men & $263 \pm 57$ & $240 \pm 60$ & $257 \pm 64$ & $P=0.088$ \\
\hline Women & $279 \pm 69$ & $281 \pm 58$ & $271 \pm 57$ & $P=0.458$ \\
\hline Mean platelet volume & & $f L$ & & \\
\hline All & $7.89 \pm 0.76^{\mathrm{a}}$ & $8.21 \pm 0.66^{b}$ & $8.25 \pm 0.72^{b}$ & $P<0.001$ \\
\hline Men & $7.86 \pm 0.98^{a}$ & $8.19 \pm 0.82^{b}$ & $8.23 \pm 0.89^{\mathrm{b}}$ & $P=0.003$ \\
\hline Women & $7.92 \pm 0.59^{\mathrm{a}}$ & $8.23 \pm 0.54^{b}$ & $8.26 \pm 0.62^{b}$ & $P=0.001$ \\
\hline
\end{tabular}

\footnotetext{
Values are means \pm standard deviations at the end of each intervention period (mean of weeks 4 and 5 ), $n=45$ (18 men and 27 women). Means in a row with superscripts without a common letter differ, $P<$ 0.05 .

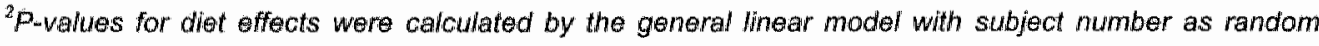
factor and diet and perfod as fixed factors.
}

\section{Ex vivo and in vitro platelet aggregation}

In all subjects, ex vivo platelet aggregation time (Ta) as measured by filtragometry did not differ among those consuming the 3 diets ( $P=0.200$ for diet effects, Table 4.4). In men only ( $P=0.036$ for diet effects), Ta increased by $69 \mathrm{~s}$ during consumption of the linoleic acid diet relative to the diet high in stearic acid ( $P=$ $0.040,95 \% \mathrm{Cl}$ for the difference 2 to $136 \mathrm{~s}$ ). The aggregation time during consumption of the linoleic acid diet tended to increase compared with that when the 
oleic acid diet was consumed $(P=0.198,95 \% \mathrm{Cl}$ for the difference -16 to $113 \mathrm{~s}$ ). The diets high in stearic acid or oleic acid did not differ in their effects on aggregation time $(P=1.00,95 \% \mathrm{Cl}$ for the difference -47 to $87 \mathrm{~s})$. No diet effects were evident in women $(P=0.713$ for diet effects).

Table 4.4 Effects on ex vivo platelet aggregation variables as measured by fitragometry during consumption of diets enriched in stearic, oleic, and linoleic acids for 5 weeks in healthy men and women."

\begin{tabular}{|c|c|c|c|c|}
\hline & $\begin{array}{c}\text { Stearic } \\
\text { acid diet }\end{array}$ & $\begin{array}{c}\text { Oleic } \\
\text { acid diet }\end{array}$ & $\begin{array}{l}\text { Linoleic } \\
\text { acid diet }\end{array}$ & $\begin{array}{l}\text { P for diet } \\
\text { effects }^{2}\end{array}$ \\
\hline Aggregation time (Ta) & & $s$ & & \\
\hline All & $113 \pm 96$ & $109 \pm 62$ & $142 \pm 125$ & $P=0.200$ \\
\hline Men & $109 \pm 70^{\mathrm{a}}$ & $117 \pm 61^{\text {ats }}$ & $164 \pm 127^{b}$ & $P=0.036$ \\
\hline Women & $115 \pm 110$ & $104 \pm 62$ & $126 \pm 123$ & $P=0.713$ \\
\hline Aggregation slope (Ts) & & $m m H g / s$ & & \\
\hline All & $0.61 \pm 0.68$ & $0.52 \pm 0.58$ & $0.71 \pm 1.06$ & $P=0.243$ \\
\hline Men & $0.48 \pm 0.42$ & $0.38 \pm 0.37$ & $0.40 \pm 0.60$ & $P=0.789$ \\
\hline Women & $0.68 \pm 0.79$ & $0.62 \pm 0.68$ & $0.94 \pm 1.26$ & $P=0.259$ \\
\hline Maximum aggregation (Amax) & & $m m H g$ & & \\
\hline All & $81 \pm 110$ & $97 \pm 121$ & $94 \pm 123$ & $P=0.795$ \\
\hline Men & $48 \pm 82$ & $74 \pm 113$ & $49 \pm 95$ & $P=0.657$ \\
\hline Women & $99 \pm 121$ & $113 \pm 126$ & $128 \pm 133$ & $P=0.786$ \\
\hline Desaggregation induction time (Tdi) & & $s$ & & \\
\hline All & $29.5 \pm 24.1$ & $24.6 \pm 11.2$ & $24.2 \pm 12.7$ & $P=0.400$ \\
\hline Men & $21.7 \pm 12.0$ & $22.2 \pm 5.5$ & $23.1 \pm 13.5$ & $P=0.723$ \\
\hline Women & $34.1 \pm 28.4$ & $26.5 \pm 14.0$ & $25.2 \pm 12.2$ & $P=0.521$ \\
\hline
\end{tabular}

Values are means \pm standard deviations, $n=18$ men and 27 women, at the end of each intervention period (weak 5). Means in a row with superscripts without a common letter differ, $P<0.05$

${ }^{2} P$-values for diet effects were calculated' by the general linear model with subject number as random factor and diet and period as fixed factors.

There were no diet effects for collagen-induced platelet aggregation or ADPinduced platelet aggregation in whole blood in vitro (Table 4.5). Because effects on in vitro platelet aggregation induced by $5 \mu \mathrm{mol} / \mathrm{L}$ ADP were comparable to those induced by $15 \mu \mathrm{mol} / \mathrm{L}$ ADP, only results with a final concentration of $15 \mu \mathrm{mol} / \mathrm{L}$ are reported. 
Table 4.5 Effects on in vitro platelet aggregation in whole blood induced by either collagen or ADP during consumption of diets enriched in stearic, oleic, and linoleic acids for 5 weeks in healthy men and women."

\begin{tabular}{|c|c|c|c|c|}
\hline & $\begin{array}{c}\text { Stearic acid } \\
\text { diet }\end{array}$ & $\begin{array}{l}\text { Oleic acid } \\
\text { diet }\end{array}$ & $\begin{array}{c}\text { Linoleic acid } \\
\text { diet }\end{array}$ & $\begin{array}{l}\text { P for diet } \\
\text { effects }\end{array}$ \\
\hline \multicolumn{5}{|c|}{ Collagen-induced platelet aggregation $(2 \mathrm{mg} / \mathrm{L})^{3}$} \\
\hline Aggregation time (Tai) & & $\operatorname{Min}$ & & \\
\hline All & $0.93 \pm 0.23$ & $0.99 \pm 0.30$ & $0.90 \pm 0.25$ & $P=0.146$ \\
\hline Men & $1.04 \pm 0.22$ & $1.17 \pm 0.29$ & $0.97 \pm 0.31$ & $P=0.091$ \\
\hline Women & $0.86 \pm 0.22$ & $0.87 \pm 0.25$ & $0.85 \pm 0.20$ & $P=0.909$ \\
\hline Aggregation velocity ( $\mathrm{Va}$ ) & & $\Omega / \min$ & & \\
\hline All & $6.11 \pm 2.84$ & $6.28 \pm 3.06$ & $5.86 \pm 2.75$ & $P=0.776$ \\
\hline Men & $5.21 \pm 2.00$ & $5.49 \pm 1.97$ & $5.35 \pm 2.17$ & $P=0.805$ \\
\hline Women & $6.73 \pm 3.18$ & $6.80 \pm 3.55$ & $6.21 \pm 3.08$ & $P=0.717$ \\
\hline Maximum aggregation (Imax) & & $\Omega$ & & \\
\hline All & $12.4 \pm 5.5$ & $13.3 \pm 4.8$ & $12.0 \pm 5.1$ & $P=0.449$ \\
\hline Men & $11.3 \pm 4.5$ & $13.7 \pm 4.8$ & $12.1 \pm 4.3$ & $P=0.232$ \\
\hline Women & $13.2 \pm 6.1$ & $12.9 \pm 4.9$ & $11.9 \pm 5.6$ & $P=0.513$ \\
\hline \multicolumn{5}{|c|}{ ADP-induced platelet aggregation (15 $\mu \mathrm{mol} / \mathrm{L})$} \\
\hline Aggregation time (Tai) & & $\operatorname{Min}$ & & \\
\hline All & $0.58 \pm 0.23$ & $0.57 \pm 0.19$ & $0.59 \pm 0.25$ & $P=0.705$ \\
\hline Men & $0.74 \pm 0.20$ & $0.65 \pm 0.21$ & $0.63 \pm 0.23$ & $P=0.316$ \\
\hline Women & $0.48 \pm 0.18$ & $0.52 \pm 0.16$ & $0.57 \pm 0.26$ & $P=0.380$ \\
\hline Aggregation vellocity ( $\mathrm{Va}$ ) & & $\Omega / \min$ & & \\
\hline All & $4.65 \pm 2.51$ & $5.03 \pm 2.42$ & $4.41 \pm 2.38$ & $P=0.518$ \\
\hline Men & $3.53 \pm 2.07$ & $4.57 \pm 1.92$ & $4.23 \pm 2.26$ & $P=0.374$ \\
\hline Women & $5.42 \pm 2.54$ & $5.36 \pm 2.72$ & $4.51 \pm 2.49$ & $P=0.424$ \\
\hline Maximum aggregation (Imax) & & $\Omega$ & & \\
\hline All & $8.8 \pm 5.1$ & $10.4 \pm 4.5$ & $8.9 \pm 4.5$ & $P=0.304$ \\
\hline Men & $7.7 \pm 5.8$ & $10.4 \pm 4.1$ & $8.9 \pm 4.5$ & $P=0.410$ \\
\hline Women & $9.6 \pm 4.5$ & $10.4 \pm 4.9$ & $8.9 \pm 4.6$ & $P=0.564$ \\
\hline
\end{tabular}

\footnotetext{
Talues are means \pm standard deviations, $n=18$ men and 27 women at the end of each intervention period (week 5).

${ }^{2} P$-values for diet effects were calculated by the general linear model with subject number as random factor and diet and period as fixed factors. The 3 diets did not differ.

${ }^{3}$ values are means of 2 measurements.
}

\section{Coagulation and fibrinolysis}

Coagulation (factor VIlam activity, prothrombin fragment 1 and 2 , and fibrinogen) and fibrinolytic (PAI activity and tPA/PAl-1 complexes) factors did not differ among the 3 diets (Table 4.6). These variables did also not differ between men and women. 
Table 4.6 Coagulation and fibrinolytic variables during consumption of diets enriched in stearic, oleic, and linoleic acids for 5 weeks in healthy men and women. ${ }^{1}$

\begin{tabular}{|c|c|c|c|c|}
\hline & $\begin{array}{l}\text { Stearic } \\
\text { acid diet }\end{array}$ & $\begin{array}{c}\text { Oleic } \\
\text { acid diet }\end{array}$ & $\begin{array}{l}\text { Linoleilc } \\
\text { acid diet }\end{array}$ & $\begin{array}{l}\text { P for diet } \\
\text { effects }\end{array}$ \\
\hline Factor VIlam activity & & $\%$ of standard & & \\
\hline All & $98 \pm 31$ & $100 \pm 32$ & $97 \pm 33$ & $P=0.398$ \\
\hline Men & $99 \pm 26$ & $98 \pm 22$ & $99 \pm 26$ & $P=0.908$ \\
\hline Women & $98 \pm 34$ & $102 \pm 37$ & $96 \pm 37$ & $P=0.245$ \\
\hline Prothrombin fragment $1+2$ & & $n m o l / L$ & & \\
\hline All & $2.51 \pm 2.98$ & $2.51 \pm 2.95$ & $2.78 \pm 3.14$ & $P=0.360$ \\
\hline Men & $3.12 \pm 4.01$ & $2.67 \pm 3.62$ & $2.96 \pm 3.74$ & $P=0.482$ \\
\hline Women & $2.11 \pm 2.05$ & $2.40 \pm 2.49$ & $2.67 \pm 2.75$ & $P=0.115$ \\
\hline Fibrinogen & & $g / L$ & & \\
\hline All & $3.2 \pm 0.5$ & $3.2 \pm 0.5$ & $3.2 \pm 0.7$ & $P=0.940$ \\
\hline Men & $3.1 \pm 0.5$ & $3.0 \pm 0.6$ & $3.2 \pm 0.9$ & $P=0.599$ \\
\hline Women & $3.2 \pm 0.6$ & $3.3 \pm 0.4$ & $3.2 \pm 0.5$ & $P=0.389$ \\
\hline PAl activity & & $k U / L$ & & \\
\hline All & $10.47 \pm 7.25$ & $9.89 \pm 7.15$ & $9.79 \pm 6.82$ & $P=0.346$ \\
\hline Men & $12.76 \pm 7.01$ & $11.65 \pm 6.63$ & $10.85 \pm 6.96$ & $P=0.077$ \\
\hline Women & $8.94 \pm 7.12$ & $8.72 \pm 7.37$ & $9.09 \pm 6.76$ & $P=0.842$ \\
\hline TPAPAI- 1 complexes & & $\mu g / L$ & & \\
\hline All & $43.1 \pm 33.6$ & $41.2 \pm 33.8$ & $39.0 \pm 23.7$ & $P=0.533$ \\
\hline Men & $57.0 \pm 42.1$ & $49.9 \pm 41.1$ & $45.2 \pm 22.9$ & $P=0.293$ \\
\hline Women & $33.9 \pm 23.1$ & $35.4 \pm 27.2$ & $34.8 \pm 23.7$ & $P=0.894$ \\
\hline
\end{tabular}

"Values are means \pm standard deviations, $n=18$ men and 27 women at the end of each intervention period (pooled weeks 4 and 5).

${ }^{2} P$-values for diet effects were calculated by the general linear model with subject number as random factor and diet and period as fixed factors. The 3 diets did not differ.

\section{DISCUSSION}

The purpose of this well-controlled crossover study was to evaluate the effects of stearic, oleic, and linoleic acids on platelet aggregation, coagulation, and fibrinolytic factors, and hematological variables in healthy men and women. When $7 \%$ of energy of these fatty acids was exchanged among the diets, small differences on these markers of thrombotic tendency appeared. Compared with the stearic acid diet, the diet high in linoleic acid decreased ex vivo platelet aggregation in men only. Moreover, stearic acid decreased platelet volume relative to both other fatty acids in both men and women. Effects on coagulation and fibrinolytic variables did not differ 
after consumption of the 3 fatty acids. Therefore, the finding in previous studies that stearic acid is highly thrombogenic $(12,13)$ is not supported by the present study.

Ex vivo platelet aggregation time in men increased with consumption of linoleic acid relative to the stearic acid diet. In 2 earlier studies with the filtragometer, linoleic acid prolonged aggregation time compared with a mixture of saturated fatty acids (23) or a mixture of saturated and monounsaturated fatty acids (24). A prolonged aggregation time as measured by filtragometry indicates lower in vivo platelet aggregability and is negatively associated with mortality from coronary heart disease (21). In the study of Hornstra et al (23) only men participated, whereas in the study of Fleischman et al (24) both men and women participated. Unfortunately, in the latter study, results were not reported for men and women separately. In our study, ex vivo platelet aggregation time was significantly increased by linoleic acid in men, but not in women relative to stearic acid. Compared with oleic acid, this effect tended to be significant $(P=0.198)$. These findings indicate a gender-dependent effect of dietary fatty acid intake on ex vivo platelet aggregation. In contrast to the other 2 studies $(23,24)$, we could specifically attribute the observed effects to stearic acid. Whether other saturated fatty acids would have given similar effects, remains to be clarified.

Stearic acid, oleic acid, and linoleic acid did not differ in their effects on in vitro whole blood platelet aggregation variables induced by either ADP or collagen, a technique used in many other studies. This extends the findings of Hunter et al (25), who reported the effects of stearic acid, oleic acid, and linoleic acid in a crossover study with only 6 young healthy men. When experimental diets were consumed for 2 weeks, ADP-induced platelet aggregation in platelet-rich plasma (PRP) was not affected (25). Several studies focused on the effects of oleic and linoleic acids, but results were inconsistent. As in our study, there was no difference in effect between oleic acid and linoleic acid in most of the studies $(17,18,25-28)$. An exception is the study of Burri et al (19) with 7 healthy male subjects in which $7-8 \%$ of energy of oleic acid and linoleic acid were exchanged. Consumption of the diet high in linoleic acid decreased ADP- and collagen-induced platelet aggregation relative to oleic acid. In another study, consumption of oleic acid as well as linoleic acid decreased collageninduced platelet aggregation compared with a diet high in saturated fatty acids (29). In the studies mentioned earlier, PRP was used to measure platelet aggregation, whereas in the last-mentioned study, platelet aggregation was analysed in whole blood. Finally, effects depend on the way in which platelet aggregation is induced. In the study of Lahoz et al (18), consumption of linoleic acid but not oleic acid enhanced platelet aggregation induced by ADP, relative to saturated fatty acids. This proaggregatory effect was not observed when collagen or adrenalin was used 
as the inducer. In the other study (26), oleic acid and intoleic acid increased collagen- but not ADP-induced platelet aggregation compared with saturated fatty acids. in general, in vitro platelet aggregation studies are difficult to compare because of differences in methodologies. Different anticoagulants may be used or different inducers (collagen, ADP, adrenalin, or thrombin) at different concentrations; in some studies, PRP was used, and in others whole blood.

Stearic acid, oleic acid, and linoleic acid did not differ in their effects on factor VIlam activity. Hunter et al (25) also observed comparable effects of stearic acid and these 2 cis-unsaturated fatty acids using 3 different methods to assess factor VII activity. In addition, when the effects of dietary oleic acid and linoleic acid were compared in a study with subjects aged between 45 and $65 \mathrm{y}$ old, these fatty acids did not differently affect factor VII coagulant activity (30). In contrast, in 2 studies with healthy young male and female students, oleic acid consumption reduced factor VII coagulant activity compared with linoleic acid $(28,31)$. In one of these studies, the concentration of activated factor VII (FVIla), however, did not differ between subjects consuming the 2 diets (28). FVlla was not measured in the other study (31). These contrasting findings $(28,30,31)$ cannot be attributed to differences in the age of the subjects, because in 2 other studies in young healthy human subjects, consumption of oleic acid and linoleic acid did not differently affect factor VII coagulant activity $(32,33)$. Thus despite the use of a wide variety of methods to measure factor VIl activity, the effects of stearic, oleic, and linoleic acid consumption on this coagulation factor did not differ.

Although concentrations of fibrinogen $(6,7)$ and prothrombin fragment 1 and $2(7)$ are positively associated with the risk of coronary heart disease, only a few studies have investigated the effects of dietary fatty acids on these coagulation variables. Although some studies reported different effects of oleic acid and linoleic acid on factor $\mathrm{VII}$, concentrations of prothrombin fragment 1 and 2 and fibrinogen did not differ $(28,31)$. Similar to Hunter et al $(25)$, we also found comparable effects of stearic, oleic, and linoleic acids on these coagulation variables. In contrast, when $8 \%$ of energy from stearic acid was replaced by oleic acid, fibrinogen concentrations increased by $0.15 \mathrm{~g} / \mathrm{L}$ in a recent study by Baer et al (34). In addition, compared with a diet rich in myristic and lauric acids, stearic acid raised fibrinogen concentrations (16). When $7-8 \%$ of energy from stearic acid was exchanged for palmitic acid, however, fibrinogen was not affected (14). The effects of lauric and palmitic acid consumption on concentrations of fibrinogen and prothrombin fragment 1 and 2 did not differ from those of oleic acid (35). Thus, although the effects of oleic and linoleic acid consumption on fibrinogen concentrations seem to be comparable, the effects 
of stearic acid relative to the other saturated fatty acids or unsaturated fatty acids were inconsistent.

As markers of fibrinolytic activity, concentrations of IPA and PAl-1 antigen, IPA and PAI activities (6), and concentrations of IPA/PAl-1 complexes (36) are related to the risk of coronary heart disease. Various earlier studies evaluated the effects of dietary fatty acid composition on variables of the fibrinolytic system. In our study, stearic, oleic, and linoleic acid consumption did not affect PAl activity and concentrations of tPA/PAI- 1 complexes, which are strongly correlated with plasma levels of PAl activity or IPA antigen (36). These findings not only agree with the results of the study of Hunter et al (25), but also with the few studies that have compared oleic acid and linoleic acid. In one study, high-fat diets rich in oleic or linoleic acids did not differ in their effects on tPA activity and PAll-1 antigen concentrations (33). Dietary oleic and linoleic acids also had comparable effects on tPA and PAl activities $(28,31)$. Therefore, our study does not provide evidence that these 3 fatty acids have differential effects on fibrinolytic variables.

In both men and women, platelet volume was decreased after consumption of the diet high in stearic acid. Stearic acid-enriched diets also decreased platelet volume compared with diets rich in palmitic acid $(14,37,38)$. Larger platelets are associated with increased platelet reactivity and risk of myocardial infarction $(39,40)$. Survivors, 6 months after a myocardial infarction, had a $0.43 \mathrm{fL}$ lower mean platelet volume than nonsurvivors (39). In our study, platelet volumes of the subjects during consumption of the stearic acid diet were 0.32 and $0.35 \mathrm{fL}$ lower than when they consumed diets high in oleic acid and linoleic acid, respectively.

To summarise, when $7 \%$ of dietary energy of stearic acid was replaced by linoleic acid, ex vivo platelet aggregation was beneficially affected in men. On the other hand, stearic acid reduced platelet volume relative to the other 2 fatty acids, whereas effects on coagulation and fibrinolytic variables did not differ among the 3 fatty acids. Overall, we therefore conclude that our results do not provide evidence that stearic acid is highly thrombogenic, as suggested by some earlier studies $(12,13)$

\section{REFERENCES}

1. Robbie $\mathbb{L}$ and Libby P. Inflammation and atherothrombosis. Ann N Y Acad Sci 2001; 947: 167-79; discussion 79-80.

2. Badimon L. Atherosclerosis and thrombosis: lessons from animal models. Thromb Haemost 2001; 86: 356-65.

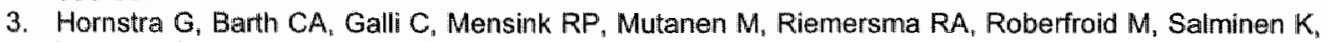
Vansant $G$ and Verschuren PM. Functional food science and the cardiovascular system. Br J Nutr 1998; 80 Suppl 1: $\$ 113-46$.

4. Thaulow $E$, Erikssen J, Sandvik L, Stormorken $H$ and Cohn PF. Blood platelet count and function are related to total and cardiovascular death in apparently healthy men. Circulation 1991; 84: 613-7. 
Stearic, oleic, and linoleic acids and thrombotic tendency

5. Elwood PC, Renaud S, Sharp DS, Beswick AD, O'Brien „R and Yamell JW. Ischemic heart disease and platelet aggregation. The Caerphilly Collaborative Heart Disease Study. Circulation 1991; 83: 38 44.

6. Ridker PM. Fibrinolytic and inflammatory markers for arterial occlusion: the evolving epidemiology of thrombosis and hemostasis. Thromb Haemost 1997; 78: 53-9.

7. Miller GJ, Bauer KA, Barzegar $S$, Cooper JA and Rosenberg $\mathbb{R D}$. Increased activation of the haemostatic system in men at high risk of fatal coronary heart disease. Thromb Haemost 1996; 75 $767-71$.

8. Meade TW, Ruddock V, Stirling $Y$, Chakrabarti $R$ and Miller GJ. Fibrinolytic activity, clotting factors, and long-term incidence of ischaemic heart disease in the Northwick Park Heart Study. Lancet 1993; 342: $1076-9$.

9. Zhou $L$ and Nilsson A. Sources of eicosanoid precursor fatty acid pools in tissues. J Lipid Res 2001: 42: $1521-42$.

10. Hornstra $G$ and Kester $A D$. Effect of the dietary fat type on arterial thrombosis tendency: systematic studies with a rat model. Atherosclerosis 1997; 131: 25-33.

11. Renaud $S$, Kuba $K_{4}$ Goulet $C$, Lemire $Y$ and Allard $C$. Relationship between fatty-acid composition of platelets and platelet aggregation in rat and man. Relation to thrombosis. Circ Res 1970; 26: 553-64.

12. Renaud $S$, Dumont $E$, Godsey $F$, Suplisson $A$ and Thevenon $C$. Platelet functions in relation to dietary fats in farmers from two regions af France. Thromb Haemost 1979; 40: 518-31.

13. Mitropoulos KA, Miller GJ, Martin JC, Reeves BE and Cooper J. Dietary fat induces changes in factor VII coagulant activity through effects an plasma free stearic acid concentration. Arterioscler Thromb 1994; 14: 214-22.

14. Kelly FD, Sinclair $A J$, Mann NJ, Turner AH, Abedin L and Li D. A stearic acidl-rich diet improves thrombogenic and atherogenic risk factor profiles in healthy males. Eur $J$ Clin Nutr 2001; 55: 88-96.

15. Tholstrup $T$, Marckmann $P_{x}$ Jespersen $J$ and Sandstrom B. Fat high in stearic acid favorably affects blood lipids and factor VII coagulant activity in comparison with fats high in palmitic acid or high in myristic and lauric acids. Am J Clin Nutr 1994; 59: 371-7.

16. Bladbjerg $E_{4}$ Tholstrup $T$, Marckmann $P$, Sandstrom $B$ and Jespersen J. Dietary changes in fasting levels of factor VII coagulant activity (FVII:C) are accompanied by changes in factor VII protein and other vitamin K-dependent proteins. Thromb Haemost 1995; 73: 239-42.

17. Mutanen $M_{v}$ Freese $R$, Valsta $L M$, Aholla $\|$ and Ahistrom A. Rapeseed oil and sunflower oil diets enhance platelet in vitro aggregation and thromboxane production in healthy men when compared with milk fat or habitual diets. Thromb Haemost 1992; 67: 352-6.

18. Lahoz $C$, Alonso $R$, Ordovas $J M$, Lopez-Farre $A$, de Oya $M$ and Mata $P$. Effects of dietary fat saturation on eicosanoid production, platelet aggregation and blood pressure. Eur J Clin invest 1997; 27: $780-7$.

19. Burri BJ, Dougherty RM, Kelley DS and lacono JM. Platelet aggregation in humans is affected by replacement of dietary linoleic acid with oleic acid. Am J Clin Nutr 1991; 54: 359-62.

20. Thijssen MA and Mensink RP. Small differences in the effects of stearic acid, oleic acid and linoleic acid on the serum lipoprotein prafile of humans. Am J Clin Nutr 2005; 82: 510-6.

21. Hornstra $G$ and ten Hoor $F$. The filtragometer: a new device for measuring platelet aggregation in venous blood of man. Thromb Diath Haemorn 1975; $34: 531-44$.

22. Clauss A Gerinnungsphysiologische Schnellmethode zur bestimmung des fibrinogens. Acta haematologica 1957; 17: 237-46.

23. Hornstra $G$, Chait A, Karvonen MJ, Lewis $B$, Turpeinen $O$ and Vergroesen AJ. Influence of dietary fat on platelet function in men. Lancet 1973; 1: 1155-7.

24. Fleischman $A I$, Justice $D$, Bierenbaum $M L$, Stier $A$ and Sullivan $A$. Beneficial effect of increased dietary linoleate upon in vivo platelet function in man. J Nutr 1975; 105: 1286-90.

25. Hunter KA, Crosbie LC, Weir A, Miller GJ and Dutta-Roy AK. A residentiall study comparing the effects of diets rich in stearic acid, oleic acid, and linoleic acid on fasting blood lipids, hemostatic variables and platelets in young healthy men. Journal of Nutritional Biochemistry 2000; $11: 408-16$.

26. Turpeinen AM, Pajari AM, Freese R, Sauer R and Mutanen M. Replacernent of dietary saturated by unsaturated fatty acids: effects of platelet protein kinase $C$ activity, urinary content of 2,3-dinor-TXB2 and in vitro platelet aggregation in healthy man. Thromb Haemost 1998; 80: 649-55.

27. MCDonald BE, Gerrard JM, Bruce VM and Corner EJ. Comparison of the effect of canola oil and sunflower oil on plasma lipids and lipoproteins and on in wivo thromboxane A2 and prostacyclin production in healthy young men. Am J Clin Nutr 1989; 50: 1382-8. 


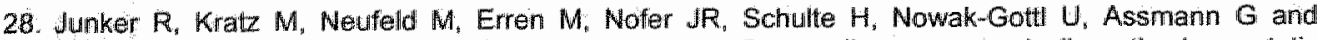
Wahrburg $U$. Effects of diets containing olive oil, sunflower oil, or rapeseed oil on the hemostatic system. Thromb Haemost 2001; 85: 280-6.

29. Kwon JS. Snook JT. Wardlaw GM and Hwang DH. Effects of diets high in saturated fatty acids, canola oil, or safflower oil on platelet function, thromboxane B2 formation, and fatty acid composition of platelet phospholipids. Am J Clin Nutr 1991: 54:351-8.

30. Foley $M$, Ball $M$, Chisholm $A$, Duncan $A$, Spears $G$ and Mann J. Should mono- or polly-unsaturated fats replace saturated fat in the diet? Eur J Clin Nutr 1992; 46: 429-36.

31. Turpeinen AM and Mutanen M. Similar effects of diets high in oleic or linoleic acids on coagulation and fibrinolytic factors in healthy humane. Nutr Metab Cardiovasc Dis 1999; 9: 65-72.

32. Marckmann $P$, Sandstiom $B$ and Jespersen $\mathrm{J}$. Effects of total fat content and fatty acid composition in diet on factor VIl coagulant activity and bilood lipids. Atherosclerosis 1990; 80: 227-33.

33. Heinrich J, Wahrburg $U$, Marting $H$ and Assmann $G$. The effect of diets, rich in mono- or polyunsaturated fatty acids, on lipid metabolism and haemostasis. Fibrinolysis 1990; 4:76-8.

34. Baer DJ. Judd JT, Clevidence BA and Tracy RP. Dietary fatty acids affect plasma markers of inflammation in healthy men fed controlled diets: a randomized crossover study. Am J Clin Nutr 2004; 79: $969-73$.

35. Temme EH, Mensink RP and Hornstra G. Effects of diets enriched in lauric, palmitic or oleic acids on blood coagulation and fibrinolysis. Thromb Haemost 1999; 81: 259-63.

36. Wiman $B$, Andersson $T$, Hallquist $J$, Reuterwall $C$, Ahlbom $A$ and deFaire U. Plasma levels of tissue plasminogen activator/plasminogen activator inhibitor-1 complex and von Willebrand factor are significant risk markers for recurrent myocardial infarction in the Stockholm Heart Epidemiology Program (SHEEP) study. Arterioscler Thromb Vasc Biol 2000; 20: 2019-23.

37. Waring LE, Hooper SR, Wilson AK, LI D, Francis M, Kelly FD, Dimitriadis E, Mann NJ, Turner AH and Sinclair $A J$. The influence of stearic acid in chocolate on thrombotic risk factors in blood. Proceedings of the Nutrition Society of Australia 1998; 22: 264.

38. Schoene NW, Allman MA , Doughtery RM and lacono JM. Dissimilar responses of platelets to dietary stearic and palmitic acids. Am J Clin Nutr $1994 ; 60$ : 1059 S.

39. Martin JF, Bath PM and Burr ML. Influence of platelet size on outcome after myocardial infarction. Lancet 1991: 338: 1409-11,

40. Endler $G$, Klimesch $A$, Sunder-Plassmann $H$, Schillinger $M$, Exner $M$, Mannhalter $C$, Jordanova $N$, Christ $G$, Thalharnmer $R_{k}$ Huber $K$ et al. Mean platelet volume is an independent risk factor for myocardial infarction but not for coronary antery disease. Br J Haematol 2002; 117: 399-404. 


\title{
Effects of stearic, oleic, and linoleic acids on biomarkers of lipid peroxidation and inflammation in healthy human subjects
}

\author{
Myriam A.M.A. Thijssen ${ }^{1}$, Samar Basu" ${ }^{2}$, and Ronald P. Mensink ${ }^{1}$
}

Submitted for publication

'Nutrition and Toxicology Research Institute Maastricht (NUTRIM), Department of Human Biology. Maastricht University. Maastricht, The Netherlands

${ }^{2}$ Department of Geriatrics and Clinical Nutrition Research, Uppsala University, Uppsala, Sweden 


\section{ABSTRACT}

Background: Markers of lipid peroxidation and inflammation, which are related to cardiovascular disease risk, are affected by the dietary fatty acid composition.

objective: To examine the effects of stearic, oleic, and linoleic acids on biomarkers of oxidative stress and inflammation.

Design: Forty-five healthy subjects (18 men and 27 women) consumed 3 experimental diets enriched in stearic acid, oleic acid, or linoleic acid (exchange of $7 \%$ of energy) for 5 weeks in a randomised, crossover study. Diets contained $38 \%$ of energy as fat. As biomarkers of non-enzymatic and enzymatic lipid peroxidation, urinary excretions of 8-iso-prostaglandin $F_{2 x}$ (8-iso-PGF $\left.F_{2 \alpha}\right)$ and 15-keto-dihydroprostaglandin $F_{2 a}\left(15-K-D H-P G F_{2 \alpha}\right)$ were analysed. Concentrations of highsensitivity CRP (hsCRP) were measured as biomarker of inflammation.

Results: No effects were observed on urinary excretion of 8-iso- $P G F_{2 \alpha}(P=0.154)$ and 15-K-DH-PGF $2 x=0.492)$. Plasma concentrations of hsCRP did not differ between the three diets $(P=0.408$ ) and were $1.44 \pm 1.59 \mathrm{mg} / \mathrm{L}$ (mean \pm standard deviation) during consumption of the stearic acid diet, $2.00 \pm 2.64 \mathrm{mg} / \mathrm{L}$ on the oleic acid diet and $2.05 \pm 3.57 \mathrm{mg} / \mathrm{L}$ on the linoleic acid diet. Serum concentrations of $/ \mathrm{L}$ 10 were $7.00 \pm 8.49 \mathrm{pg} / \mathrm{mL}, 7.08 \pm 8.03 \mathrm{pg} / \mathrm{mL}$ and $6.29 \pm 5.68 \mathrm{pg} / \mathrm{mL}$ on the diets rich in stearic, oleic, or linoleic acids ( $P=0.268$ for diet effects).

Conclusions: In healthy non-smoking human subjects, stearic, oleic, and linoleic acids - three dietary fatty acids with 18 carbon atoms, but with different degrees of unsaturation - do not have different effects on markers of lipid peroxidation or the inflammatory response. 
Stearic, oleic, and linoleic acids and lipid peroxidation and inflammation

\section{INTRODUCTION}

It is well established that the fatty acid composition of the diet affects cardiovascular disease risk (1). When compared with saturated fatty acids, monounsaturated and polyunsaturated fatty acids lower LDL cholesterol, while effects on HDL cholesterol are comparable (2). However, dietary fatty acids not only affect the serum lipoprotein profile but also other cardiovascular risk markers such as lipid peroxidation and inflammation.

Lipid peroxidation and inflammation are importantly involved in the pathogenesis of atherosclerosis and cardiovascular diseases $(3,4)$. When lipids or lipoprateins become modified by oxidation, an inflammatory response is initiated. Especially polyunsaturated fatty acids are thought to be susceptible to oxidative modification because of the presence of multiple double bonds. Indeed, several human studies reported that dietary linoleic acid increased in vitro the susceptibility of LDL to copper-induced oxidation $(5,6)$ but compelling evidence that this occurs in vivo is lacking. In fact, data from dietary studies using urinary isoprostane concentrations, a biomarker for in vivo oxidative stress, are contradictory (7-9). $F_{2}$-Isoprostanes are free radical catalysed products of arachidonic acid (10). 8-Iso-prostaglandin $F_{2 a}$ (8iso-PGF ${ }_{2 \alpha}$ ) is a major isoprostane that is considered to be a reliable indicator of lipid peroxidation and oxidative stress (11). In addition, 15-keto-dihydro-prostaglandin $F_{2 \alpha}$ (15-K-DH-PGF $F_{2 \alpha}$, a major metabolite of prostaglandin $F_{2 \alpha}$ which is a cyclooxygenase mediated product of arachidonic acid, is regarded as a reliable indicator of enzymatic lipid peroxidation and inflammatory responses (12).

Although interest is growing, not many studies addressed the effects of individual fatty acids on inflammatory markers and markers of immune function. As parameter of inflammation, the acute-phase reactant high-sensitivity C-reactive protein (hsCRP), which is a strong predictor of cardiovascular events, is frequently used (13). Moreover, the accumulation of inflammatory cells in an atherosclerotic plaque is orchestrated by the production of immunomodulatory molecules such as chemoattractants, adhesion molecules, pro- and anti-inflammatory cytokines and growth factors (14). N-3 polyunsaturated fatty acids from fish oil may reduce $\mathrm{C}$ reactive protein concentrations $(15,16)$, although some studies also reported no effects (17). Data from human studies investigating the effects of fatty acids other than $n-3$ polyunsaturated fatty acids on inflammation and lipid peroxidation markers are, however, limited.

Recently, we have reported that at realistic intakes differences between the effects of stearic, oleic, and linoleic acids on the serum lipoprotein profile are small (18). Whether effects on lipid peroxidation and inflammatory markers are also 
comparable has not been investigated before. Therefore, the purpose of the present study was to examine in humans the effects of these three $\mathrm{C} 18$ fatty acids with increased degree of unsaturation on biomarkers of oxidative stress and inflammation.

\section{SUBJECTS AND METHODS}

\section{Subjects}

Subjects were recruited by advertisements in local newspapers and a university hospital newsletter, and by posters in university buildings. The screening and eligibility criteria of the subjects were described in detail before (18). Fifty-eight healthy, non-smoking, slightly hypercholesterolemic subjects were selected for the study. None of the participants used medication or a prescribed diet known to affect serum lipids or thrombosis tendency. Thirteen subjects withdrew mainly in the first 2 weeks of the study because of reasons specifically related to the strict study protocol (4 subjects), stressful personal or job circumstances (5 subjects), and physical illness ( 2 subjects in the first intervention period and 1 subject in the second intervention period). One subject was excluded after the first intervention period because he did not follow the protocol. Ultimately, 45 subjects, 18 men and 27 women, completed the study protocol. The characteristics of these subjects are shown in Table 5.1. Sixteen women were postmenopausal and 5 used oral contraceptives. The subjects were asked not to change their level of physical exercise or their use of alcohol, vitamins or oral contraceptives during the study. Participants were fully informed of study requirements. All subjects had given their written informed consent, before they entered the study.

Table 5.1 Characteristics of the participants. ${ }^{1}$

\begin{tabular}{llcl}
\hline & \multicolumn{1}{c}{ Men } & Women & \multicolumn{1}{c}{ All } \\
\hline & \multicolumn{1}{c}{$n=18$} & $n=27$ & $n=45$ \\
Age $(\mathrm{y})$ & $54.0 \pm 9.9$ & $49.7 \pm 10.4$ & $51.4 \pm 10.3$ \\
BMI $\left(\mathrm{kg} / \mathrm{m}^{2}\right)$ & $26.0 \pm 2.2$ & $24.1 \pm 2.8$ & $24.9 \pm 2.7$ \\
Systolic blood pressure $(\mathrm{mmHg})$ & $127 \pm 12$ & $118 \pm 14$ & $122 \pm 14$ \\
Diastalic blood pressure $(\mathrm{mmHg})$ & $80 \pm 6$ & $74 \pm 9$ & $77 \pm 8$ \\
Total cholesterol $(\mathrm{mmol} / \mathrm{L})$ & $6.19 \pm 0.78$ & $5.94 \pm 0.73$ & $6.04 \pm 0.75$ \\
LDL cholesterol $(\mathrm{mmol} / \mathrm{L})$ & $3.17 \pm 0.57$ & $3.29 \pm 0.53$ & $3.24 \pm 0.54$ \\
HDL cholesterol $(\mathrm{mmol} / \mathrm{L})$ & $1.17 \pm 0.29$ & $1.70 \pm 0.56$ & $1.48 \pm 0.54$ \\
Triacylglycerols $(\mathrm{mmol} / \mathrm{L})$ & $1.37 \pm 0.61$ & $0.99 \pm 0.45$ & $1.15 \pm 0.55$ \\
\hline
\end{tabular}

Values are means \pm standard deviations. 


\section{Experimental design and diets}

The study had a randomised, multiple crossover design. Each participant consumed each of the 3 different diets in random order during three 5-week periods. Between each intervention period was a washout period of at least 1 week, during which the participants consumed their habitual diets. One diet was high in stearic acid (C18:0), another high in oleic acid (C18:1), and the third one high in linoleic acid (C18:2). The protocol of the study was approved by the Medical Ethics Committee of Maastricht University (18).

Before participants started the study, their total energy intake was estimated with the Harris-Benedict equation (19). The study diets were formulated at 16 different levels of energy intake ranging from 6 to $13.5 \mathrm{MJ}$ per day. During the intervention periods, subjects received experimental products (bread, margarines, and cake) in which the normal fats were replaced by experimental fats.

Experimental fats were produced by NIZO Food Research (Ede. The Netherlands). The high-stearic acid fat was composed of $9.0 \%$ palm oil, $5.5 \%$ safflower oil, $5.0 \%$ olive oil, $33.5 \%$ cocoa butter, $18.0 \%$ high-oleic sunflower oil and $29.0 \%$ glycerol tri-stearate. The high-oleic acid fat consisted of $19.5 \%$ palm oill, $26.0 \%$ olive oil, $7.5 \%$ cocoa butter, and $47.0 \%$ high-oleic sunflower oil. The highlinoleic acid fat was a mixture of $20.0 \%$ palm oil, $52.0 \%$ safflower oil, $7.0 \%$ olive oil, $9.0 \%$ cocoa butter and $12.0 \%$ high-oleic sunflower oil.

The experimental products supplied $60 \%$ of total fat energy at a targeted total fat intake of $37 \%$ of energy. For the remaining $40 \%$ of the total fat intake, subjects consumed daily a certain amount of 'free-choice' fat-containing products. These products had to be recorded in a diary. Subjects visited the university at least once every week to receive a new supply of products. At each visit, subjects were weighed and diaries were checked by a dietician. Individual allowances were adjusted, when subjects' weight changed $>1.5 \mathrm{~kg}$ from initial weight during the first week of the study or $>2 \mathrm{~kg}$ during the following weeks. Mean daily intakes of energy, protein, carbohydrates, fat, cholesterol, and fibre as calculated by foodfrequency questionnaires, which were filled in by the subjects at the end of each period, are summarised in Figure 5.1. The prescribed nutrient composition of the 3 diets did not differ, except for a difference of $7 \%$ in energy intake provided by stearic, oleic, or linoleic acids. 


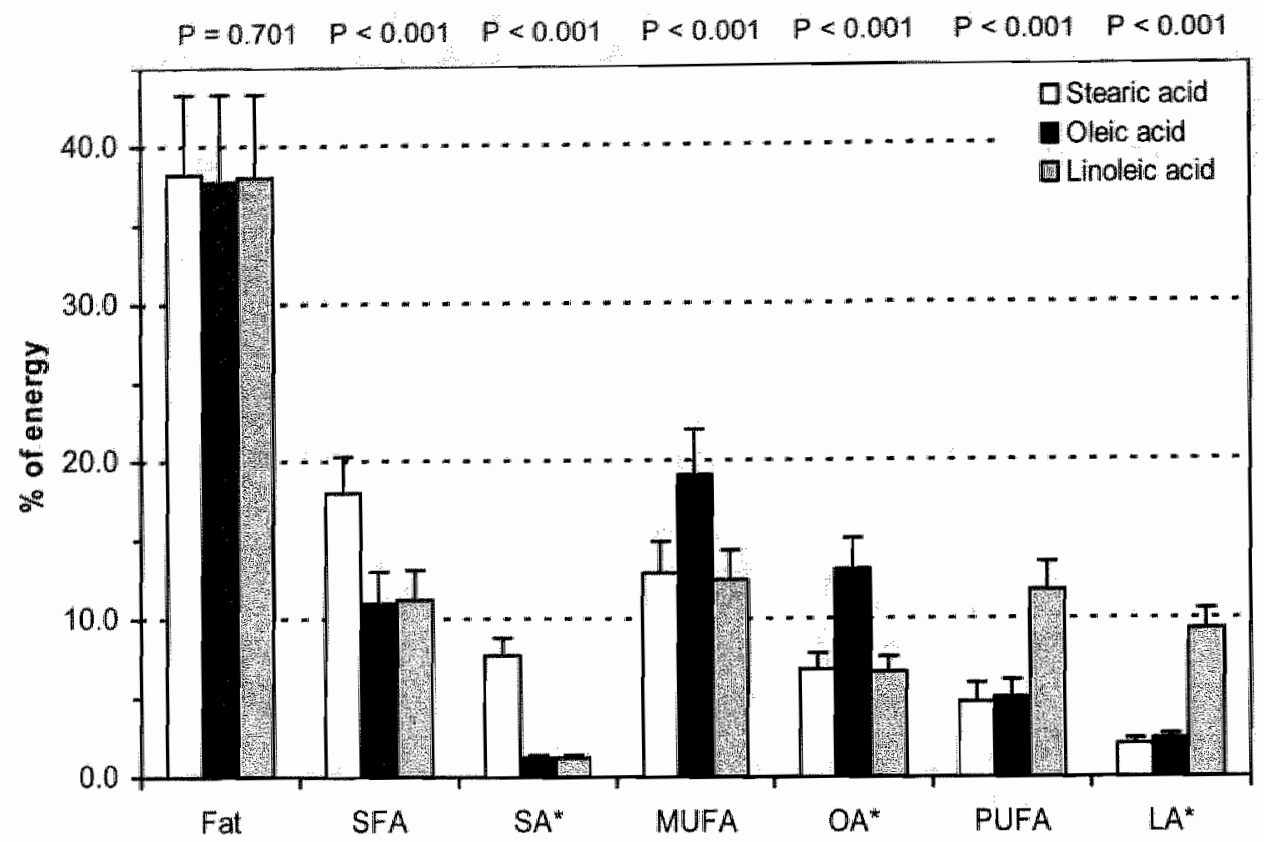

Figure 5.1 Mean nutrient composition of the 3 diets according to the foodfrequency questionnaires. ${ }^{1,2,3}$

\footnotetext{
'Values are means \pm standard deviations, $n=45$ (18 men and 27 women) as calculated from the foodfrequency questionnaires. P-values for diet effects were calculated by general linear model with subject number as random factor and diet and period as fixed factors.

${ }^{2}$ Intakes of energy $(8.5 \pm 1.6 \mathrm{MJ})$, carbohydrates $(46.1 \pm 6.1 \%$ of energy), proteins $(13.9 \pm 2.0 \%$ of anergy), alcohol $(2.2 \pm 2.3 \%$ of energy), cholesterol $(17.7 \pm 3.6 \mathrm{mg} / \mathrm{Ml})$ and dietary fibre $(3.1 \pm 0.7 \mathrm{~g} / \mathrm{MJ})$ ) did not differ significantly between the 3 diets.

${ }^{3}$ Abbreviations used: saturated fatty acids (SFA), stearic acid (SA), monounsaturated fatty acids (MUFA), oleic acid (OA), polyunsaturated fatty acids (PUFA), linoleic acid (LA).

*As provided by the experimental fats only.
}

\section{Blood sampling and urine collection}

Venous blood samples with the volunteer in a recumbent position were obtained after an overnight fast twice at the end of each period (weeks 4 and 5). Blood was sampled with minimum stasis by using a $0.9 \mathrm{~mm}$-needle (PrecisionGlide, BectonDickinson Vacutainer systems, Plymouth, United Kingdom) in week 4 or with a 1.0 mm-infusion needle (Microflex, Vygon, Ecouen, France) in week 5 . All venipunctures were done by the same person, in the same room, and mostly at the same time of the day. The first $6 \mathrm{~mL}$ of blood was collected in EDTA tubes (Becton Dickinson Vacutainer Systems) and used for the analysis of high-sensitivity $\mathrm{C}$-reactive protein 
(hsCRP). The following $9 \mathrm{~mL}$ was collected in sodium citrate tubes (Becton Dickinson Vacutainer Systems) and used for the antibody array analysis of immunomodulatory molecules. Finally, $10 \mathrm{~mL}$ blood was collected in a serum tube (Corvac, Becton Dickinson Vacutainer Systems). EDTA and citrate tubes were kept on ice and centrifuged $3500 \times \mathrm{g}$ for $30 \mathrm{~min}$ within 1 hour after venipuncture. Plasma samples were snap-frozen in liquid nitrogen and stored at $-80^{\circ} \mathrm{C}$. At least 1 hour after venipuncture, serum was obtained by centrifugation at $3500 \times \mathrm{g}$ for $30 \mathrm{~min}$ at $4^{\circ} \mathrm{C}$ and stored at $-80^{\circ} \mathrm{C}$.

At the end of each intervention period, subjects collected a 24-hour urine sample. The urine samples were frozen and stored at $-20^{\circ} \mathrm{C}$.

\section{Non-enzymatic and enzymatic lipid peroxidation}

Unextracted 24-hour urine samples were analysed for free 8-iso-prostaglandin $F_{2 \alpha}$ (8-iso-PGF $2 \alpha$, non-enzymatic lipid peroxidation) and 15-keto-dihydro-prostaglandin $\mathrm{F}_{2 \alpha}$ (15-K-DH-PGF $\mathrm{F}_{2 \alpha}$, enzymatic lipid peroxidation) by specific and validated RIA analyses as described earlier $(12,20)$. Concentrations of 8 -iso-PGF $2 \alpha$ and $15-\mathrm{K}-\mathrm{DH}$ $\mathrm{PGF}_{2 \alpha}$ were adjusted for creatinine concentrations measured with a commercial kit (IL Test, Instrumentation Laboratories, Lexington, United States).

\section{High-sensitivity C-reactive protein}

High-sensitivity C-reactive protein (hsCRP) concentrations were measured in pooled EDTA plasma samples of weeks 4 and 5 by an immunoturbidimetric assay ( $K$ ASSAY CRP-2, Kamiya Biomedical Company, Seattle, United States) as described previously (21).

\section{Cytokine expression profiles}

Before analysis of cytokine expression profiles, citrated plasma samples from weeks 4 and 5 of each diet were pooled, for men and women separately. To measure expression patterns of several cytokines, chemokines and growth factors, the human cytokine antibody array III (RayBiotech Inc., Norcross, United States) was used according to the manufacturer's instructions. Six arrays were analysed, namely 1 for the stearic acid diet, 1 for the oleic acid diet and 1 for the linoleic acid diet for respectively male and female subjects. Array spot intensity was detected by using a LAS-3000 Lite Image reader (Raytest GmbH. Straubenhart, Germany) on the basis of chemiluminescence imaging. Intensity of the spots was quantified by densitometry using AIDA software version 3.50 (Raytest $\mathrm{GmbH}_{\text {. Straubenhart, }}$ Germany), correcting for differences in background staining of the gel. Comparison of the expression profiles, which consisted of 42 different immunomodulatory 
molecules, was possible after normalisation of the individual arrays using the positive controls present on each membrane. Differences in responses were calculated and expressed relative to the oleic acid diet as percentage of change.

\section{High-sensitivity interleukin-10}

Concentrations of interleukin-10 (IL-10) were analysed in pooled serum samples of weeks 4 and 5 by high-sensitivity enzyme-linked immunosorbent assays (human (h) IL-10, Biotrak ELISA system, Amersham Biosciences, Buckinghamshire, United Kingdom).

\section{Statistical analysis}

All statistical analyses were performed using SPSS 11 for Macintosh OS X package. The data were analysed with the general linear model (GLM) procedure. A probability level (P-value) of $<0.05$ was considered statistically significant. Differences in effects on IL-10, hsCRP and lipid peroxidation parameters were examined with diet and period as fixed factors and subject number as random factor. To analyse whether effects of diet were modified by gender, the diet $x$ gender interaction term was added to the model as fixed factor. Between diets comparisons were corrected for 3-group comparisons by the Bonferroni correction. Confidence intervals $(\mathrm{Cl}, 95 \%)$ were calculated for the differences between the diets. Pearson's correlations between concentrations of hsCRP and IL-10, and urinary excretion of 8iso-PGF $F_{2 c}$ and $15-\mathrm{K}-\mathrm{DH}-\mathrm{PGF}_{2 a}$ were determined to examine linear relationships between parameters.

\section{RESULTS}

\section{Lipid peroxidation}

Urinary excretion of 8-iso-PGF $F_{2 \alpha}(P=0.154$ for diet effects) did not differ significantly between the 3 diets (Figure 5.2). When oleic acid in the diet was substituted by stearic acid or linoleic acid, urinary excretion of 8-iso-PGF $F_{2 \alpha}$ increased by 0.03 $\mathrm{nmol} / \mathrm{mmol}$ creatinine $(\mathrm{P}=0.304,95 \% \mathrm{Cl}$ for the difference: -0.01 to $0.07 \mathrm{nmol} / \mathrm{mmol}$ creatinine) and $0.03 \mathrm{nmol} / \mathrm{mmol}$ creatinine $(P=0.263,95 \% \mathrm{Cl}$ for the difference: 0.01 to $0.07 \mathrm{nmol} / \mathrm{mmol}$ creatinine), respectively. Urinary excretion of 8-iso-PGF $2 \alpha$ did not differ between the diets rich in stearic acid and linoleic acid $(P=1.00,95 \%$ $\mathrm{Cl}$ for the difference: -0.04 to $0.04 \mathrm{nmol} / \mathrm{mmol}$ creatinine). Urinary excretion of $15-\mathrm{K}$ DH-PGF $2 x$ was also not affected by the 3 diets ( $P=0.492$ for diet effects). Compared with the oleic acid diet, urinary excretion of $15-\mathrm{K}-\mathrm{DH}-\mathrm{PGF}_{2 \alpha}$ increased by $0.01 \mathrm{nmol} / \mathrm{mmol}$ creatinine $(P=0.733,95 \% \mathrm{Cl}$ for the difference: -0.01 to 0.03 
$\mathrm{nmol} / \mathrm{mmol}$ creatinine) on the stearic acid diet and by $0.01 \mathrm{nmol} / \mathrm{mmol}$ creatinine (P $=1.00,95 \% \mathrm{Cl}$ for the difference: -0.01 to $0.03 \mathrm{nmol} / \mathrm{mmol}$ creatinine) on the linoleic acid diet. In addition, urinary excretion of $15-\mathrm{K}-\mathrm{DH}-\mathrm{PGF}_{2 \alpha}$ did not differ on the stearic acid and linoleic acid diets $(P=1.00,95 \% \mathrm{Cl}$ for the difference: -0.02 to 0.02 $\mathrm{nmol} / \mathrm{mmol}$ creatinine). None of the dietary effects differed significantly between men and women.

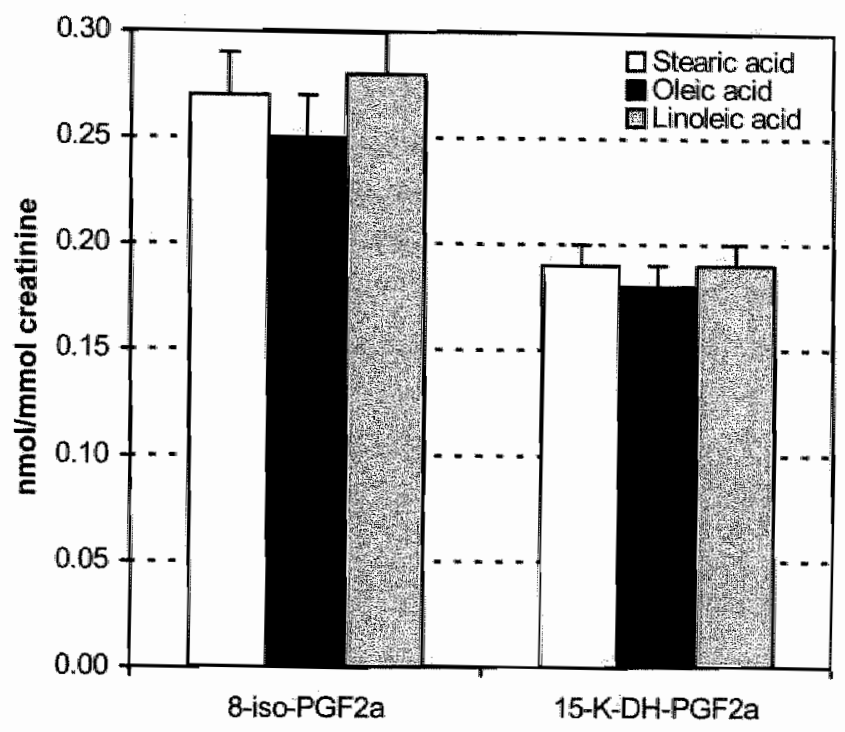

Figure 5.2 Urinary excretion of 8-iso-PGF $F_{2_{\alpha}}$ and 15-K-DH-PGF $F_{2_{a}}$ as parameters of lipid peroxidation during consumption of diets enriched in siearic, oleic, and linoleic acids for 5 weeks by healthy humans, $n=45$ (18 men and 27 women). ${ }^{1,2}$

'Values are means \pm standard error of the mean at the end of each intervention period (24-hour urine in week 5).

${ }^{2}$ There were no significant differences between the 3 diets, $p<0.05$ (general linear model with subject number as random factor and diet and period as fixed factors).

\section{High-sensitivity C-reactive protein (hsCRP)}

Concentrations of hsCRP (Figure 5.3) did not differ significantly between the 3 diets $(P=0.408)$. When stearic acid in the diet was substituted by oleic acid or linoleic acid, hsCRP concentrations increased non-significantly by $0.56 \mathrm{mg} / \mathrm{L}(\mathrm{P}=0.767$, $95 \% \mathrm{Cl}$ for the difference: -1.77 to $0.64 \mathrm{mg} / \mathrm{L})$ and $0.59 \mathrm{mg} / \mathrm{L}(\mathrm{P}=0.715,95 \% \mathrm{Cl}$ for the difference: -1.79 to $0.62 \mathrm{mg} / \mathrm{L})$, respectively. Dietary effects did not depend on gender. 


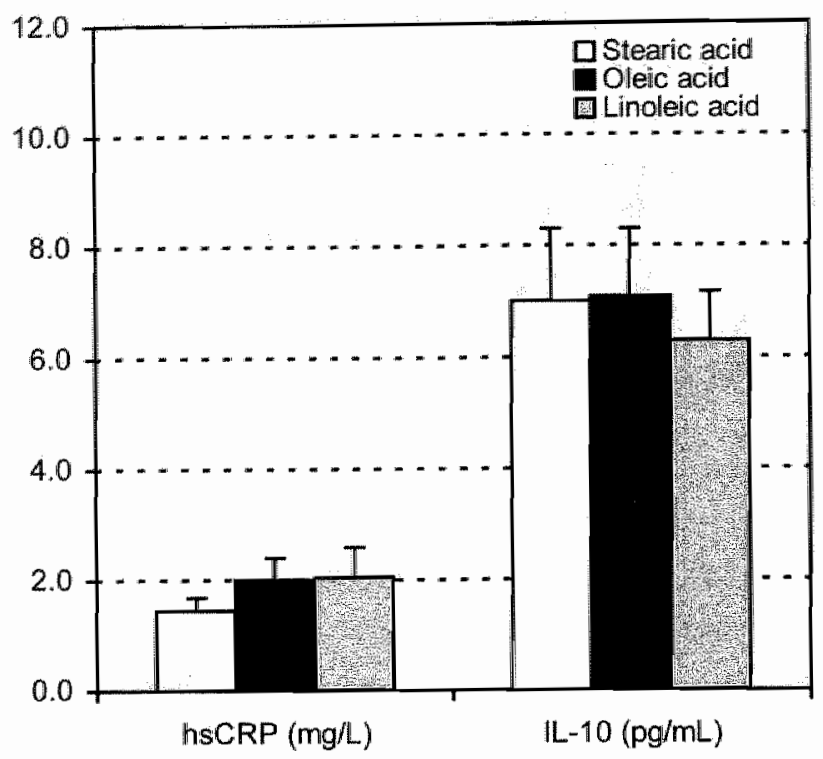

Figure 5.3 Inflammatory parameters during consumption of diets enriched in stearic, aleic, and finoleic acids for 5 wreks by healthy humans, $n=45$ (18 men and 27 women). ${ }^{1,2}$

"Values are means \pm standard error of the mean at the end of each intervention period (pooled weeks 4 and 5).

${ }^{2}$ There were no significant differences between the 3 diets, $P<0.05$ (general linear model with subject number as randorn factor and diet and period as fixed factors).

\section{Expression profiles of immunomodulatory molecules}

Twenty cytokines, chemokines or growth factors of the 42 different spots on the antibody arrays were detectable in plasma and were quantified separately for male and female subjects (Figures 5.4 and 5.5). During all 3 diets, relative expression of almost all 20 cytokines was higher in men than in women. Moreover, the observed changes of several immunomodulatory molecules differed between men and women during the diets. While in men opposite changes of stearic acid and linoleic acid were observed for interleukin-8 (IL-8), macrophage derived chemokine (MDC), thrombopoietin (TPO), epidermal growth factor (EGF), platelet-derived growth factor $\beta$ (PDGF $\beta$ ) and vascular endothelial growth factor (VEGF), changes in women were opposite for RANTES, EGF, PDGF $\beta$, VEGF, tumour necrosis factor $\alpha(T N F \alpha)$ and turnour necrosis factor $\beta$ (TNFB). Compared with the oleic acid diet, relative expressions of monocyte chemotactic protein 1 (MCP-1), EGF, TPO and leptin was decreased by more than $5 \%$ by stearic acid in men and of MCP-1, EGF, TNF $\alpha$ and TNF $\beta$ in women, whereas relative expressions of most other cytokines was 
increased. Relative expressions of MCP-1, PDGF $\beta$ and VEGF was decreased by more than $5 \%$ in men during the linoleic acid diet and of IL-8, RANTES, TPO, PDGF 3 , VEGF and leptin in women, compared with the oleic acid diet. Observed changes between stearic acid and oleic acid were less than $5 \%$ for $\| L-8, M D C$, oncostatin M (OSM), angiogenin (Ang) in men and for IL-8, TPO and VEGF and leptin in women. Effects of linoleic acid were comparable to those of oleic acid for

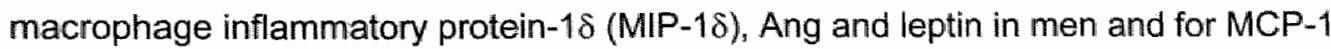
and MIP-18 in women.

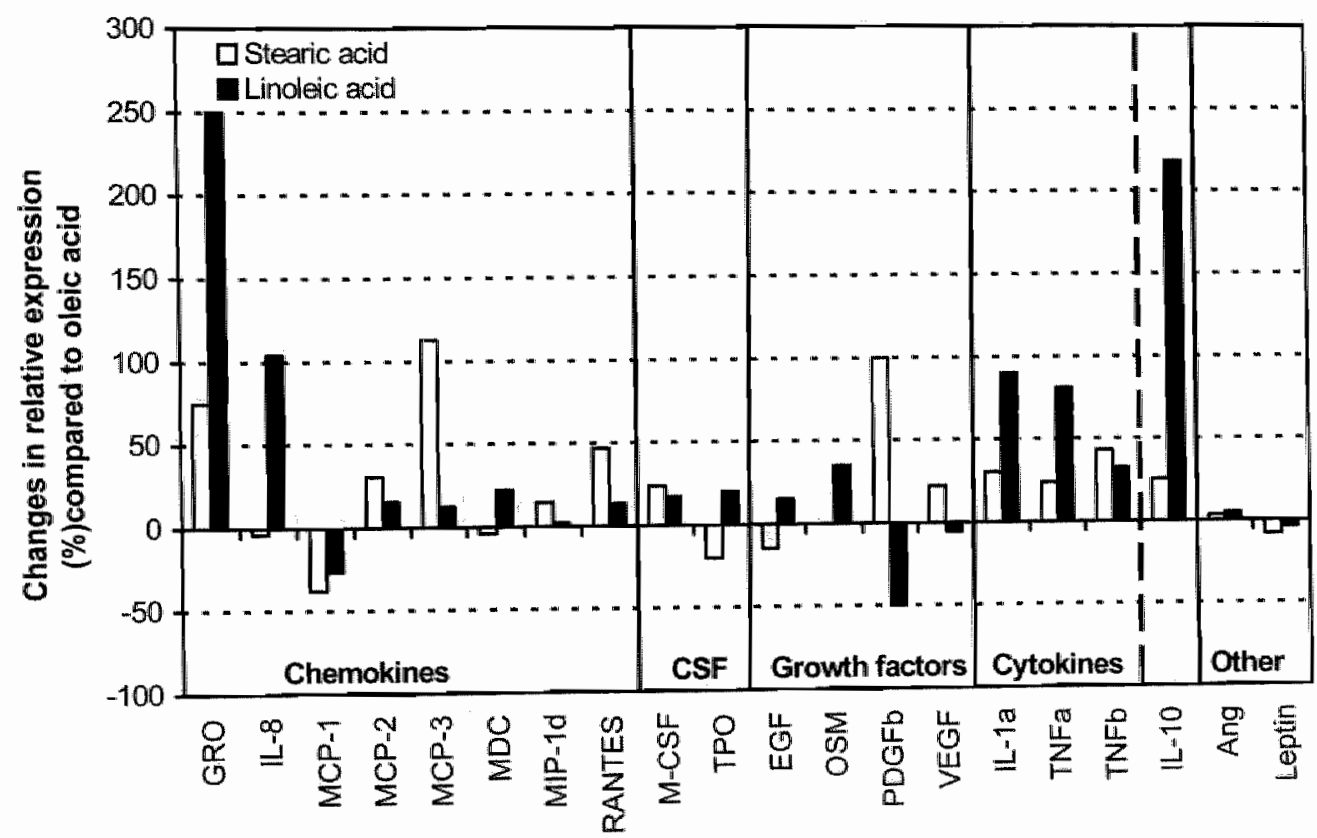

Figure 5.4 Changes in relative expression levels of different cytokines, chemokines and growth factors as measured by an antibody array in male subjects $(n=18)^{1,2}$

${ }^{1}$ Changes in effects of the stearic and linoleic acids diets ane expressed relative to the oleic acid diet. The immunomodulatory molecules are divided into different classes i.e. chemokines, colony stimulating factors (CSF), growth factors, and pro- ( $L-1 \alpha$, TNF $\alpha$ and TNF $\beta)$ and anti- ( $(L-10)$ inflammatory cylokines. 'Abbreviations used: Growth regulated protein (GRO), interleukin-8 (L-8), monocyte chemotactic protein 1 (MCP-1), monocyte chemotactic protein 2 (MCP-2), monocyte chemotactic protein 3 (MCP-3). macrophage derived chemokine (MDC), macrophage inflammatory protein-10 (MP-15), macrophage colony stimulating factor (M-CSF), thrombopoietin (TPO), epidermal growth factor (EGF), oncostatin M (OSM), platelet-derived growth factor $\beta$ (PDGF $\beta$ ), vascular endothelial growth factor (VEGF), interloukin$1 \alpha(L-1 \alpha)$, tumour necrosis factor $\alpha$ (TNF $\alpha)$, tumour necrosis factor $\beta$ (TNF $\beta$ ), interlewkin-10 (IL-10) and angrogenin (Ang). 


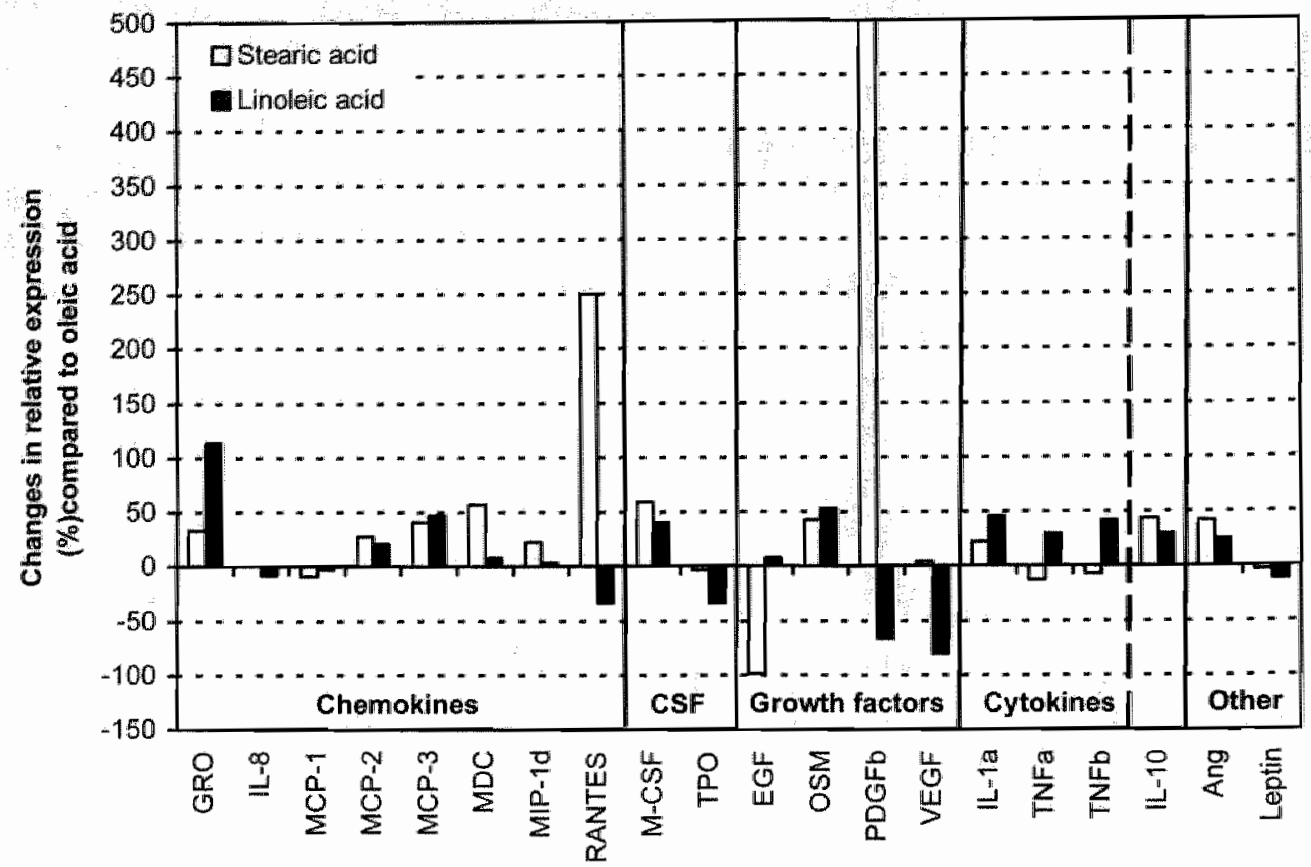

Figure 5.5 Changes in relative expression levels of different cytokines, chemokines and growth factors as measured by an antibody array in female subjects $(n=27)$. $^{12}$

"Changes in effects of the stearic and linoleic acids diets are expressed relative to the oleic acid diet. The immunomodulatory molecules are divided into different classes i.e. chemakines, colony stimulating factors (CSF), growth factors, and pro- (IL-1 $\alpha$, TNF $\alpha$ and TNFB) and anti- ( $L-10)$ inflammatory cytokines.

${ }^{2}$ Abbreviations used: Growth regulated protein (GRO), interleukin-8 (IL-8), monocyte chemotactic protein 1 (MCP-1), monocyte chemotactic protein 2 (MCP-2), monocyte chemotactic protein 3 (MCP-3), mecrophage derived chemokine (MDC), macrophage inflammatory protein-18 (MP-15), macrophage colony stimulating factor (M-CSF), thrombopoietin (TPO), epidermal growth factor (EGF), oncostatin $M$ (OSM), platelettaderived growth factor $\beta$ (PDGF 9 ), vascular endothelial growth factor (VEGF), interleukin-

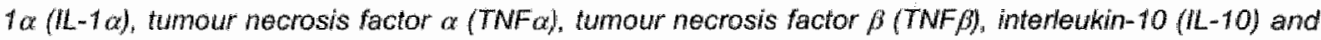
angiogenin (Ang).

\section{High-sensitivity interleukin-10}

To confirm the data of the cytokine antibody array, IL-10 was chosen to analyse by a high-sensitivity ELISA. Data are shown in Figure 5.3. No statistically significant changes in serum concentrations of IL-10 were observed ( $P=0.268$ for diet effects). The diet rich in linoleic acid reduced IL-10 concentrations by $0.66 \mathrm{pg} / \mathrm{mL}(P=0.183$, $95 \% \mathrm{Cl}$ for the difference: -1.64 to $0.32 \mathrm{pg} / \mathrm{mL})$ and $0.73 \mathrm{pg} / \mathrm{mL}(\mathrm{P}=0.143,95 \% \mathrm{Cl}$ for the difference: -1.71 to $0.25 \mathrm{pg} / \mathrm{mL}$ ) relative to the diets rich in respectively stearic acid and oleic acid. When stearic acid was substituted by oleic acid, the 
difference in $\mathrm{IL}-10$ concentrations was $0.07 \mathrm{pg} / \mathrm{mL}(P=0.892,95 \% \mathrm{Cl}$ for the difference: -0.91 to $1.05 \mathrm{pg} / \mathrm{mL}$ ). Dietary effects did not differ significantly between men and women. In men ( $P=0.248$ for diet effects), mean IL-10 concentrations were $5.91 \pm 3.68 \mathrm{pg} / \mathrm{mL}$ on the stearic acid diet, $6.82 \pm 5.74 \mathrm{pg} / \mathrm{mL}$ on the oleic acid diet, and $6.26 \pm 4.51 \mathrm{pg} / \mathrm{mL}$ on the linoleic acid diet, while IL-10 concentrations were respectively $7.77 \pm 10.73 \mathrm{pg} / \mathrm{mL}, 7.27 \pm 9.45 \mathrm{pg} / \mathrm{mL}$, and $6.30 \pm 6.49 \mathrm{pg} / \mathrm{mL}$ in women ( $P=0.096$ for diet effects).

\section{Correlations}

Urinary excretion of 8-iso-PGF ${ }_{2 \alpha}$ when expressed as $\mathrm{nmol} / \mathrm{mmol}$ creatinine, was significantly correlated with that of 15-K-DH-PGF 2 in the stearic acid group $(r=$ $0.582, \mathrm{P}<0.001)$ as well as in the oleic acid group $(r=0.469, \mathrm{P}=0.001)$. The correlation coefficient nearly reached statistical significance when subjects consumed the linoleic acid diet $(r=0.290, P=0.053)$. No significant correlations of hsCRP or IL-10 with urinary excretion of 8 -iso-PGF $2 a$ or $15-\mathrm{K}-\mathrm{DH}-\mathrm{PG} \mathrm{F}_{2 \alpha}$ were observed.

\section{DISCUSSION}

In the present study the effects of stearic acid, oleic acid, and linoleic acid were investigated on biomarkers of lipid peroxidation and inflammation of apparently healthy men and women. Urinary isoprostanes were measured as in vivo markers of lipid peroxidation. HsCRP was measured as marker of inflammation. Moreover, using an array containing antibodies against several chemokines, growth factors and cytokines, inflammatory responses were evaluated. No dietary effects were found.

Although various studies suggested that the in vitro susceptibility to lipid peroxidation of fatty acids is positively related to its number of double bonds, this concept is not confirmed by studies using in vivo biomarkers of lipid peroxidation. Isoprostanes represent a reliable and sensitive marker of in vivo lipid peroxidation and oxidative stress (10). Increased levels of isoprostanes have been reported in cardiovascular diseases (22). In our study, however, fatty acids with 18 carbon atoms and increased degree of unsaturation - stearic acid, oleic acid, and linoleic acid - did not differ in their effects on in vivo lipid peroxidation as measured by urinary excretion of 8 -iso-PGF $F_{2 a}$ and 15-K-DH-PGF 2 in healthy, middle-aged subjects. These observations agree with the results of other well-controlled dietary studies which compared the effects of oleic acid and linoleic acid on concentrations of isoprostanes in urine and plasma of humans $\left(7,9_{n} 23\right)$. In post-menopausal 
women, these 2 fatty acids did also not differ in their effects on the plasma concentrations of $F_{2}$-isoprostanes, thiobarbituric acid reactive substances (TBARS) or malondialdehydes (MDA) (23). Furthermore, in young healthy subjects, oleic acid and linoleic acid had comparable effects on concentrations of plasma TBARS and urinary excretion of 8-iso-PGF ${ }_{2 \alpha}$ (7). In another study, high-oleic acid and highlinoleic acid diets did not differ in their effects on the urinary excretion of 8-iso-

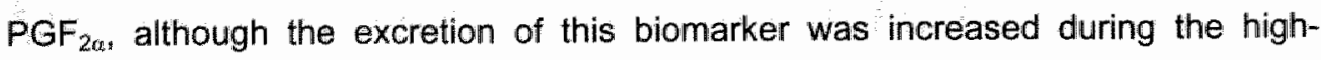
linoleic acid diet relative to the baseline saturated fat diet (9). In this latter study, the mean age of the subjects was only $27 y$. Hence, effects of fatty acids on in vivo parameters of oxidative stress may not depend on age. Relative to a diet rich in saturated fatty acids, a rapeseed oil diet rich in monounsaturated and polyunsaturated fatty acids did also not increase parameters of lipid peroxidation including hydroperoxides and malondialdehydes in plasma and 8-iso-PGF $F_{2 \alpha}$ in plasma and urine (24). Whether the presence of antioxidants in oils rich in monounsaturated or polyunsaturated fatty acids may compensate for the oxidative effects of fatty acids remains to be unravelled. However, fish oil which is poor in antioxidants did not differently affect urinary and plasma 8-iso-PGF $F_{2 \alpha}$ concentrations, when compared with saturated fatty acids (25). Although these findings may also suggest that these in vivo markers of lipid peroxidation are not diet-sensitive, this is contradicted by findings that supplements of the conjugated linoleic acid (CLA) isomer trans-10, cis-12 CLA increased urinary excretion of 8-iso-PGF $2 \alpha$ and of 15-KDH-PGF $F_{2 x}$ relative to supplements containing a mixture of CLA isomers or placebo oil (26). Taken together, these studies do not provide evidence that dietary fatty acids affect in vivo biomarkers of lipid peroxidation.

In contrast, when effects of diets rich in oleic and linoleic acids were compared using in vitro methods to measure lipid peroxidation, several earlier studies have shown that diets rich in oleic acid lowered the susceptibility of LDL to oxidative modification when compared with diets rich in linoleic acid $(5,6,8,27-30)$. When in vitro oxidation of LDL was induced by metal ions, lag time decreased, oxidation rate increased and formation of conjugated dienes or lipid peroxides increased on the diets rich in linoleic acid. When in vitro as well as in vivo methods were used, results were inconsistent. In two human studies in vitro susceptibility of LDL to oxidation increased by linoleic acid relative to oleic acid, whereas no or slightly decreased concentrations of conjugated dienes or malondialdehyde in plasma and lipid hydroperoxides or thiobarbituric acid reactive substances (TBARS) in plasma lipoprotein fractions were measured (8). Thus, it is doubtful whether in vitro methods evaluating LDL susceptibility to oxidation truly reflect the in vivo situation (31). 
Data about the effects of individual dietary fatty acids on hSCRP concentrations are scarce. Some studies focused on the effects of n-3 polyunsaturated fatty acids but results were inconsistent. In two studies, hsCRP concentrations were reduced by the n-3 polyunsaturated fatty acids, $\alpha$-linolenic acid (16), or EPA and DHA (15), while in two other studies no effects of the marine $n-3$ polyunsaturated fatty acids, EPA and DHA, were found $(17,32)$. In another recent study, effects of diets enriched with trans fatty acids, C12:0-C16:0 saturated fatty acids, stearic acid, oleic acid, or carbohydrates were compared. Although trans fatty acids increased hsCRP concentrations relative to the other diets, no significant different effects of stearic acid and oleic acid were found after 5 weeks of consumption of each diet (33), which agrees with our findings. While in that study only male subjects participated, we also found no different effects of stearic, oleic, and linoleic acids in female healthy subjects. This may indicate that effects on hsCRP concentration are independent of gender. However, more research in human subjects is necessary to clarify the effects of the dietary fatty acid composition on hSCRP concentrations.

To generate new leads for the potential inflammatory effects of stearic, oleic, and linoleic acids, expression profiles of multiple cytokines were measured by an antibody array. The measurement of expression signatures of immunomodulatory molecules such as cytokines, chemokines and growth factors by an antibody array is an interesting new tool to detect multiple cytokines simultaneously and to evaluate inflammatory effects of fatty acids (34). In our study, women not only had higher levels of many immunomodulatory molecules than men, but expression profiles induced by dietary stearic, oleic, and linoleic acids differed aiso between men and women. However, for most cytokines no consistent patterns emerged. IL-10 levels, however, were increased in both men and women on the stearic and linoleic acid diets. Samples were therefore also analysed at the individual level by ELISA but results were not in agreement. Although analytical sensitivity for IL-10 differed between ELISA $(0.1 \mathrm{pg} / \mathrm{mL})$ and antibody array $(10 \mathrm{pg} / \mathrm{mL})$, we do not have a clear explanation for these discrepant findings. Thus, the effects of fatty acids on the cytokine profile need to be addressed in future studies into more detail.

In summary, although dietary fatty acid composition may influence lipid peroxidation, stearic, oleic, and linoleic acids did not differ in their effects on biomarkers of in vivo mon-enzymatic and enzymatic lipid peroxidation of healthy nonsmoking human subjects. Inflammatory response as measured by hsCRP was also not affected by one of these 3 fatty acids. 


\section{REFERENCES}

1. Hu FB, Stampfer MJ, Manson JE, Rimm E, Colditz GA, Rosner BA, Hennekens CH and Willett WC. Dietary fat intake and the risk of coronary heart disease in women. N Engl J Med 1997; 337: 1491-9.

2. Mensink RP, Zock PL, Kester AD and Katan MB. Effects of dietary fatty acids and carbohydrates on the ratio of serum total to HDL cholesterol and on serum lipids and apolipoproteins: a meta-analysis of 60 controlled trials. Am J Clin Nutr 2003; $77: 1146-55$.

3. Libby $P$. Inflammation in atherosclerosis. Nature $2002 ; 420: 868-74$

4. Lusis A. Atherosclerosis. Nature 2000; 407: 233-41.

5. Mata $\mathrm{P}$. Alonso $R$, Lopez-Farre $A$, Ordovas $J M$, Lahoz $C$, Garces $C$, Caramelo $C$, Codoceo $R$. Blazquez $E$ and de Oya $M$. Effect of dietary fat saturation on LDL oxidation and monocyte adhesion to human endathelial cells in vitro. Arterioscler Thromb Vasc Biol 1996; 16: 1347-55.

6. Reaven P, Parthasarathy $S$, Grasse BJ, Miller E, Steinberg D and Witztum JL. Effects of oleate-rich and linoleate-rich diets on the susceptibility of low density lipoprotein to oxidative modification in mildly hypercholesterolemic subjects. J Clin Invest 1993; 91:668-76.

7. Freese $R$, Alfthan $G$, Jauhiainen M, Basu $S$, Erlund $I$, Salminen I, Aro A and Mutanen M. High intakes of vegetables, berries, and apples combined with a high intake of linoleic or oleic acid only slightly affect markers of lipid peroxidation and lipoprotein metabolism in healthy subjects. Am $J$ Clin Nutr 2002; $76: 950-60$.

8. Turpeinen AM, Alfthan G, Valsta L, Hietanen E, Salonen JT, Schunk H, Nyyssonen K and Mutanen M. Plasma and lipoprotein lipid peroxidation in humans on sunflower and rapeseed oil dilets. Lipids. 1995; 30: 485-92.

9. Turpeinen $A M$, Basu $S$ and Mutanen M. A high linoleic acid diet increases oxidative stress in vivo and affects nitric oxidle metabolism in humans. Prostaglandins Leukot Essent Fathy Acids 1998; $59: 229$ 33.

10. Roberts LJ and Morrow JD. Measurement of F(2)-isoprostanes as an index of oxidative stress in wivo. Free Radic Biol Med 2000; $28: 505-13$

11. Basu S. Isoprostanes: novel biaactive products of lipid peroxidation. Free Radic Res 2004; 38: 10522.

12. Basu S. Radioimmunoassay of 15-keto-13,14-dihydio-prostaglandin F2alpha: an index for inflammation via cyclooxygenase catalysed lipid peroxidation. Prostaglandins Leukot Essent Fatty Acids 1998; 58: 347-52.

13. Ridker PM, Rifai N, Rase L, Buring JE and Cook NR. Comparison of C-reactive protein and lowdensity lipoprotein cholesteral levels in the prediction of first cardiovascular events. $N$ Engl J Med 2002; 347: 1557-65.

14. Young $\mathrm{JL}$, Libby $P$ and Schonbeck $U$. Cytakines in the pathogenesis of atherosclerasis. Thromb Haemost 2002; 88: 554-67.

15. Pischon $T$ " Hankinson SE, Hotamisligill GS, Rifai $N_{*}$ Willett WC and Rimm EB. Habitual dietary intake of $n-3$ and $n-6$ fatty acids in relation to inflammatory markers among US men and women. Circulation 2003; 108: $155 \sim 60$.

16. Rallidis LS, Paschos G, Liakos GK, Velissaridou AH, Anastasiadis G and Zampelas A. Dietary alphalinolenic acid decreases C-reactive protein, serum amyloid $A$ and interleukin- 6 in dyslipidaemic patients. Atherosclorosis 2003; 167: 237-42.

17. Madsen $T$, Christensen JH, Blom M and Schmidt EB. The effect of dietary $n-3$ fatty acids on serum concentrations of C-reactive protein; a dose-response study. Br J Nutr 2003; 89:517-22.

18. Thijssen MA and Mensink RP. Small differences in the effects of stearic acid, oleic acid and linoleic acid on the serum lipoprotein profile of humans. Am J Cin Nutr 2005; 82: 510-6.

19. Harris $\mathrm{J}$ and Benedict $F$. A biometric study of basal metabolism in man. Carnegie Institute of Washington. Washington, 1919.

20. Basu $S$. Radioimmunoassay of 8-iso-prostaglandin F2alpha: an index for oxidative injury via free radical catalysed lipid peroxidation. Prostaglandins Leukot Essent Fatty Acids 1998: 58: 319m25.

21. Huddleston DJ, Deitrick $C L$, Budrean SA and Katholi RE. Performance characteristics of an automated method for high-sensitivity CRP on the Roche cobas mira analyzer. JALA 2001; 6: 32-3.

22. Patrono $C$. Falco $A$ and Davi $G$. Isoprostane formation and inhibition in atherothrombosis. Curr Opin Pharmacol 2005; 5: 198-203. 
23. Higdon JV, Liu J, Du SH, Morrow JD, Ames BN and Wander RC. Supplementation of postmenopausal women with fish oil rich in eicosapentaenoic acid and docosahexaenoic acid is not associated with greater in vivo lipid peroxidation compared with oils rich in oleate and linoleate as assessed by plasma malondialdehyde and F(2)-isoprostanes. Am J Clin Nutr 2000; 72; 714-22.

24. Sodergren $E$, Gustafsson $I B, B a s u S$, Nourooz-Zadeh $J$, Nalsen $C$, Turpeinen $A$, Berglund $L$ and Vessby B. A diet containing rapeseed oil-based fats does not increase lipid peroxidlation in humans when compared to a diet rich in saturated fatty acids. Eur J Clin Nutr 2001; 55: 922-31.

25. Tholstrup $T$, Hellgren $L I$, Petersen M, Basu $S$, Straarup EM, Schnohr P and Sandstrom B. A solid dietary fat containing fish oil redistributes lipoprotein subclasses without increasing oxidative stress in men. I Nutr 2004; 134: $1051-7$.

26. Riserus U, Basu $S$, Jovinge S, Fredrikson GN, Arnlov J and Vessby B. Supplementation with conjugated linoleic acid causes isomer-dependent oxidative stress and elevated C-reactive protein: a potential link to fatty acid-induced insulin resistance. Circulation 2002; 106: 1925-9.

27. Kratz $M$, Cullen $P$, Kannenberg $F$, Kassner A, Fobker $M$, Abuja $P M_{8}$ Assmann $G$ and Wahrburg $U$. Effects of dietary fatty acids on the composition and oxidizability of low-density lipoprotein. Eur $J$ Clin Nutr 2002; 56: 72-81.

28. Bonanome A, Pagnan A, Biffanti S, Opportuno A, Sorgato $F$, Dorella M, Maiorino $M$ and Ursini $F$. Effect of dietary monounsaturated and polyunsaturated fatty acids on the susceptibility of plasma low density lipoproteins to oxidative modification. Arterioscler Thromb 1992; 12: 529-33.

29. Reaven P, Parthasarathy S, Grasse BJ, Miller E, Almazan F, Mattson FH, Khoo JC, Steinberg D and Witztum JL. Feasibility of using an oleate-rich diet to reduce the susceptibility of low-density lipoprotein to oxidative modification in humans. Am J Clin Nutr 1991; 54: 701-6.

30. Berry EM, Eisenberg $S$. Haratz $D$, Friedlander $Y$, Norman $Y$, Kaufmann NA and Stein $Y$. Effects of diets rich in monounsaturated fatty acids on plasma lipoproteins--the Jerusalem Nutrition Study: high MUFAs vs high PUFAs. Am J Clin Nutr 1991; 53: 899-907.

31. Mensink RP, Aro A, Den Hond E, German JB, Griffin BA, Ten Meer HU, Mutanen Mr Pannemans D and StahI W. PASSCLAIM - Diet-related cardiovascular disease. Eur J Nutr 2003; 42 Suppl 1: 16 $\| 27$.

32. Geelen $A$, Brouwer IA, Schouten $E G$, Kluft $C$, Katan MB and Zock PL. Intake of $18-3$ fatty acids from fish does not lower serum concentrations of $\mathrm{C}$-reactive protein in healthy subjects. Eur I Clin Nutr 2004; 58: 1440-2.

33. Baer DJ, Judd JT, Clevidence BA and Tracy RP. Dietary fatty acids affect plasma markers of inflammation in healthy men fed contralled diets: a randiomized crossover study. Am J Clin Nutr 2004; 79: 969-73.

34. Huang RP, Huang $R$, Fan $Y$ and $L$ in $Y$. Simultaneous detection of multiple cytokines from conditioned media and patient's sera by an antibody-based protein array system. Anal Biochem 2001; 294: 55-62. 


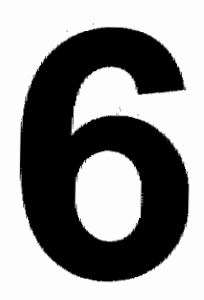

\section{Effects of specific CLA isomers on plasma fatty acid profile and expression of desaturases in} humans

Myriam A.M.A. Thijssen ${ }^{1}$, Corinne Malpuech-Brugère ${ }^{2}$, Stéphane Gregoire ${ }^{3}$, Jean Michel Chardigny ${ }^{3}$, Jean Louis Sébédio ${ }^{3}$, and Ronald P. Mensink ${ }^{4}$

Lipids 2005; 40(2): 137-145

"Nutrition and Toxicology Research Institute (NUTRIM), Department of Human Biology, Maastricht University, Maastricht, The Netherlands

${ }^{2}$ Unité du Métabolisme Protéino-Energétique, INRA, Clermont Ferrand, France

${ }^{3}$ Unité de Nutrition Lipidique, INRA, Dijon, France 


\section{ABSTRACT}

Hurnan studies suggest that conjugated linoleic acid changes fatty acid metabolism, possibly through effects on MRNA expression of desaturase and elongase enzymes. In this respect, differential effects of the two most common dietary CLA isomers, cis-9, trans-11 (c9,t11) and trans-10, cis-12 (t10,c12) CLA, have hardly been studied. We therefore gave 25 healthy, overweight men and women daily for 6 weeks a drinkable dairy product containing $3 \mathrm{~g}$ of oil that was rich in oleic acid. For the next 18 weeks, the control group $(n=7)$ continued to use this product, whereas the second $(n=9)$ and third groups $(n=9)$ received products with $3 \mathrm{~g}$ of purified $c 9, t 11$ CLA or $t 10, c 12$ CLA. For each g of $c 9, t 11$ CLA consumed, its proportion in plasma phospholipids increased by $0.26 \%$. For $\$ 10, c 12$ CLA, this value was $0.20 \%$. The $110, c 12$ CLA isomer increased plasma triacylglycerol levels of conjugated C18:3, whereas $C 9, t 11$ CLA increased those of both conjugated $C 18: 3$ and $C 20: 3$. In plasma phospholipids, the $\triangle 9$ desaturation index of C18:0 (C18:1n-9/C18:0) was decreased by $110, c 12 C L A$ ( $P=0.03$ for diet effects), and the $\triangle 6$ desaturation index ((C18:3n-6+C20:3n-6)/C18:2n-6) was decreased by both CLA isomers $(P<0.01$ for diet effects). The 45 desaturation index (C20:4n-6/C20:3n-6) and the 49 desaturation index of $\mathrm{C16:0}$ (C16:1n-7/C16:0) were not affected. No effects were seen on MRNA expression of desaturases and elongase in peripheral blood mononuclear cells (PBMC). We therefore conclude that incorporation of $c 9, t 11$ and $\$ 10, c 12 C L A$ into plasma lipids reflects dietary intakes. Compared with oleic acid, $\triangle 9$ and 46 desaturation indices in plasma phospholipids are decreased after consumption of $c 9, t 11$ or $t 10, c 12 C L A$. Effects on desaturation indices were, however, not reflected by changes at the transcriptional level for the various desaturases and elongase enzymes in PBMC. 


\section{INTRODUCTION}

Conjugated linoleic acid (CLA) refers to a group of positional and geometrical isomers of linoleic acid containing conjugated double bonds. Cis-9, trans-11 (c9, t11) CLA is the most common CLA isomer in nature and is present in ruminant products, whereas commercially available capsules enriched with CLA also contain other isomers like trans-10, cis-12 $(t 10, c 12)$ CLA (1). Because of their postulated health benefits $(2,3)$, dietary supplements with CLA are now widely available. To explain these health effects "several mechanisms have been proposed, including regulation of genes coding for enzymes known to modulate lipid and fatty acid metabolism such as desaturases $(2,4)$.

Desaturases are involved in the formation of long-chain metabolites from precursor fatty acids like stearic, linoleic, and $\alpha$-linolenic acids. Studies in mice and rats have indeed reported that CLA, mainly the $t 10, c 12$ isomer, suppressed $\Delta 9$ desaturase mRNA expression or enzyme activity (5-7). Moreover, the $c 9, t 11$ isomer decreased $\Delta 6$ desaturase activity in liver microsomes (5). In cell culture studies, effects of $t 10, c 12$ CLA on $\Delta 9$ desaturase activity were confirmed in a human hepatoma-derived cell line (HepG2) $(8,9)$. However, effects of $c 9, t 11$ CLA on desaturase activities are inconsistent $(8,9)$. Furthermore, effects of both CLA isomers at the mRNA expression level of desaturases have hardly been studied. As desaturation products play an important role in many processes including eicosanoid production, lipid metabolism, and immune function $(2,3)$, inhibition of desaturation may influence health. Most human studies, however, have been carried out using a mixture of CLA isomers and have not focused on specific effects of the major CLA isomers (10-12). Isomer-specific effects of CLA, as observed in animal studies, may explain conflicting results in humans $(4,13)$. Therefore, to examine whether $c 9, t 11$ CLA and $t 10, c 12$ CLA affect desaturation differently in humans, we investigated the effects of these two CLA isomers on the fatty acid compositions of plasma phospholipids (PL), cholesteryl esters (CE), and triacylglycerols (TAG). In addition, effects on mRNA expression of $\Delta 9, \Delta 6$, and $\Delta 5$ desaturases and of elongase by peripheral blood mononuclear cells (PBMC) were studied. Recently, the human $\Delta 5$ (14), $\Delta 6(15)$, and $\Delta 9$ (16) desaturase, and elongase (17) genes have been characterised and reverse transcription quantitative PCR (RT-qPCR) protocols were developed based upon the desaturase and elongase gene sequences. 


\section{EXPERIMENTAL PROCEDURES}

\section{Subjects}

Healthy male and female volunteers were recruited via advertisements in local newspapers. Interested people were informed about the purposes and requirements of the study and had to give their written informed consent before they entered the screening procedure. This procedure consisted of two fasting blood samples for analysis of serum lipids and lipoproteins, hematological parameters, C-reactive protein, and liver and kidney functions, measurement of blood pressure, and collection of a morning urine specimen for analysis of glucose. Participants had to meet all of the eligibility criteria: aged 35-65 y, body mass index between 25 and 30 $\mathrm{kg} / \mathrm{m}^{2}$, diastolic blood pressure below $95 \mathrm{mmHg}$ and systolic blood pressure below $160 \mathrm{mmHg}$, fasting serum total cholesterol concentrations less than $7.0 \mathrm{mmol} / \mathrm{L}$, serum triacylglycerol concentrations below $3.0 \mathrm{mmol} / \mathrm{L}$, and plasma glucose below $6.0 \mathrm{mmol} / \mathrm{L}$. Furthermore, subjects were apparently healthy as indicated by a medical questionnaire, not pregnant, and weight stable during the past 3 months; had no history of atherosclerotic disease or malignancy within the past $5 y$, normal liver and kidney function, no glycosuria or anemia, no abuse of drugs or alcohol, and no use of any medication known to affect lipid or glucose metabolism. Blood donation or participation in another biomedical trial was not allowed within 4 weeks before the start of the study or during the study.

The Medical Ethics Committee of the Maastricht University had approved the study protocol. This study was part of a multicenter study as reported elsewhere (18). For 25 subjects of the placebo group and the high-dose CLA groups of the Maastricht cohort, desaturase expression in PBMC and fatty acid compositions of plasma lipids were analysed. During the screening period, their body mass indexes ranged from 24.4 to $30.5 \mathrm{~kg} / \mathrm{m}^{2}$ (mean $27.4 \mathrm{~kg} / \mathrm{m}^{2}$ ). The subjects' fasting serum lipid levels ranged from 3.2 to $6.8 \mathrm{mmol} / \mathrm{L}$ for total cholesterol (mean $5.0 \mathrm{mmol} / \mathrm{L}$ ), from 0.8 to $2.8 \mathrm{mmol} / \mathrm{L}$ for $\mathrm{HDL}$ cholesterol (mean $1.2 \mathrm{mmol} / \mathrm{L}$ ), and from 0.4 to 2.4 $\mathrm{mmol} / \mathrm{L}$ for triacylglycerols (mean $1.2 \mathrm{mmol} / \mathrm{L}$ ).

\section{Study design}

The study had a randomised, double-blind, placebo-controlled, parallel design. During the first 6 weeks of the trial (run-in period), all volunteers consumed daily a dietary supplement providing $3 \mathrm{~g}$ of high-oleic sunflower oil (placebo). After the runin period, subjects were randomly allocated to one of the three treatment groups. For the next 18 weeks of the study (intervention period), one group $(n=7)$ continued to consume the placebo dairy product daily. The second $(n=9)$ and third $(n=9)$ 
groups consumed the dairy product with $3 \mathrm{~g}$ of purified $c 9, t 11$ CLA or $3 \mathrm{~g}$ of $t 10, c 12$ CLA, respectively.

Dietary supplements containing CLA were provided as an acidified drinkable dairy product produced by Danone (Palaiseau, France) as described earlier (18). The two different isomers of CLA, $c 9, t 11$ CLA and $t 10, c 12$ CLA, were incorporated as a triacylglycerol in the dairy drinks and were produced by Natural Lipids Ltd (Hovdebygda, Norway). Different flavours were addled to the products. The placebo product used during the run-in period had a different flavour from the one used during the intervention period. Bottles were packaged in boxes of 14 .

Participants consumed one bottle daily $(100 \mathrm{~mL})$ of this dietary supplement between lunch and dinner. In a diary, participants had to record the daily time of consumption of the supplements and to note any signs of illness, medication used, alcohol consumption and any deviations from the study protocol. Subjects were urged not to change their habitual diet, level of physical exercise, smoking habits, or use of alcohol during the study. Volunteers visited the university at least once every two weeks to receive a new supply of supplements. Supplements that were left over had to be returned and were counted as a measure of compliance. Compliance was also checked by analysis of the fatty acid composition of plasma phospholipids. Furthermore, at each visit a dietician checked the diary.

\section{Blood sampling}

Blood samples were obtained at the end of the run-in period (week 6) and at the end of the intervention period (week 24) after an overnight fast. Moreover, participants were instructed not to use alcohol during the previous day and not to smoke on the morning before blood sampling. Venous blood was sampled using a vacutainer system with the volunteer in recumbent position. For RNA isolation from PBMC, blood was collected into two EDTA tubes and kept on ice until leukocyte isolation. In addition, one EDTA tube was collected to obtain plasma for analysis of the fatty acid composition of plasma lipids. This tube was centrifuged within 1 hour after venipuncture at $3500 \times \mathrm{g}$ for $30 \mathrm{~min}$ at $4^{\circ} \mathrm{C}$. Plasma samples were snap-frozen in liquid nitrogen and stored at $-80^{\circ} \mathrm{C}$.

\section{Leukocyte isolation}

PBMC were isolated from blood by gradient centrifugation using Lymphoprep (Nycomed Ltd, Birmingham, United Kingdom). Before isolation of PBMC, blood was diluted by addition of an equal volume of Hanks' balanced salt solution (HBSS, Gibco BRL, Life Technologies, Breda, The Netherlands). Then 2 volumes of diluted blood were layered over 1 volume of Lymphoprep in a $50-\mathrm{mL}$ centrifuge tube 
(Greiner Bio-One; Alphen a/d Rijn. The Netherlands). After centrifugation at $800 \times \mathrm{g}$ for $30 \mathrm{~min}$ at $4^{\circ} \mathrm{C}$, the interphase containing PBMC was transferred into a new 50 $\mathrm{mL}$ centrifuge tube. PBMC were washed with an equal volume of HBSS and centrifuged for 10 minutes at $250 \times \mathrm{g}$ at $4^{\circ} \mathrm{C}$. The cell pellet was resuspended in 1.5 $\mathrm{mL}$ Trizol reagent (Gibco BRL, Gaithersburg, MD, United States) and transferred into an RNase-free $2 \mathrm{~mL}$ tube (Eppendorf, Hamburg, Germany).

\section{RNA preparation}

Total RNA from PBMC was prepared according to the manufacturer's instructions of the Trizol reagent (Gibco BRL). Briefly, $300 \mu \mathrm{L}$ chloroform was added to separate phases. After incubation for 2-3 $\mathrm{min}$ at room temperature and centrifugation for 15 min at $12000 \times g\left(4^{\circ} \mathrm{C}\right)$, the water phase, containing the RNA, was pipetted into a clean RNase-free tube. Then, the RNA was precipitated by addition of $750 \mu \mathrm{L}$ isopropanol. After incubation for $20 \mathrm{~min}$ at $-80^{\circ} \mathrm{C}$ and centrifugation for $10 \mathrm{~min}$ at $12000 \times g\left(4^{\circ} \mathrm{C}\right)$, the RNA pellet was washed twice with $75 \%$ ethanol. In each washing step, the samples were centrifuged for $5 \mathrm{~min}$ at $7500 \times g\left(4^{\circ} \mathrm{C}\right)$. Finally, RNA was dried and dissolved in $50 \mu \mathrm{L}$ RNase-free water by incubation at $55-60^{\circ} \mathrm{C}$ for 10 min. Subsequently both RNA samples were pooled and further purified using the RNeasy mini kit (Qiagen, Leusden, The Netherlands). During this purification procedure, RNA was treated on-column with DNase (RNase-free DNase set, Qiagen) as described in the manufacturer's protocol. Before storage at $-80^{\circ} \mathrm{C}$, the RNA concentrations were measured spectrophotometrically at $260 \mathrm{~nm}$. All RNA preparations must have an A260/A280 ratio of $>1.8$ to ensure RNA purity.

\section{cDNA synthesis}

Aliquots of $350 \mathrm{ng}$ of total cellular RNA were reverse-transcribed. All samples were denatured for $5 \mathrm{~min}$ at $85^{\circ} \mathrm{C}$. Reverse transcription of RNA was performed in $40 \mu \mathrm{L}$ RT mixture containing first strand buffer, $10 \mathrm{mmol} / \mathrm{L}$ DTT, $400 \mathrm{U}$ M-MLV reverse transcriptase, $20 \mathrm{U}$ ribonuclease inhibitor (all provided by Gibco BRL), $5 \mu \mathrm{mol} / \mathrm{L}$ random hexamers (Applied Biosystems, Nieuwerkerk a/d ljssel, The Netherlands) and $375 \mu \mathrm{mol} / \mathrm{L}$. deoxynucleotides (Amersham Pharmacia Biotech, Woerden, The Netherlands). After hexanucleatides had been annealled for $10 \mathrm{~min}$ at $22^{\circ} \mathrm{C}, \mathrm{cDNA}$ synthesis was performed for $90 \mathrm{~min}$ at $37^{\circ} \mathrm{C}$, followed by an enzyme inactivation step for 3 min at $95^{\circ} \mathrm{C}$. Finally, cDNA was rapidly chilled to $4^{\circ} \mathrm{C}$ and stored at $-20^{\circ} \mathrm{C}$ until use. 


\section{Reverse transcription quantitative PCR (RT-qPCR)}

A RT-qPCR protocol was developed for the quantification of the human housekeeping gene $\beta$-actin and desaturase and elongase enzymes. Primers and probe for the desaturase and elongase assays were derived from Genbank sequence NM_013402 for $\Delta 5$ desaturase (fatty acid desaturase 1), NM_004265 for $\Delta 6$ desaturase (fatty acid desaturase 2), NM_005063 for $\Delta 9$ desaturase (stearoylCoA desaturase) and NM_021814 for elongase (ELOVL5) using Primer Express 1.5 software (Applied Biosystems). To prevent pseudogene amplification of $\Delta 9$ desaturase, a minor groove binder (MGB) probe was developed to anneal specifically to the cDNA strand of the functional gene. Primer and probe sequences for $\beta$-actin were identical to those described by Kreuzer et al (19) and those for $\Delta 6$ desaturase similar as described by Leonard et al (20). All probes were dual-labelled with a fluorescent FAM reporter dye at the $5^{\prime}$ end and a TAMRA quencher dye (or a non-fluorescent quencher and MGB for $\Delta 9$ desaturase) at the $3^{\prime \prime}$ end. Primer and probe sequences are listed in Table 6.1.

Table 6.1 Primer and probe sequences for reverse transcription quantitative PCR.

\begin{tabular}{|c|c|c|c|}
\hline $\begin{array}{l}\text { Target } \\
\text { sequence }\end{array}$ & Primer or probe & Sequence $\left(5^{\prime}-3^{\prime}\right)$ & $\begin{array}{l}\text { Amplicon } \\
\text { length (bp) }\end{array}$ \\
\hline B-Actin & $\begin{array}{l}\text { B-Actin forward } \\
\beta \text {-Actin reverse } \\
\beta \text {-Actin probe }\end{array}$ & $\begin{array}{l}\text { agc ctc gcc ttt gcc ga } \\
\text { ccg ccg ccc gtc cac acc cgc c } \\
\text { ctg gtg cot ggg gcg }\end{array}$ & 176 \\
\hline $\begin{array}{l}\Delta 5 \\
\text { Desaturase }\end{array}$ & $\begin{array}{l}\Delta 5 \text { Desaturase forward } \\
\Delta 5 \text { Desaturase reverse } \\
\triangle 5 \text { Desaturase probe }\end{array}$ & $\begin{array}{l}\text { ggt gta caa cat cag cga gtt ca } \\
\text { aat cag gag aga gtt cat ata ctt ctt cac } \\
\text { cag gat gcc acg gat ccc ttt gtg }\end{array}$ & 148 \\
\hline $\begin{array}{l}\Delta 6 \\
\text { Desaturase }\end{array}$ & $\begin{array}{l}\triangle 6 \text { Desaturase forward } \\
\triangle 6 \text { Desaturase reverse } \\
\triangle 6 \text { Desaturase probe }\end{array}$ & $\begin{array}{l}\text { tgg caa tgg ctg gat tcc ta } \\
\text { cag ctt ggg cct gag agg t } \\
\text { cct cat cac ggc ctt tgt cct tgc }\end{array}$ & 65 \\
\hline $\begin{array}{l}\Delta 9 \\
\text { Desaturase }\end{array}$ & $\begin{array}{l}\Delta 9 \text { Desaturase forward } \\
\Delta 9 \text { Desaturase reverse } \\
\Delta 9 \text { Desaturase probe }\end{array}$ & $\begin{array}{l}\text { gcc ctg tat ggg atc act ttg a } \\
\text { acg atg agc tcc tgc tgt tat } g \\
\text { cta cot gca agt tct aca }\end{array}$ & 108 \\
\hline Elongase & $\begin{array}{l}\text { Elongase forward } \\
\text { Elongase reverse } \\
\text { Elongase probe }\end{array}$ & $\begin{array}{l}\text { aac agg agt atg gga agg caa a } \\
\text { gga cac gga taa tct tca tat ctg att } \\
\text { ctt ctg tca ggg cac acg cac cg }\end{array}$ & 86 \\
\hline
\end{tabular}

Thirty-five ng of cDNA was amplified in a total reaction volume of $25 \mu \mathrm{L}$ containing $12.5 \mu \mathrm{L}$ universal master mix (Applied Biosystems), $7.5 \mathrm{pmol}$ of each primer and 5 pmol probe. PCR reactions were performed in an optical 96-well reaction plate (Applied Biosystems) on an ABI PRISM 7000 Sequence Detection System (Applied 
Table 6.2 Incorporation of CLA isomers and its metabolites into plasma phospholipids at the end of the run-in period and at the end of the experimental period.

\begin{tabular}{|c|c|c|c|c|c|c|}
\hline \multirow[b]{2}{*}{ Fatty acid } & \multicolumn{3}{|c|}{ Run-in period ${ }^{1,2}$} & \multicolumn{3}{|c|}{ Experimental period $^{1,2}$} \\
\hline & Placebo & C9, $t 11$ & $T 10, c 12$ & Placebo & $C 9, t 11$ & $T 10, c 12$ \\
\hline & \multicolumn{6}{|c|}{$\%$ of total fatty acids ( $w / W$ ) } \\
\hline & $n=6$ & $n=8$ & $n=6$ & $n=6$ & $n=8$ & $n=6$ \\
\hline$C 9, t 11$ & $0.15 \pm 0.06$ & $0.11 \pm 0.05$ & $0.11 \pm 0.04$ & $0.16 \pm 0.05^{a}$ & $0.88 \pm 0.40^{\mathrm{b}}$ & $0.22 \pm 0.06^{\mathrm{a}}$ \\
\hline$T 10, c 12$ & ND & ND & ND & $N D^{a}$ & $0.03 \pm 0.05^{\mathrm{a}}$ & $0.61 \pm 0.27^{b}$ \\
\hline$C, C$ CLA & ND & ND & ND & $N D^{a}$ & $0.01 \pm 0.00^{6}$ & $N^{a}$ \\
\hline$T, t$ CLA & ND & ND & ND & $N D^{a}$ & $0.02 \pm 0.01^{b}$ & $0.02 \pm 0.01^{b}$ \\
\hline$t 11 \mathrm{C} 18: 1$ & $0.34 \pm 0.11$ & $0.34 \pm 0.13$ & $0.27 \pm 0.10$ & $0.31 \pm 0.11$ & $0.25 \pm 0.07$ & $0.23 \pm 0.02$ \\
\hline Conjugated $\mathrm{C} 18: 3$ & ND & ND & ND & ND & ND & ND \\
\hline Conjugated $\mathrm{C} 20: 3$ & ND & ND & ND & ND & ND & ND \\
\hline
\end{tabular}

Values are means \pm standerd deviations. $N D$, not detectable $(<0.01 \%$. For statistical analysis, not detectable values were set at zero.

${ }^{2}$ Values in a row without a common superscript differ from each other $(P<0.017)$,

Table 6.3 incorporation of CLA isomers and its metabolites into plasma cholesteryl esters and triacylg/ycerols at the end of the experimental period.

\begin{tabular}{|c|c|c|c|c|c|c|}
\hline \multirow[b]{2}{*}{ Fatty acid } & \multicolumn{3}{|c|}{ Cholesteryl esters, ${ }^{1,2}$} & \multicolumn{3}{|c|}{ Triacylglycerols $^{1,2}$} \\
\hline & Placebo & $C 9,+11$ & $T 10, c 12$ & Placebo & $C 9, t 11$ & $T 10, c 12$ \\
\hline & \multicolumn{6}{|c|}{$\%$ of total fatty acids ( $w / w)$} \\
\hline & $n=6$ & $n=7$ & $n=6$ & $n=6$ & $n=7$ & $n=6$ \\
\hline$C 9, t 11$ & $0.12 \pm 0.05^{\mathrm{a}}$ & $0.61 \pm 0.24^{b}$ & $0.16 \pm 0.05^{a}$ & $0.34 \pm 0.09^{a}$ & $1.16 \pm 0.33^{b}$ & $0.42 \pm 0.13^{a}$ \\
\hline$T 10, C 12$ & $N D^{a}$ & $0.04 \pm 0.02^{a t}$ & $0.42 \pm 0.18^{\mathrm{b}}$ & $N D^{a}$ & $0.06 \pm 0.02^{\mathrm{a}}$ & $0.53 \pm 0.27^{b}$ \\
\hline $\mathrm{C}, c \mathrm{CLA}$ & $N D^{a}$ & $0.02 \pm 0.01^{6}$ & $N D^{a}$ & $N^{a}$ & $0.02 \pm 0.02^{b}$ & $0.01 \pm 0.01^{a}$ \\
\hline$T, t C L A$ & $N D^{a}$ & $0.03 \pm 0.01^{b}$ & $0.02 \pm 0.01^{b}$ & $N D^{a}$ & $0.04 \pm 0.02^{b}$ & $0.03 \pm 0.01^{t}$ \\
\hline $111 \mathrm{C} 18: 1$ & ND & ND & ND & $1.55 \pm 0.83^{\mathrm{a}}$ & $0.81 \pm 0.29^{b}$ & $0.97 \pm 0.05^{\mathrm{ab}}$ \\
\hline Conjugated $\mathrm{C} 18: 3$ & $N^{a}$ & $N D^{a}$ & $0.03 \pm 0.01^{b}$ & $N^{a}$ & $0.05 \pm 0.04^{\mathrm{a}}$ & $0.20 \pm 0.12^{b}$ \\
\hline Conjugated $\mathrm{C} 20: 3$ & ND & ND & ND & $N D^{a}$ & $0.03 \pm 0.03^{b}$ & $0.00 \pm 0.00^{\mathrm{a}}$ \\
\hline
\end{tabular}

Values are means \pm standard deviations. ND, not detectable $(<0.01 \%$. For statistical analysis, not detectable values were set at zero.

${ }^{2}$ For each lipid class, values in a row without a common superscript differ from each other $(P<0,017)$.

\section{Fatty acid compositions of plasma lipid classes}

At baseline, only the proportion of Mead acid (C20:3n-9) in PL was significantly different between the three diet groups $(P=0.048$ for differences between the three groups). Supplementation of CLA isomers resulted in decreases in the proportions of oleic acid (C18:1n-9), C16:1n-9, C20:3n-9 and dihomo-y-linolenic acid (C20:3n-6) in one or more plasma lipid classes (Tables 6.4 and 6.5). Although these decreases were more pronounced in the $t 10,012$ group, differences between the two CLA 
groups never reached statistical significance. The decreases were compensated for by increases in linoleic acid $(C 18: 2 n-6)$ and CLA. In CE ( $P=0.029$ for diet effects), the proportions of C18:2n-6 were higher in the t10,c12 CLA group than in the $c 9, t 11$ $C L A(P=0.044)$ and the placebo group $(P=0.011)$. Moreover, in TAG $(P=0.017$ for diet effects), proportions of C18:2n-6 were higher in both CLA intervention groups $(P=0.038$ for $c 9, t 11$ and $P<0.01$ for $t 10, c 12)$ than in the placebo group.

Table 6.4 Fatty acid composition of plasma phospholipids at the end of the run-in period and at the end of the experimental period.

\begin{tabular}{|c|c|c|c|c|c|c|}
\hline \multirow[b]{2}{*}{ Fatty acid } & \multicolumn{3}{|c|}{ Run-in period ${ }^{1,2}$} & \multicolumn{3}{|c|}{ Experimental period $^{1,2}$} \\
\hline & Placebo & $c 9, t \| 1$ & $T 10, c 12$ & Placebo & $C 9, t 11$ & $T 10, c 12$ \\
\hline & \multicolumn{6}{|c|}{$\%$ of total fatty acids $(w / w)$} \\
\hline & $n=6$ & $n=8$ & $n=6$ & $n=6$ & $n=8$ & $n=6$ \\
\hline C16:0 & $28.73 \pm 1.24$ & $28.53 \pm 1.67$ & $27.98 \pm 0.95$ & $28.51 \pm 1.71$ & $28.05 \pm 1.68$ & $28.32 \pm 1.38$ \\
\hline C16:1n-9 & $0.24 \pm 0.04$ & $0.22 \pm 0.04$ & $0.20 \pm 0.01$ & $0.24 \pm 0.03^{\mathrm{a}}$ & $0.20 \pm 0.03^{b}$ & $0.18 \pm 0.03^{6}$ \\
\hline Ci6:1n-7 & $0.64 \pm 0.19$ & $0.67 \pm 0.27$ & $0.54 \pm 0.13$ & $0.66 \pm 0.19$ & $0.58 \pm 0.21$ & $0.45 \pm 0.05$ \\
\hline C18:0 & $15.42 \pm 0.50$ & $15.20 \pm 1.11$ & $14.62 \pm 1.57$ & $14.99 \pm 0.74$ & $15.11 \pm 0.72$ & $15.21 \pm 0.84$ \\
\hline C18:1n-9 & $10.80 \pm 1.13$ & $11.24 \pm 1.58$ & $9.51 \pm 1.22$ & $10.75 \pm 1.62$ & $9.77 \pm 0.69$ & $9.01 \pm 1.09$ \\
\hline C18:1n-7 & $1.53 \pm 0.24$ & $1.45 \pm 0.17$ & $1.38 \pm 0.16$ & $1.40 \pm 0.17$ & $1.44 \pm 0.25$ & $1.29 \pm 0.16$ \\
\hline$C 18: 2 n-6$ & $21.12 \pm 2.25$ & $22.12 \pm 2.58$ & $22.31 \pm 1.61$ & $20.97 \pm 2.03$ & $22.21 \pm 2.49$ & $23.50 \pm 1.96$ \\
\hline$C 18: 3 n-6$ & $0.09 \pm 0.05$ & $0.11 \pm 0.05$ & $0.09 \pm 0.05$ & $0.10 \pm 0.03$ & $0.08 \pm 0.06$ & $0.03 \pm 0.04$ \\
\hline$C 18: 3 n-3$ & $0.19 \pm 0.04$ & $0.21 \pm 0.07$ & $0.14 \pm 0.03$ & $0.22 \pm 0.02$ & $0.23 \pm 0.07$ & $0.22 \pm 0.07$ \\
\hline C20:3n-9 & $0.25 \pm 0.14^{\mathrm{a}}$ & $0.14 \pm 0.03^{b}$ & $0.14 \pm 0.04^{b}$ & $0.22 \pm 0.09^{\mathrm{a}}$ & $0.12 \pm 0.04^{\mathrm{b}}$ & $0.10 \pm 0.03^{b}$ \\
\hline$C 20: 3 n-6$ & $3.81 \pm 0.85$ & $3.10 \pm 0.91$ & $3.66 \pm 0.71$ & $3.93 \pm 0.67^{a}$ & $2.91 \pm 0.96^{b}$ & $2.65 \pm 0.40^{b}$ \\
\hline$C 20: 4 n-6$ & $9.98 \pm 1.35$ & $9.61 \pm 1.95$ & $11.37 \pm 0.51$ & $10.35 \pm 2.15$ & $10.51 \pm 1.54$ & $10.50 \pm 1.60$ \\
\hline$c 20 \cdot 5 n-3$ & $0.89 \pm 0.42$ & $0.95 \pm 0.38$ & $0.99 \pm 0.41$ & $0.94 \pm 0.34$ & $0.96 \pm 0.50$ & $0.91 \pm 0.46$ \\
\hline$C 22: 4 n-6$ & $0.38 \pm 0.05$ & $0.33 \pm 0.09$ & $0.38 \pm 0.12$ & $0.41 \pm 0.02$ & $0.40 \pm 0.07$ & $0.42 \pm 0.16$ \\
\hline$C 22: 5 n-6$ & $0.18 \pm 0.03$ & $0.13 \pm 0.04$ & $0.16 \pm 0.05$ & $0.20 \pm 0.03$ & $0.16 \pm 0.03$ & $0.19 \pm 0.08$ \\
\hline$C 22: 5 n-3$ & $0.90 \pm 0.16$ & $0.82 \pm 0.18$ & $0.95 \pm 0.09$ & $0.96 \pm 0.15$ & $1.01 \pm 0.17$ & $1.01 \pm 0.19$ \\
\hline$C 22: 6 n-3$ & $2.40 \pm 0.48$ & $2.85 \pm 0.59$ & $3.42 \pm 0.90$ & $2.79 \pm 0.93$ & $3.34 \pm 0.95$ & $3.10 \pm 0.90$ \\
\hline
\end{tabular}

${ }^{7}$ Values are means \pm standard deviations.

${ }^{2}$ Values in a row without a common superscript differ from each other $(P<0.017)$. 
Table 6.5 Fatty acid composition of plasma cholesteryl esters and triacylglycerols at the end of the experimental period.

\begin{tabular}{|c|c|c|c|c|c|c|}
\hline \multirow[b]{2}{*}{ Fatty } & \multicolumn{3}{|c|}{ Cholesteryl esters ${ }^{1,2}$} & \multicolumn{3}{|c|}{ Triacylglycerols ${ }^{1,2}$} \\
\hline & Placebo & $\mathrm{Cg}_{,} \mathrm{t11}$ & $T 10, c 12$ & Placebo & $C_{9, t 11}$ & $T 10, c 12$ \\
\hline & \multicolumn{6}{|c|}{$\%$ of total fatty acids $(w / w)$} \\
\hline & $n=6$ & $n=7$ & $n=6$ & $n=6$ & $n=7$ & $n=6$ \\
\hline $\mathrm{C} 16: 0$ & $10.82 \pm 1.02$ & $10,81 \pm 0.98$ & $9.89 \pm 0.79$ & $29.00 \pm 4.14$ & $28.52 \pm 4.49$ & $25.84 \pm 2.54$ \\
\hline $\mathrm{C} 16: 1 \mathrm{n}-9$ & $0.50 \pm 0.12^{\mathrm{a}}$ & $0.40 \pm 0.11^{\mathrm{ab}}$ & $0.32 \pm 0.04^{b}$ & $0.96 \pm 0.14$ & $0.81 \pm 0.22$ & $0.83 \pm 0.09$ \\
\hline C. $16: \ln -7$ & $3.30 \pm 1.20$ & $2.74 \pm 1.12$ & $2.12 \pm 0.34$ & $4.26 \pm 0.87$ & $3.68 \pm 1.20$ & $3.28 \pm 0.62$ \\
\hline $\mathrm{C} 18: 0$ & $0.60 \pm 036$ & $0.78 \pm 0.14$ & $0.75 \pm 0.16$ & $4.12 \pm 0.96$ & $4.26 \pm 0.99$ & $3.72 \pm 0.57$ \\
\hline C18:1n-9 & $20.07 \pm 2.14^{a}$ & $18.21 \pm 1.53^{\mathrm{ab}}$ & $16.98 \pm 2.19^{b}$ & $36.76 \pm 2.48$ & $33.18 \pm 4.27$ & $34.51 \pm 4.30$ \\
\hline C18:1n-7 & $1.10 \pm 0.39$ & $1.49 \pm 0.43$ & $1.11 \pm 0.33$ & $3.17 \pm 0.79$ & $2.74 \pm 0.48$ & $3.00 \pm 0.27$ \\
\hline$C 18: 2 n-6$ & $51.29 \pm 4.83^{a}$ & $52.84 \pm 2.96^{a}$ & $57.18 \pm 2.62^{b}$ & $12.37 \pm 4.39^{\mathrm{a}}$ & $16.67 \pm 3.52^{b}$ & $18.68 \pm 1.85^{b}$ \\
\hline$C 18: 3 n-6$ & $1.23 \pm 0.45$ & $1.06 \pm 0.40$ & $0.83 \pm 0.34$ & $0.30 \pm 0.15$ & $0.32 \pm 0.13$ & $0.34 \pm 0.24$ \\
\hline C18:3n-3 & $0.63 \pm 0.07$ & $0.64 \pm 0.10$ & $0.61 \pm 0.15$ & $0.98 \pm 0.44$ & $0.96 \pm 0.25$ & $1.30 \pm 0.49$ \\
\hline$C 20: 3 n-9$ & $0.07 \pm 0.05$ & $0.05 \pm 0.01$ & $0.03 \pm 0.01$ & $0.15 \pm 0.07$ & $0.13 \pm 0.04$ & $0.12 \pm 0.07$ \\
\hline$C 20: 3 n-6$ & $0.92 \pm 0.15^{\mathrm{a}}$ & $0.67 \pm 0.21^{b}$ & $0.61 \pm 0.09^{b}$ & $0.23 \pm 0.04$ & $0.25 \pm 0.08$ & $0.24 \pm 0.07$ \\
\hline$C: 20: 4 n-6$ & $7.09 \pm 2.19$ & $7.30 \pm 0.82$ & $7.01 \pm 1.10$ & $1.04 \pm 0.38$ & $1.54 \pm 0.56$ & $1.37 \pm 0.41$ \\
\hline$c 20: 5 n-3$ & $0.98 \pm 0.57$ & $1.11 \pm 0.58$ & $0.81 \pm 0.38$ & $0.17 \pm 0.07$ & $0.27 \pm 0.18$ & $0.24 \pm 0.11$ \\
\hline$c 22: 4 n-6$ & ND & ND & ND & $0.13 \pm 0.04$ & $0.15 \pm 0.03$ & $0.18 \pm 0.07$ \\
\hline$C 22: 5 n-6$ & ND & ND & ND & $0.08 \pm 0.02$ & $0.07 \pm 0.02$ & $0.10 \pm 0.05$ \\
\hline$C 22.5 n-3$ & $\mathrm{ND}$ & ND & ND & $0.29 \pm 0.09$ & $0.38 \pm 0.21$ & $0.43 \pm 0.10$ \\
\hline$C 22: 6 n-3$ & $0.45 \pm 0.19$ & $0.55 \pm 0.21$ & $0.51 \pm 0.16$ & $0.38 \pm 0.16$ & $0.67 \pm 0.37$ & $0.69 \pm 0.28$ \\
\hline
\end{tabular}

"Values are means \pm standard deviations. ND, not detectable $(<0.0 \% \%)$.

${ }^{2}$ For each lipid class, walues in a row without a common superscript differ from each other $(P<0.017)$. 


\section{Effects of individual CLA isomers on desaturation indices and mRNA expressions}

From the fatty acid compositions of PL, CE and TAG the ratio of $C 20: 4 n-6 / C 20: 3 n-6$ was calculated as an index for $\Delta 5$ desaturation, the ratio of $(C 18: 3 n-6+C 20: 3 n$ 6)/C18:2n-6 for $\Delta 6$ desaturation, and the ratios of $C 16: 1 n-7 / C 16: 0$ and of $C 18: 1 n$ $9 / C 18: 0$ for $\Delta 9$ desaturation (Figure 6.1). With respect to the $\Delta 5$ and $\Delta 6$ desaturation indices, comparable patterns were seen in all three lipid classes. The $\Delta 5$ desaturation index was slightly higher in both CLA groups than in the placebo group, but differences between groups did not reach statistical significance $(P=0.249$ in $P L, P=0.148$ in $C E, P=0.444$ in TAG for diet effects). The $\Delta 6$ desaturation index in PL was significantly decreased in both CLA groups $(P<0.01$ for diet effects). Compared with the placebo group the decrease in the $c 9, t 11$ group was $0.06(\mathrm{P}=$ $0.013,95 \% \mathrm{Cl}$ for the difference: -0.102 to -0.014$)$ and in the $110, c 12$ group 0.08 ( $P$ $<0.01,95 \% \mathrm{Cl}$ for the difference: -0.125 to -0.031$)$. This change nearly reached statistical significance in CE ( $P=0.054$ for diet effects), but not in TAG ( $P=0.328$ for diet effects). Also for the $\Delta 9$ desaturation index, dietary effects were observed. Compared with the placebo group, the $\mathrm{C} 18: 1 \mathrm{n}-9 / \mathrm{C} 18: 0$ ratio in $\mathrm{PL}(\mathrm{P}=0.032$ for diet effects) was significantly decreased in the $t 10, c 12$ CLA supplemented group ( $P=$ $0.010,95 \% \mathrm{Cl}$ for the difference: -0.232 to -0.010$)$ and tended to decrease in the $c 9, t 11$ group ( $P=0.102,95 \% \mathrm{Cl}$ for the difference: -0.172 to 0.036$)$. In $C E$, effects on the same index nearly reached statistical significance ( $P=0.079$ for diet effects) and both CLA isomers tended to decrease the $\triangle 9$ desaturation index relative to the placebo $(P=0.048$ for $c 9, t 11 \mathrm{CLA}, 95 \% \mathrm{Cl}$ for the difference: -68.85 to 7.65 and $P=$ 0.050 for $\mathrm{t} 10, \mathrm{c} 12 \mathrm{CLA}, 95 \% \mathrm{Cl}$ for the difference: -71.17 to 8.22 ). In contrast, intervention groups did not differ significantly in their effects on the $\Delta 9$ desaturation index when calculated as $\mathrm{C} 16: 1 \mathrm{n}-7 / \mathrm{C} 16: 0(\mathrm{P}=0.116$ in $\mathrm{PL}, \mathrm{P}=0.223$ in $\mathrm{CE}, \mathrm{P}=$ 0.296 in TAG). 
A

$$
P=0.249 \quad P=0.148 \quad P=0.444
$$

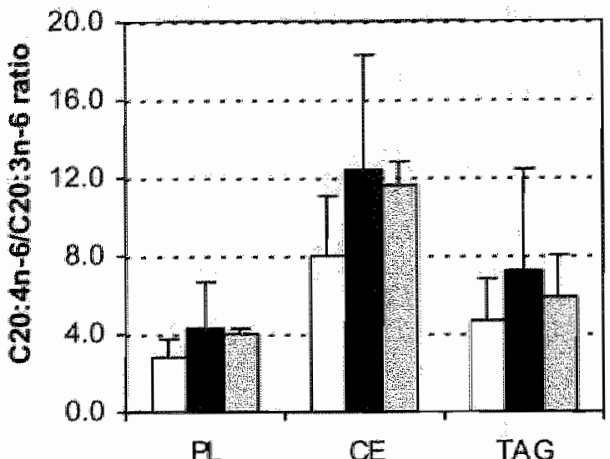

C

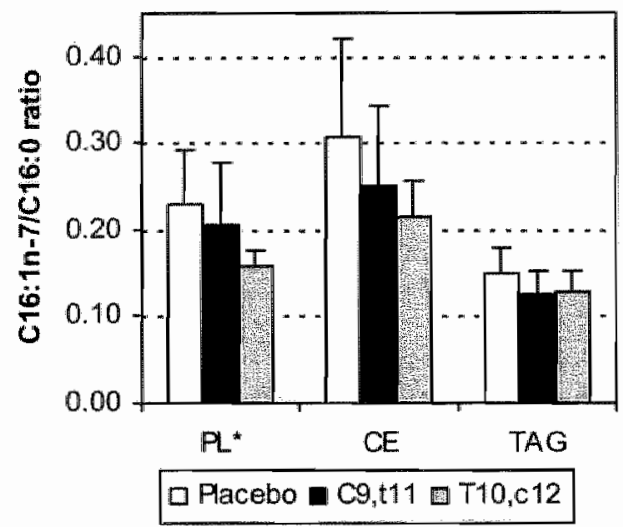

B $P=0.007 \quad P=0.054 \quad P=0.328$

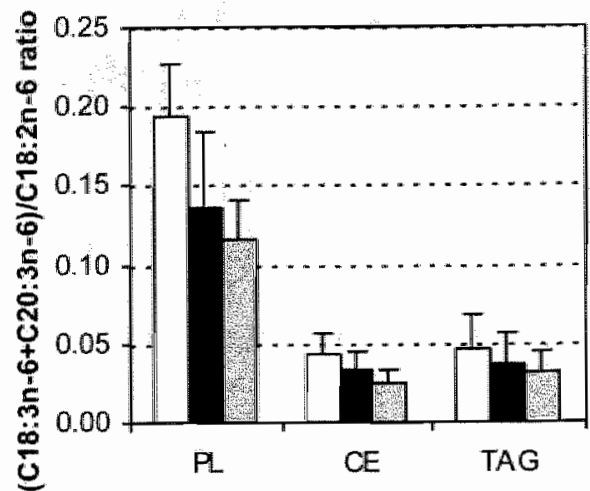

D

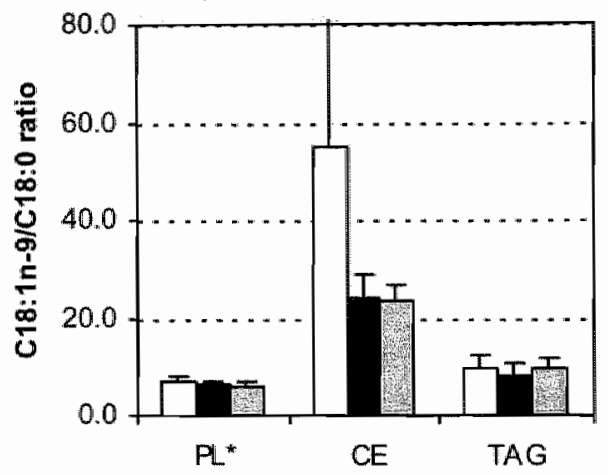

Figure 6.1 Effects of placebo, $c 9,111$ and i10,c12 CLA on (a) $\triangle 5$ (C20:4n-6/C20:3n-6), (b) $\Delta 6$ ('C18:3n-6+C20:3n-6)/C18:2n-6), and $(c, d) \Delta 9$ (C16:1n-7/C16:0 and $C 18: 1 n-9 / C 18: 0)$ desaturation indices. ${ }^{1}$

"Values are means \pm standard deviations. $N=6$ in the placebo group, $n=7$ in the 09,111 group for $C E$ and $T A G$ and $n=8$ for $P L$ and $n=6$ in the $110, \mathrm{C} 12$.

" $\triangle 9$ desaturation indices in phospholipids are multiplied by 10 , because indices are very low owing to the high abundance of saturated fatty acids in phospholipids.

MRNA expression of $\Delta 5, \Delta 6$, and $\Delta 9$ desaturases and elongase did not differ between the three intervention groups (Figure 6.2). P-values for diet effects were respectively 0.914 for $\Delta 5$ desaturase, 0.563 for $\Delta 6$ desaturase, 0.234 for $\Delta 9$ desaturase and 0.807 for elongase. The various desaturation indices in $\mathrm{PL}, \mathrm{CE}$ and TAG were not correlated with their respective mRNA levels. 


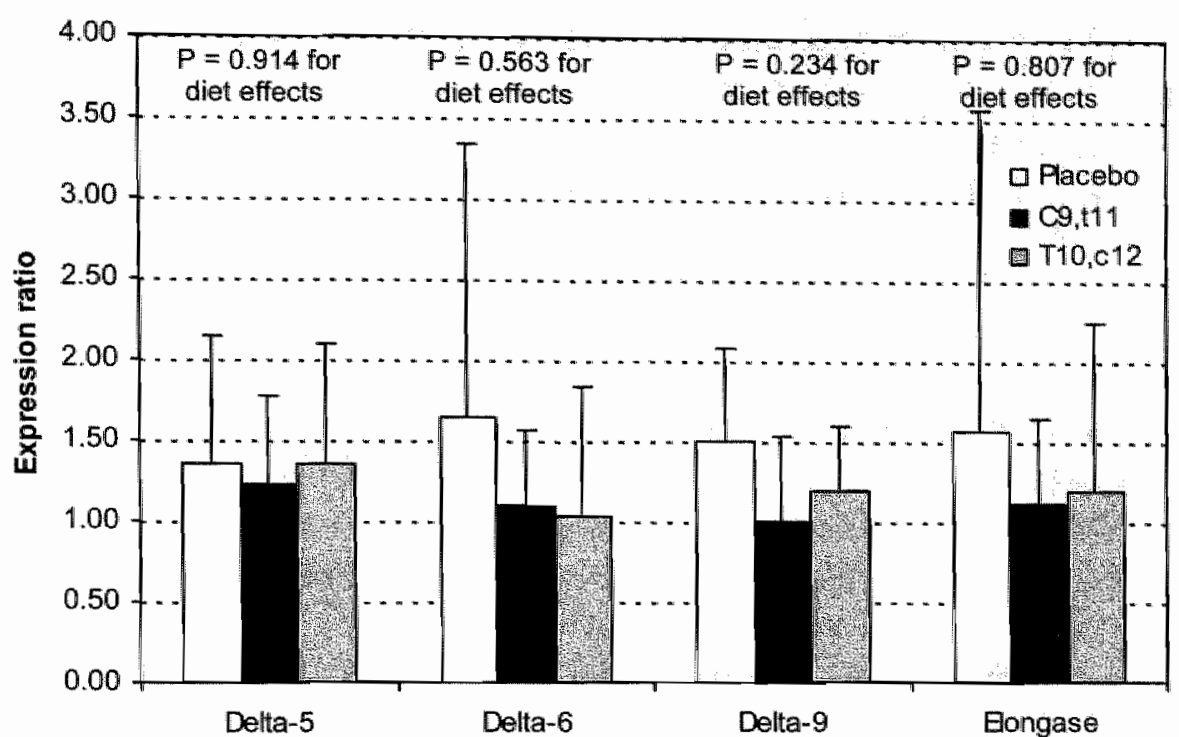

Figure 6.2 Effects of placebo, $c 9, t 11$ and $t 10, c 12 C L A$ on $\triangle 5, \triangle 6$, and $\triangle 9$ desaturase and elongase expression ratios. ${ }^{1,2,3}$

"Values (means \pm standard deviations) are obtained using TaqMan procedures (comparative cycle threshold method) and are normalised to the housekeeping gene p-actin and relative to the run-in period. ${ }^{2}$ No statistically significant differences were observed between treatments.

${ }^{3}$ All samples were analysed in duplicate. $N=6$ in the placebo group, $n=7$ in the $c 9,111$ group and $n=6$ in the 110,012 group.

\section{DISCUSSION}

In this study we evaluated the effects of $c 9, t 11$ CLA and $t 10, c 12$ CLA, the two most common CLA isomers in the diet, on the fatty acid compositions of plasma PL, CE, and TAG. As these effects may be mediated through effects of CLA on desaturase activity, we also studied effects on $m R N A$ expression of $\triangle 5, \triangle 6$ and $\triangle 9$ desaturases and elongase by PBMC. Our results suggest that $c 9, t 11 \mathrm{CLA}$ and $t 10, c 12$ CLA affect the fatty acid composition of plasma lipid classes differently but do not change mRNA expression of desaturases or elongase in PBMC.

Both $c 9, t 11$ CLA and $t 10, c 12$ CLA were incorporated into plasma $P L, C E$ and TAG. Based on the proportional increases in $P L$, it can be estimated that each $g$ of $c 9, t 11$ CLA in the diet increases its proportion in PL with $0.26 \%$. For $110, c 12$ CLA, this estimate is $0.20 \%$. These values are in good agreement with those of a recent study in which healthy men received each CLA isomer in increasing doses from 0 to 0.6 to 1.2 to $2.4 \mathrm{~g}$ per day (26). In that study, both isomers were incorporated in a 
dose-dependent manner into plasma phosphatidylcholine (PC) and $C E$, and into total lipids of PBMC. In plasma PC, the proportions of $c 9, t 11$ CLA increased from 0.21 to 0.32 to 0.52 to $0.79 \%$ in $\mathrm{PC}_{\text {, }}$ or on average $0.25 \%$ per $\mathrm{g}$ of $c 9, t 11 \mathrm{CLA}$. Similarly, for $t 10, c 12 \mathrm{CLA}$ it can be calculated that for each $\mathrm{g}$ in the diet, the increase in PC was $0.17 \%$. These estimates agree very well with our values. Moreover, these findings are in concordance with studies in rats and mice, in which incorporation of $c 9, t 11$ CLA into lipid fractions was also slightly higher than that of $t 10, c 12$ CLA $(27,28)$.

Because $c 9,111 \mathrm{CLA}$ - not the $110, c 12 \mathrm{CLA}$ isomer - was already present in plasma PL after the run-in period, this CLA isomer should have been provided by the habitual diet. By assuming a linear relationship between the intake of $c 9, t 11$ CLA and its incorporation into plasma PL (26), it can be calculated that the habitual diet of our subjects should have provided daily about $430 \mathrm{mg}$ of $c 9, t 11$ CLA. This is much higher than the mean estimated intake of $200 \mathrm{mg}$ in the Netherlands Cohort Study (29). In other western countries comparable dietary CLA intakes were observed (30). Foods that provide the $c 9, t 11 \mathrm{CLA}$ isomer are ruminant products such as meat, cheese, milk, and yogurt, in which c9,t11 CLA accounts for $75-90 \%$ of total CLA (1). Part of the discrepancy between our estimates and these studies can be explained by the fact that methods to assess dietary intakes underestimate real intakes (30). However, the largest part may be explained by the conversion of vaccenic acid (t11 C18:1) into c9,t11 CLA in vivo, as observed in several human studies $(31,32)$. If one assumes a conversion rate of $19 \%$ of $t 11 \mathrm{C} 18: 1$ into $c 9, t 11$ CLA (32), a habitual daily intake of approximately $1200 \mathrm{mg}$ of $111 \mathrm{C} 18: 1$ is necessary to explain a difference of $230 \mathrm{mg}$ in $c 9, t 11 \mathrm{CLA}$ intake. In the Netherlands Cohort Study, daily intake of $t 11 \mathrm{C} 18: 1$ was $700-800 \mathrm{mg}$ (29). Thus, our data on $c 9,111$ CLA levels in plasma PL after the run-in period can be explained by habitual intakes of this isomer and by the conversion of $t 11 \mathrm{C} 18: 1$ into $c 9, t 11 \mathrm{CLA}$.

The fatty acid composition of plasma TAG suggested that the $110, c 12$ CLA isomer was mainly converted into the conjugated $\mathrm{C} 18: 3$ metabolite, whereas supplementation with the $c 9,111$ CLA isomer increased both C18:3 and C20:3 CLA metabolites, though to a lesser extent. Similar results have been observed in rats (28). This might suggest a blockade of the elongation step by $t 10, c 12$ CLA, which we could not, however, demonstrate at the mRNA expression level in PBMC. It is also possible that the conjugated $\mathrm{C} 18: 3$ metabolite of $t 10, c 12 \mathrm{CLA}$ has a lower affinity for elongase than the conjugated $\mathrm{C} 18: 3$ metabolite of $c 9, t 11 \mathrm{CLA}$.

In contrast to several other studies $(10,11)$, CLA supplementation significantly changed the fatty acid compositions of plasma $\mathrm{PL}, \mathrm{TAG}$ and $\mathrm{CE}$. In general, proportions of $C 18: 1 n-9, C 16: 1 n-9, C 20: 3 n-9$ and $C 20: 3 n-6$ acids decreased at the 
expense of CLA and C18:2n-6. These effects were more pronounced in the $t 10, c 12$ CLA group than in the $c 9, t 11$ CLA-supplemented group, although differences between the two CLA groups did not reach statistical significance. Smedman and Vessby (12) found comparable effects on the fatty acid composition of serum PL in humans consuming $4.2 \mathrm{~g}$ of CLA isomers $(c 9, t 11: 110, c 12$ as $50: 50)$ per day for 12 weeks. In addition, in that study aiso proportions of stearic (C18:0), $\gamma$-linoleic (C18:3n-6), docosatetraenoic (C.22:4n-6), and docosapentaenoic (C22:5n-3) acids increased and that of palmitic acid $(\mathrm{C} 16: 0)$ decreased. It is possible that the intervention periods of 4 weeks (11) or 45 days (10) were too short to change the composition of plasma lipids. Surprisingly, in our study proportions of linoleic acid increased. Thus, linoleic acid was not displaced by conjugated linoleic acids in plasma lipids as suggested earlier (12). Because linoleic acid is an essential fatty acid and is not produced endogenously, this effect might suggest a decrease in $\Delta 6$ desaturation. However, unlike some other studies $(5,9,11)$, we did not find decreased proportions of longer-chain metabolites of linoleic acid including arachidonic acid, which is an important precursor for eicosanoids.

With respect to the $\Delta 9$ desaturation index, our data confirmed those of Smedman and Vessby (12). In their study, a daily supplement of $4.2 \mathrm{~g}$ of a mixture of CLA isomers resulted in a decreased $\Delta 9$ desaturation index (12). Although the $\Delta 9$ desaturation index in that study was only calculated from the conversion of $\mathrm{C} 18: 0$ into $\mathrm{C} 18: 1 \mathrm{n}-9$, we calculated it also from the conversion of $\mathrm{C} 16: 0$ into $\mathrm{C} 16: 1 \mathrm{n}-7$. However, only the $C 18: 1 n-9 / C 18: 0$ ratio was significantly reduced in PL by the $t 10, c 12 \mathrm{CLA}$ isomer. This may indicate that the preferred substrate of $\Delta 9$ desaturase is $C 18: 0$ rather than $C 16: 0$, as also is suggested by stable-isotope studies in humans $(33,34)$. In addition, $\mathrm{C} 16: 0$ is preferentially elongated instead of $\triangle 9$ desaturated (34). Also in cell culture $(8,9)$ and animal studies $(5-7)$, the 110,612 CLA isomer inhibited $\Delta 9$ desaturase activity. In contrast, the $c 9, t 11$ CLA isomer did not affect $\Delta 9$ desaturase activity in all these studies, except for one. In a human hepatoma-derived cell line (HepG2 cells), the c9, $111 \mathrm{CLA}$ isomer slightly decreased $\Delta 9$ desaturase activity when added at nonphysiological concentrations (9).

As for a mixture of CLA isomers (12), the $\triangle 6$ desaturation index was decreased by $c 9, t 11$ as well as by $t 10, c 12$ CLA. In contrast, in Hep $G 2$ cells $t 10, c 12$ CLA, but not $c 9, t 11$ CLA, suppressed $\triangle 6$ desaturation (9). Furthermore, in hepatic rat microsomes $c 9, t 11$ CLA decreased $\Delta 6$ desaturation of linoleic acid but not that of $\alpha$ linolenic acid. In that study, $t 10, c 12$ CLA decreased the $\triangle 6$ desaturation of linoleic acid only at the highest concentration (5). Taken together, whereas in vitro effects of the individual CLA isomers on $\triangle 6$ desaturation are rather inconsistent, in wivo both 
CLA isomers seem to decrease $\triangle 6$ desaturation activity in humans. Unlike Smedman and Vessby (12), who reported an increase in the $\Delta 5$ desaturation index, we found no effect on this index. In contrast, in HepG2 cells, $t 10, c 12$ CLA even suppressed $\triangle 5$ desaturation (9). Therefore, effects of the individual CLA isomers on $\triangle 5$ desaturase activities are until now rather inconsistent and clearly deserve further exploration.

No effects of the $110, c 12$ and $c 9, t 11$ CLA isomers on mRNA expression in PBMC were evident. Only a few studies have evaluated the effects of CLA on MRNA expression of desaturases before $(7,8)$. In mice that were fed a mixture of CLA isomers, other isomers than $c 9, t 11$ CLA were held responsible for the inhibitory effect on stearoyl-CoA desaturase gene 1 mRNA expression (7). However, in cell culture studies, Choi et al (8) found that the $t 10, c 12$ and $c 9, t 11$ CLA isomers did not influence mRNA expression in human-derived HepG2 cells. In that study, $t 10, c 12$ CLA decreased $\triangle 9$ desaturase activity but did not change desaturase protein levels. Hence, $t 10, c 12$ CLA might regulate the activity of $\Delta 9$ desaturase without any effect at the transcriptional level.

To quantify mRNA expression ratios of the $\Delta 5, \Delta 6$, and $\Delta 9$ desaturases, and elongase we developed RT-qPCR assays. With this method, the PCR product is already accurately detected during the PCR amplification, which is less timeconsuming and laborious than conventional PCR techniques, because no post-PCR handling is required. Although assays for $\Delta 5$ and $\Delta 6$ desaturase, and elongase were easily developed, for $\triangle 9$ desaturase or stearoyl-CoA desaturase a pseudogene has been reported (16), which asked for additional precautions. Instead of the more regular dual-labelled probes, we therefore used an MGB probe, which is more specific to the target sequence and does not anneal to the pseudogene sequence. These assays can easily be used in large-scale human studies. Tissue accessibility, however, remains a problem. We chose to analyse desaturase expression in PBMC, as liver tissue is for obvious reasons difficult to obtain. Although for some genes a correlation between liver and PBMC mRNA levels has been demonstrated (35), it is still unknown whether mRNA expression ratios of $\Delta 5, \Delta 6$, and $\triangle 9$ desaturases and elongase in PBMC are representative for those in the liver. This may also explain the lack of effects of the two CLA isomers on MRNA expression. Future studies should therefore concentrate to validate molecular signatures (e.g. mRNA, protein and metabolic profiles) in PBMC as a marker for other, less accessible tissues and organs.

In conclusion, incorporation of the individual CLA isomers, $c 9, t 11$ and $t 10, c 12$, into plasma lipids ( $P L, C E$ and TAG) reflects dietary intakes. Compared with oleic acid, $\Delta 9$ and $\Delta 6$ desaturation indices in plasma phospholipids are decreased after 
consumption of $c 9,111$ or $110, c 12$ CLA. Effects on desaturation indices, however. were not reflected by changes at the transcriptional level for the various desaturases and elongase enzymes in peripheral blood mononuclear cells.

\section{REFERENCES}

1. Chin SF, Lit W, Storkson JM, Ha YL and Pariza MW. Dietary sources of conjugated dienoic isomers of linoleic acid, a newly recognized class of anticarcinogens. Joumal of food composition and analysis $1992 ;$ : $185-97$.

2. Belury MA. Dietary conjugated linoleic acid in health; physiological effects and mechanisms of action. Annu Rev Nutr 2002; 22: 505-31.

3. Pariza MW, Park $Y$ and Cook ME. The biologically active isomers of conjugated linoleic acid. Prog Lipid Res 2001; 40: 283-98.

4. Evans M. Brown $J$ and Mclintosh M. Isomer-specific effects of conjugated linoleic acid (CLA) on adiposity and lipid metabolism. I Nutr Biochem 2002; 13: 508.

5. Bretilion L, Chardigny JM, Gregoire S, Berdeaux $O$ and Sebredio JL. Effects of conjugated linoleic acid isomers on the hepatic microsomal desaturation activities in vitro. Lipids 1999; 34: 965-9.

6. Park $Y$, Storkson JM, Ntambi JM, Cook ME, Sin CJ and Pariza MW'. Inhibition of hepatic stearoyl-CoA desaturase activity by trans-10, cis-12 conjugated linoleic acid and its derivatives. Biochim Biophys Acta 2000; 1486: 285-92.

7. Lee KN, Pariza MW and Ntambi JM. Conjugated linoleic acid decreases hepalic steraroyl-CoA desalturase mRNA expression. Biochem Biophy's Res Commun 1998; 248; 817-21.

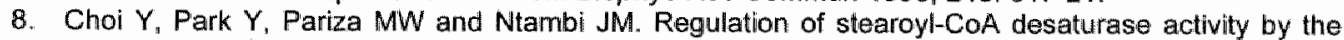
trans-10, cis-12 isomer of conjugated linoleic acid in HepG2 cells. Biochem Biophys Res Commun $200 \%: 284: 689-93$

9. Eder $K$ Slomma $N$ and Becker $K$. Trans-10,cis -12 conjugated linolela acid suppresses the desaturation of linoleic and alpha-linolenic acids in HepG2 cells. N Nutr 2002; 132: 11 15-21.

10. Petridou A, Mougios $V$ and Sagredos A. Supplementation with CLA: isomer incorporation into serum lipids and effect on body fat of women. Lipids 2003; 38: 805-11.

11. Mougios V. Matsakas A, Petridou A, Ring $S$, Sagredos A, Melissopoulou A, Tsigilis $N$ and Nikolaidis M. Effect of supplementation with conjugated linoleic acid on human serum lipids and body fat. J Nutr Biochem 2001; 12: 585-94.

12. Smedman $A$ and Vessby $B$. Conjugated linoleic acid supplementation in humans--metabolic effects. Lipids 2001; 36: 773-81.

13. Terpstra AH. Effect of conjugated linoleic acid an body composition and plasma lipids in humans: an overview of the literature. Am J Clin Nutr 2004; 79: 352-61.

14. Cho HP. Nakamuna M and Clarke SD. Cloning, expression, and fatty acid regulation of the human delta-5 desaturase. IBrol Chem 1999; 274:37335.9.

15. Cho HP. Nakamura MT and Clarke SD. Cloning, expression, and nutritional regulation of the mammalian Delta- 6 desaturase. I Biol Chem 1999; 274:471.7.

16. Zhang L, Ge L. Parmoo S, Stenn $K$ and Prouty SM. Human stearoyl-CoA desaturase: altermative transcripts generated from a single gene by usage of tandem polyadenylation sites. Blocham $J 1999$; 340: $255-64$.

17. Leonard AE , Bobik EG, Dorado J, Kroeger PE "Chuang LT, Thurmond JM, Parker-Barnes JM, Das T, Huang YS and Mukerji P. Cloning of a human CDNA encoding a nowel enzyme involved int the elongation of long-chain polyunsaturated fatty acids. Biochem $J 2000 ; 350 ; 765-70$.

18. Malpuech-Brugere $C$. Verboeket-Van De Venne WP. Mensink RP Arnal MA Morio B, Brandolini M Saebo A, Lassel TS, Chardigny JM, Sebedio JL at al. Effects of Two Conjugated Linoleic Acid Isomers on Body Fat Mass in Overweight Humans, Obes Res 2004; 12: 501-8.

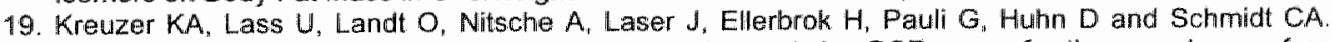
Highly sensitive and specific fluorescence reverse transcription-PCR assay for the pseudogene-free detection of beta-actin transcripts as quantitative reference. Chin Chem 1999; 45: 297-300.

20. Leonard AE, Kelder B. Bobik EG, Chuang LT, Parker-Barnes JM, Thumond JM, Kroeger PE. Kopchick JJ, Huang $Y S$ and Mukerji $P$. CDNA cloning and characterization of human Deltasdesaturase involved in the biosynthesis of arachidonic acid. Biochem $J 2000 ; 347: 719-24$. 
21. Applied Biosystems. Relative quantitation of gene expression. In: ABI PRISM 7700 Sequence Detection System - User Bulletin \#2. 1997.

22. Sebiedio $J \mathrm{~L}$, Juaneda $\mathrm{P}$, Dobson $\mathrm{G}$, Ramilison I, Martin $J C$, Chardigny $J M$ and Christie $W W$. Metabolites of conjugated isomers of linoleic acid (CLA) in the rat. Blochim Biophys Acta 1997; 1345: 5.10.

23. Folch $J$, Lees $M$ and Sloane Stanley $G H$. A simple method for the isolation and purification of total lipids from animal tissues. Joumal of blological chemistry 1957; 226: 497-509.

24. Kaluzny MA, Duncan LA, Merritt MV and Epps DE. Rapid separation of lipid classes in high yield and purity using bonded phase columns. J Lipid Res $1985 ; 26: 135-40$.

25. Sebedio $\sqrt{ } \mathrm{L}$, Juaneda $\mathrm{P}$, Gregoire $\mathrm{S}$, Chardigny JM, Martin JC and Ginies $\mathrm{C}$. Geometry of conjuglated double bonds of CLA isomers in a commercial mixture and in their hepatic $20: 4$ metabolites. Lipids 1999; 34: 1319-25.

26. Burdge GC, Lupoli $B$, Russill $\Downarrow J$, Tricon $S_{\|}$Kew $S$, Banerjee T, Shingfield KJ, Beever DE, Grimble $\mathrm{RF}_{\text {, Willams }} \mathrm{CM}$ ot al. Incorporation of cis-9,trans- 11 or trans-10, cis- 12 conjugated linoleic acid into plasma and cellular lipids in healthy men. J Lipid Res 2004; 45: 736-41.

27. Kelley DS, Bartolini $\mathrm{GL}$, Warren $J \mathrm{M}_{1}$ Simon VA, Mackey $\mathrm{BE}$ and Erickson $\mathrm{KL}$. Contrasting effects of $t 10, c 12$ - and $c 9, t 11$-conjugated linoleic acid isomeirs on the fatty acid profiles of mouse liver lipids. Lipids 2004; 39: 135-41.

28. Sebedio JL, Angioni $E$, Chardigny $J M$, Gregoire $S$, Juaneda $P$ and Berdeaux $O$. The effect of conjugated linoleic acid isomers on fatty acid profiles of liver and adipose tissues and their conversion to isomers of $16: 2$ and $18: 3$ conjugated fatty acids in rats. Lipids 2001; $36: 575-82$.

29. Voorrips LE, Brants HA, Kardinaal AF, Hiddink GJ, wan den Brandt PA and Goldbohm RA. Intake of conjugated linoleic acid, fat, and other fatty acids in relation to postmenopausal breast cancer: the Netherlands Cohort Study on Diet and Cancer. Am J Clin Nutr 2002; 76: 873-82.

30. Ritzenthaler KL, McGuire MK, Falen $R$, Shultz TD, Dasgupta $N$ and McGuire MA. Estimation of conjugated linoleic acid intake by written dietary assessment methodologies underestimates actual intake evaluated by food duplicate methodology. I Nutr 2001: 131: 1548-54.

31. Adlof RO, Duval $\mathrm{S}$ and Emken EA. Biosynthesis of conjugated linoleic acid in humans. Lipids 2000; 35: 131-5.

32. Turpeinen AM, Mutanen $M$, Aro $A$, Salminen $1_{x}$ Basu S, Palmquist DL and Griinari JM. Bioconversion of vaccenic acid to conjugated linoleic acid in thumans. Am J Clin Nutr 2002; 76: 504-10.

33. Emken EA. Metabolism of dietary stearic acid relative to other fatty acids in human subjects. Am $J$ Clin Nutr 1994; 60: 1023S-8S.

34. Rhee SK, Kayani $A_{W}$, Ciszek $A$ and Brenna JT. Desaturation and interconversion of dietary stearic and palmitic acids in human plasma and lipoproteins. Am J Clin Nutr 1997; 65: 451-8.

35. Powell EE and Kroon PA. Low density lipoprotein receptor and 3-hydroxy-3-methylglutaryl coenzyme A reductase gene expression in thuman mononuclear leukocytes is regulated coordinately and parallels gene expression in humam liver. $J$ Clin Imves! 1994; $93: 2168-74$. 
General Discussion 


\section{GENERAL DISCUSSION}

The major objectives of the studies described in this thesis were to evaluate the effects of stearic acid, oleic acid, and linoleic acid on the serum lipoprotein profile, on the thrombotic tendency, and on biomarkers of lipid peroxidation and inflammation of healthy human subjects. In another human study, the effects of the conjugated linoleic acid (CLA) isomers $c 9, t 11$ and $t 10, c 12$ CLA were investigated on the fatty acid profile of serum lipids and the expression of desaturases and elongases in peripheral blood mononuclear cells (PBMC).

\section{STEARIC, OLEIC, AND LINOLEIC ACIDS AND CARDIOVASCULAR DISEASE RISK}

The effects of stearic acid, oleic acid, and linoleic acid were studied in a crossover designed study in healthy, non-smoking human subjects $(n=45)$ as described in Chapters 3,4 and 5. Both male $(n=18)$ and female $(n=27)$ subjects participated. Each participant consumed in random order each of the 3 different diets during three 5 -week periods. Diets provided $38 \%$ of energy from fat of which $60 \%$ was supplied by the experimental fats of which bread, margarines and cakes were produced. The prescribed nutrient composition of the diets did not differ, except for a $7 \%$ difference in energy intake provided by stearic, oleic, or linoleic acids. The mean daily energy intake and the composition of the diets were estimated by food frequency questionnaires filled in at the end of each intervention period. Dietary adherence was confirmed by the fatty acid composition of serum phospholipids.

\section{Lipoprotein profile}

\section{Total, LDL, and HDL cholesterol}

Because dairy fat is rich in saturated fatty acids, milk and milk-derived products have for long had a negative image concerning the risk to develop cardiovascular diseases. Lauric, myristic, palmitic, and stearic acids account approximately for $3 \%$, $11 \%, 28 \%$, and $10 \%$ of total fatty acids in milk fat, respectively (Table 7.1 ). Furthermore, a considerable part of the saturated fatty acids in milk fat, about $10 \%$ of total fatty acids, are short- and medium-chain fatty acids (MCFA). Earlier studies at our department already reported the effects of medium-chain fatty acids, lauric acid, myristic acid, and palmitic acid on concentrations of serum lipids and lipoproteins relative to those of oleic acid. Because study designs were largely comparable to that of our study, in Figure 7.1 data of our study and those of Temme et al $(1,2)$ were combined. 
Table 7:1 Fatty acid composition of milk fat.

\begin{tabular}{|c|c|c|}
\hline Fatty acid & Notation & $\%$ of total fatty acids (w/w) \\
\hline Saturated fatty acids & & 64.0 \\
\hline Short-chain fatty acids & $C 4: 0$ and $C 6: 0$ & 5.9 \\
\hline Medium-chain fatty acids & $\mathrm{C} 8: 0$ and $\mathrm{C} 10: 0$ & 4.0 \\
\hline Lauric acid & $\mathrm{C} 12: 0$ & 3.3 \\
\hline Myristic acid & $\mathrm{C} 14: 0$ & 10.7 \\
\hline Palmitic acid & C16:0 & 27.6 \\
\hline Stearic acid & $\mathrm{C} 18: 0$ & 10.1 \\
\hline Monounsaturated fatty acids & & 30.0 \\
\hline Palmitoleic acid & C.16:1m-7 & 2.6 \\
\hline Oleic acid & C18:1n-9 & 26.0 \\
\hline Polyunsaturated fatty acids & & 4.0 \\
\hline Linoleic acid & $C 18: 2 n-6$ & 2.5 \\
\hline$\alpha$-Linolenic acid & C.18:3n-3 & 1.4 \\
\hline Trans fatty acids & & $1.5-6.5$ \\
\hline Vaccenic acid & $T 11 \mathrm{C} 18: 1$ & 1.0 \\
\hline Elaidic acid & $\operatorname{TgC} 18: 1$ & 0.2 \\
\hline Conjugated linoleic acids (CLA) & & $<0.5$ \\
\hline 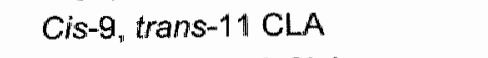 & $C 9, t 11 \mathrm{C} 18: 2$ & 0.4 \\
\hline Trans-10, cis- 12 CLA & $T 10, C 12 C_{18: 2}$ & $<0.01$ \\
\hline
\end{tabular}

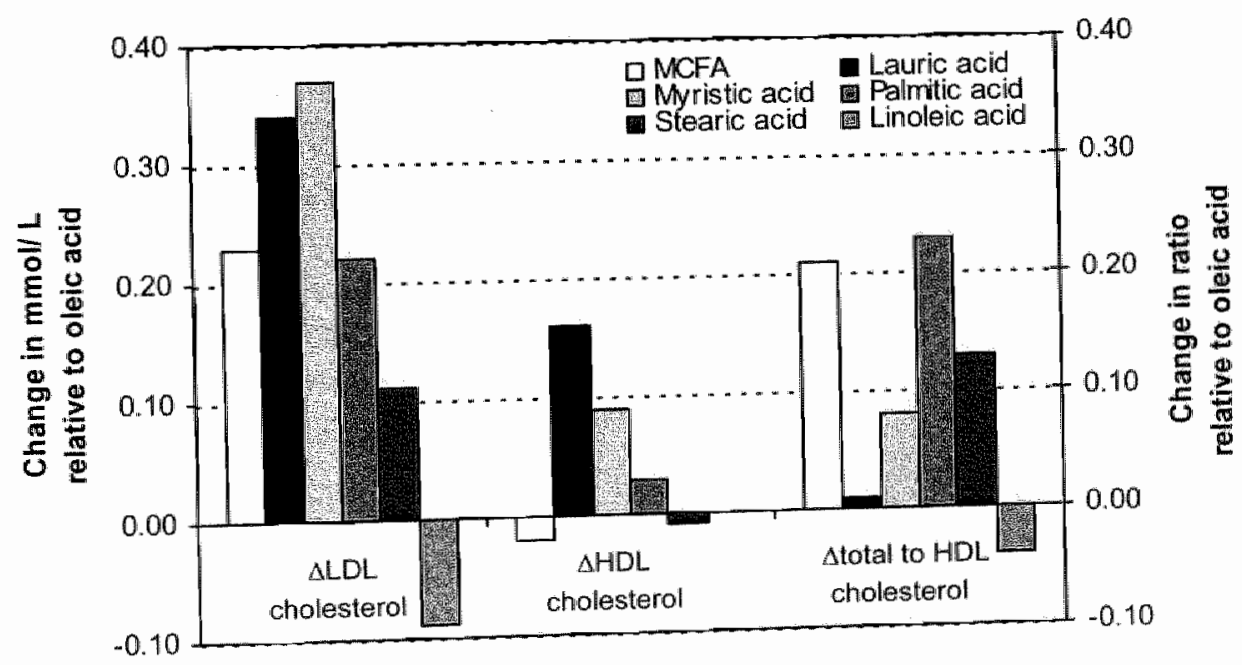

Figure 7.1 Mean changes in LDL and HDL cholesterol concentrations, and total to HDL cholesteral ratio, when 10\% of energy from oleic acid is exchanged for medium-chain fatty acids (MCFA), lauric acid, myristic acid, or palmitic acid $(1,2)$, or stearic acid, or linoleic acid (Chapter 3). 
When $10 \%$ of dietary energy from oleic acid was replaced by lauric acid (C12:0), myristic acid (C14:0), or palmitic acid (C16:0), total, LDL, and HDL cholesterol concentrations increased $(1,2)$. Strikingly, stearic acid (C18:0) increased total and LDL cholesterol concentrations less than the other saturated fatty acids. With increasing chain length from lauric acid to stearic acid, the HDL cholesterol elevating effects of the saturated fatty acids decreased. As a consequence, palmitic acid increased the total to HDL cholesterol ratio and thereby cardiovascular disease risk more than the other saturated fatty acids did. Markedly, because of its effects on HDL cholesterol, lauric acid affected the total to HDL cholesterol ratio even more beneficially than stearic acid, which increased the total and LDL cholesterol concentrations less than the other saturated fatty acids. Hence, saturated fatty acids differ in their effects on the serum lipoprotein profile. Because linoleic acid did not differ from oleic acid in its effects on HDL cholesterol and lowered concentrations of total and LDL cholesterol, linoleic acid slightly decreased the total to HDL cholesterol ratio relative to oleic acid.

Several dietary intervention studies compared the effects of stearic acid to those of the other long-chain saturated fatty acids. Natural as well as synthetic fats high in stearic acid resulted in lower concentrations of total or LDL cholesterol than diets high in lauric and myristic acids, myristic and palmitic acids, myristic acid or palmitic acid (3-8). Therefore, stearic acid has been suggested to differ from the other saturated fatty acids and would affect cardiovascular disease risk more beneficially

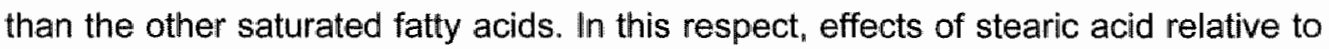
lauric acid are not yet clear. When data from our studies were summarised, lauric acid had more beneficial effects on the concentration of HDL cholesterol and on the total to HDL cholesterol ratio whereas stearic acid had less harmful effects on the total and LDL cholesterol concentrations than the other saturated fatty acids. Relative to trans fatty acids, the effects of stearic acid are rather inconsistent. In the study of Zock et al (9), stearic acid and trans fatty acids did not differ in their effects on total, LDL, and HDL cholesterol concentrations. However, in another study stearic acid decreased the concentrations of total and LDL cholesteral compared with trans fatty acids (10).

With increasing degree of unsaturation, the differences in effects on serum lipid and lipoprotein concentrations between the three $\mathrm{C} 18$ fatty acids - stearic acid, oleic acid, and linoleic acid - did not reach statistical significance in our study. Also most other studies observed no different effects on the serum lipoprotein profile when stearic acid was exchanged by oleic acid (6) or oleic acid by linoleic acid (11-14). If the effects of stearic acid are compared to those of linoleic acid, linoleic acid significantly decreased total and LDL cholesterol or increased HDL cholesterol 
concentrations $(5,9)$ : Dietary exchange of fatty acids in the earlier mentioned studies was, however, larger than in our study and sometimes dietary intake of linoleic acid was even unrealistically high. Other possible explanations for the differences in effects between studies will be discussed later in this chapter.

In a recent meta-analysis the effects of the individual saturated, monounsaturated, polyunsaturated, and trans fatty acids were summarised using data of 60 clinical trials (15). The results of our study are compared to the predicted changes from the equations of this meta-analysis in Figure 7.2. As already predicted by the equations of Mensink et al (15), the effects of linoleic acid relative to the other fatty acids were overestimated by the equations of Keys et al (16) and Hegsted et al (17). Despite these comparable smaller changes of total cholesterol concentrations, also some discrepancies exist between the observed changes in our dietary intervention study and the predicted changes (15). While observed changes of LDL cholesterol concentrations largely reflected predicted changes, mainly changes of HDL cholesterol concentrations were smaller than in the meta-analysis. Observed changes in the effects of stearic, oleic, and linoleic acids on the major cardiovascular disease risk marker, the total to HDL cholesterol ratio were, however, comparable to those predicted.

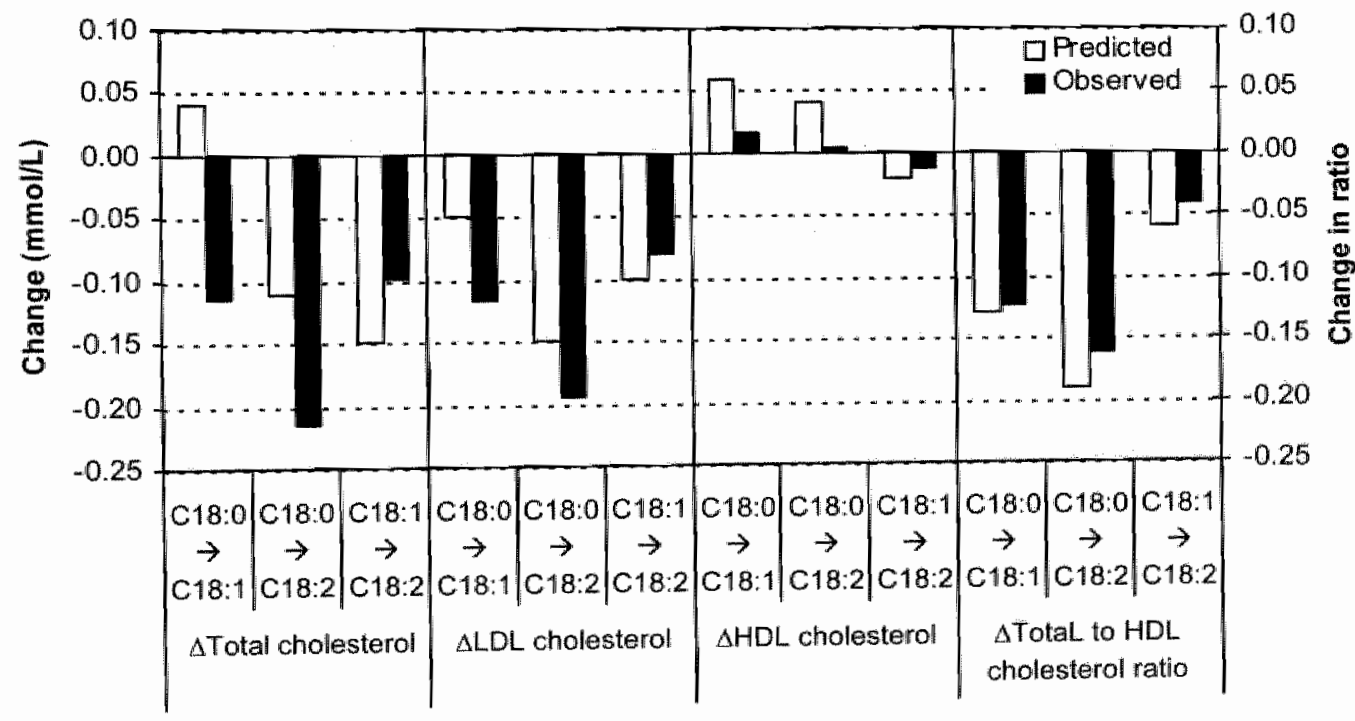

Figure 7.2 Mean changes in total, LDL and HDL cholesterol concentrations and total to HDL cholesterol ratio, when 10\% of energy from stearic acid (C18:0) or oleic acid (C18:1) is exchanged by oleic acid (C18:1) or linoleic acid (C18:2) as predicted (white bars) by the equations of Mensink et al (15) and observed (black bars) in our study. 


\section{Lipid and lipoprotein subclasses and particle sizes}

A. relatively new technique to analyse concentrations of lipoprotein particles and their subclasses, and to measure the particle size of lipoproteins is NMR spectroscopy (18). In our study, particle concentrations of VLDL, LDL, and HDL subclasses and particle sizes of VLDL, LDL, and HDL did not differ between healthy subjects when they consumed diets rich in stearic, oleic, or linoleic acids. These results are in agreement with the effects on the more traditional cardiovascular disease risk markers. As some lipoprotein subclasses such as small, dense LDL are positively associated with cardiovascular disease risk $(19,20)$, this new technique is a promising new tool to analyse the effects of fatty acids on the subclass distribution of lipoproteins.

\section{Thrombotic tendency}

Dietary fatty acid composition not only affects the lipoprotein profile but also thrombotic tendency might be influenced by the exchange of fatty acids in the diet. In our study the effects of stearic, oleic, and linoleic acids were investigated on platelet aggregation, and variables of coagulation and fibrinolysis. In the past, stearic acid has been assumed to exert prothrombotic effects but more recent studies did not confirm the unbeneficial effects of stearic acid on platelet aggregation, coagulation as well as fibrinolysis, relative to other fatty acids (Chapter 4).

\section{Platelet aggregation}

Various earlier studies reported in particular thrombogenic effects of saturated fatty acids in animal models and in humans, In rats, $n-6$ and $n-3$ polyunsaturated fatty acids decreased arterial thrombosis tendency as measured with the aortic loop technique, whereas the saturated fatty acids with 12 to 16 carbon atoms had opposing effects (21). Myristic acid was the strongest prothrombotic fatty acid, whereas linoleic acid was the strongest antithrombotic fatty acid. In another study with rats, diets high in butter or stearic acid enhanced thrombin-induced aggregation, which is related to changes in the fatty acid composition of platelet phospholipids. Furthermore, the severity of thrombotic lesions was increased relative to oleic and linoleic acids (22). Also in human studies prothrombotic effects of stearic acid have been suggested. In French farmers, for example, dietary stearic acid intake changed the fatty acid composition of platelet phospholipids and was positively correlated with an increased platelet activity (23).

In our study, two different methods were used to evaluate the effects of stearic, oleic, and linoleic acids on platelet aggregation. Using filtragometry, a method to 
measure ex vivo platelet aggregation, gender-dependent effects were found. In men, ex vivo platelet aggregation time was favourably prolonged by linoleic acid relative to the diet rich in stearic acid. Already in two other studies $(24,25)$ a prolonged platelet aggregation time was reported when mixtures of saturated fatty acids or saturated and monounsaturated fatty acids were substituted by linoleic acid. We could now specifically attribute the observed effects to stearic acid. Most other studies used in vitro techniques to examine platelet aggregation. With this approach, stearic, oleic, and linoleic acids did not differ in their effects on in vitro whole blood platelet aggregation parameters either induced by ADP or collagen. Others also found comparable effects of stearic, oleic, and linoleic acids on ADP-induced platelet aggregation (26) or of oleic and linoleic acids using different methodologies (26-31). Compared with other fatty acids, effects of stearic acid on in vitro platelet aggregation did not differ from those of trans fatty acids (32) and palmitic acid (33). However, in one study stearic acid improved in vitro platelet aggregation relative to palmitic acid (7). In the earlier mentioned studies of Temme et al $(1,2)$ also mediumchain fatty acids, lauric, myristic, and palmitic acids did not differ in their effects on in vitro whole blood platelet aggregation as compared with oleic acid (34). Hence, in recent studies no thrombotic effects of saturated fatty acids in particular of stearic acid were reported on in vitro platelet aggregation relative to unsaturated fatty acids. Thus, stearic acid may affect in vitro platelet aggregation similarly when compared with oleic and linoleic acids.

\section{Coagulation}

Stearic, oleic, and linoleic acids did not differ in their effects on the coagulation variables measured in our study - factor Vllam activity and concentrations of prothrombin fragment 1 and 2 , and of fibrinogen. In the past, stearic acid was suggested to increase concentrations of coagulation factor VII $(35,36)$, which is associated with an increased cardiovascular disease risk (37). These thrombogenic effects on coagulation factor VII were, however, not confirmed in more recent, wellcontrolled dietary intervention studies. As in our study, Hunter et al (26) observed comparable effects of stearic, oleic, and linoleic acids using 3 different methods to measure factor VII activity. When the effects of dietary oleic acid and linoleic acid were compared, most studies reported also no different effects of these two unsaturated fatty acids on factor VII coagulant activity in young healthy subjects $(38,39)$ and middle-aged subjects $(40)$. In contrast, in two studies with healthy young male and female students, oleic acid reduced factor VII coagulant activity compared with linoleic acid $(31,41)$. No explanation exists for the effects observed in the latter two studies. Despite the use of a wide variety of methods to measure factor VII 
activity, no distinct effects of stearic, oleic, and linoleic acids were found in middleaged human subjects.

Although only a few studies have examined the effects of stearic acid and unsaturated fatty acids on factor VII activity simultaneously, several earlier studies have compared the effects of stearic acid to those of the other saturated fatty acids. Fats high in stearic acid decreased factor VII activity relative to fats high in lauric and myristic acids, or palmitic acid $(7,8)$. In another study, a stearic acid diet decreased concentrations of factor VII antigen as well as of factor VII coagulant activity relative to a diet rich in lauric, myristic, and palmitic acids (42). In the studies of Temme et al, diets rich in lauric, myristic, and palmitic acids increased factor Vllam activity relative to the oleic acid diet $(43,44)$. These effects were more pronounced in women than in men. In our study no gender-dependent effects were apparent. Thus, the effects of stearic acid on factor VII activity may be less harmful than those of the other saturated fatty acids with 12 to 16 carbon atoms.

With respect to the effects on concentrations of fibrinogen and prothrombin fragment 1 and 2, no differences were observed between the experimental diets. Prothrombin fragment 1 and 2 is a marker for thrombin formation in wivo, while fibrinogen is both the precursor for fibrin and an acute phase reactant which is increased in inflammation. As in other studies, the fatty acid composition of the diet did not change fasting concentrations of prothrombin fragment 1 and 2 $(26,31,44,45)$. In one study, however, stearic acid decreased concentrations of prothrombin fragment 1 and 2 compared to a diet rich in myristic and lauric acids but in the same study fibrinogen concentrations were raised by stearic acid (42). In another study, an increase in fibrinogen concentrations was also observed when dietary saturated fatty acids with 12 to 16 carbon atoms, oleic acid or trans fatty acids were substituted by stearic acid (46). Oleic and linoleic acids did not differ in their effects on fibrinogen concentrations $(26,31,41)$. Therefore, the effects of oleic and linoleic acids seem to be comparable on fibrinogen concentrations whereas the effects of stearic acid relative to the other saturated or unsaturated fatty acids are inconsistent.

\section{Fibrinolysis}

Major regulators of fibrinolysis are tissue plasminogen activator (TPA) and its inhibitor plasminogen activator inhibitor-1 (PAl-1). In most studies no different postprandial responses to meals rich in myristic and palmitic acids, palmitic acid, stearic acid, oleic acid, or linoleic acid were observed on fibrinolytic variables (4749). Myristic acid, palmitic acid, stearic acid, oleic acid, linoleic acid, $\alpha$-linolenic acid, and trans fatty acids did also not differ in their effects on fasting levels or activities in 
human intervention studies $(8,26,31,50)$. In concordance, in our study stearic, oleic, and linoleic acids did also not differ in their effects on PAl activity and concentrations of tPA/PAl-1 complexes. Hence, fibrinolytic variables may not be influenced by the fatty acid composition of the diet.

\section{Lipid peroxidation}

To investigate the effects of stearic, oleic, and linoleic acids on lipid peroxidation, urinary 24-hour excretions of 8-iso-prostaglandin $F_{2 \alpha}$ (8-iso-PGF $F_{2 \alpha}$ ) and 15-ketodihydro-prostaglandin $F_{2 \alpha}\left(15-\mathrm{K}-\mathrm{DH}-\mathrm{PGF}_{2 \alpha}\right)$ were measured as described in Chapter 5 . Elevated concentrations of $F_{2}$-isoprostanes have been associated with increased risk to develop cardiovascullar diseases (51). Stearic, oleic, and linoleic acids did not differ in their effects on these biomarkers of non-enzymatic and enzymatic lipid peroxidation, respectively. This agrees with earlier dietary studies, in which comparable effects of oleic and linoleic acids were observed on concentrations of isoprostanes in urine or plasma of humans (52-54). Although these findings may suggest that these in vivo markers are not diet-sensitive, this is contradicted by results from a study investigating the effects of CLA isomers. Relative to supplements containing a mixture of CLA isomers or placebo oil, the urinary excretion of 8 -iso-PGF $F_{2 \alpha}$ and $15-\mathrm{K}-\mathrm{DH}-\mathrm{PGF}_{2 \mathrm{\alpha}}$ was significantly increased after consumption of a supplement containing the CLA isomer trans-10, cis-12 CLA in men with metabolic syndrome (55). Thus, the urinary excretion of isoprostanes is a useful marker to evaluate dietary effects on in vivo lipid peroxidation.

Discrepancies exist between dietary studies, which investigated effects on in vivo methods and of those using in vitro methods. Earlier studies showed that diets rich in oleic acid lowered the in vitro susceptibility of LDL to oxidative modification induced by metal ions when compared with diets rich in linoleic acid (56-62). In these studies, lag time increased, rate of oxidation decreased and formation of conjugated dienes or lipid peroxides decreased on the oleic-acid diet. Hence, data about the effects of oleic and linoleic acids on lipid peroxidation are inconsistent using different methods. This could be explained by the difficulties of in vitro methods evaluating LDL susceptibility to oxidative modification to reflect the in wivo situation but also the compounds measured differ from each other.

\section{Inflammation}

Since atherosclerosis is considered as a chronic inflammatory disease, a broad range of inflammation markers has been investigated in patients with cardiovascular diseases (63). Increased concentrations of (soluble) cellular adhesion molecules or pro-inflammatory cytokines and decreased concentrations of anti-inflammatory 
cytokines have been associated with an increased risk of cardiovascular diseases $(64,65)$. Although most studies focused on the in vitro effects of fatty acids on endothelial and immune cell function (66), some studies have now reported effects on circulating in vivo markers of inflammation. Literature about the effects of fatty acids on endothelial cell adhesion molecules and cytokines has been reviewed extensively in Chapter 2 .

In our study, the effects of stearic, oleic, and linoleic acids did not differ on concentrations of high-sensitivity C-reactive protein (hsCRP) as described in Chapter 5. Previous studies investigated mainly the effects of $n-3$ polyunsaturated fatty acids on concentrations of hsCRP. Some of these studies $(67,68)$ but not all $(69,70)$ reported decreased concentrations of hsCRP by the consumption of $n-3$ polyunsaturated fatty acids. Dietary trans fatty acids increased hSCRP relative to diets rich in saturated fatty acids with 12 to 16 carbon atoms, stearic ${ }_{\text {. }}$ and oleic acids (46). Therefore, changes in the dietary fatty acid composition may result in different effects on hsCRP concentrations.

An interesting new tool to detect multiple inflammatory molecules simultaneously and to evaluate inflammatory effects of fatty acids is by antibody arrays. The effects of stearic, oleic, and linoleic acids on the expression profile of 42 immunomodulatory molecules including cytokines, chemokines and growth factors were evaluated but results were inconsistent. A high-sensitivity ELISA of IL-10 of the individual samples could not confirm the data obtained by the antibody arrays. Although with the use of antibody arrays easily insights of the total profile of immunomodulatory molecules could be obtained, inflammatory effects in the individual subjects are more easily distinguished using quantitative assays of the different cytokines. However, it remains to be recommended to analyse expression profiles using one antibody array per subject on each diet. Future studies are necessary to address the effects of fatty acids on the expression profile of immunomodulatory molecules in healthy human subjects.

Some other new biomarkers of inflammation are the acute phase reactants serum amyloid $A$ (SAA) and fibrinogen and the messenger cytokine interleukin- 6 $(71,72)$. Also increased concentrations of CD40 ligand, a transmembrane protein related to tumour necrosis factor $\alpha(T N F \alpha)$, have been associated with cardiovascular events (73). Because of the huge amount of possible markers of inflammation, it remains to be established which biomarker - or set of biomarkers of inflammation is most appropriate in the risk assessment of cardiovascular diseases. 


\section{Potential mechanisms}

Several mechanisms have been proposed to explain why stearic acid is less hypercholesterolemic than the other saturated fatty acids. One hypothesis is that stearic acid is poorly absorbed, which may be related to the dietary source and the stereospecific distribution of the stearic acid over the glycerol backbone of the triacylglycerol molecule.

Earlier studies have compared the absorption, digestibility, or faecal excretion of stearic acid with those of other fatty acids in animals as reviewed by Kritchevsky (74). From these studies, it was concluded that stearic acid is less well absorbed than lauric, myristic, palmitic, oleic, or linoleic acids. In humans, however, considerable variations have been reported and absorption rates of stearic acid varied between 68 to $98 \%(6,75,76)$. In a more recent study, absorption of stearic acid $(94 \%)$ was lower than that of palmitic acid $(97 \%)$ and other fatty acids including lauric, myristic, oleic, and linoleic acids which were absorbed for more than $99 \%$ (77). However, these differences in absorption could not explain the differential effects of these fatty acids on the serum lipoprotein profile $(10,77)$.

It also has been suggested that the effects of stearic acid depend on its dietary source and the stereospecific distribution of stearic acid over the glycerol backbone of triacylglycerols. Of the natural fats containing stearic acid such as cocoa butter and shea butter, it is known that stearic acid is predominantly located at the sn-1 and $s n-3$ positions of glycerol in triacylglycerols, whereas in synthetic fats stearic acid is randomly distributed over all three $s n-1, s n-2$ and $s n-3$ positions due to interesterification (78). Although animal studies have shown enhanced absorption of fatty acids at the $s n-2$ position of dietary triacylglycerols, in humans little evidence exists that the position of stearic acid on the triacylglycerol affects biologicai functions (78). Stearic acid present in synthetic fats as tristearins is less readily absorbed than mono- or distearins from natural sources (79) but the magnitude of the difference turned out to be too small to result in different effects on serum lipids and lipoproteins. Grande et al (3) showed that cocoa butter rich in stearic acid and an interesterified fat with an identical fatty acid composition but made by hydrogenation and randomisation of different fats and oils, had identical effects on concentrations of serum total cholesterol. Several other studies could also not demonstrate a different response of natural and synthetic fats rich in palmitic, stearic, oleic, or $\alpha$-linolenic acids on fasting lipid and lipoprotein concentrations (8082).

When changes in concentrations of HDL cholesterol between diets enriched in stearic, oleic, or linoleic acids were related to the dietary source of stearic acid, no consistent results were obtained. In our study, dietary stearic acid as provided by a 
combination of cocoa butter and tri-stearate, did not decrease HDL cholesterol concentrations when compared with oleic or linoleic acids. Also no different effects of stearic, oleic, and linoleic acids were observed on HDL cholesterol concentrations when either a synthetic fat was used in which the stearic acid was predominantly located at the $s n-1$ and $s n-3$ positions of the glycerol backbone (26) or natural fats such as cocoa butter (5). In another human study, stearic acid as provided by a synthetic fat did not differ in its effects on HDL cholesterol compared with oleic acid (6). However, in the study of Zock and Katan (9), stearic acid decreased concentrations of HDL cholesterol by $0.06 \mathrm{mmol} / \mathrm{L}$, when $8 \%$ of dietary energy of linoleic acid was substituted by an interesterified fat providing stearic acid. Judd et al (10) also found that substituting oleic acid by a synthetic fat providing stearic acid decreased HDL cholesterol concentrations.

Metabolic differences between (saturated) fatty acids may partly explain differences in hypercholesterolemic effects. Stable-isotope studies in healthy human subjects indicated that stearic acid is more rapidly converted by $\Delta 9$ desaturase than palmitic acid $(83,84)$. As a result, the fatty acid profile of lipids and lipoproteins changed (83). Dietary consumption of stearic acid increased concentrations of oleic acid in triacylglycerols and cholesteryl esters compared with dietary palmitic acid (6). Therefore, the biological effects of stearic acid might be more comparable to those of oleic acid than to those of the other saturated fatty acids.

Thus, although several possible mechanisms have been discussed, it is not possible to explain the specific effects of stearic acid compared with the other saturated fatty acids from a metabolic perspective. The cholesterol-neutral effects of stearic acid could not be explained by a reduced absorption of stearic acid but positional effects of stearic acid cannot be excluded. Also, effects on gene expression have never been studied into detail. Probably more than one or still unknown mechanisms might be responsible for the specific effects of stearic acid on the serum lipoprotein profile, thrombotic tendency, lipid peroxidation, and inflammation.

\section{FATTY ACID DESATURATION AND ELONGATION}

The hepatic desaturase and elongase enzymes are importantly involved in fatty acid metabolism and lipid synthesis $(85,86)$. Several factors including dietary fatty acids and hormones such as leptin are known to regulate expression of desaturases and elongases (87). To investigate the mechanisms by which fatty acids regulate fatty acid desaturation and elongation, the effects of the two individual conjugated linoleic acid (CLA) isomers, $c 9, t 11$ and $t 10, c 12$ CLA, were evaluated in a human 
intervention study. Moreover, in cell culture experiments the effects of stearic, oleic, and linoleic acids were investigated on the transcriptional and translational regulation of desaturases and elongases in a human hepatoma-derived cell line (HepG2 cells). To measure mRNA expression by real-time reverse transcription quantitative polymerase chain reactions (RT-qPCRs), specific assays were developed based upon the gene sequences of $\Delta 5, \Delta 6$, and $\Delta 9$ desaturases and of elongase (ELOVL5). As the expression of $\beta$ actin would not be influenced by the different interventions, $\beta$ actin was used as a housekeeping gene.

\section{Conjugated linoleic acids}

In contrast to most human studies that have investigated the effects of a mixture of CLA isomers, we have evaluated isomer-specific effects of the pure isomers, $c 9, t 11$ and $t 10, c 12$ CLA on the plasma fatty acid profile and expression of desaturases of healthy humans (Chapter 6). The study had a parallel design and 20 healthy, slightly overweight men $(n=10)$ and women $(n=10)$ participated. A run-in period of 6 weeks, in which all participants daily consumed a dairy product containing $3 \mathrm{~g}$ of high-oleic sunflower oil (placebo), was followed by an intervention period of 18 weeks. During this intervention period, the control group continued to use this product, whereas the second and third groups received products with $3 \mathrm{~g}$ of purified $c 9_{n} t 11$ or $t 10, c 12$ CLA. At the end of the intervention period, the fatty acid composition of plasma lipids - phospholipids, cholesteryl esters, and triacylglycerols - was analysed. Also mRNA expressions of desaturases and elongase were measured in peripheral blood mononuclear cells (PBMC).

Dietary CLA isomers changed the fatty acid composition of lipid fractions in three different ways. Firstly, like most other fatty acids, the two isomers of CLA were incorporated into lipid fractions. In agreement with another human study (88), $c 9, t 11$ and $t 10,012$ CLA were incorporated in a dose-dependent manner into plasma phospholipids, and also in cholesteryl esters and triacylglycerols. As observed in animal studies, the incorporation of $c 9, t 11$ into lipid fractions was slightly higher than that of $t 10, c 12$ CLA $(89,90)$. Secondly, the $t 10, c 12$ isomer was mainly converted into the $\mathrm{C} 18: 3$ metabolite, whereas supplementation with $c 9, t 11$ CLA increased both $\mathrm{C} 18: 3$ and $\mathrm{C} 20: 3$ conjugated isomers. Those findings agree with previous studies in rats (90). In the third place, except for the CLA isomers, also the percentage of other fatty acids changed in the plasma lipid fractions. Surprisingly, in our study the proportions of linoleic acid increased in plasma phospholipids, cholesteryl esters and triacylglycerols, which suggest a decrease in $\Delta 6$ desaturation. However, proportions of long-chain metabolites of linoleic acid did not decrease in contrast to other studies (91-93). 
Compared with $c 9,111 \mathrm{CLA}, t 10, c 12$ CLA decreased the $\triangle 9$ desaturation index of C18:0, but not that of $\mathrm{C} 16: 0$, In another human study, a mixture of CLA isomers resulted in a decreased $\Delta 9$ desaturation index (94). Also in cell culture studies $(91,95)$ and animal studies $(93,96,97)$, the $110, c 12$ isomer inhibited $\Delta 9$ desaturation activity. Moreover, as in the study of Smedman and Vessby (94), both CLA isomers decreased the $\Delta 6$ desaturation index as calculated from the ratio of $C 18: 3 n-6$ plus $\mathrm{C} 20: 3 n-6$ to $\mathrm{C} 18: 2 n-6$. With respect to the $\Delta 5$ desaturation index, results are rather inconsistent. In our study, no different effects of $c 9, t 11, t 10, c 12$ CLA or placebo (high-oleic acid sunflower oil) were observed. In another human study, the $\Delta 5$ desaturation index increased when a mixture of CLA isomers was consumed at the expense of oleic acid (94). In contrast, in HepG2 cells $t 10, c 12$ CLA inhibited $\triangle 5$ desaturation (91). Hence, particularly $t 10, c 12 \mathrm{CLA}$ decreased desaturation indices, which may result in less desirable physiological effects of this CLA isomer.

CLA may modulate gene expression of enzymes involved in fatty acid metabolism like desaturases and elongases. However, although $c 9, t 11$ and $t 10, c 12$ CLA isomers differed in their effects on desaturation indices, in our study no different effects of the individual CLA isomers were found on the mRNA expression of $\Delta 5, \Delta 6$, and $\triangle 9$ desaturases and elongase (ELOVL5) in PBMC relative to placebo. In mouse hepatocytes, mRNA expression of stearoyl-CoA desaturase (SCD) gene 1 or $\Delta 9$ desaturase was inhibited by $t 10,012$ CLA but not by $c 9, t 11$ CLA (97). Moreover, in HepG2 cells $t 10, c 12$ CLA decreased $\triangle 9$ desaturation of palmitic acid but mRNA expression and protein levels of $\triangle 9$ desaturase were not influenced by $t 10, c 12$ or $c 9, t 11$ CLA isomers (95). Hence, $t 10, c 12$ CLA might regulate the activity of $\Delta 9$ desaturase without any effect at the transcriptional or translational levels.

Health benefits of CLA isomers have been reported mainly in animal studies. Until recently, only mixtures of CLA isomers were used in humans but now some recent studies have reported the individual effects of the pure $c 9, t 11$ and $t 10, c 12$ CLA isomers. C9, 111 and $110, c 12$ CLA did not affect body fat composition in our study (98). In another human study, the $c 9, t 11$ and $t 10, c 12$ CLA isomers did also not change body weight, bady fat or fat-free mass and parameters of immune function such as lymphocyte subpopulations, ex vivo cytokine production, or CRP concentrations. In a dose-dependent manner, both $c 9, t 11$ and $t 10, c 12$ CLA decreased mitogen-induced lymphocyte activation beneficially (99). On the blood lipid profile, however, opposing effects of the two isomers were observed (100). $C 9, t 11$ CLA decreased the total to HDL cholesterol ratio, when compared with $t 10, c 12 \mathrm{CLA}$. Beneficial health effects of one or both of these CLA isomers are therefore not proved yet. In a recent overview the results of studies using mixtures of CLA isomers in humans have been summarised (101). In general, the effects of 
both CLA isomers on body fat and plasma lipids in humans were considerably less than expected from animal studies. The $110, c 12$ CLA isomer may even have some undesirable side effects.

Im conclusion, the $c 9, t 11$ and $t 10, c 12$ CLA isomers differ in their effects on the plasma fatty acid profile. Health effects of CLA, if any, are less than anticipated from animal studies.

\section{Regulation of desaturases and elongases}

Other fatty acids are also known to modulate the expression of desaturases and elongases. Most attention has been paid to the regulation of $\Delta 9$ desaturase. Diets containing linoleic acid, arachidonic acid and $\alpha$-linolenic acid repressed the mRNA expression of the mouse SCD1 gene, relative to a fat-free diet and diets rich in saturated or monounsaturated fatty acids (102). The effects of $n-6$ and $n-3$ polyunsaturated fatty acids on $\Delta 9$ desaturase expression were confirmed by studies in adipocytes (103), and in mouse liver cells $(104,105)$. Suppressive effects of polyunsaturated fatty acids increased with the degree of unsaturation (102-104). Hence, it is generally accepted that polyunsaturated fatty acids inhibit mRNA expression of $\Delta 9$ desaturase in animal models.

Also expression of $\Delta 5$ and $\Delta 6$ desaturases in rat and mice hepatocytes is inhibited by diets containing $n-6$ or $n-3$ polyunsaturated fatty acids such as linoleic acid or fish fatty acids relative to a diet rich in oleic acid or a fat-free diet (106-109). More recently, the effects of fatty acids were reported on the expression of the different elongases. In rats fed diets supplemented with fish oil hepatic mRNA expression of $\Delta 5, \Delta 6$, and $\Delta 9$ desaturases and some but not all elongases decreased relative to rats fed a diet rich in oleic acid (110). Thus, the $\Delta 5, \Delta 6$, and $\Delta 9$ desaturases, and elongases might be regulated coordinately.

Through interaction with nuclear receptors, fatty acids regulate expression of desaturase and elongase genes. Nuclear receptors such as peroxisome proliferatoractivated receptors (PPARs), sterol regulatory element-binding proteins (SREBPS), and the liver $X$ receptors (LXRs) play a pivotal role in the expression of lipogenic genes $(85,111,112)$. PPARs are ligand-activated transcription factors that regulate gene expression through binding to specific DNA sequences called peroxisome proliferator response elements (PPREs). Indeed, PPAR $\alpha$ agonists like fibrates and WY14,643 have been shown to activate mRNA expression of desaturase and elongase enzymes in rats (113). A wide variety of saturated and unsaturated fatty acids are known as ligands of PPAR $(114,115)$. Not only PPAR $\alpha$ but also other nuclear receptors or transcription factors like sterol regulatory element-binding proteins (SREBPS) and the liver $X$ receptors (LXRs) might be involved in the 
regulation of desaturases and elongases by fatty acids $(85,111,112)$. Especially the SREBP-1a and SREBP-1C isoforms were reported to activate the human promoter of $\Delta 9$ desaturase (116). Also $L X R \alpha$, the oxysterol receptor that mediates regulation of gene expression by cholesterol or its metabolites, has been associated with the regulation of desaturases and elongases in rats $(113,117)$.

To investigate the effects of fatty acids on desaturation and elongation, we performed some cell culture experiments in a human hepatoma-derived cell line (HepG2 cells). In these experiments, we observed that linoleic acid decreased $\Delta 6$ and $\Delta 9$ desaturation indices of fatty acids in membrane phospholipids relative to oleic and linoleic acids but the suppressive effects of linoleic acid could not be confirmed at the transcriptional level by the mRNA expression of $\Delta 5, \Delta 6$, and $\Delta 9$ desaturases and elongase (Figure 7.3). The PPAR $\alpha$ agonists fenofibric acid and ciprofibrate induced mRNA expression of desaturases and elongase mainly of $\Delta 5$ and $\triangle 9$ desaturase. Previous studies already reported that PPAR $\alpha$ agonists induced mRNA expression of $\triangle 9$ desaturase. Expression of mouse liver stearoyl-CoA desaturase expression was induced by the addition of clofibrate or gemfibrozil to the diet of mice (105). In HepG2 cells, ciprofibrate increased expression of stearoyl-CoA desaturase (118). Moreover, adult rats fed the PPAR $\alpha$ agonist $W Y 14,643$ had elevated elongase activity and mRNA abundance of elongases (ELOVL1, ELOVL5 and ELOVL6) and $\Delta 5, \Delta 6$, and $\triangle 9$ desaturases (110). Hence, PPAR $\alpha$ is involved in the regulation of desaturases and elongases. To investigate whether desaturases and elongase are regulated at the transcriptional or translational level, HepG2 cells were incubated with or without a transcription inhibitor (actinomycin D) or translation inhibitor (cycloheximide). Results were rather inconsistent (Figure 7.3). Because we could not investigate extensively the regulation of desaturases and elongases by fatty acids and the involvement of nuclear factors herein in HepG2 cells, our results should be considered as preliminary. To draw more definite conclusions, these cell culture experiments should be extended. 


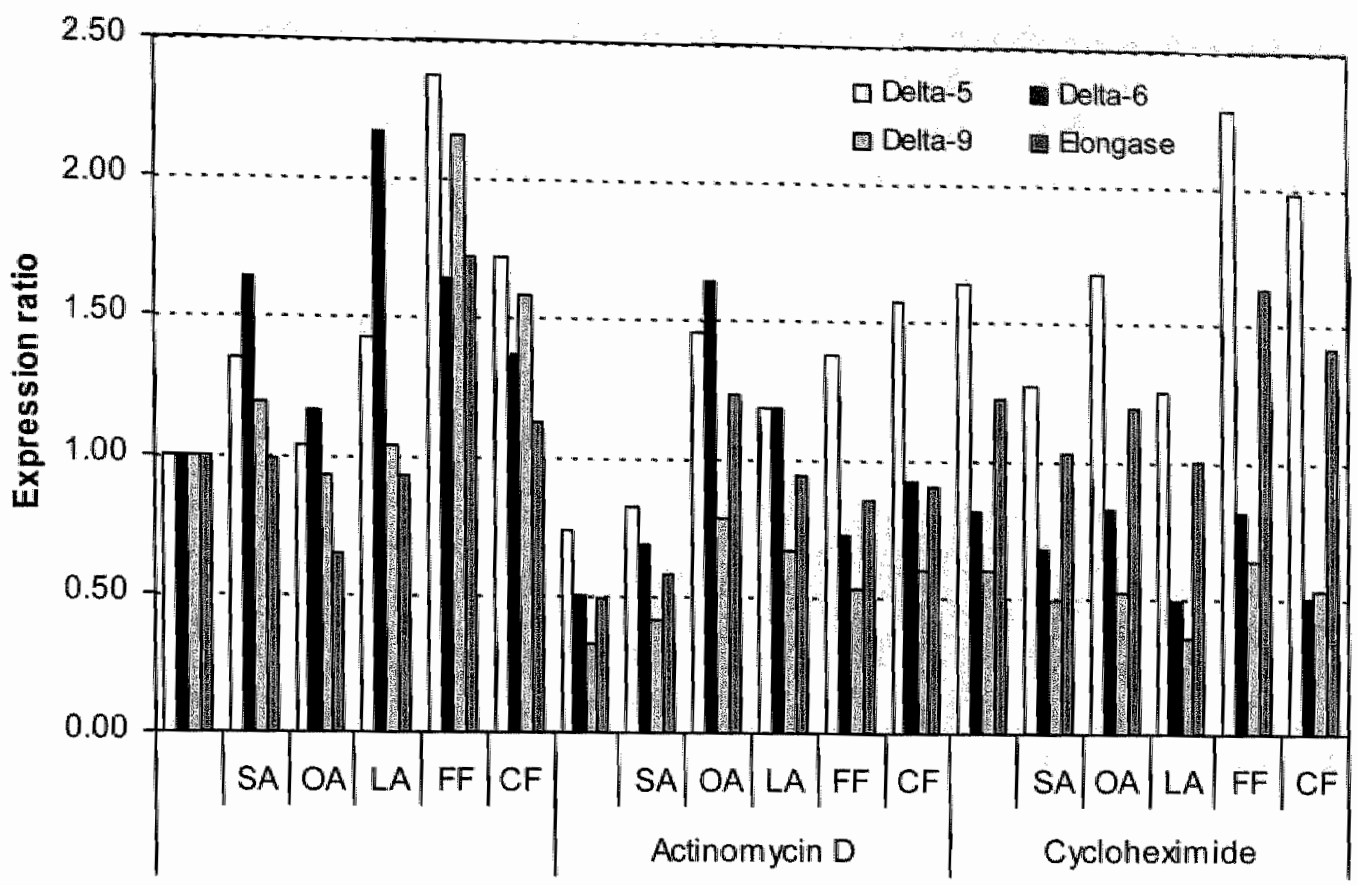

Figure 7.3 Differential induction of $M R N A$ expression of $45, \triangle 6$, and 49 desaturases and elongase (ELOVL5) by incubation of HepG2 cells with $200 \mu M$ of stearic (SA) oleic (OA) or linoleic acid (LA) or $0.3 \mathrm{mM}$ of fenofibric acid (FF) or ciprofibrate (CF) for 24 hours. ${ }^{1,2}$

"Values were obtained using TaqMan procedures (comparative cycle threshold method) and are normalised to the housekeeping gene $\beta$-actin and relative to control HepG2 cells incubated with medium containing $0.1 \%$ BSA, $0.1 \%$ DMSO and $0.2 \%$ ethanol. All samples were analysed in duplicate.

${ }^{2}$ Transcription was inhibited by the addition of actinomycin $D(5 \mu \mathrm{g} / \mathrm{mL})$ to the culture medium for 6 hours or translation by the addition of cycloheximide $(10 \mathrm{pg} / \mathrm{mL}$ ) for 24 hours.

Regulation of desaturases and elongases by fatty acids or fibrates has mostly been investigated in animal studies. Whether animal or cell models reflect the in wivo situation in humans is still unknown. In human intervention studies, the accessibility of liver tissue is difficult, as not almost impossible. Therefore, in our human intervention study with the pure CLA isomers, mRNA was isolated from PBMC which are easily obtained by venipuncture. However, it is unknown whether mRNA expression or activity of desaturases and elongase in PBMC would reflect desaturation and elongation of fatty acids in liver cells. In rats, a tissue-specific expression of fatty acid elongases was reported (113). It remains to be established whether the effects of fatty acids on elongation are tissue- or cell-specific or that elongases with comparable functions in different tissues are involved in fatty acid 
metabolism. The RT-qPCRs of $\Delta 5, \Delta 6$, and $\Delta 9$ desaturases, and of elongase (ELOVL5) in humans would be valuable to investigate the effects of fatty acids in different tissues. Moreover "new technologies like microarray analysis and bioinformatics will make it possible to study the regulation of a lot of genes involved in fatty acid metabolism simultaneously. In this way, new insights could be gathered about the molecular mechanisms underlying the regulatory effects of fatty acids on fatty acid metabolism including desaturation and elongation in different tissues.

\section{CONCLUSIONS}

In the past, reduction of dietary fat intake has been the major focus of dietary recommendations to lower cardiovascular risk. In the last decades, evidence is accumulating that an exchange of harmful fatty acids by fatty acids with beneficial effects on lipid and lipoprotein metabolism, thrombotic tendency, lipid peroxidation and inflammation rather than a reduction of the total dietary fatty acid intake would decrease cardiovascular disease risk. In our study, only small differences in the effects of stearic, oleic, and linoleic acids have been observed on lipid and lipoprotein concentrations, thrombotic tendency, and risk markers of lipid peroxidation and inflammation. When $7 \%$ of energy of stearic acid in the diet was exchanged by oleic or linoleic acids, changes in the concentrations of total and LDL cholesterol were less than expected from earlier studies. Stearic, oleic, and linoleic acids did not differ in their effects on other parameters of the serum lipoprotein profile. Relative to the other long-chain saturated fatty acids - in particular myristic acid and palmitic acid - stearic acid had more beneficial effects on serum total and LDL cholesterol concentrations.

With respect to thrombotic tendency, no different effects of stearic, oleic, and linoleic acids on coagulation and fibrinolytic factors were found but stearic acid may affect these variables beneficially relative to the other saturated fatty acids. Compared with diets rich in oleic or linoleic acids, stearic acid decreased platelet volumes. However, in men ex vivo platelet aggregation was beneficially affected by linoleic acid relative to stearic acid. Moreover, in recent studies no thrombotic effects of saturated fatty acids in particular of stearic acid were reported on in vitro platelet aggregation relative to unsaturated fatty acids. Although the effects of stearic acid on lipid peroxidation and inflammation have not been studied yet relative to lauric, myristic, and palmitic acids, no different effects of stearic, oleic, and linoleic acids were observed on the urinary excretion of isoprostanes and concentrations of hsCRP. 
Mainly due to its effects on the lipoprotein profile, stearic acid is a unique saturated fatty acid. Whether its effects are indeed comparable to those of monounsaturated and polyunsaturated fatty acids has to be considered carefully. It is unknown whether cardiovascular disease risk itself is reduced, when other saturated fatty acids in the diet are substituted by stearic acid. For food applications, however, the incorporation of stearic acid is preferred to that of palmitic acid, the most common saturated fatty acid in the diet, and of trans fatty acids from hydrogenated oils.

\section{REFERENCES}

1. Temme EH, Mensink RP and Hornstra G. Effects of medium chain fatty acids (MCFA), Inyristic acid, and oleic acid on serum lipoproteins in healthy subjects J Lipid Res 1997; 38; 1746-54.

2. Temme EH, Mensink RP and Hornstra $G$. Comparison of the effects of diets enriched in Hauric, palmitic, or oleic acids on serum lipids and lipoproteins in healthy women and men. Am $J \mathrm{C} / \mathrm{h}$ Nutr $1996 ; 63 ; 897-903$

3. Grande F. Anderson JT and Keys A. Comparison of effects of palmitic and stearic acids in the diet on serum cholesterol in man. Am \& Clin Nutr 1970; 23: 1184m.93.

4. Snook JT, Park S, Williams G. Tsai YH and Lee N. Effect of synthetic triglycerides of myristic, palmitic, and stearic acid on serum lipoprotein metabolism. Eur J Cin Nutr 1999; 53: 597-605.

5. Kris-Etherton PM, Derr J, Mitchell DC, Mustad VA, Russell ME, McDonmell ET, Salabsky D and Pearson TA. The role of fatty acid saturation on plasma lipids, lipoproteins, and apolipoproteins: I. Effects of wholle food diets high in cocoa butter, olive oil, soybean oil, dairy butter, and milk chocolate on the plasma lipids of young men. Metabolism i $993 ; 42: 121-9$.

6. Bonanome A and Grundy SM. Effect of dietary stearic acid on plasma cholesterol and lipoprotein levels. NEngl J Med 1988; 318: 1244-8.

7. Kelly FD, Sinclair $A J$, Mann $N J$, Turner $A H$, Abedin $L$ and $L i D$. A stearic acid-rich diet improves thrombogenic and atherogenic risk factor profiles in healthy males. Eur J Clin Nutr 2001; 55: 88-96.

8. Tholstrup T. Marckmann P. Jespersen $\mathrm{J}$ and Sandstrom B. Fat high in stearic acid favorably affects blood liplds and factor VIl coagulant activity in comparison with fats high in pallmitic acid or high in myristic and lauric acids. Am J Clin Nutr 1994; 59: 371-7.

9. Zock PL and Katan MB. Hydrogenation alternatives: effects of trans fatty acids and stearic acid versus linoleic acid on serum lipids and lipoproteims in humans. J Lipid Res 1992; 33: 399-410.

10. Judd JT. Baer D., Clevidence BA, Kris-Etherton P. Muesing RA and Iwene M. Dietary cis and trans monounsaturated and saturated FA and plasma lipids and lipoproteins in men. Lipids 2002; 37; 123 31.

11. Mensink RP and Katian MB. Effect of a diet enriched with monounsaturated or polyunsaturated fatty acids on levels of low-density and high-density lipoprotein chollesteral in healthy women and men. $N$ Engl $J$ Mad 1989; $321: 436-41$.

12. Howard BV, Hannah JS, Heiser CC, Jablonski KA, Paidi MC, Alarif L Robbins DC and Howard WJ Polyunsaturated fatty acids result in greater cholesterol lowering and less triacylglycerol elevation than do monounsaturated fatty acids in a dosemresponse comparison in a multiracial study group. Am 1 Clin Nutr 1995; $62: 392-402$.

\#3. Hodson L. Skeaff CM and Chishoim WA. The effect of replacing dietary saturated fat with polyunsaturated or monounsaturated fat on plasma lipids in free-living young adults. Eur $J$ Clin Nutr 2001: 55: $908-15$

14. Mattson FH and Grundy SM. Comparison of effects of dietary saturated, monounsaturated. and polyunsaturated fatty acids on plasma lipids and lipoproteins in man. J Lipid Res 1985; 26:194-202.

15. Mensink RP, Zock PL, Kester AD and Katan MB. Effects of dietary fatty aclids and carbohydrates on the ratio of serum total to HDL cholesterol and on serum lipids and apolipoproteins: a meta-analysis of 60 controlled trials. Am J Ciin Nutr 2003: $77: 1146-55$

16. Keys A, Andierson JT and Grande F. Serum cholesterol response to changes in the diet lV. Particular saturated fatty acids in the diet. Metabolism 1965; 14:776-87. 
17. Hegsted DM, MCGandy RB, Myers ML and Stare FJ. Quantitative effects of dietary fat on serum cholesterol in man. Am J Clin Nutr 1965 17: 281-95.

18. Freedman DS, Otvos JD, Jeyarajah EJ, Shalaurova I, Cupples LA, Parise H, D'Agostino RB, Wilson PW and Schaefer EJ. Sex and age differences in lipoprotein subclasses measured by nuclear magnetic resonance spectroscopy: the Framingham Study. Clin Chem 2004; 50: 1189-200.

19. Griffin BA, Freeman DJ, Tait GW, Thomson J, Caslake MJ, Packard CJ and Shepherd J. Role of plasma triglyceride in the regulation of plasina low density lipoprotein (LDL) subfractions: relative contribution of small, dense LDL to coronary heart disease risk. Atherosclerosis 1994; 106: 241-53.

20. Gardner CD, Fortmann SP and Krauss RM. Association of small low-density lipoprotein particles with the incidence of coronary artery disease in men and women. JAMA 1996; 276: 875-81.

21. Homstra $G$ and Kester $A D$. Effect of the dietary fat type on arterial thrombosis tendency: systematic studies with a rat model. Atherosclerosis 1997; 131: 25-33.

22. Renaud $S$, Kuba K, Goullet $C$, Lemire $Y$ and Allard $C$. Relationship between fatty-acid composition of platelets and platelet aggregation in rat and man. Relation to thrombosis. Circ Res 1970; 26: 553-64.

23. Renaud $S$, Dumont $E$, Godsey $F$. Suplisson $A$ and Thevenon $C$. Platelet functions in relation to dietary fats in farmers from two regians of France. Thromb Haemost 1979; 40: 518-31.

24. Hornstra $G$, Chait $A$, Karvonen MJ, Lewis $B$, Turpeinen $O$ and Vergroesen $A J$. Influence of dietary fat on platelet function in men. Lancet 1973; 1: 1155-7.

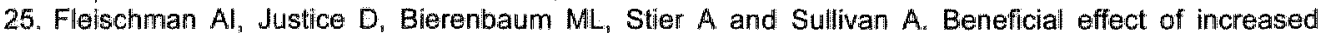
dietary linoleate upon in vivo platelet function in man. J Nutr 1975; 105: 1286-90.

26. Hunter KA, Crosbie LC, Weir A, Miller G.J and Dutta-Roy AK. A residential study comparing the effects of diets rich in stearic acid, oleic acid, and linoleic acid on fasting blood lipids, hemostatic variables and platelets in young healthy men. Journal of Nutritional Biochemistry 2000; 11: 408-16.

27. Turpeinen AM, Pajari AM, Freese R, Sauer R and Mutanen M. Replacement of dietary saturated by unsaturated fatty acids: effects of platelet protein kinase $C$ activity, urinary content of 2,3-dinor-TXB2 and in vitro platelet aggregation in healthy man. Thromb Haemost 1998; 80:649-55.

28. Mutanen $M$, Freese $R$, Valsta $L M_{n}$ Ahola I and Ahlstrom A. Rapeseed oil and sunflower oil diets enhance platelet in vitro aggregation and thromboxane production in healthy men when compared with milk fat or habitual diets. Thromb Haemost 1992; 67: 352-6.

29. Lahoz $C$, Alonso $R$, Ordovas $J M$, Lopez-Farre $A$, de Oya $M$ and Mata $P$. Effects of dietary fat saturation on eicosanoid production, platelet aggregation and blood pressure. Eur J Clin Invest 1997" 27: $780-7$.

30. MCDonald BE, Gerrard JM, Bruce VM and Corner EJ. Comparison of the effect of canola oil and sunflower oil on plasma lipids and lipoproteins and on in vivo thromboxane A2 and prostacyclin production in healthy young men. Am J Clin Nutr 1989; 50: 1382-8.

31. Junker $R$, Kratz $M$, Neufeld $M$, Erren $M$, Nofier JR, Schulte $H$, Nowak-Gottl U, Assmann $G$ and Wahrburg U. Effects of diets containing alive oil, sunflower oil, or rapeseed oil on the hemostatic system. Thromb Haemost 2001; 85: 280-6.

32. Turpeinen AM, Wubert $J$, Aro $A$, Lorenz $R$ and Mutanen $M$. Similar effects of diets rich in stearic acid or trans-fatty acids on platelet function and endothellal prostacyclin production in humans. Arterioscler Thromb Vasc Biol 1998; 18: 316-22.

33. Kelly FD, Sinclair A.J, Mann NJ, Turner AH, Raffin FL, Blandford MV and Pike MJl. Short-term diets enriched in stearic or palmitic acids do not alter plasma lipids, platelet aggregation or platelet activation status. Eur J Clin Nutr 2002; 56: $490-9$.

34. Temme EH, Mensink RP and Hornstra G. Individual saturated fatty acids and effects on whole blood aggregation in vitro, Eur J Clin Nutr 1998; 52: 697-702.

35. Mitropoulos KA, Miller GJ, Martin JC. Reeves BE and Cooper J. Dietary fat induces changes in factor VIl coagulant activity through effects on plasma free stearic acid concentration. Arterioscler Thromb $1994 ; 14: 214-22$

36. Girelli D, Olivieri $O$, Arigliano PL, Guarini $P$, Bassi $A$ and Corrocher $R$. Influences of lipid and non-lipid nutritional parameters on factor VII coagulant activity in normal subjects: the Nove study. Eur J Clin Invest 1996; 26: 199-204.

37. Miller GJ, Bauer KA, Barzegar $S_{n}$ Cooper JA and Rosenberg RD. Increased activation of the haemostatic system in men at high risk of fatal coronary heart disease. Thromb Haemost 1996" 75 : $767-71$

38. Marckmann P, Sandstrom B and Jespersen J. Effects of total fat content and fatty acid composition in diet on factor VIl coagulant activity and blood lipids. Atherosclerosis 1990; 80: 227-33. 
39. Heinrich $J$, Wahrburg $U$, Marting $H$ and Assmann $G$. The effect of diets, rich in mono- or polyunsaturated fatty acids, on lipid metabolism and haemostasis. Fibrinolysis 1990; 4: 76-8.

40. Foley M, Ball M, Chisholm A, Duncan A; Spears G and Mann J. Should mono- or poly-unsaturated fats replace saturated fat in the diet? Eur J Clin Nutr $1992 ; 46: 429-36$.

41. Turpeinen AM and Mutanen M. Similar effects of diets high in oleic or linoleic acids on coagulation and fibrinolytic factors in healthy humans. Nutr Metab Cardiovasc. Dis 1999; 9: 65-72.

42. Bladbjerg EM, Tholstrup T, Marckmann P, Sandstrom B and Jespersen J. Dietary changes in fasting levels of factor VII coagulant activity (FVII:C) are accompanied by changes in factor VII protein and other vitamin K-dependent proteins. Thromb Haemost 1995; 73: 239-42.

43. Temme EH. Individual saturated fatty acids and cardiovascular risk markers. (thesis). Human Biology. Maastricht University, 1997.

44. Temme EH, Mensink RP and Hornstra G. Effects of diets enriched in lauric, palmitic or oleic acids on blood coagulation and fibrinolysis. Thromb Haemost $1999 ; 81: 259-63$.

45. Agren $\mathrm{J} J$, Vaisanen $S$, Hanninen $O$, Muller $A D$ and Hornstra $G$. Hemostatic factors and platelet aggregation after a fish-enriched diet or fish oil or docosahexaenoic acid supplementation. Prostaglandins Leukot Essent Fatty Acids 1997; 57: 419-21.

46. Baer DJ, Judd JT, Clewidence BA and Tracy RP. Dietary fatty acids affect plasma markers of inflammation in healthy men fed controlled diets: a randomized crossover study. Am J Ciin Nutr 2004; 79: 969-73.

47. Hunter KA, Crosbie LC, Horgan GW, Miller GJ and Dutta-Roy AK Effect of diets rich in oleic acid, stearic acid and linoleic acid on postprandial haemostatic factors in young healthy men. Br J Nutr 2001; 86: 207-15.

48. Tholstrup $T$. Andreasen $K$ and Sanstrom B. Acute effect of high-fat meals rich in either stearic or myristic acid on hemostatic factors in healthy young men. Am J Clin Nutr 1996; 64: 168-76.

49. Tholstrup T, Miller GJ, Bysted A and Sandstrom B. Effect of individual dietary fatty acids on postprandial activation of blood coagulation factor VII and fibrinolysis in healthy young men. Am J Clin Nutr 2003; 77: 1125-32.

50. Mutanen $\mathrm{M}$ and Aro A. Coagulation and fibrinolysis factors in healthy subjects consuming high stearic or trans fatty acid diets. Thromb Haemost 1997; 77: 99-104.

51. Patrono $C_{x}$ Falco A and Davi G. Isoprostane formation and inhibition in atherothrombosis. Curr Opin Pharmacol 2005, 5: 198-203.

52. Freese R, Alfthan G, Jauhiainen M, Basu S, Erlund I, Salminen I, Aro A and Mutanen M. High intakes of vegetables, berries, and apples combined with a high intake of linoleic or oleic acid only silghtly affect markers of lipid peroxidation and lipoprotein metabolism in healthy subjects. Am J Clin Nutr $2002 ; 76: 950-60$.

53. Turpeinen AM, Basu S and Mutanen M. A high linoleic acid diet increases oxidative stress in vivo and affects nitric oxide metabolism in humans. Prostaglandins Leukot Essent Fatty Acids 1998; $59: 229-$ 33.

54. Higdion JV, Liu J, Du SH, Morrow JD, Ames BN and Wander RC. Supplementation of postmenopausal women with fish oil rich in eicosapentaenoic acid and docosahexaenoic acid is not associated with greater in vivo lipid peroxidation compared with oils rich in oleate and linoleate as assessed by plasma mallondialdehyde and F(2)-isoprostames. Am J Clin Nutr 2000; 72: 714-22.

55. Riserus $U$, Basu $S$, Jovinge $S$, Fredrikson $G N$, Arnlow $J$ and Vessby $B$. Supplementation with conjugated linoleic acid causes isomer-dependent oxidative stress and elevated C-reactive protein: a potential link to fatty acid-induced insulin resistance. Circulation 2002; 106: $1925-9$.

56. Berry EM, Eisenberg $S$. Haratz $D$. Friedlander $Y$, Norman $Y$, Kaufmann NA and Stein $Y$. Effects of diets rich in monounsalturated fatty acids on plasma lipoproteins--the Jerusalem Nutrition Study: high MUFAs vs high PUFAs. Am J Clin Nutr 1991; 53: 899-907.

57. Bonanome $A$, Pagnan $A$, Biffanti $S$, Opportuno $A$, Sorgato $F$, Dorella $M$, Maiorino $M$ and Ursini $F$, Effect of dietary monounsaturated and polyunsaturated fatty acids on the susceptibility of plasma low density lipoproteins to oxidative modification. Arterioscler Thromb 1992; 12: 529-33.

58. Kratz $M$, Cullen $P$, Kannenberg $F$, Kassner A, Fobker M, Abuja PM, Assmann $G$ and Wahrburg $U$. Effects of dietary fatty acids on the composition and oxidizability of low-density lipaprotein. Eur $J$ Clin Nutr 2002; $56: 72-81$.

59. Mata P. Alonsio $R_{n}$ Lopez-Farre A, Ordovas JM, Lahoz C, Garces C, Caramelo C, Codoceo $R$, Blazquez $E$ and de Oya $M$. Effect of dietary fat saturation on $L D L$ oxidation and monocyte adhesion to human endothelial cells in vitro. Arterioscler Thromb Vasc Biol 1996; 16: 1347-55. 
60. Reaven $P$, Parthasarathy $S$, Grasse $B J$, Miller $E$, Steinberg $D$ and Witztum $J L$. Effects of oleate-rich and linoleaterrich diets an the susceptibility of low density lipoprotein to oxidative modification in millily hypercholesterolemic subjects. J Clin invest 1993; 91:668-76.

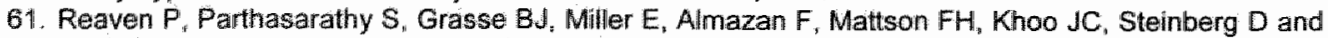
Witztum JL. Feasibility of using an oleate-rich diet to reduce the susceptibility of low-density lipoprotein to oxidative modification in humans. Am J Clin Nutr 1991; 54: $701-6$.

62. Turpeinen AM, Alfthan $\mathcal{C}$, Valsta $L$, Hiletanen $E$, Salonen JT, Schiunk $H$, Nyyssonen $K$ and Mutanen M. Plasma and lipoprotein lipid peroxidation in humans on sunflower and rapeseed ail diets. Lipids 1995; 30: 485-92

63. Libby $P$, Ridker PM and Maseri A. Inflammation and atherosclerosis. Circulation 2002; 105: 1135-43.

64. Lind L. Circulating markers of inflammation and atherosclerosis. Atherosclerosis 2003; 169: 203-14.

65. Magliano DJ, Liew D. Ashton EL. Sundararajan $V$ and MCNeil JJ. Novell biomedical risk markers for cardiovascular disease. $J$ Cardiovasc Risk $2003 ; 10: 4 \uparrow-55$.

66. Yaqoob $P$. Fatty acids and the immune system: from basic science to clinical applications. Proc Nutr Sac 2004; 63: $89-104$.

67. Rallidis LS, Paschos G, Liakos GK, Velissaridou AH, Anastasiadis G and Zampelas A. Dietary alphalinolenic acid decreases C-reactive protein, serum amyloid $A$ and interleukin- 6 in dyslipidaemic patients. Atheroscherosis 2003; 167: 237-42.

68. Pischon T, Hankinson SE, Hotamisligil GS, Rifai N, Willett WC and Rimm EB. Habitual dietary intake of $n-3$ and $n-6$ fatty acids in relation to inflammatory markers among US men and women. Circulation 2003; 108: 155-60.

69. Geelen A, Brouwer $\mid A$, Schouten EG, Kluft $C$, Katan MB and Zock PL. Intake of n-3 fatty acids from fish does not lower serum concentrations of C-reactive protein in healthy subjects. Eur al Clin Nutr 2004; $58: 1440-2$.

70. Madsen $T$, Christensen $\mathrm{JH}_{1}$ Blom $M$ and Schmidt EB. The effect of dietary $n-3$ fatty acids on serum concentrations of C-reactive protein: a dose-response study. Br J Nutr 2003; 89:517-22.

71. Ridker $P M$, Hennekens $\mathrm{CH}_{3}$, Buring JE and Rifai $N$. C-reactive protein and other markers of inflammation in the prediction of cardiowascular disease in women. $N$ Engl $J$ Med $2000 ; 342: 836-43$.

72. Libby $P$ and Ridker PM. Novel inflammatory markers of coronary risk: theory versus practice. Circulation 1999; 100: 1148-50.

73. Ballantyne CM and Nambi $\mathrm{V}$. Markers of inflammation and their clinical significance. Atheroscler Supp/ 2005; 6: 21-9.

74. Kritchevsky D. Stearic acid metabolism and atherogenesis: history. Am J Clin Nutr 1994; 60: 997S$1001 S$.

75. Denke MA and Grundy SM. Effects of fats high in stearic acid on lipid and lipoprotein concentrations in men. Am J Clin Nutr 1991; 54: 1036-40.

76. Dougherty RM, Allman MA and lacono JM. Effects off diets containing high or low amounts of stearic acid on plasma lipoprotein fractions and fecal fatty acid excretion of men. Am J Clin Nutr 1995; 61: $1120-8$.

77. Baer D.J, Judd JT, Kris-Etherton PM, Zhao $G$ and Emken EA. Stearic acid absorption and its metabolizable energy value are minimally lower than those of ather fatty acids in healthy men fed mixed diets. INutr 2003; 133: 4129-34.

78. Hunter JE. Studies on effects of dietary fatty acids as related to their position on triglycerides. Lipids 2001; 36: 655 488 .

79. Mattson FH. The absorbability of stearic acid when fed as a simple or mixed triglyceride. Journal of Nutrition $1959 ; 69: 338-42$.

80. Becker $C_{1}$ Lund $P$, Holmer $G$, Jensen $H$ and Sandstrom $B$. Effects of butter oil blends with increased concentrations of stearic, oleic and linolenic acid on blood lipids in young adults. Eur $J$ Clïn Nutr 1999 ; 53. $535-41$.

81. Zack PL, de Vries JH, de Fouw NJ and Katan MB. Positional distribution of fatty acids in dietary triglycerides: effects on fasting blood lipoprotein concentrations in humans. Am J Clin Nutr 1995; 61: 48-55.

82. Nestel PJ, Noakes $M$, Belling GB, McArthur $R$ and Clifton PM. Effect on plasma lipids of interesterifying a mix of edible oils. Am J Clin Nutr 1995; $62: 950-5$.

83. Rhee SK, Kayani AJ, Ciszek A and Brenna JT. Desaturation and interconversion of dietary stearic and palmitic acids in human plasma and lipoproteins. Am J Clin Nutr 1997; 65: 451-8.

84. Emken EA. Metabolism of dietary stearic acid relative to other fatty acids in human subjects. Am of Clin Nutr 1994; 60: 1023S-8S. 
85. Nakamura MT and Nara TY. Structure, function, and dietary regulation of delta6, delta5, and delta9 desiaturases. Annu Rev Nutr 2004; 24: 345-76.

86. Leonard AE, Pereira SL, Sprecher H and Huang Y'S. Elongation of long-chain fatty acids. Prog Lipid Res 2004; 43: 36-54.

87. Ntambi JM and Miyazaki M. Regulation of stearoyl-COA desaturases and role in metabolism. Prog Lipid Res 2004; 43: 91-104.

88. Burdge GC, Lupoli B, Russell JJ, Tricon S, Kew S, Banerjee T. Shingfield KJ, Beever DE, Grimble RF. Williams CM et al. incorporation of cis-9, trans-11 or trans-10, cis-12 conjugated linoleic acid into plasma and cellular lipids in healthy men. J Lipid Res 2004; 45: 736-41.

89. Kelley DS, Bartolini GL, Warren JM, Simon VA, Mackey BE and Erickson KL. Contrasting ffects of $\mathrm{t} 10, \mathrm{ct2}$ - and $\mathrm{c9}, \mathrm{t} 11$-conjugated linoleic acid isomers on the fatty acid profiles of mouse liver lipids. Lipids 2004; $39: 135-41$.

90. Sebedio JL, Angioni $E$, Chardigny $J M$, Gregoire $S$, Juaneda $P$ and Berdeaux $O$. The effect of conjugated linoleic acid isomers on fatty acid profiles of liver and adipose tissues and their conversion to isomers of $16: 2$ and $18: 3$ conjugated fatty acids in rats. Lipids $2001 ; 36: 575-82$.

91. Eder $K$, Slomma $N$ and Becker $K$. Trans-10, cis-12 conjugated linoleic acid suppresses the desaturation of linoleic and alpha-linolenic acids in HepG2 cells. J Nutr 2002; 132: 1115-21.

92. Mougios $V$, Matsakas A, Petridou A, Ring S, Sagredos A, Melissopoulou A, Tsigilis N and Nikolaidis M. Effect of supplementation with conjugated linoleic acid on human serum lipids and body fat. I Nutr Biochem 2001; 12 : 585-94.

93. Bretilion L, Chardigny JM, Gregoire $S$, Berdeaux $O$ and Sebedio JL. Effects of conjugated linaleic acid isomers on the hepatic microsomal desaturation activities in vitro. Lipids 1999; 34: 965-9.

94. Smedman A and Vessby B. Conjugated linoleic acid supplementation in humans--metabolic effects. Lipids 2001; 36: 773-81.

95. Choi Y, Park $Y$, Pariza MW and Ntambi JM. Regulation of stearoyl-CoA desaturase activity by the trans-10,cis-12 isomer of conjugated linoleic acid in HepG2 cells. Biochem Biophys Res Commun 2001; $284: 689-93$.

96. Park $Y$, Storkson JM, Ntambi JM, Cook ME, Sih CJ and Pariza MW. Inhibition of hepatic stearoyl-CoA desaturase activity by trans-10, cis-12 conjugated linoleic acid and its derivatives. Biochim Biophys Acta 2000; 1486: 285-92.

97. Lee KN, Pariza MW and Ntambi JM. Conjugated linoleic acid decreases hepatic stearoyl-CoA desaturase mRNA expression. Biachem Biophys Res Commun 1998; 248: 817-21.

98. Malpuech-Brugere C, Verboeket-Van De Venne WP, Mensink RP, Arnal MA, Morio B, Brandolini M Saebo A, Lassel TS, Chardigny JM, Sebedio JL et al. Effects of Two Conjugated Linoleic Acid Isomers on Body Fat Mass in Overweight Humans. Obes Res 2004; 12: 591-8.

99. Tricon S, Burdge GC, Kew S, Banerjee T. Russell JJ, Grimble RF, Williams CM, Calder PC and Yaqoob P. Effects of cis-9,trans-11 and trans-10,cis-12 conjugated linoleic acid on immune cell function in healthy humans. Am J Clin Nutr 2004; $80: 1626-33$.

100. Tricon S, Burdge GC, Kew S, Banerjee T, Russell JJ, Jones EL, Grimble RF, Williams CM, Yaqoob $P$ and Calder PC. Opposing effects of cis-9, trans-11 and trans-10, cis-12 conjugated linoleic acid on blood lipids in healthy hurnans. Am J Clin Nutr 2004; 80: 614-20.

101. Terpstra AH. Effect of conjugated linoleic acid on body composition andi plasma lipids in humans: an overview of the literature. Am J Clin Nutr 2004; 79: 352-61.

102. Ntambi JM. Dietary regulation of stearoyl-CoA desaturase 1 gene expression in mouse liver. $J$ Biol Chem 1992; 267: 10925-30.

103. Sessler AM, Kaur N. Palta JP and Ntambi JM. Regulation of stearoyl-CoA desaturase $1 \mathrm{mRN} / \mathrm{A}$

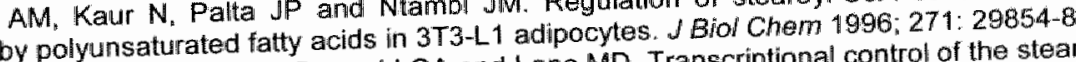

104. Landschulz KT, Jump DB, MacDougald OA and Lane MD. Transcriptional control of the stearoyl-COA desaturase-1 gene by polyunsaturated fatty acids. Biochem Biophys Res Commun 1994; 200: 763-8.

105. Miller $\mathrm{CW}$ and Ntambi JM. Peroxisome proliferators induce mouse liver stearoyl-CoA desaturase 1 gene expression. Proc Natl Acad Sci U S A 1996; 93: 9443-8 gene expression. Proc Natl Acad Sci U S A 1996; 93: 9443-8.
106. Cho HP, Nakamura MT and Clarke SD. Cloning, expression, and nutritional regulation of the
mammalian Delta- 6 desaturase. J Biol Chem 1999; $274: 471-7$.

107. Cho HP, Nakamura M and Clarke SD. Cloning, expression, and fatty acid regulation of the human delta-5 desaturase. J Biol Chem 1999; $274: 37335-9$

108. Tang $C$, Cho HP. Nakamura MT and Clarke SD. Regulation of human delta-6 desaturase gene transcription: identification of a functional direct repeat-1 element. J Lipid Res $2003 ; 44: 686-95$. 
109. Nakamura MT, Cho HP and Clarke SD. Regulation of hepatic delta-6 desaturase expression and its role in the polyunsaturated fatty acid inhibition of fatty acid synthase gene expression in mice. J Nutr 2000,130: 1561-5.

110.Wang Y, Botolin D, Christian B, Busik $J, X_{u} J$ and Jump DB. Tissue-specific, nutritional and developmental regullation of rat fatty acid elongases. J Lipid Res 2005.

111. Jump DB and Clarke SD. Regulation af gene expression by dietary fat. Annu Rev Nutr 1999; 19:6390.

112.Sampath F and Nitambi JM. Polyunsaturated fatty acid regulation of gene expression. Nutr Rev 2004; $62333-9$.

113. Wang $Y$, Kurdi-Haidar $B$ and Oram JF. LXR-mediated activation of macrophage stearoyl-CoA desaturase generates unsaturated fatty acids that destabilize ABCA1. J Lipid Res 2004; 45: 972-80.

114.Forman $\mathrm{BM}$, Chen $\mathrm{J}$ and Evans RM. Hypolipidemic drugs, polyunsaturated fatty acids, and eicosanoids are ligands for peroxisome proliferator-activated receptors alpha and delta. Proc Natl Acad SicI U S A 1997; 94: 4312-7.

115. Kliewer SA, Sundseth SS, Jones SA Brown PJ, Wisely GB, Koble CS, Devchand P, Wahli W, Willson TM, Lenhard JM et al. Fatty acids and eicosanoids regulate gene expression through direct interactions with peroxisome proliferator-activated receptors alpha and gamma. Proc Nat/ Acad Sci U S. A 1997; $94 ; 4318-23$.

116.Bene $H_{i}$ Lasky $D$ and Ntambil JM. Cloning and characterization of the human stearoyl-CoA desaturase gene promoter: transcriptional activation by sterol regulatory element binding protein and repression by polyunsaturated fatty acids and cholesterol. Biochem Biophys Res Commun 2001; 284: 1194-8.

117. Ntambi JM. Regulation of stearoyl-CoA desaturase by polyunsaturated fatty acids and cholesterol. $J$ Lipid Res 1999; 40: 1549-58.

118. Rodriguez $C$, Cabrero $A$, Roglans N, Adzet T, Sanchez RM, Vazquez M, Ciudad CJ and Laguna JC. Differential induction of stearoyl-CoA desaturase and acyl-CoA oxidase genes by fibrates in HepG2 cells. Biochem Pharmacol 2001; 61: 357-64. 
Fatty acid nomenclature and abbreviations 


\section{FATTY ACID NOMENCLATURE}

\begin{tabular}{ll}
\hline Notation & Common name \\
\hline Saturated fatty acids & Lauric acid \\
C12:0 & Myristic acid \\
C14:0 $16: 0$ & Palmitic acid \\
C18:0 & Stearic acid \\
Monounsaturated fatty acids & \\
C16:1n-7 & Palmitoleic acid \\
C18:1n-9 & Oleic acid \\
N-9 polyunsaturated fatty acids & \\
C20:3n-9 & Mead acid \\
C22:3n-9 & Dihomo-Mead acid \\
N-6 polyunsaturated fatty acids & \\
C18:2n-6 & Linoleic acid \\
C18:3n-6 & $\gamma$-Linolenic acid \\
C20:3n-6 & Dihomo- - -linolenic acid \\
C20:4n-6 & Arachidonic acid \\
C22:4n-6 & Adrenic acid \\
C22:5n-6 & Osbond acid \\
N-3 polyunsaturated fatty acids & \\
C18:3n-3 & $\alpha$-Linolenic acid \\
C18:4n-3 & Stearidonic acid \\
C20:4n-3 & Eicosatetraenoic acid \\
C20:5n-3 & Eicosapentaenoic acid (EPA) \\
C22:5n-3 & w3-Docosapentaenoic acid \\
C22:6n-3 & Docosahexaenoic acid (DHA) \\
Conjugated linoleic acids (CLA) & \\
C9, $t 11$ CLA & Cis-9, trans-11 CLA, rumenic acid \\
T110,c12 CLA & Trans-10 cis-12 CLA \\
T11 C18:1 & Vaccenic acid \\
\hline
\end{tabular}




\section{ABBREVIATIONS}

$\triangle P$

15-K-DH-PGF $2 \alpha$

8-iso-PGF 2ct $_{\text {ct }}$

ADP

Amax

Ang

Apo A-I

Apo B

$\mathrm{BMI}$

C

CE

CF

$\mathrm{Cl}$

$\mathrm{CH}_{3}$

CLA

COA

$\mathrm{COOH}$

CRP

CSF

$\mathrm{Ct}$

CV

D-dimers

DHA

EGF

ELISA

ELOVL

EPA

E-selectin

factor Vllam

FAME

FF

FVlla

GLM

GRO

HDL

HELO

HepG2

hsCRP pressure difference

15-keto-dihydro-prostaglandin $\mathrm{F}_{2 \mathrm{a}}$

8-iso-prostaglandin $\mathrm{F}_{2 \mathrm{x}}$

adenosine di-phosphate

ex vivo maximum platelet aggregation

angiogenin

apolipoprotein A-I

apolipoprotein B

body mass index

carbon

cholesteryl esters

ciprofibrate

confidence interval

methyl

conjugated linoleic acids

coenzyme A

carboxyl

C-reactive protein

colony stimulating factor

cycle threshold

coefficient of variation

fibrin degradation products

docosahexaenoic acid

epidermal growth factor

enzyme-linked immunosorbent assay

gene family of elongases

eicosapentaenoic acid

selectin derived from endothelial cells

factor VII amidolytic

fatty acid methyl ester

fenofibric acid

activated factor VII

general linear model

growth regulated protein

high-density lipoprotein

human fatty acid elongase

human hepatoma-derived cell line

high sensitivity $\mathrm{C}$-reactive protein 
ICAM-1

$\| \mathrm{FN} \gamma$

IL

Imax

LA

LDL

LFA-1

LPS

LXR

MCFA

MCP

M-CSF

MDA

MDC

MGB

MIP-1 $\delta$

MRNA

MUFA

NMR

OA

OSM

P-value

PAI

PBMC

PDGFB

PG

$\mathrm{PGI}_{2}$

$\mathrm{PGI}_{3}$

PL

PPAR

PPRE

PRP

PTF1 + 2

PUFA

$\mathrm{Rn}$

RT-qPCR

SA

SAA

$S C D$

SFA intercellular adhesion molecule-1

interferon $\gamma$

interleukin

in vitro maximum platelet aggregation

linoleic acid

low-density lipoprotein

leukocyte-function-associated antigen-1

lipopolysaccharide

liver $X$ receptor

medium-chain fatty acids

monocyte chemotactic protein

macrophage colony stimulating factor

malondialdehydes

macrophage derived chemokine

minor groove binder

macrophage inflammatory protein- $-1 \delta$

messenger RNA

monounsaturated fatty acids

nuclear magnetic resonance

oleic acid

oncostatin $\mathrm{M}$

probability level

plasminogen activator inhibitor

peripheral blood mononuclear cells

platelet-derived growth factor $\beta$

prostaglandin

prostaglandin $\mathrm{I}_{2}$

prostacyclin

phospholipids

peroxisome proliferator-activated receptor peroxisome proliferator response element

platelet-rich plasma

prothrombin fragment 1 and 2

polyunsaturated fatty acids

fluorescence threshold

reverse transcription quantitative $\mathrm{PCR}$

stearic acid

serum amyloid $A$

stearoyl-CoA desaturase

saturated fatty acids 


$\begin{array}{ll}\text { SREBP } & \text { sterol regulatory element-binding protein } \\ \text { Ta } & \text { ex vivo platelet aggregation time } \\ \text { TAG } & \text { triacylglycerols } \\ \text { Tai } & \text { in vitro platelet aggregation time } \\ \text { TBARS } & \text { thiobarbituric acid reactive substances } \\ \text { TC } & \text { total cholesterol } \\ \text { Tdi } & \text { ex vivo platelet desaggregation induction time } \\ \text { TNF } & \text { tumour necrosis factor } \\ \text { tPA } & \text { tissue plasminogen activator } \\ \text { TPO } & \text { thrombopoietin } \\ \text { trans } & \text { trans fatty acids } \\ \text { Ts } & \text { ex vivo platelet aggregation slope } \\ \text { TX } & \text { thromboxane } \\ \text { Va } & \text { in vitro platelet aggregation velocity } \\ \text { VCAM-1 } & \text { vascular cell adhesion molecule-1 } \\ \text { VEGF } & \text { vascular endothelial growth factor } \\ \text { VLDL } & \text { very low-density lipoprotein }\end{array}$


Summary 


\section{SUMMARY}

Cardiovascular diseases are a major cause of morbidity and mortality in western and developed countries. Because a diversity of risk markers is related with its prevalence " cardiovascular diseases have a multifactorial aetiology. Some of these risk markers such as an unfavourable lipoprotein profile, increased thrombotic tendency, increased oxidative stress and low-grade inflammation can be affected by changing total fat or fatty acid intake. In the past, reduction of the dietary fat intake has been the major focus of dietary recommendations to lower cardiovascular disease risk. In the last decades, evidence is accumulating that an exchange of harmful fatty acids by fatty acids with more beneficial effects rather than a reduction in total fat intake decreases cardiovascular disease risk more effectively.

Dependent on their structure and function, fatty acids exert differential effects on cardiovascular risk markers. In this thesis, the effects of fatty acids - in particular of the C18 fatty acids stearic acid, oleic acid, and linoleic acid and of conjugated linoleic acids (CLA) - on cardiovascular disease risk markers have been described. Also effects on fatty acid desaturation and elongation were investigated.

Earlier studies have suggested comparable effects of stearic acid - a saturated fatty acid - and oleic acid - a cis-monounsaturated fatty acid - on the distribution of cholesterol over the various lipoproteins, which are the major transporters of lipids in the blood and differentially affect cardiovascular risk. In addition, other studies have found similar effects of oleic acid and linoleic acid - a cis-polyunsaturated fatty acid. If true, than these three $\mathrm{C} 18$ fatty acids should have comparable effects on the serum lipoprotein profile. We therefore initiated a crossover study with 45 healthy non-smoking human subjects. Each participant consumed in random order each of the 3 different diets during three 5 -week periods. Diets provided $38 \%$ of energy from fat of which $60 \%$ was supplied by the experimental fats. These fats were incorporated into bread, margarines, and cakes. The nutrient composition of the diets did not differ, except for a $7 \%$ difference in energy intake provided by stearic, oleic, or linoleic acids. Except for the effects on the serum lipoprotein profile, also other cardiovascular risk markers (thrombotic tendency, lipid peroxidation, and inflammation) were studied.

Only small differences in the effects of stearic, oleic, and linoleic acids were observed on lipid and lipoprotein concentrations. Changes in the concentrations of the atherogenic LDL and anti-atherogenic HDL cholesterol concentrations were less than expected from earlier studies. Stearic, oleic, and linoleic acids did also not differ in their effects on lipoprotein particle sizes, another risk marker of cardiovascular diseases. Based on these findings and other studies from the 
literature, the most favourable lipoprotein profile is achieved when a mixture of cisunsaturated fatty acids replaces in particular palmitic and myristic acids - two saturated fatty acids - and trans fatty acids in the diet.

With respect to thrombotic tendency, earlier studies have suggested prothrombotic effects of stearic acid. More recent studies, however, could not confirm these unbeneficial effects of stearic acid on platelet aggregation, coagulation, and fibrinolysis. We also found no different effects of stearic, oleic, and linoleic acids on coagulation and fibrinolytic factors. Stearic acid decreased platelet volumes compared with oleic or linoleic acids. Larger platelets are associated with increased cardiovascular risk. On the other hand, ex vivo platelet aggregation in men was affected unbeneficial by stearic acid relative to linoleic acid. Therefore, our results do not indicate that stearic acid is thrombogenic compared with oleic and linoleic acids.

The atherogenicity of lipid particles is largely increased by lipid peroxidation. With increasing degree of unsaturation of fatty acids, lipid peroxidation is expected to increase. In our study, no different effects of stearic, oleic, and linoleic acids were observed on the urinary excretion of the $F_{2}$-isoprostanes 8-iso-prostaglandin $F_{2 \alpha}$ and 15-keto-dihydro-prostaglandin $F_{2 \alpha}$, which are biomarkers of respectively nonenzymatic and enzymatic lipid peroxidation. In contrast, results from studies using in vitro methods to measure LDL susceptibility to oxidation suggest that linoleic acid is more readily oxidised than cis-monounsaturated or saturated fatty acids. The in vivo relevance of this latter method is, however, limited.

Several inflammatory risk markers may be involved in the development of cardiovascular diseases. High sensitivity $\mathrm{C}$-reactive protein (hSCRP) is a circulating acute phase reactant that reflects systemic inflammation. Stearic, oleic, and linoleic acids did not differ in their effects on this marker. The effects of these $\mathrm{C} 18$ fatty acids on multiple immunomodulatory molecules were simultaneously detected by the use of antibody arrays. However, results were not consistent and future studies are needed to address the effects of fatty acids on the cytokine profile into more detail.

In conclusion, differences between the effects of the $\mathrm{C} 18$ fatty acids stearic, oleic, and linoleic acids on the serum lipoprotein profile are less tham was predicted based on earlier studies. Effects on other cardiovascular risk markers were also marginal. Whether the effects on cardiovascular disease risk itself are comparabie, is unknown. For food applications, the use of stearic acid may be preferred over that of myristic and palmitic acids - two saturated fatty acids in the diet - and of trans fatty acids from hydrogenated oils. 
Desaturation and elongation enzymes might be regulated differently by the individual fatty acids. As almost all human studies reported the effects of a mixture of CLA isomers, we have investigated the isomer-specific effects of the two most common CLA isomers - cis-9,trans-11 $(c 9, t 11)$ and trans-10, cis-12 $(t 10, c 12)$ CLA on fatty acid desaturation and elongation. In a double-blind, placebo-controlled study with parallel design, 25 healthy overweight men and women consumed daily a dietary supplement providing $3 \mathrm{~g}$ of high-oleic sunflower oil (placebo) during the first 6 weeks of the trial (run-in period). After randomisation, one group $(n=7)$ continued to consume the placebo dairy product daily for the next 18 weeks of the study (intervention period). The second $(n=9)$ and third $(n=9)$ groups consumed the dairy product with $3 \mathrm{~g}$ of purified $c 9, t 11$ CLA or $3 \mathrm{~g}$ of $t 10, c 12$ CLA, respectively. Dietary supplements containing CLA were provided as an acidified drinkable dairy product.

Compared with $c 9, t 11$ CLA, $t 10, c 12$ CLA lowered the ratio of $C 18: 1 \mathrm{n}-9$ to $C 18: 0$ in plasma phospholipids, suggesting a decreased $\Delta 9$ desaturation index but the C16:1n-7 to C16:0 ratio was not affected. Both CLA isomers decreased the $\Delta 6$ desaturation index as calculated from the ratio of $c 18: 3 n-6$ plus $C 20: 3 n-6$ to C18:2n-6. MRNA expressions of desaturases and elongase in peripheral blood mononuclear cells (PBMC) were, however, not affected. Hence, effects on desaturation indices were not reflected by changes at the transcriptional level. It is unknown, however, whether mRNA expressions or activities of desaturases and elongases in PBMC reflect those in the liver, the major organ for desaturation and elongation of fatty acids. Therefore, it is interesting to identify the similarities and differences in the molecular effects of fatty acids on fatty acid metabolism in PBMC, in the liver or other tissues. 
Samenvatting 


\section{SAMENVATTING}

Hart- en vaatziekten vormen een belangrijke oorzaak van ziekte en sterfte in westerse en ontwikkelde landen. Omdat vele risicomerkers gerelateerd zijn aan de prevalentie, hebben hart- en vaatziekten een multifactoriële etiologie. Sommige risicomerkers zoals een ongunstig lipoproteïnenprofiel, verhoogde thromboseneiging, verhoogde axidatieve stress en een laag-gradige chronische ontsteking worden beinnvloed door een verandering in de totale vet- of vetzuurinname. In het verleden werd in voedingsadviezen om het risico op hart- en vaatziekten te verlagen vooral de nadruk gelegd op het reduceren van de vetinname. In de laatste decennia bestaan er echter steeds meer bewijzen dat een uitwisseling van ongezonde vetzuren door vetzuren met gunstige effecten tot een lager risico op hart- en vaatziekten leidt dan het verlagen van de totale vetinname.

Vetzuren hebben afhankelijk van structuur en functie verschillende effecten op risicomerkers voor hart- en vaatziekten. In dit proefschrift zijn vooral de effecten van de C18 vetzuren - stearinezuur, oliezuur, linolzuur en geconjugeerd linolzuur (CLA) op risicomerkers voor hart- en vaatziekten beschreven. Ook zijn de effecten op de desaturatie en elongatie van vetzuren onderzocht.

Eerdere studies suggereerden vergelijkbare effecten van stearinezuur - een verzadigd vetzuur - en oliezuur - een cis enkelvoudig onverzadigd vetzuur - op de verdeling van cholesterol over de verschillende lipoproteïnen. Dit zijn de belangrijkste transporters van cholesterol in het bloed en ze beïnvloeden het risico op hart- en vaatziekten verschillend. Bovendien hebben andere studies vergelijkbare effecten van oliezuur en linolzuur - een cis meervoudig onverzadigd vetzuur - gevonden. Indien dit klopt, dan zouden deze drie $\mathrm{C} 18$ vetzuren vergelijkbare effecten op het serum lipoproteïnenprofiel hebben. De effecten van stearinezuur, oliezuur en linolzuur werden onderzocht in een cross-over studie met 45 gezonde, niet-rokende proefpersonen. Elke deelnemer gebruikte de 3 verschillende voedingen in willekeurige volgorde gedurende drie perioden van 5 weken. De voedingen bevatten 38 energieprocenten vetten, waarvan $60 \%$ werd geleverd door experimentele vetten. Deze vetten werden verwerkt in brood, margarine en cake. Behalve een verschil van $7 \%$ in de energie inname van stearinezuur, oliezuur of linolzuur, was de voorgeschreven voedingssamenstelling van de drie voedingen gelijk. Naast de effecten op het serum lipoproteïnenprofiel, werden ook andere risicomerkers van hart- en vaatziekten (thromboseneiging, lipidenperoxidatie en inflammatie) bestudeerd.

Slechts kleine verschillen werden waargenomen in de effecten van stearinezuur, oliezuur en linolzuur op de lipiden- en lipoproteïnenconcentraties. De veranderingen 
in de concentraties van de atherogene LDL en niet-atherogene $\mathrm{HDL}$ cholesterolconcentraties waren kleiner dan werd verwacht op basis van de eerdere studies. Stearinezuur, oliezuur en linolzuur verschilden ook niet in de effecten op de deeltjesgrootte van de lipoproteïnen, een andere risicomerker van hart-en vaatziekten. Gebaseerd op deze bevindingen en andere studies in de literatuur wordt het meest gunstige lipoproteïnenprofiel bereikt wanneer palmitinezuur en myristinezuur - 2 verzadigde vetzuren - en trans vetzuren in de voeding worden vervangen door een mengsel van cis-onverzadigde vetzuren.

Met betrekking tot de thromboseneiging hebben eerdere studies gesuggereerd dat stearinezuur prothrombotische effecten heeft. Meer recentere studies hebben deze nadelige effecten van stearinezuur op de bloedplaatjesaggregatie, stolling en fibrinolyse niet bevestigd. In onze studie verschilden de effecten van stearinezuur, oliezuur en linolzuur op factoren betrokken bij de stolling en fibrinolyse ook niet. In vergelijking met voedingen rijk aan oliezuur en linolzuur, verlaagde stearinezuur het volume van de bloedplaatjes. Grotere bloedplaatjes zijn geassocieerd met een hoger risico op hart- en vaatziekten. Aan de andere kant werd de ex vivo bloedplaatjesaggregatie in mannen nadelig beïnvloed door stearinezuur ten opzichte van linolzuur. Daarom duiden onze resultaten er niet op dat stearinezuur thrombogener is dan oliezuur of linolzuur.

De atherogeniteit van lipidendeeltjes wordt sterk vergroot door lipidenperoxidatie. De gedachte is dat onverzadigde vetzuren de kans op lipidenperoxidatie vergroten. Echter, de effecten van stearinezuur, oliezuur en linolzuur op de excretie in de urine van de $F_{2}$-isoprostanen, 8-iso-prostaglandine $F_{2 \alpha}$ (8-iso-PGF $F_{2 \alpha}$ ) en 15-keto-dihydroprostaglandine $F_{2 \alpha}\left(15-K-D H-P G F_{2 \alpha}\right.$ ), die biomerkers zijn voor respectievelijk nietenzymatische en enzymatische lipidenperoxidatie, waren niet verschillend. Dit is in tegenspraak met de resultaten van studies waarin in vitro methoden werden gebruikt om de oxideerbaarheid van LDL door metaalionen te meten. In deze studies is gevonden dat linolzuur eerder geoxideerd wordt dan cis-enkelvoudige onverzadigde of verzadigde vetzuren. De in vivo relevantie van deze laatstgenoemde methoden is echter beperkt.

Verschillende ontstekingsmerkers kunnen betrokken zijn bijj de ontwikkeling van hart-en vaatziekten. Het C-reactieve proteïne (CRP) is een circulerend acute fase eiwit, dat bij ontstekingen sterk verhoogd is. Stearinezuur, oliezuur en linolzuur verschilden niet in hun effecten op deze risicomerker. De effecten van deze C18 vetzuren op andere eiwitten betrokken bij een immuunreactie werden gedetecteerd met behulp van antilichaam arrays. De resultaten waren echter moeilijk te interpreteren en toekomstige studies zijn noodzakelijk om de effecten van vetzuren op het cytokinenprofiel in detail te onderzoeken. 
Op basis van deze bevindingen concluderen wij dat de verschillen in de effecten van de $\mathrm{C} 18$ vetzuren stearinezuur, oliezuur en linolzuur op het lipoproteïnenprofiel kleiner zijn dan verwacht uit eerdere studies. De effecten op andere risicomerkers voor hart-en vaatziekten zijn ook gering. Of de effecten op het risico op hart- en vaatziekten zelf ook vergelijkbaar zijn, is nog onbekend. Voor voedingstoepassingen kan echter worden gesteld dat het toepassen van stearinezuur de voorkeur heeft boven het toepassen van myristine- en palmitinezuur - twee verzadigde vetzuren in de voeding - en die van trans vetzuren uit gehydrogeneerde oliën.

Desaturatie en elongatie enzymen worden verschillend gereguleerd door de individuele vetzuren. Omdat bijna alle humane studies de effecten van een mengsel van CLA isomeren hebben gerapporteerd, hebben wij de isomeer-specifieke effecten van de twee meest voorkomende CLA isomeren - cis-9,trans- $11(c 9, t 11)$ en trans-10,cis-12 $(110, c 12)$ CLA - onderzocht op de desaturatie en elongatie van vetzuren. In een dubbelblinde, placebo-gecontroleerde studie met een parallel design, gebruikten 25 gezonde mannen en vrouwen met overgewicht gedurende de eerste 6 weken van de studie (run-in periode) dagelijks een voedingssupplement dat 3 gram zonnebloemolie met een hoog gehalte oliezuur (placebo) bevatte. $\mathrm{Na}$ randomisatie bleef één groep $(n=7)$ het placebo zuivelproduct dagelijks gebruiken voor de daaropvolgende 18 weken van de studie (interventieperiode). De tweede ( $n$ $=9$ ) en derde $(n=9)$ groep consumeerden een zuivelproduct met respectievelijk 3 gram $c 9, t 11$ CLA of $t 10, c 12$ CLA.

In vergelijking met $c 9, t 11$ CLA verlaagde de $t 10, c 12$ CLA isomeer de $C 18: 1 \mathrm{n}$ 9/C18:0 ratio in plasma fosfolipiden, duidend op een verminderde $\Delta 9$ desaturatie activiteit. De C16:1n-7/C16:0 ratio werd echter niet beïnvloed. Beide CLA isomeren verlaagden de $\Delta 6$ desaturatie index, die werd berekend uit de ratio van $C 18: 3 n-6$ en C20:3n-6 ten opzichte van C18:2n-6. De mRNA expressie van desaturases en elongase in perifere bloed mononucleaire cellen (PBMC) werd echter niet beïnvloed. Hieruit volgt dat de effecten op de desaturatie indices niet werden weerspiegeld door veranderingen op transcriptioneel nivo. Het is echter onbekend of de mRNA expressies van desaturases en elongases in PBMC een weerspiegeling zijn van desaturatie en elongatie in de lever, dat het belangrijkste orgaan is voor de desaturatie en elongatie van vetzuren. Daarom is het van belang om verschillen en overeenkomsten te identificeren in de moleculaire effecten van vetzuren op het metabolisme in PBMC en in de lever of andere weefsels. 


\section{Dankwoord}




\section{DANKWOORD}

Ergens aan beginnen is niet altijd eenvoudig (zo ook het begin van dit dankwoord), maar wat je doet moet je goed doen en waar je aan begint ook afmaken. Gelukkig is dankzij de steun van velen dit proefschrift tot stand gekomen en dat is iets om trots op te zijn. Dank je wel voor alle steentjes die er door een ieder aan zijn bijgedragen.

Allereerst will ik graag alle proefpersonen die aan de voedingsstudies hebben deelgenomen bedanken. Bedankt voor alle tijd die jullie voor de studies hebben vrijgemaakt. Het eten van de producten en volgens de opgelegde richtijinen, voedingsdagboekjes bijhouden, voedingsvragenlijsten invullen en op tijd bloed laten prikken, was niet altijd een eenvoudige opgave. Zonder jullie gegevens was dit proefschrift niet tot stand gekomen.

Dan wil ik ook mijn promotor, prof. dr. ir. R.P. Mensink, graag bedanken. Beste Ronald, bedlankt voor het aanleren van de onderzoeksvaardigheden die van belang zijn bij het opzetten, het uitvoeren en het (statistisch) analyseren van voedingsstudies. Ook wil ik je graag bedanken voor de goede samenwerking en begeleiding. I $\mathrm{k}$ vond het fijn dat je altijd weer met een kritische blik naar mijn manuscripten wilde kijken. Het onderzoek was verder niet mogelijk geweest zonder de financiële ondersteuning van de Stichting Zuivel, Voeding en Gezondheid, nu de Nederlandse Zuivel Organisatie geheten. Ik wil Gert-Jan Hiddink en Theo Ockhuizen graag bedanken voor hun altijd weer oprechte interesse in de resultaten en de voortgang van het onderzoek.

De beoordelingscommissie bestaande uit prof. dr. E. Mariman, prof. dr. A. Bast, dr. M. Oude Egbrink, prof. dr. W. Saris en dr. ir. P. Zock wil ik graag bedanken voor het doorlezen en beoordelen van mijn proefschrift.

Verschillende collega's van Humane Biologie zijn nauw betrokken geweest bij de voedingsstudies en het analyseren van de resultaten. Tijdens de studies werden de proefpersonen vakkundig begeleid door de diëtisten Mirjam en Kirsten. Altijd stonden er weer ontbijtjes klaar of was er een luisterend oor voor de proefpersonen. Bedankt voor de gezellige samenwerking en goede ondersteuning op voedingsgebied. Het berekenen van alle voedingsdata uit de dagboekjes en voedingsvragenlijsten was een hele klus! Ook wil ik graag alle analisten die betrokken zijn geweest bij het uitvceren van de analyses en experimenten bedanken. Frank, Sjoerd, Hasibe, Maurice, Martine, Jacquelien en Wendy, vele bloedmonsters, analyses en cellen zijn door jullie handen gegaan. Bedankt voor het altijd weer paraat zijn om bij te springen op de drukkere momenten. Jogchum, jou wil ik graag bedanken voor je betrokkenheid, goede adviezen en deskundige hulp bij het opzetten van de moleculaire assays en celkweekstudies. 
Loek en Paul, met computerproblemen kon ik altijd weer bij jullie terecht. Bedankt daarvoor! Ook de medewerkers van het secretariaat van Humane Biologie, vooral llona en Claudia, wil ik graag bedanken voor jullie ondersteuning. En dan waren er nog vele collega's en ex-collega's van Humane Biologie, die altijd wel weer voor me klaarstonden om ergens mee te helpen, ervaringen uit te wisselen, een soms ingewikkelde vraag op te lossen of gewoon voor een praatje op de gang. ledereen bedankt voor jullie collegialiteit en de leuke Maastrichtse werkomgeving. Eefje en Margriet, ook buiten het werk om kon ik bij jullie terecht. Bedankt voor de gezellige uitstapjes, etentjes en (inspannende) ontspannende uurtjes.

Lunchen met de collega's uit de middenlob van Humane Biologie om 12 uur was vaste prik. 's Zomers lekker buiten in het zonnetje en anders wel in de mensa. Verder waren jullie er ook altijd voor een praatje tussendoor. Annemarie, Ariënne, Daniëlle, Elke N, Elke T, Frank, Jacquelien, Jogchum, Julia, Julian, Kirsten, Marjolijn, Martine, Maurice, Mirjam, Pascal, Sandra, Sjoerd, Stefan en Wilhelmine, bedankt voor jullie gezelligheid. Petra, middeniob of niet, ik vond je er toch wel bij horen. Bedankt voor de fijne gesprekken. Stefan, samen konden we het over koetjes en kalfjes hebben en niet alleen in de figuurlijke zin. Ik heb genoten van onze gezellige samenwerking. Succes met jouw proefschrift.

In de weekenden was er toch ook nog wel tijd voor ontspanning. Annemieke en Dennis, Simone en Chris, Bregje, Gwen, Juliëtte, Marianke, Marissa, Meintje, Pauline, Wietske, Patrick en Ingrid, Angelie en Rob, Amanda en Mario, Peter en Irma, René en Angelique en Gerry en Martje, bedankt voor alle gezellige weekendjes weg, feestjes en bezoekjes over en weer. Hopeijk is de afstand in kilometers nog lang niet te groot om te overbruggen.

Annemiek, van collega tot goede vriendin in Maastricht. Samen hebben we vaak lekker gegeten, geborreld en heel wat afgekletst. Toen ik werk vond in Almelo, woonde juist daar jouw tweelingzus Dorien. Beter had ik het niet kunnen treffen. Hopelijk kunnen we nog lang samen gezelligheid maken, ook al gaan jullie misschien binnenkort wel weer over de grenzen verhuizen. Over internationaal gesproken, ook in Denemarken kunnen we altijd terecht om weer eens heerlijk terug te keren naar hoe ik ooit opgegroeid ben. Wendy en Roderik, elk jaar is het weer gezellig om bij jullie op de boerderij een weekendje mee te komen helpen. Helaas hebben we het afgelopen jaar over moeten slaan, maar dat halen we nog wel in. Annemiek en Wendy, fijn dat jullie mijn paranimfen willen zijn.

Lieve familieleden, velen van jullie hebben vaak geïnformeerd naar mijn scriptie, maar gellukkig weet inmiddels iedereen wat een proefschrift inhoudt. Graag wil ik jullie bedanken voor alle belangstelling, vertrouwen en gezelligheid, ook in moeilijke tijden. 
Mijn ouders wil ik graag bedanken voor alle steun, vertrouwen en de mogelijkheden die jullie me altijd hebben geboden. Mam ${ }^{\dagger}$, jammer dat je het allemaal niet meer mee kunt maken, maar je was minstens net zo trots geweest als pap. Pap en Martijn, samen weten we wat we aan elkaar hebben. Gelukkig hebben jullie altijd tijd om naar me te luisteren. $\mathrm{k}$ hoop dat ik er ook altijd voor jullie kan zijn. Lieve Martijn, een fijnere broer had ik me niet kunnen wensen.

Lieve Gert-Jan, soms lopen dingen niet zoals we het zouden verwachten. Toch hoop ik dat we samen altijd liefde en geluk kunnen vinden. Bedankt voor je inzet, steun en vertrouwen, en dat je er altijd voor me wilt te zijn!

Myriam 
Curriculum vitae 


\section{CURRICULUM VITAE}

Myriam Anna Maria Anthonia Thijssen was born on September 10, 1976 in Beers. After graduating secondary school at the Elshofcollege in Nijmegen, she started in 1993 with her study to become a medical laboratory technician (graduation direction clinical chemistry) at the Higher Laboratory School in Nijmegen. As part of this study, a clinical and research training period was performed at the laboratory of the Maasziekenhuis in Boxmeer. She graduated in July 1997. Afterwards, from 1997 to 2001, she studied Biomedical Sciences at the Faculty of Medicine of the University of Leiden. During training periods, she participated in different research projects at the department of Immunohematology and Blood Transfusion in the Leiden University Medical Centre (LUMC) with prof.dr. M. Giphart as supervisor and at the immunological laboratory of the department of Pediatrics, also at the LUMC with $d r$. $M$. van Tol and dr. M. Schilham as supervisors. The final training period was spent at the Central Clinical Chemical Laboratory at the University Medical Centre St. Radboud in Nijmegen and was supervised by dr. D. Swinkels and dr. J. de Kok. Finally she graduated in April 2001. At the same time she started her PhD project at the department of Human Biology of the Faculty of Health Sciences at Maastricht University. From 2001 to 2005 she performed the studies, which are described in this thesis. A dietary intervention study with healthy subjects was conducted to investigate the effects of stearic, oleic, and linoleic acids on risk markers for cardiovascular diseases. The effects of these fatty acids were also investigated in cell culture studies. Funthermore, effects of CLA isomers on desaturation and elongation of fatty acids were studied. Since June 2005 she is employed as clinical chemist trainee at the Ziekenhuisgroep Twente in Almelo/Hengelo. 
Myriam Anna Maria Anthonia Thijssen werd geboren op 10 september 1976 in Beers. Na het behalen van haar WWO diploma aan het Elshofcollege in Nijmegen, startte ze in 1993 met haar studie tot medisch analist (afstudeerrichting klinische chemie) aan de Hogere Laboratorium Opleiding in Nijmegen. Als onderdeel van deze studie werd een klinische en onderzoeksstage gedaan in het laboratorium van het Maasziekenhuis in Boxmeer. Ze studeerde in jull 1997 af. Vervolgens studeerde ze van 1997 tot 2001 Biomedische Wetenschappen aan de Faculteit Geneeskunde van de Universiteit Leiden. Gedurende stageperiodes werkte ze mee aan verschillende onderzoeksprojecten bij de afdeling Immunohematologie en Bloedbank in het Leids Universitair Medisch Centrum (LUMC) onder begeleiding van prof.dr. M. Giphart en bij het laboratorium immunologie van de afdeling Kindergeneeskunde eveneens in het LUMC onder begeleiding van dr. M. van Tol en dr. M. Schilham. Het afsluitende onderzoeksproject werd uitgevoerd bil het Centraal Klinisch Chemisch Laboratorium van het Universitair Medisch Centrum St. Radboud in Nijmegen en was onder begeleiding van dr. D. Swinkels en dr. J. de Kok. Uiteindelijk studeerde ze in april 2001 af. Tegelijkertijd startte ze oak haar promotieonderzoek bij de capaciteitsgroep Humane Biologie van de Faculteit Gezondheidswetenschappen van de Universiteit Maastricht. Van 2001 tot 2005 werden de studies uitgevoerd die in dit proefschrift zijn beschreven. Een voedingsinterventiestudie in gezonde proefpersonen werd gedaan om de effecten van stearinezuur, oliezuur en linolzuur te onderzoeken op risicomerkers voor harten vaatziekten. De effecten van deze vetzuren werden ook onderzocht in celkweekstudies. Verder werden de effecten van CLA isomeren op desaturatie en elongatie van vetzuren onderzocht. Sinds juni 2005 is ze als klinisch chemicus in opleiding bij de Ziekenhuisgroep Twente te Almelo/Hengelo. 


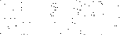


List of publications 


\section{LIST OF PUBLICATIONS}

\section{Full papers}

Thijssen MA, Swinkels DW, Ruers TJ and de Kok JB. Difference between free circulating plasma and serum DNA in patients with colorectal liver metastases. Anticancer Research 2002; 22: 421-5.

Thijssen MA and Mensink RP. Fatty acids and atherosclerotic risk. Chapter in: Handbook of Experimental Pharmacology volume 170: Atherosclerosis: Diet and Drugs edited by Eckardstein von A. 2005 Berlin - Heidelberg, Germany: Springer.

Thijssen MA, Malpuech-Brugère C, Gregoire S, Chardigny JM, Sébédio JL, and Mensink RP. Effects of specific CLA isomers on plasma fatty acid profile and expression of desaturases in humans. Lipids 2005; 40(2): 137-45.

Thijssen MA and Mensink RP. Small differences in the effects of stearic acid, oleic acid, and linoleic acid on the serum lipoprotein profile of humans. American Journal of Clinical Nutrition 2005; 82(3): 510-6.

Thijssen MA and Mensink RP. Effecten van vetzuren in de voeding op totaal, LDL en HDL cholesterol concentraties. Nederlands Tijdschrift voor Klinische Chemie en Laboratoriumgeneeskunde 2005; 30(3): 199-203.

Thijssen MA, Hornstra $G$ and Mensink RP. Stearic, oleic, and linoleic acids have comparable effects on markers of thrombotic tendency in healthy human subjects. Journal of Nutrition 2005; 135(12): 2805-11.

Thijssen MA, Basu S and Mensink RP. Effects of stearic, oleic, and linoleic acids on biomarkers of lipid peroxidation and inflammation in healthy humans. Submitted for publication. 


\section{Abstracts}

Thijssen MA and Mensink RP. Effects of stearic acid (C18:0), oleic acid (C18:1) and linoleic acid (C18:2) on lipid and lipoprotein concentrations in humans. Poster presentation at the EAS congress April 2004 in Seville.

Thijssen MA, Sébédio J-L, Saebo A, Lassel TS and Mensink RP. Effects of cis-9, trans-11 and trans-10, cis-12 conjugated linoleic acid on the plasma fatty acid profile and expression of desaturases in humans. Oral presentation at the ISSFAL congress June 2004 in Brighton. 